\title{
Tissue-specific insulin resistance in human obesity
}

Citation for published version (APA):

van der Kolk, B. (2018). Tissue-specific insulin resistance in human obesity: A physiological approach to lipid metabolism. [Doctoral Thesis, Maastricht University]. Gildeprint Drukkerijen. https://doi.org/10.26481/dis.20180503bk

Document status and date:

Published: 01/01/2018

DOI:

10.26481/dis.20180503bk

Document Version:

Publisher's PDF, also known as Version of record

\section{Please check the document version of this publication:}

- A submitted manuscript is the version of the article upon submission and before peer-review. There can be important differences between the submitted version and the official published version of record.

People interested in the research are advised to contact the author for the final version of the publication, or visit the DOI to the publisher's website.

- The final author version and the galley proof are versions of the publication after peer review.

- The final published version features the final layout of the paper including the volume, issue and page numbers.

Link to publication

\footnotetext{
General rights rights.

- You may freely distribute the URL identifying the publication in the public portal. please follow below link for the End User Agreement:

www.umlib.nl/taverne-license

Take down policy

If you believe that this document breaches copyright please contact us at:

repository@maastrichtuniversity.nl

providing details and we will investigate your claim.
}

Copyright and moral rights for the publications made accessible in the public portal are retained by the authors and/or other copyright owners and it is a condition of accessing publications that users recognise and abide by the legal requirements associated with these

- Users may download and print one copy of any publication from the public portal for the purpose of private study or research.

- You may not further distribute the material or use it for any profit-making activity or commercial gain

If the publication is distributed under the terms of Article $25 \mathrm{fa}$ of the Dutch Copyright Act, indicated by the "Taverne" license above, 


\section{Tissue-specific insulin resistance in human obesity}

A physiological approach to lipid metabolism 


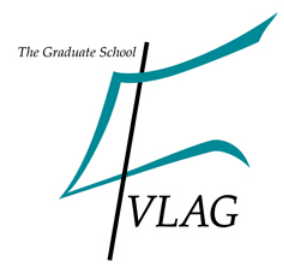

\section{NASD}

The studies presented in this thesis were performed within NUTRIM School for Nutrition and Translational Research in Metabolism, which participates in the Graduate School VLAG (Food Technology, Agrobiotechnology, Nutrition and Health Sciences), accredited by the Royal Netherlands Academy of Arts and Sciences. Financial support by the Netherlands association for the Study of Obesity (NASO) for the publication of this thesis is gratefully acknowledged.

Cover design: $\quad$ E. Jagtman - evelienjagtman.com

Layout: $\quad$ B.W. van der Kolk and F.V.A. Coenen

Printed by: Gildeprint-gildeprint.nl

ISBN: $\quad 978-94-6233-929-3$

(C) B.W van der Kolk, 2018, Maastricht

For articles published or accepted for publication, the copyright has been transferred to the respective publisher. No parts of this thesis may be reproduced, stored in a retrieval system, or transmitted in any form or by any means without the permission of the author, or, when appropriate, from the publishers of the manuscript. 


\title{
Tissue-specific insulin resistance in human obesity
}

\section{A physiological approach to lipid metabolism}

\author{
PROEFSCHRIFT
}

Ter verkrijging van de graad doctor aan de Universiteit Maastricht,
op gezag van de Rector Magnificus, Prof. dr. Rianne M. Letschert,
volgens het besluit van het College van Decanen,
in het openbaar te verdedigen
op donderdag 3 mei 2018 om 14.00 uur

door

Bertine Willemina van der Kolk

Geboren op 23 september 1987 te IJsselmuiden 


\section{Promotor:}

Prof. dr. E.E. Blaak

\section{Copromotores:}

Dr. J.W.E. Jocken

Dr. M.M.J. van Greevenbroek

\section{Beoordelingscommissie:}

Prof. dr. M.K.C. Hesselink, voorzitter

Prof. dr. W.D. van Marken Lichtenbelt

Dr. M.C.G.J. Brouwers

Prof. dr. ir. E.J.M. Feskens (Wageningen University and Research)

Dr. L. Hodson (University of Oxford, UK) 


\section{Table of contents}

Chapter 1 General introduction 7

Chapter 2 Altered skeletal muscle fatty acid handling is associated with the degree of insulin resistance in overweight and obese humans

Chapter 3 Angiopoietin-like protein 4 and postprandial skeletal muscle lipid metabolism in overweight and obese prediabetics

Chapter 4 Effect of diet-induced weight loss on Angiopoietin-like protein 4 and adipose tissue lipid metabolism in overweight and obese humans

Chapter 5 Plasma lipid profiling of tissue-specific insulin resistance in human obesity

Chapter 6 Abdominal subcutaneous adipose tissue gene expression in relation to tissue-specific insulin resistance in human obesity

Chapter 7 General discussion

Addendum Summary

Samenvatting

Valorization

Dankwoord

List of publications 


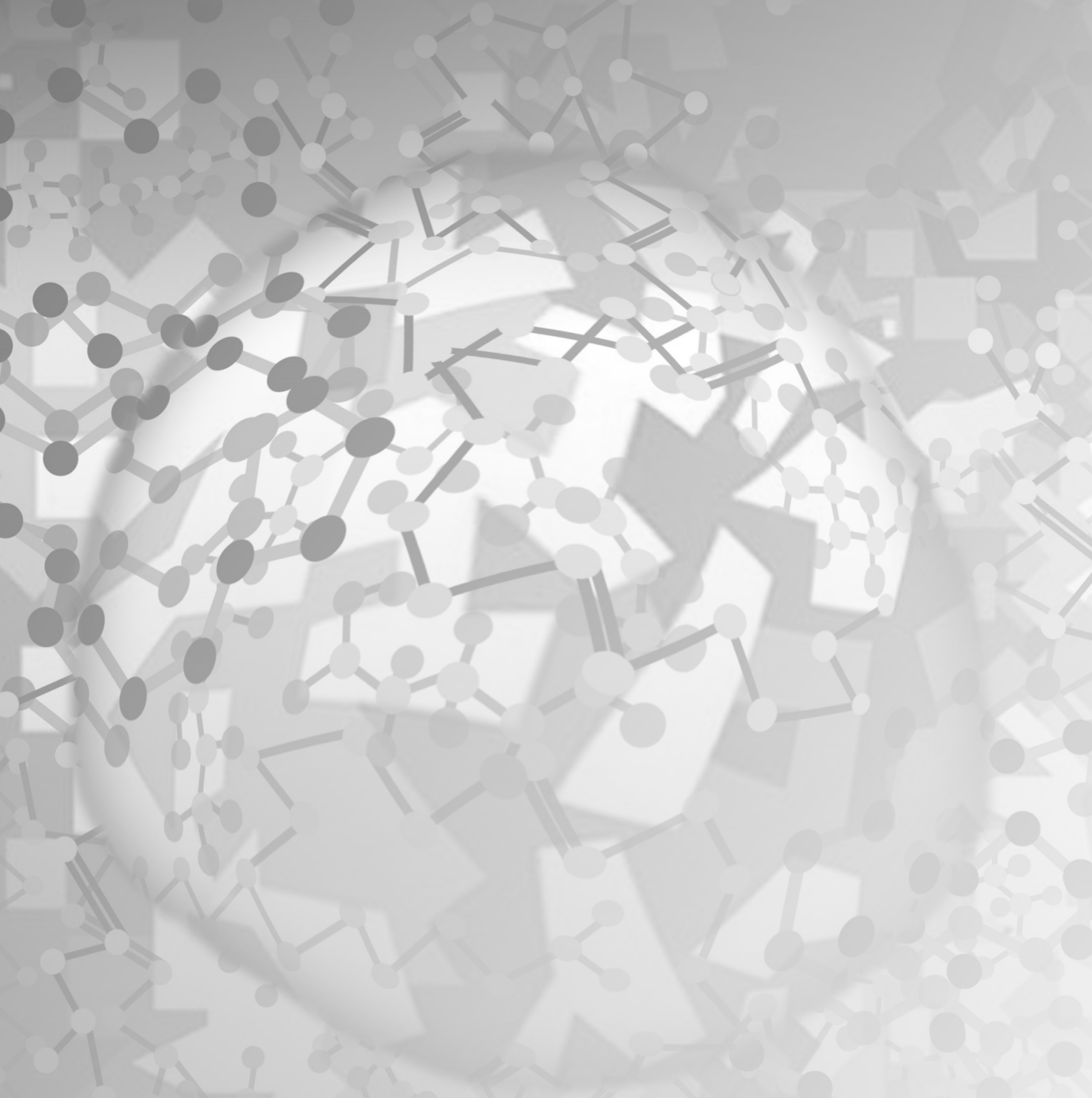


Chapter 1

General Introduction 
8 | Chapter 1 


\section{Obesity and insulin resistance}

\section{Obesity prevalence}

The prevalence of obesity has risen to epidemic proportions over the last decades and affects people of all ages and socioeconomic groups (1). In 2014, more than $39 \%$ of the world adult population was overweight $\left(\mathrm{BMI}>25 \mathrm{~kg} / \mathrm{m}^{2}\right)$ and about $13 \%$ was obese $\left(\mathrm{BMI}>30 \mathrm{~kg} / \mathrm{m}^{2}\right)$ (2). In 2015, in the Netherlands, over $50 \%$ of the individuals over 20 years of age were overweight or obese (3).

The increasing prevalence of obesity is a major health concern. In 2010, overweight and/or obesity was estimated to cause 3.4 million deaths worldwide (4). Additionally, obesity increases the risk for developing chronic diseases such as type 2 diabetes mellitus (5), cardiovascular diseases (6), mental disorders (7) and several cancer types (8). In the upcoming years, the expectation is that obesity-related complications will continue to increase and will have large public health and socioeconomic consequences.

\section{Obesity and cardiometabolic health}

A disrupted energy homeostasis, due to a dysbalance between energy intake and energy expenditure, is often accompanied by the development of obesity and its related metabolic complications. A positive energy balance, which is a long-term surplus of energy intake from carbohydrates, lipids and/or proteins over energy expenditure, leads to energy storage as fat in the body and to weight gain (9). An inactive lifestyle as well as calorie-dense food consumption are main causes for body weight changes, next to genetic predisposition and other environmental and biological factors (10). Impaired energy homeostasis and obesity are strongly associated with insulin resistance, development of type 2 diabetes and cardiometabolic complications (11).

Obesity is linked to the development of insulin resistance, which is defined as an impaired sensitivity to insulin of its main metabolic target organs e.g. adipose tissue, skeletal muscle, liver and pancreas. Insulin resistance is a major contributor to hyperglycemia and hyperlipidemia, which are all risk factors towards the development of type 2 diabetes and cardiovascular diseases. Notably, the 'World Health Organization (WHO) Global report on diabetes 2016' reports a doubled prevalence of diabetes since 1980, rising from $4.7 \%$ to $8.5 \%$ in the worldwide adult population. Moreover, this report estimates the total burden of deaths from high blood glucose near 3.7 million cases (12), including 2.2 million deaths caused by 
higher-than-optimal blood glucose concentrations and related cardiovascular disease complications (12). In addition, the WHO estimated that 17.7 million people died from cardiovascular diseases in 2015, representing 31\% of all global deaths (13). Strikingly, insulin resistance increases the risk for cardiovascular diseases even in the absence of hyperglycemia $(14,15)$. Thus, understanding the etiology of insulin resistance is a key step in the prevention of cardiometabolic diseases.

\section{Insulin resistance and tissue-specificity}

In humans, intermediate states of impaired glucose metabolism (prediabetes) can be identified by measuring plasma glucose and insulin concentrations in the fasting state and after an oral glucose tolerance test (OGTT). Insulin resistance together with increased $\beta$-cell failure results in an increased blood glucose concentrations in the non-diabetic range. These prediabetes states are classified as impaired fasting glucose (IFG) or impaired glucose tolerance (IGT) (16). Individuals with IFG, defined by fasting glucose $>5.6 \mathrm{mmol} / \mathrm{L}$, mainly show hepatic insulin resistance and a normal or slightly lower whole-body insulin sensitivity. In contrast, individuals with IGT, defined by a $2 \mathrm{~h}$ glucose concentration $>7.8 \mathrm{mmol} / \mathrm{L}$, have a normal to slightly reduced hepatic insulin resistance and show moderate to severe reduced peripheral (skeletal muscle) insulin sensitivity. However, the pathophysiological mechanisms do overlap substantially between IFG and IGT as both states are characterized by hyperglycemia. In addition, individuals who have combined IFG and IGT show both hepatic and peripheral (skeletal muscle) insulin resistance (17).

These prediabetes states represent distinct pathophysiological pathways towards cardiometabolic diseases. Up to now, there is evidence that interventions that increase insulin sensitivity are organ specific, at least for a part of their effects. For instance, physical activity was shown to mainly affect muscle insulin sensitivity (18), while metformin treatment might improve hepatic insulin resistance (19). In addition, a diet low in fat and high in complex carbohydrates may be beneficial for prediabetic individuals with hepatic insulin resistance, while the Mediterranean diet may improve muscle insulin sensitivity (20).

Rodent studies may provide important links to a better understanding of human substrate metabolism in relation to insulin resistance. In mice, genetic manipulation of the insulin receptor signaling pathways in different organs had major effects on the mice phenotypes and metabolic functioning of these organs (21). For instance, mice with muscle-specific insulin receptor knockout (MIRKO) had profound insulin resistance in muscle, but glucose tolerance 
was normal due to insulin-independent glucose uptake in muscle (22). This comes along with increased glucose uptake in adipose tissue (22). In mice with liver-specific insulin receptor deletion (LIRKO), insulin suppression of hepatic glucose output was completely abolished, and hyperlipidemia and progressive liver dysfunction was observed (23). Notably, the MIRKO mouse demonstrated a development of adaptive mechanisms in adipose tissue to compensate for muscle insulin resistance to maintain glucose homeostasis while the LIRKO mouse was unable to respond to hyperinsulinemia (21). So far, these rodent studies have helped us revealing distint metabolic profiles when insulin receptor signaling pathways are affected in a tissue-specific manner. However, human studies focusing on tissue-specific insulin resistance phenotypes are limited so far.

\section{Interorgan cross-talk in obesity and insulin resistance}

As illustrated above, insulin resistance can develop simultaneously in multiple organs and the insulin resistance severity may vary between different organs. Insulin tightly regulates the distribution and utilization of the energy-rich carbohydrates and fatty acids. Therefore the metabolic insulin sensitive organs such as adipose tissue, liver and skeletal muscle play an important role in human energy metabolism. Dysfunction of these organs cause or contribute to the development of (tissue-specific) insulin resistance and cardiometabolic diseases. Figure 1 shows a schematic overview of organ crosstalk in obese insulin resistant conditions.

Adipose tissue plays a central role in energy metabolism and is closely related to the adverse health effects associated with obesity. The two major functions of the adipose tissue related to lipid metabolism are: i) lipid storage by the uptake of meal-derived fatty acids from the circulation and store them as triacylglycerol (TAG) in the postprandial phase and ii) to supply non-adipose tissue with energy in the form of non-esterified fatty acids (NEFAs) in conditions of increased energy demand (e.g. fasting and exercise) (9). Under conditions of chronic positive energy balance, the adipocytes become enlarged and the adipose tissue lipid buffering capacity is often exceeded. This results in lipid overflow into the circulation and subsequently to non-adipose tissues such as liver, skeletal muscle and pancreas (24). If lipid supply exceeds the fat oxidative capacity in these non-adipose tissues, ectopic fat accumulation may occur. This ectopic fat accumulation is associated with the development of insulin resistance.

In the liver, an increased lipid supply from the adipose tissue may stimulate the endogenous formation of TAG under obese insulin resistant conditions. The lipid overflow 
leads to elevated secretion of very low-density lipoprotein (VLDL)-TAG into the circulation (25). Together with a higher hepatic glucose production and reduced insulin clearance, this results in increased systemic glucose and insulin concentrations. Subsequently, these processes might affect the lipid overflow to other tissues (26).

The skeletal muscle is recognized as a key organ in peripheral insulin sensitivity as it accounts for $70-80 \%$ of the total glucose disposal under postprandial conditions (27). Often skeletal muscle insulin resistance refers to an impaired insulin regulation of glucose homeostasis. Notably, lipid metabolism is important as well. An increased lipid supply from adipose tissue and liver results in an increased uptake of systemic endogenous and dietary lipids into the skeletal muscle. Furthermore, a reduced capacity to oxidize fatty acids is often observed in obese insulin resistant conditions, which might be due to mitochondrial dysfunction (28). These factors together may contribute to the increased accumulation of intramuscular lipids (e.g. TAG, diacylglycerol (DAG)) and lipid intermediates (e.g. ceramides and acylcarnitines), leading to lipotoxicity and cellular dysfunction (29). Subsequently, these processes might disrupt the insulin signaling and insulin-mediated glucose uptake, resulting in lipid-induced insulin resistance (30).

In the pancreas, ectopic fat deposition might result in lipotoxicity and decreased glucosestimulated insulin secretion by the beta-cell, thereby accelerating hyperglycemia and the development of insulin resistance in other tissues. This process may require a long time as this is illustrated by the observation that the obese insulin resistant state is often associated with higher plasma insulin concentrations (i.e. compensatory hyperinsulinemia) rather than decreased insulin levels (24).

Finally, the gastrointestinal tract plays a major part in organ crosstalk and lipid metabolism as well. The primary task of the gastrointestinal tract is to digest and absorb marconutrients, including lipids. For instance, dietary lipids are packaged into lipoprotein particles called chylomicrons, which will be transported via the lymphe nodes towards peripheral tisues and the liver. Additionally, the gut is an endocrine organ regulating the secretion of satiety hormones and incretins, thereby affecting energy and substrate metabolism of the host (31). Importantly in the last decade, the residents of the intestine, the gut microbiota, have been recognized as an active metabolic organ. They produce short-chain fatty acids, bile acids and inflammatory factors with significant impact on host energy/substrate metabolism and insulin sensitivity (32). Up to now, there is accumulating evidence that obesity-associated alterations in the gut microbiota can also affect host lipid and 


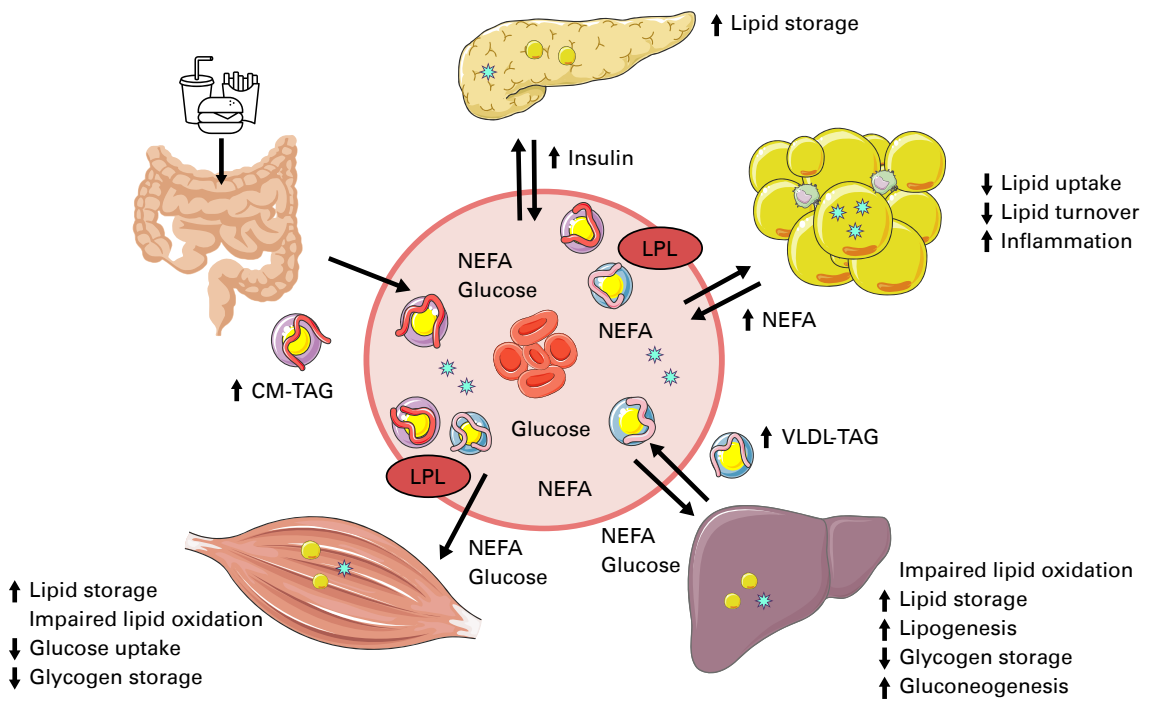

Figure 1. Schematic overview of inter-organ crosstalk in obesity-induced insulin resistance During long-term positive energy balance (i.e. when energy intake exceeds energy expenditure), systemic lipid overload contributes to ectopic (non-adipose) lipid storage. Loss of the adipose tissue buffer capacity may increase circulating NEFA and TAG. Fatty acids are taken up by peripheral tissues like skeletal muscle, liver and pancreas. An impaired lipid oxidation in these tissues may direct these lipids towards storage, possibly leading to the development of insulin resistance. LPL, located at the luminal side of the capillary endothelium, plays a central role in the clearance of TAG-rich plasma lipoprotein particles in skeletal muscle and adipose tissue. In addition, inflammatory cytokines may be secreted from adipose tissue and they may decrease local and whole-body insulin sensitivity. LPL: lipoprotein lipase, NEFA: non-esterified fatty acid, CM-TAG: chylomicron triacylglycerol ((5), VLDL-TAG: very-low density lipoprotein triacylglycerol $(\bigcirc)$, ectopic lipid storage $(\bigcirc)$, inflammatory cytokines ( $($ 数).

glucose metabolism in adipose tissue, liver and skeletal muscle. However most mechanistic evidence is based on animal studies so far $(32,33)$.

To better understand the complex inter-organ crosstalk in insulin resistance, the next paragraphs will discuss in more detail the role of adipose tissue (dys)function as well as the role of liver and skeletal muscle in lipid metabolism and insulin resistance. 


\section{Adipose tissue function and dysfunction}

The development of obesity is accompanied by a substantial increase in adipose tissue mass. However, increased adipose tissue mass per se might not be the most important contributor to the development of obesity-related metabolic disorders. Adipose tissue function and distribution of body fat may also play a prominent role in cardiometabolic health (34). The adipose tissue organ is composed of different discrete anatomical depots, all with different size and metabolic function $(35,36)$. Adipose tissue accumulation in the upper body (abdominal region) is associated with increased cardiometabolic and mortality risk, while lower body (gluteofemoral region) fat accumulation is considered to be protective against obesity-related disorders (35). Moreover, with respect to the upper-body adipose tissue depots, enlarged visceral adipose tissue confers increased risk for cardiometabolic risk factors compared to subcutaneous adipose tissue. This could possibly be due to functional differences such as a pro-inflammatory phenotype (37).

Traditionally, the only function that was ascribed to adipose tissue was that of insulator and energy storing tissue. However, nowadays it is commonly accepted that adipose tissue is a dynamic endocrine organ. It is involved in the regulation of various homeostatic processes including lipid storage and mobilization which is also called lipid buffering capacity. The adipose tissue continuously switches from being a net storage organ in times of a positive energy balance to a net release organ in times of a negative energy balance. In addition, adipose tissue is involved in regulation of appetite and satiety, and secretion of cytokines and adipokines related to the development of local and systemic low-grade inflammation $(9,38-$ 40).

In the next paragraphs, I will discuss the relationship between adipose tissue lipid buffering capacity and insulin resistance in more detail. Additionally, I will highlight the role of adipose tissue differentiation capacity and adipose tissue inflammation in obesity-induced insulin resistance.

\section{Adipose tissue lipid uptake and storage}

In times of a positive energy balance, i.e. the fed state, the adipose tissue buffers and stores dietary fatty acids in the form of TAGs (41). Lipoprotein lipase (LPL), located at the luminal side of the capillary endothelium, plays a central role in the clearance of TAG-rich plasma lipoproteins particles (42). It is the rate-limiting enzyme in extracellular lipolysis as it catalyzes the hydrolysis of endogenous VLDL-TAG and exogenous chylomicron-TAG into glycerol 
and NEFAs (43). The activity of LPL is under tight nutritional and hormonal control in a tissue-specific manner. In humans, adipose LPL activity is markedly elevated in the fasted state compared with the fed state (44). While adipose tissue LPL activity oscillates, LPL mRNA and protein mass differ only slightly (42). This suggests that the activity of LPL is primarily regulated at the post-translational level. Indeed, in adipose tissue, the postprandial rise in insulin is a major activator of LPL activity $(43,45)$.

Recently, angiopoietin-like protein 4 (ANGPTL4) has emerged as an important inhibitor of LPL activity in the fasted state (46). But the role of ANGPTL4 in human adipose tissue LPL activity is not well understood and current data are mainly derived from animal studies. In rodent adipose tissue studies, increased ANGPTL4 concentrations inhibit adipose tissue LPL activity via transient binding to LPL and conversion to inactive monomers under fasting conditions (47). Moreover, it has been shown that ANGPTL4 promotes intracellular degradation of LPL in murine adipocytes in in vitro studies (48). It has also been reported in rodent studies that increased ANGPTL4 expression leads to a reduced plasma TAG clearance by adipose tissue (49) and this inhibiting effect was blunted in ANGPTL4 knockout mice (49). It is known that ANGPTL4 is expressed in human adipocytes (50) and it has been shown that during long-term fasting (50) and following acute physical activity (50-52) adipose tissue expression and plasma ANGPTL4 concentrations are increased in humans. Moreover, insulin has been shown to reduce circulating ANGPTL4, as revealed by hyperinsulinemiceuglycemic clamp studies in humans (53-55). Nevertheless, it remains to be elucidated whether systemic and/or adipose tissue ANGPTL4 levels are also involved in regulating adipose tissue LPL activity in humans and whether this is impaired under insulin resistant conditions. Besides insulin and ANGPTL4, LPL activity is also regulated by apolipoproteins (APO-C1, -2, -3, -5, APO-E), Gastric inhibitory polypeptide (GIP), Glycosylphosphatidylinositol anchored high density lipoprotein binding protein 1 (GPIHBP1) and other ANGPTLs (-3 and -8), which are reviewed in detail elsewhere $(42,56)$.

LPL activity is not wel understood in humans under obese insulin resistant conditions. Basal LPL activity has been reported to be delayed but preserved in obese individuals when compared to lean healthy individuals (57). During hyperinsulinemia, it has been shown that fatty acid spillover from LPL-mediated TAG hydrolysis across adipose tissue was less suppressed in obese individuals $(57,58)$. It was recently demonstrated that men with type 2 diabetes have a similar ability to store VLDL-TAG in adipose tissue compared to non-diabetic men, despite greater circulating postprandial VLDL-TAG concentrations (59). 
Moreover, a delayed insulin-mediated stimulation of adipose tissue LPL activity was found in obesity, insulin resistance and type 2 diabetes (60-64). This resulted in an impaired clearance of chylomicron-derived TAG. In obese individuals, a decreased clearance of VLDL-TAG by adipose tissue was observed after an overnight fast, whilst in the postprandial state chylomicron-TAG clearance was reduced (65). Subsequently, VLDL-TAG seemed to compete with chylomicrons for LPL-mediated clearance $(60,65)$. In line, the latter study demonstrated that the relative quantity of meal lipids stored in adipose tissue after the intake of subsequent meals was significantly reduced in abdominally obese versus lean individuals (65). Together, these data suggest a less efficient removal of dietary lipids by adipose tissue under obese insulin resistant conditions. The impaired removal of dietary lipids in combination with increased liver VLDL production $(26,66)$ may contribute to increased lipid spillover and ectopic fat deposition. To summarize, in obese insulin resistant conditions, elevated TAG concentrations are observed. Both an increased liver VLDL production $(26,66)$ as well a reduced clearance of circulating VLDL-TAG and chylomicron-TAG by adipose tissue have been shown to play a significant role in this phenomenon.

In addition to an impaired LPL action in obese and insulin-resistant conditions, disturbances in the uptake of the liberated NEFAs may contribute to an impaired total lipid uptake by adipose tissue. A significant proportion of the fatty acids that are hydrolyzed from TAG by intravascular LPL lipolysis are not taken up by the adipose tissue and they will 'spill over' into the plasma NEFA pool (67). Under normal physiological conditions, LPL-derived NEFAs are taken up by passive diffusion or active fatty acid transporters, like fatty acid translocase (CD36), plasma membrane bound fatty acid binding protein (FABPpm) and a family of fatty acid transport proteins (FATP1-6) (68). The process of fatty acids trapping into the adipocytes is dependent on the concentration gradient across the adipocyte membrane and plasma. The concentration gradient is regulated by enzymes involved in fatty acid reesterification and intracellular lipolysis $(41,69)$. In the adipocytes, the NEFAs will be mostly directed towards re-esterification and storage of TAG, thereby lowering the NEFA concentration intracellularly.

\section{Adipose tissue lipolysis}

In times of a negative energy balance, e.g. during fasting or increased physical activity, the adipose tissue releases fatty acids in the form of NEFAs for oxidation in other organs. This process is called intracellular lipolysis (70). It involves the hydrolysis of stored neutral TAGs into glycerol and NEFAs via the action of three consecutive lipases: adipose tissue TAG lipase 
(ATGL), hormone-sensitive lipase (HSL) and monoacylglyceride lipase (MGL) (71,72). The catecholamines, adrenalin and noradrenalin, and the natriuretic peptides, atrial natriuretic peptide (ANP) and the brain natriuretic peptide (BNP), act as pro-lipolytic hormones, whereas insulin is the most potent anti-lipolytic hormone in human adipose tissue (70).

In obesity, whole-body lipolysis under fasting conditions (also called basal lipolysis) may be increased because of the increased total adipose tissue mass. Indeed, an increased total NEFA flux is often observed during fasting in obese insulin resistant conditions. In contrast, the rate of NEFA release per $\mathrm{kg}$ fat mass is considerably decreased in obesity (73). In line, this reduced lipolysis per unit fat mass during fasting and catecholamine stimulation has been shown to be associated with lower adipose tissue ATGL and HSL expression and activity in obese insulin resistant individuals $(74,75)$. Furthermore, insulin-mediated suppression of fatty acid release has been shown to be blunted in obesity, impaired glucose tolerant and type 2 diabetes individuals (62,76). Nevertheless, the differences in circulating NEFA concentrations between obese and lean participants are generally modest and appear not to be proportionally increased to the size of adipose tissue mass (77). In summary, obesity and insulin resistance are characterized by an increased basal and a blunted catecholamine and natriuretic peptide-stimulated lipolysis in subcutaneous adipocytes.

\section{Adipose tissue differentiation capacity}

During periods of a chronic positive energy balance, adipocytes become overloaded with TAG and the adipose tissue will expand to accomodate extra TAG storage. This process is firstly determined by an increase in adipocyte size (hypertrophy) and subsequently by an increased adipocyte number (hyperplasia) through a process called adipogenesis (78). In general, the total adipocyte number remains stable during adulthood although cells are renewed during life. It has been estimated that there is a yearly $~ 10 \%$ adipocyte turnover (79). During the $\sim 10$ year lifespan of human adipocytes, the TAG content is renewed six times on average (80).

Hypertrophic adipocytes have been more strongly associated with insulin resistance and its metabolic complications than hyperplastic adipose tissue (81-83). Moreover, adipocyte hypertrophy has been shown to be a key phenotypic characteristic of non-obese and obese type 2 diabetes patients (84), while adipocyte number was lower compared to BMI-matched obese persons without metabolic complications (85-87). Finally, a reduced lipid turnover, due to mitochondrial dysfunction, in adipocytes was also associated with obesity (88) and hypertrophic dysfunctional adipose tissue (89). Together these data a diminished adipocyte 
differentiation capacity, which might result in a reduced TAG storing capacity in obese insulin resistant individuals. Subsequently, this may contribute to a limited lipid buffering capacity.

\section{Adipose tissue inflammation}

Adipose tissue contains, besides adipocytes, a wide variety of stromal vascular cells, including endothelial cells, fibroblasts, preadipocytes and immune cells. The latter have been increasingly implicated in the development of insulin resistance (90). Next to being a lipid storage organ, adipose tissue is also an secretory organ (40) that actively secretes adipokines, including cytokines, chemokines and hormones. These factors can act locally (autocrine and/or paracrine) or systemically as they can be secreted into the circulation (figure 1).

Obese adipose tissue is characterized by secretion of pro-inflammatory cytokines (40), but the trigger for adipose tissue low-grade inflammation is poorly understood. Low-grade inflammation could originate from a rapid expansion of adipose tissue. This could provide intrinsic signals to stimulate an inflammatory response, thereby accommodating tissue remodeling (91). These intrinsic signals may include adipocyte death, hypoxia and mechanotransduction stress arising from interactions between the cell and the extracellular matrix. Alternatively, gut-derived substances such as dietary components or metabolites might stimulate an inflammatory response in adipose tissue (92).

In rodents, an expanded adipose tissue mass is associated with a switch towards a more pro-inflammatory phenotype (93). This is accompanied by an increased production of proinflammatory cytokines such as tumor necrosis factor alpha (TNF- $\alpha$ ), interleukin-6 (IL-6) and monocyte chemoattractant protein-1 (MCP-1) (39). For instance, mice studies show that increased MCP-1 expression attracts macrophages to the adipose tissue, which might polarize from anti-inflammatory M2 to pro-inflammatory cytokine producing M1 macrophages $(94,95)$. This in turn might create an environment for attraction of other immune cells (96) and might accelerate local inflammation (93). However, the role of pro-inflammatory macrophages in human adipose tissue is still under intense debate (97).

Local adipose tissue inflammation interacts also with adipose tissue lipid metabolism. Through release of inflammatory factors, immune cells can affect adipose tissue lipid buffering capacity and lipolysis (98). For instance, in vitro studies show that IL-6 and TNF- $\alpha$ stimulate adipocyte lipolysis (99-101), and might thereby contribute to systemic fatty acid release. Moreover, these cytokines can inhibit adipocyte differentiation $(102,103)$, further limiting 
adipose tissue buffering capacity. This deteriorates adipose tissue function and accelerates local and whole-body insulin resistance.

In addition, adipose tissue inflammation might result in systemic low-grade inflammation and may exert detrimental effects on insulin signaling in peripheral tissues, including skeletal muscle and liver. For example, in vitro evidence shows that adipose tissue derived TNF- $\alpha$ impairs GLUT-4 translocation and glucose uptake in human myotubes, although findings are inconsistent $(104,105)$. Moreover, it has been demonstrated that the adipokine adiponectin increases skeletal muscle and liver fat oxidation in vitro $(106,107)$. Therefore, decreased adiponectin concentrations, as observed in obese conditions, may impact fat oxidation, and as such, affect lipid accumulation and insulin sensitivity in both skeletal muscle and liver.

\section{Hepatic lipid metabolism}

The liver plays an important role in whole-body lipid homeostasis and a pathophysiological link between hepatic lipid metabolism and insulin resistance has been known for decades (26). Hepatic insulin resistance is related to accumulation of lipid metabolites in the liver, which may be caused by multiple factors (108). This phenomenon can be explained by an increased NEFA supply from the expanded visceral adipose tissue (the 'portal hypothesis') or an increased intake of dietary fat. In addition, hepatic lipid accumulation may be explained by a reduction in postprandial lipid clearance, an increased uptake of lipoprotein remnants and an increased spillover of NEFA from subcutaneous adipose tissue in the circulation $(109,110)$. Furthermore, hepatic mitochondrial dysfunction and an increased de novo lipogenesis are associated with elevated hepatic lipid accumulation as well $(111,112)$. These processes are reviewed in detail elsewhere $(24,26)$.

As mentioned before, insulin resistance is also linked with an increased secretion of hepatic VLDL-TAG. One role of VLDL is to transport excess energy out of the liver, predominantly in the form of TAG, which in turn elevates plasma TAG levels. VLDL assembly and secretion is a substrate-dependent process that is highly regulated by the availability of fatty acids (25). The fatty acids that are used for VLDL synthesis originate from several endogenous sources. They are mainly coming from the circulating NEFA pool, lipoprotein remnants that are cleared by the liver, intracellular lipids and de novo lipogenesis (113). The total flux of lipids to the liver is an important determinant of hepatic VLDL production and secretion, which can be suppressed by insulin $(114,115)$. Hepatic insulin 
resistance may increase circulating VLDL-TAG concentrations due to diminished insulinmediated suppression of VLDL production and secretion (26). In addition, as VLDL- and chylomicron-TAG compete for the same clearance by LPL in peripheral tissues (116), increased VLDL-TAG in the fasting state may result in delayed clearance of TAG-rich lipoprotein particles in the postprandial state due to prolonged elevated VLDL-TAG concentrations.

\section{Skeletal muscle function and dysfunction}

As skeletal muscle is responsible for $70-80 \%$ of insulin-stimulated whole-body glucose disposal, it plays an important role in the pathogenesis of whole-body insulin resistance (27). Disturbances in skeletal muscle lipid metabolism have been suggested to contribute to the development of muscle insulin resistance and type 2 diabetes (30).

An increased lipid supply from adipose tissue and liver may result in an increased muscle uptake of systemic lipids, but this depends on the source and type of fatty acids. An increased lipid supply together with a reduced capacity to adapt fat oxidation accordingly might contribute to the accumulation of detrimental bioactive lipid intermediates, such as DAG and ceramides (29). This in turn may induce lipotoxicity. In recent years, it has become clear that there is a complex interplay between lipid supply, muscle lipid turnover and subcellular localization and composition of bioactive lipid metabolites. All these factors are involved in the development of a reduced insulin-mediated glucose uptake. They may interfere with the glucose transporter 4 (GLUT-4) translocation to the skeletal muscle membrane (117).

In the next paragraphs, skeletal muscle lipid metabolism will be described in more detail. Lipid uptake, muscle LPL activity, lipid synthesis, lipolysis, lipid oxidation and lipotoxicity will be reviewed. In addition, it will be discussed how a disturbed lipid metabolism may contribute to the development of insulin resistance.

\section{Skeletal muscle lipid uptake}

Under fasting conditions, skeletal muscle takes up fatty acids derived from the plasma NEFA pool as well as those liberated after LPL-mediated lipolysis of VLDL-TAG in the capillary bed of skeletal muscle. However, the quantitive contribution of the latter process compared to total NEFA uptake in fasting conditions is not clear. A slightly but significantly higher uptake of plasma-derived NEFA during fasting has been shown in skeletal muscle of obese versus lean (118) and insulin-resistant versus control individuals (63). This increased uptake 
was observerd despite comparable plasma NEFA concentrations. In contrast, two other human in vivo studies showed no difference in skeletal muscle fatty acid uptake $(119,120)$. The first study compared an insulin resistant group with a control group, while the second compared impaired glucose tolerant individuals with normal glucose tolerant individuals. Despite the somewhat contradicting results, these data may point towards more pronounced disturbances in TAG metabolism rather than NEFA under obese insulin resistant conditions.

In the postprandial state, both VLDL-TAG and chylomicron-TAG are present in the circulation and these particles compete for LPL-mediated hydrolysis. It has been shown that chylomicron-TAG is the preferred substrate for LPL, but it competes with VLDL-TAG for extracellular lipolysis (116). VLDL-TAG makes a large contribution to circulating TAG, even in the postprandial phase (121). Compared to adipose tissue, it has been suggested that uptake of TAG-derived fatty acids after LPL hydrolysis is more efficient in skeletal muscle (122). Moreover, substantial fatty acid spillover also occurs in skeletal muscle, although it has been suggested that the extent of fatty acid spillover is less in skeletal muscle than in adipose tissue (123). These fatty acids merge with the plasma NEFA pool to compete for cellular uptake (124).

The contribution of TAG-derived fatty acids to skeletal muscle lipid uptake may be at least equally important as plasma NEFA $(122,124)$. Elevated plasma TAG concentrations have been associated with whole-body insulin resistance. As discussed above, this might be due to increased liver VLDL production $(26,66)$ and/or impaired clearance of circulating TAG by adipose tissue in the postprandial state (60-64). Previously, our group has demonstrated higher postprandial plasma TAG concentrations and an increased net TAG extraction across forearm muscle in individuals with IFG compared to IGT (125). Furthermore, despite a similar TAG supply, we showed higher postprandial VLDL-TAG extraction by skeletal muscle in insulin resistant men compared to BMI and age matched controls with the metabolic syndrome (126). However, another study including overweight men with insulin resistance could not confirm an increased postprandial muscle TAG extraction, despite elevated TAG concentrations (63). Recently, it was shown that muscle VLDL-TAG extraction was significantly greater in men with type 2 diabetes compared with nondiabetic men in the fasting state (127). Although the evidence is not conclusive, these studies indicate an impaired skeletal muscle TAG metabolism under insulin resistant conditions. 


\section{Skeletal muscle LPL activity}

The expression and activation of muscle LPL plays a major role in skeletal muscle TAG extraction. Mice studies showed that skeletal muscle-specific deletion of LPL reduces lipid storage and increases insulin signaling in skeletal muscle (128). Additionally, muscle-specific LPL overexpression induced muscle insulin resistance, while skeletal muscle LPL knockdown showed the reverse effect (129). Although human data is limited, most studies indicate that fasting and exercise raises total LPL activity in human skeletal muscle (130,131), but results are not consistent (44). Moreover, insulin has been shown to stimulate LPL activity in adipose tissue, but does not appear to activate LPL in skeletal muscle (132). It has been hypothesized that these divergent tissue-specific LPL responses to insulin would serve to direct TAG-derived fatty acids away from muscle and towards the adipose tissue for storage (132).

In recent years, ANGPTL4 has emerged as an important inhibitor of skeletal muscle LPL activity at the post-translational level (46). In line with adipose tissue, mRNA expression of ANGPTL4 in human skeletal muscle is markedly increased during fasting (51). This is likely mediated via elevated plasma NEFA concentrations $(50,133)$ and this may offset an increase in LPL mRNA/protein concentrations. This could lead to a decreased functional LPL activity (42). However, the role of skeletal muscle ANGPTL4 in muscle LPL activity and insulin resistance in humans remains to be elucidated.

The fatty acids that are liberated via LPL-mediated lipolysis as well as these from the plasma NEFA pool can be taken up into the skeletal muscle via passive diffusion and by protein-mediated transport, such as fatty acid translocase CD36, FABPm and FATP1-6 $(68,134)$. Of these fatty acid transporters, CD36 is the best characterized. In humans, it was shown that CD36 protein expression may be acutely upregulated by insulin (135) and this upregulation may be more pronounced in insulin resistant conditions (136). Moreover, increased rates of fatty acid transport have been associated with increased localization of CD36 at the plasma membrane in individuals with type 2 diabetes, while total CD36 protein expression was not changed (137). This suggest that a permanent redistribution of CD36 to the plasma membrane occurred, which might play an essential role in the increased skeletal muscle uptake.

\section{Skeletal muscle lipid synthesis}

Once fatty acids have entered the myocyte, they bind to the cytoplasmic FABPc for transport through the cell (138). The enzyme long chain fatty acyl-CoA synthetase (LC-FACS) will 
catalyze their binding to acetyl CoA. Subsequently, they can either be directed towards storage in lipid droplets or they can be directed towards the mitochondria to be used as energy source.

Intramyocellular storage of lipids is part of lipid turnover and is regulated by several processes. This includes enzymes catalyzing the esterification of fatty acyl-CoA into TAG and lipolytic enzymes. Initiation of TAG synthesis requires coupling of fatty acids to a glycerol backbone. The subsequent steps are dependent on the rate limiting enzymes glycerol-3phosphatases (GPAT1-4) and diglyceride acyltransferase (DGAT1-2) (29). The latter enzyme has a dual role as it promotes TAG storage, but also decreases its precursor DAG which has been shown to have an inhibitory effect on insulin signaling in several studies (139). Although, there is limited evidence from human studies for a role of DGAT in insulin resistance (29), a short-term overexpression of DGAT1 in rat skeletal muscle showed beneficial effects on insulin sensitivity, despite increased TAG and DAG concentrations (140). Up to now, knowledge on muscle lipid turnover measured in vivo in humans in relation to insulin resistance is limited. In insulin resistant smokers compared with less insulin resistant non-smokers, muscle TAG concentrations and its fractional synthetic rate were not altered (141). Furthermore, a reduced fractional synthetic rate of muscle TAG was found in obese pre-diabetic individuals as compared with normal glucose tolerant individuals after exercise. This was found together with higher TAG concentrations, a reduced oxidative capacity and an impaired peripheral insulin action (142). Notably, these disturbances in muscle TAG metabolism were not found in women, indicating sex-related differences in muscle fatty acid handling (143). In addition, it was shown that IGT individuals (either isolated or in combination with IFG) had a reduced saturation and fractional synthesis of the DAG and TAG pool after a high saturated fatty acid mixed-meal (125). In combination with a reduced expression of oxidative genes, these data indicate that the insulin resistant muscle is characterized by disturbances in lipid turnover, particularly when exposed to a meal high in saturated fatty acids.

Lipid synthesis in skeletal muscle is also controlled by fatty acid desaturation which is tightly controlled by the enzyme $\Delta 9$-desaturase or steroyl-CoA desaturase 1 (SCD1). It desaturates saturated fatty acids into mono unsaturated fatty acids, more specifically stearate $(\mathrm{C} 18: 0)$ and palmitate $(\mathrm{C} 16: 0)$ into the less toxic oleate $(\mathrm{C} 18: 1 n-9)$ and palmitoleate $\left(\mathrm{C} 16: 1 n^{-7}\right)(144)$. It has been shown that unsaturated fatty acids are the preferred substrates for TAG synthesis (145). In rodent myotubes, overexpression of SCD1 resulted in a significant increase in fatty acid esterification into TAG, with decreases in fatty acid oxidation and accumulation of lipid metabolites such as ceramides. This suggests that SCD1 protects 
muscle cells from fatty acid induced insulin resistance by reducing ceramide and DAG accumulation, at least in rodents (146). However, an increased SCD1 mRNA expression has been observed in the skeletal muscle of extremely obese humans with severe muscle insulin resistance (147). Therefore, it remains an open question whether SCD1 plays a central role in the pathogenesis of insulin resistance.

\section{Skeletal muscle lipolysis}

Lipid turnover in skeletal muscle is not only determined by TAG synthesis but also by TAG lipolysis and subsequent fatty acid oxidation. As in adipose tissue, skeletal muscle lipolysis is mainly regulated by insulin and the consecutive action of ATGL and HSL $(74,148)$. An in vivo microdialysis study with obese individuals has shown a blunted catecholamine-induced lipolysis in skeletal muscle (149). Moreover, obese insulin resistant men have lower HSL and higher ATGL protein content in skeletal muscle as well as a reduced HSL mRNA expression, phosphorylation and activity (150). This marked difference in muscle lipase content in obese insulin-resistant men was accompanied by a lower DAG hydrolase activity, resulting in a $60 \%$ lower ratio of DAG to TAG hydrolase activity (151). This suggests an incomplete muscle TAG hydrolysis. Of interest, this dysbalance in lipase activity was not accompanied by increased total DAG accumulation but rather an increase in saturated DAG lipid species in the muscle membrane and increased protein kinase $\mathrm{C}$ (PKC) activation in men with type 2 diabetes versus normal glucose tolerant men $(151,152)$. These data together point towards a disturbed skeletal muscle lipolysis in obese insulin resistant conditions.

\section{Fatty acid oxidation in skeletal muscle}

In normal physiology, the aim of skeletal muscle lipid turnover is to provide intracellular fatty acids for oxidation when needed. If fatty acids are destined for oxidation, the fatty acyl-CoA is transported into mitochondria via the action of carnitine palmitoyl transferase I (CPTI) (153). This enzyme is expressed on the outer mitochondrial membrane. Next to CPTI, CD36 is expressed on mitochondrial membranes and it has been hypothesized to influence mitochondrial fatty acid transport and oxidation (154). Once inside mitochondria, fatty acylCoA enters $\beta$-oxidation, a process which generates acetyl-CoA for the tricarboxylic acid cycle. There, $\mathrm{NADH}$ and $\mathrm{FADH}_{2}$ are formed and transferred to the electron transport chain, where ultimately the intracellular energy transfer molecule adenosine triphosphate (ATP) is produced. This process is called oxidative phosphorylation. 
An impaired capacity to increase fat oxidation upon increased fatty acid availability and to switch between fat and glucose oxidation during insulin-mediated conditions has been referred to as metabolic inflexibility $(28,155)$. Under fasting conditions, fatty acid oxidation measured across skeletal muscle has been shown to be reduced in obese individuals with type 2 diabetes $(156,157)$ as well as the postprandial suppression of skeletal muscle fat oxidation (120). This apparent inflexibility also included a high reliance of obese individuals on glucose oxidation in the fasting state, but this could not be further increased during insulin infusion (120). As the absolute rate of lipid oxidation in the obese muscle was not able to change between fasting and postprandial conditions, this forms the basis for the 'metabolic inflexibility' model of skeletal muscle insulin resistance $(24,158)$.

Mitochondrial dysfunction might be one of the key factors that is responsible for the intracellular accumulation of lipids and the inhibition of insulin signaling in skeletal muscle (28). This hypothesis is based on links between insulin resistance and decreased ex vivo mitochondrial respiration, enzyme activity, fatty acid oxidation (159) and mitochondrial size (160). Several studies found low skeletal muscle oxidative capacity in insulin resistant individuals (161,162), but results are not consistent (163). Currently, in the scientific community there is a large debate ongoing whether the association between mitochondrial dysfunction and skeletal muscle insulin resistance is a causal relationship or rather a consequence of lipotoxicity (164).

\section{Lipotoxicity: lipid accumulation in skeletal muscle}

Multiple studies have reported a negative association between intramyocellular lipid (IMCL) content and insulin sensitivity in sedentary lean, obese and type 2 diabetes individuals $(165,166)$. However, this association is not present in endurance trained athletes who also have high levels of IMCL, but also are very insulin sensitive (167). This paradox lead to the hypothesis that not IMCL per se, but rather lipid intermediates, like long-chain fatty acylCoAs (LCFA-CoAs), DAG and ceramides, and their localization and fatty acid composition are related to insulin resistance. They may interfere in the insulin signaling pathway and negatively affect mitochondrial function (29).

LCFA-CoAs are the metabolically activated form of intracellular fatty acids and it commits the fatty acids to either lipid synthesis or fatty acid oxidation in the mitochondria. Several data support a link between LCFA-CoAs and insulin resistance. In rodents, studies utilizing lipid infusion (168) and high-fat diets (169) have demonstrated increased skeletal 
muscle LCFA-CoAs in conjunction with insulin resistance. In humans, weight loss reduces skeletal muscle LCFA-CoA content in obesity, concomitant with improvements in insulin sensitivity (170). Although associations with insulin resistance have been described, so far no mechanism by which LCFA-CoA causes insulin resistance have been identified. It is possible that LCFA-CoA acts as a precursor for DAG or ceramide synthesis, resulting in insulin resistance (171).

In skeletal muscle, increased DAG concentrations are associated with insulin resistance (29). DAG is an intermediate in TAG synthesis and breakdown and it is an important intracellular second messenger. Induction of insulin resistance in healthy lean individuals by lipid infusion resulted in increased DAG levels in skeletal muscle (172), while weight loss or exercise interventions decreased intramuscular DAG concentrations and improved insulin sensitivity $(173,174)$. Nevertheless, the role of DAG in this process is controversial (171). It has also been proposed that it is not total DAG content per se but rather specific DAGsubspecies $(175,176)$ or DAG intracellular localization $(152,177)$ that drives insulin resistance in humans.

Ceramides, which belong to the sphingolipid class, are frequently associated with insulin resistance as well. Accumulation of ceramides can impair insulin signaling resulting in an inhibition of GLUT-4 translocation (178). Indeed, elevated skeletal muscle ceramide levels have been observed in in obese insulin-resistant individuals (179-182), but not all studies show this association $(183,184)$. Like DAG, it has recently been postulated that specific ceramidesubspecies might play a more central role in driving insulin resistance rather than total ceramide content $(185,186)$. Moreover, diet composition plays a role in skeletal muscle lipid composition as well. For instance, it has been shown that increased levels of the saturated fatty acid palmitate can drive ceramide synthesis (187). Nevertheless, it remains an open question whether ceramides play a central role in the pathogenesis of insulin resistance.

\section{Outline of the thesis}

Research in this thesis focused on multiple aspects of lipid metabolism in relation to wholebody and tissue-specific insulin resistance.

As indicated in this introduction, the obese insulin resistant state is characterized by lipid overflow. This is mainly driven by an impaired lipid buffering capacity, and an impaired capacity to increase muscle fat oxidation upon increased supply. However, little knowledge is 
available on the contribution of dietary versus endogenous fatty acids to lipid overflow, their extraction and uptake by skeletal muscle as well fractional synthetic rate, content and composition of the skeletal muscle lipid pools in insulin resistance. In addition, previous studies have used a relatively small sample size due to methodological difficulties as well as the high costs associated with using stable isotope tracers. Therefore, in chapter 2 we studied the contribution of endogenous and dietary fatty acid sources to skeletal muscle uptake and storage in a study of overweight or obese participants $(n=74)$ with a wide range of insulin resistance. We used a combination of differential stable isotope labeling of endogenously $\left(\left[{ }^{2} \mathrm{H}_{2}\right]\right.$-palmitate) and meal-derived fatty acids ([U- $\left.{ }^{13} \mathrm{C}\right]$-palmitate tracers) in combination with arterio-venous tracee and tracer concentration measurements across forearm muscle and biochemical analysis in muscle biopsies.

Chylomicron- and VLDL-TAG are hydrolysed in the process of intravascular lipolysis by LPL. Insulin is an important regulator of LPL activity, but a considerable part of the variation in LPL activity may also be explained by other factors. The LPL inhibitor ANGPTL4 is an interesting candidate and might be involved in the altered skeletal muscle TAG extraction previously observed in insulin resistant conditions. Hence, in chapter 3 , the role of plasma ANGPTL4 in skeletal muscle lipid metabolism in overweight or obese insulin resistant individuals was studied. We investigated the relationship between plasma ANGPTL4 concentration and in vivo skeletal muscle LPL activity, but we also addressed the impact of dietary fat quality on plasma ANGPTL4 concentrations and examined whether human forearm muscle secretes ANGPTL4.

In addition to skeletal muscle, the role of plasma ANGPTL4 in relation to in vivo adipose tissue fatty acid metabolism in humans is currently unknown. Limited information is available on the role of ANGPTL4 in the impaired adipose tissue TAG extraction as observed in obese individuals in the postprandial state and whether weight loss affects in vivo adipose tissue LPL activity and ANGPTL4 in parallel. In chapter 4, the aim was to investigate fasting and postprandial plasma ANGPTL4 concentrations and their relationship with in vivo adipose tissue LPL activity and intracellular lipolysis in overweight and obese humans before and after diet-induced weight loss.

Although the development of type 2 diabetes and cardiometabolic risk is tightly coupled to insulin resistance, there are indications that insulin resistance may not develop simultaneously in different organs. For instance, in prediabetes, the IFG phenotype may be merely characterized by hepatic insulin resistance, whilst the IGT phenotype has more 
pronounced peripheral (muscle) insulin resistance. To obtain more evidence for intervention strategies targeting different tissue-related or prediabetic phenotypes, more knowledge on the distinct phenotypes is required. In chapter 5, we studied cross-sectional associations of tissuespecific insulin resistance with plasma lipidome profiles. We identified 140 lipid species which were measured by liquid chromatography-mass spectrometry. Tissue-specific insulin resistance was estimated based on a 0-120 min oral glucose tolerance test with 5 time-points. This was studied in a relatively large group of overweight or obese individuals within the context of the European multicenter DiOGenes dietary intervention study. Furthermore, in chapter 6 , in the same cohort, we investigated abdominal subcutaneous adipose tissue transcriptome by means of RNA sequencing in relation to tissue-specific insulin resistance.

Finally, in chapter 7 the main findings from the studies described in this thesis are integrated and discussed in a broader perspective and implications for future research are provided. 


\section{References}

1. Ng M, Fleming T, Robinson M, Thomson B, Graetz N, Margono C, et al. Global, regional, and national prevalence of overweight and obesity in children and adults during 1980-2013: a systematic analysis for the Global Burden of Disease Study 2013. Lancet. 2014;384:766-81.

2. World Health Organization. Fact sheet 311: obesity and overweight. 2015. http://www. who.int/mediacentre/factsheets/fs311/en; 2016.

3. GGD'en G. CBS en RIVM. Gezondheidsmonitor GGD'en; 2016.

4. Lim SS, Vos T, Flaxman AD, Danaei G, Shibuya K, Adair-Rohani H, et al. A comparative risk assessment of burden of disease and injury attributable to 67 risk factors and risk factor clusters in 21 regions, 1990-2010: a systematic analysis for the Global Burden of Disease Study 2010. Lancet. 2012;380:2224-60.

5. Kahn SE, Hull RL, Utzschneider KM. Mechanisms linking obesity to insulin resistance and type 2 diabetes. Nature. 2006;444:840-6.

6. Emerging Risk Factors Collaboration, Wormser D, Kaptoge S, Di Angelantonio E, Wood AM, Pennells L, et al. Separate and combined associations of body-mass index and abdominal adiposity with cardiovascular disease: collaborative analysis of 58 prospective studies. Lancet. 2011;377:1085-95.

7. Preiss K, Brennan L, Clarke D. A systematic review of variables associated with the relationship between obesity and depression. Obes Rev. 2013;14:906-18.

8. Renehan AG, Zwahlen M, Egger M. Adiposity and cancer risk: new mechanistic insights from epidemiology. Nat Rev Cancer. 2015;15:484-98.

9. Goossens GH. The role of adipose tissue dysfunction in the pathogenesis of obesity-related insulin resistance. Physiol Behav. 2008;94:206-18.

10. Apovian CM. Obesity: definition, comorbidities, causes, and burden. Am J Manag Care. 2016;22:s17685.

11. Samuel VT, Petersen KF, Shulman GI. Lipid-induced insulin resistance: unravelling the mechanism. Lancet. 2010;375:2267-77.

12. World Health Organization. Global report on diabetes. 2016.

13. World Health Organization. Factsheet $\mathrm{nr}$ 317: Cardiovascular diseases (CVDs). 2017. http://www.who.int/mediacentre/factsheets/fs317/en/.

14. DeFronzo RA. Insulin resistance, lipotoxicity, type 2 diabetes and atherosclerosis: the missing links. The Claude Bernard Lecture 2009. Diabetologia. 2010;53:1270-87.

15. Bornfeldt KE, Tabas I. Insulin Resistance, Hyperglycemia, and Atherosclerosis. Cell Metab. 2011;14:575-85.

16. Stefan N, Fritsche A, Schick F, Häring H-U. Phenotypes of prediabetes and stratification of cardiometabolic risk. Lancet Diabetes Endocrinol. 2016;4:789-98.

17. Faerch K, Hulmán A, Solomon TPJ. Heterogeneity of Pre-diabetes and Type 2 Diabetes: Implications for Prediction, Prevention and Treatment Responsiveness. Curr Diabetes Rev. 2016;12:30-41.

18. Bird SR, Hawley JA. Update on the effects of physical activity on insulin sensitivity in humans. BMJ Open Sport Exerc Med. 2016;2:e000143. 
19. Zheng J, Woo S-L, Hu X, Botchlett R, Chen L, Huo Y, et al. Metformin and metabolic diseases: a focus on hepatic aspects. Front Med. 2015;9:173-86.

20. Blanco-Rojo R, Alcala-Diaz JF, Wopereis S, Perez-Martinez P, Quintana-Navarro GM, Marin C, et al. The insulin resistance phenotype (muscle or liver) interacts with the type of diet to determine changes in disposition index after 2 years of intervention: the CORDIOPREV-DIAB randomised clinical trial. Diabetologia. 2015.

21. Rask-Madsen C, Kahn CR. Tissue-specific insulin signaling, metabolic syndrome, and cardiovascular disease. Arterioscler Thromb Vasc Biol. 2012;32:2052-9.

22. Brüning JC, Michael MD, Winnay JN, Hayashi T, Hörsch D, Accili D, et al. A muscle-specific insulin receptor knockout exhibits features of the metabolic syndrome of NIDDM without altering glucose tolerance. Mol Cell. 1998;2:559-69.

23. Biddinger SB, Hernandez-Ono A, Rask-Madsen C, Haas JT, Alemán JO, Suzuki R, et al. Hepatic insulin resistance is sufficient to produce dyslipidemia and susceptibility to atherosclerosis. Cell Metab. 2008;7:125-34.

24. Stinkens R, Goossens GH, Jocken JWE, Blaak EE. Targeting fatty acid metabolism to improve glucose metabolism. Obes Rev. 2015;16:715-57.

25. Nielsen S, Karpe F. Determinants of VLDL-triglycerides production. Curr Opin Lipidol. 2012;23:3216.

26. Choi SH, Ginsberg HN. Increased very low density lipoprotein (VLDL) secretion, hepatic steatosis, and insulin resistance. Trends Endocrinol Metab. 2011;22:353-63.

27. DeFronzo RA, Jacot E, Jequier E, Maeder E, Wahren J, Felber JP. The effect of insulin on the disposal of intravenous glucose. Results from indirect calorimetry and hepatic and femoral venous catheterization. Diabetes. 1981;30:1000-7.

28. Affourtit C. Mitochondrial involvement in skeletal muscle insulin resistance: A case of imbalanced bioenergetics. Biochim Biophys Acta. 2016;1857:1678-93.

29. Bosma M, Kersten S, Hesselink MKC, Schrauwen P. Re-evaluating lipotoxic triggers in skeletal muscle: relating intramyocellular lipid metabolism to insulin sensitivity. Prog Lipid Res. 2012;51:36-49.

30. Shulman GI. Ectopic Fat in Insulin Resistance, Dyslipidemia, and Cardiometabolic Disease. N Eng1 J Med. 2014;371:1131-41.

31. Mishra AK, Dubey V, Ghosh AR. Obesity: An overview of possible role(s) of gut hormones, lipid sensing and gut microbiota. Metab Clin Exp. 2016;65:48-65.

32. Canfora EE, Jocken JW, Blaak EE. Short-chain fatty acids in control of body weight and insulin sensitivity. Nat Rev Endocrinol. 2015;11:577-91.

33. Reijnders D, Goossens GH, Hermes GDA, Neis EPJG, van der Beek CM, Most J, et al. Effects of Gut Microbiota Manipulation by Antibiotics on Host Metabolism in Obese Humans: A Randomized Double-Blind Placebo-Controlled Trial. Cell Metab. 2016;24:63-74.

34. Goossens GH. The Metabolic Phenotype in Obesity: Fat Mass, Body Fat Distribution, and Adipose Tissue Function. Obes Facts. 2017;10:207-15.

35. Karpe F, Pinnick KE. Biology of upper-body and lower-body adipose tissue--link to whole-body phenotypes. Nat Rev Endocrinol. 2015;11:90-100.

36. Tchkonia T, Thomou T, Zhu Y, Karagiannides I, Pothoulakis C, Jensen MD, et al. Mechanisms and Metabolic Implications of Regional Differences among Fat Depots. Cell Metab. 2013;17:644-56. 
37. Ibrahim MM. Subcutaneous and visceral adipose tissue: structural and functional differences. Obes Rev. 2010;11:11-8.

38. Klöting N, Blüher M. Adipocyte dysfunction, inflammation and metabolic syndrome. Rev Endocr Metab Disord. 2014;15:277-87.

39. Ouchi N, Parker JL, Lugus JJ, Walsh K. Adipokines in inflammation and metabolic disease. Nat Rev Immunol. 2011;11:85-97.

40. Leal V de O, Mafra D. Adipokines in obesity. Clin Chim Acta. 2013;419:87-94.

41. Frayn K. Adipose tissue as a buffer for daily lipid flux. Diabetologia. 2002;45:1201-10.

42. Kersten S. Physiological regulation of lipoprotein lipase. Biochim Biophys Acta. 2014;1841:919-33.

43. Goldberg IJ, Eckel RH, Abumrad NA. Regulation of fatty acid uptake into tissues: lipoprotein lipaseand CD36-mediated pathways. J Lipid Res. 2009;50 Suppl:S86-90.

44. Yost TJ, Jensen DR, Haugen BR, Eckel RH. Effect of dietary macronutrient composition on tissuespecific lipoprotein lipase activity and insulin action in normal-weight subjects. Am J Clin Nutr. 1998;68:296-302.

45. Brunzell JD, Schwartz RS, Eckel RH, Goldberg AP. Insulin and adipose tissue lipoprotein lipase activity in humans. Int J Obes. 1981;5:685-94.

46. Dijk W, Kersten S. Regulation of lipoprotein lipase by Angptl4. Trends Endocrinol Metab. 2014;25:146-55.

47. Sukonina V, Lookene A, Olivecrona T, Olivecrona G. Angiopoietin-like protein 4 converts lipoprotein lipase to inactive monomers and modulates lipase activity in adipose tissue. Proc Natl Acad Sci USA. 2006;103:17450-5.

48. Dijk W, Beigneux AP, Larsson M, Bensadoun A, Young SG, Kersten S. Angiopoietin-like 4 promotes intracellular degradation of lipoprotein lipase in adipocytes. J Lipid Res. 2016;57:1670-83.

49. Kroupa O, Vorrsj E, Stienstra R, Mattijssen F, Nilsson SK, Sukonina V, et al. Linking nutritional regulation of Angptl4, Gpihbp1, and Lmf1 to lipoprotein lipase activity in rodent adipose tissue. BMC Physiol. 2012;12:1-1.

50. Kersten S, Lichtenstein L, Steenbergen E, Mudde K, Hendriks HFJ, Hesselink MK, et al. Caloric restriction and exercise increase plasma ANGPTL4 levels in humans via elevated free fatty acids. Arterioscler Thromb Vasc Biol. 2009;29:969-74.

51. Catoire M, Alex S, Paraskevopulos N, Mattijssen F, Evers-van Gogh I, Schaart G, et al. Fatty acidinducible ANGPTL4 governs lipid metabolic response to exercise. Proc Natl Acad Sci USA. 2014;111:E1043-52.

52. Norheim F, Hjorth M, Langleite TM, Lee S, Holen T, Bindesbøll C, et al. Regulation of angiopoietinlike protein 4 production during and after exercise. Physiol Rep. 2014;2.

53. Brands M, Sauerwein HP, Ackermans MT, Kersten S, Serlie MJ. Omega-3 long-chain fatty acids strongly induce angiopoietin-like 4 in humans. J Lipid Res. 2013;54:615-21.

54. Ruge T, Sukonina V, Kroupa O, Makoveichuk E, Lundgren M, Svensson MK, et al. Effects of hyperinsulinemia on lipoprotein lipase, angiopoietin-like protein 4, and glycosylphosphatidylinositolanchored high-density lipoprotein binding protein 1 in subjects with and without type 2 diabetes mellitus. Metab Clin Exp. 2012;61:652-60. 
protein 4 is differentially regulated by glucocorticoids and insulin in vitro and in vivo in healthy humans. Exp Clin Endocrinol Diabetes. 2012;120:598-603.

56. Dijk W, Kersten S. Regulation of lipid metabolism by angiopoietin-like proteins. Curr Opin Lipidol. 2016;27:249-56.

57. Sadur CN, Yost TJ, Eckel RH. Insulin responsiveness of adipose tissue lipoprotein lipase is delayed but preserved in obesity. J Clin Endocrinol Metab. 1984;59:1176-82.

58. Riemens SC, Sluiter WJ, Dullaart RP. Enhanced escape of non-esterified fatty acids from tissue uptake: its role in impaired insulin-induced lowering of total rate of appearance in obesity and Type II diabetes mellitus. Diabetologia. 2000;43:416-26.

59. Søndergaard E, Johansen RF, Jensen MD, Nielsen S. Postprandial VLDL-TG metabolism in type 2 diabetes. Metab Clin Exp. 2017;75:25-35.

60. Potts JL, Coppack SW, Fisher RM, Humphreys SM, Gibbons GF, Frayn KN. Impaired postprandial clearance of triacylglycerol-rich lipoproteins in adipose tissue in obese subjects. Am J Physiol. 1995;268:E588-94.

61. Panarotto D, Rémillard P, Bouffard L, Maheux P. Insulin resistance affects the regulation of lipoprotein lipase in the postprandial period and in an adipose tissue-specific manner. Eur J Clin Invest. 2002;32:8492.

62. Coppack SW, Evans RD, Fisher RM, Frayn KN, Gibbons GF, Humphreys SM, et al. Adipose tissue metabolism in obesity: lipase action in vivo before and after a mixed meal. Metab Clin Exp. 1992;41:264-72.

63. Bickerton AST, Roberts R, Fielding BA, Tornqvist H, Blaak EE, Wagenmakers AJM, et al. Adipose tissue fatty acid metabolism in insulin-resistant men. Diabetologia. 2008;51:1466-74.

64. Annuzzi G, Giacco R, Patti L, Di Marino L, De Natale C, Costabile G, et al. Postprandial chylomicrons and adipose tissue lipoprotein lipase are altered in type 2 diabetes independently of obesity and wholebody insulin resistance. Nutr Metab Cardiovasc Dis. 2008;18:531-8.

65. McQuaid SE, Hodson L, Neville MJ, Dennis AL, Cheeseman J, Humphreys SM, et al. Downregulation of Adipose Tissue Fatty Acid Trafficking in Obesity: A Driver for Ectopic Fat Deposition? Diabetes. 2010;60:47-55.

66. Sparks JD, Sparks CE, Adeli K. Selective hepatic insulin resistance, VLDL overproduction, and hypertriglyceridemia. Arterioscler Thromb Vasc Biol. 2012;32:2104-12.

67. Frayn KN, Coppack SW, Fielding BA, Humphreys SM. Coordinated Regulation of HormoneSensitive Lipase and Lipoprotein-Lipase in Human Adipose-Tissue in-Vivo - Implications for the Control of Fat Storage and Fat Mobilization. Adv Enzyme Regul. 1995;35:163-78.

68. Glatz JFC, Luiken JJFP, Bonen A. Membrane fatty acid transporters as regulators of lipid metabolism: implications for metabolic disease. Physiol Rev. 2010;90:367-417.

69. Frayn KN, Shadid S, Hamlani R, Humphreys SM, Clark ML, Fielding BA, et al. Regulation of fatty acid movement in human adipose tissue in the postabsorptive-to-postprandial transition. Am J Physiol. 1994;266:E308-17.

70. Morigny P, Houssier M, Mouisel E, Langin D. Adipocyte lipolysis and insulin resistance. Biochimie. 2016;125:259-66.

71. Zimmermann R, Strauss JG, Haemmerle G, Schoiswohl G, Birner-Gruenberger R, Riederer M, et al. Fat mobilization in adipose tissue is promoted by adipose triglyceride lipase. Science. 2004;306:1383-6. 
72. Fredrikson G, Tornqvist H, Belfrage P. Hormone-sensitive lipase and monoacylglycerol lipase are both required for complete degradation of adipocyte triacylglycerol. Biochim Biophys Acta. 1986;876:28893.

73. Mittendorfer B, Magkos F, Fabbrini E, Mohammed BS, Klein S. Relationship between body fat mass and free fatty acid kinetics in men and women. Obesity (Silver Spring). 2009;17:1872-7.

74. Jocken JWE, Langin D, Smit E, Saris WHM, Valle C, Hul GB, et al. Adipose triglyceride lipase and hormone-sensitive lipase protein expression is decreased in the obese insulin-resistant state. J Clin Endocrinol Metab. 2007;92:2292-9.

75. Langin D, Dicker A, Tavernier G, Hoffstedt J, Mairal A, Rydén M, et al. Adipocyte lipases and defect of lipolysis in human obesity. Diabetes. 2005;54:3190-7.

76. Laws A, Hoen HM, Selby JV, Saad MF, Haffner SM, Howard BV. Differences in insulin suppression of free fatty acid levels by gender and glucose tolerance status. Relation to plasma triglyceride and apolipoprotein B concentrations. Insulin Resistance Atherosclerosis Study (IRAS) Investigators. Arterioscler Thromb Vasc Biol. 1997;17:64-71.

77. Karpe F, Dickmann JR, Frayn KN. Fatty acids, obesity, and insulin resistance: time for a reevaluation. Diabetes. 2011.

78. Arner P, Spalding KL. Fat cell turnover in humans. Biochim Biophys Acta. 2010;396:101-4.

79. Spalding KL, Arner E, Westermark PO, Bernard S, Buchholz BA, Bergmann O, et al. Dynamics of fat cell turnover in humans. Nature. 2008;453:783-7.

80. Arner P, Bernard S, Salehpour M, Possnert G, Liebl J, Steier P, et al. Dynamics of human adipose lipid turnover in health and metabolic disease. Nature. 2011;478:110-3.

81. Weyer C, Foley JE, Bogardus C, Tataranni PA, Pratley RE. Enlarged subcutaneous abdominal adipocyte size, but not obesity itself, predicts type II diabetes independent of insulin resistance. Diabetologia. 2000;43:1498-506.

82. Eriksson JW, Smith U, Waagstein F, Wysocki M, Jansson PA. Glucose turnover and adipose tissue lipolysis are insulin-resistant in healthy relatives of type 2 diabetes patients: is cellular insulin resistance a secondary phenomenon? Diabetes. 1999;48:1572-8.

83. Moreno-Indias I, Tinahones FJ. Impaired adipose tissue expandability and lipogenic capacities as ones of the main causes of metabolic disorders. J Diabetes Res. 2015;2015:970375-12.

84. Acosta JR, Douagi I, Andersson DP, Bäckdahl J, Rydén M, Arner P, et al. Increased fat cell size: a major phenotype of subcutaneous white adipose tissue in non-obese individuals with type 2 diabetes. Diabetologia. 2016;59:560-70.

85. Pasarica M, Xie H, Hymel D, Bray G, Greenway F, Ravussin E, et al. Lower total adipocyte number but no evidence for small adipocyte depletion in patients with type 2 diabetes. Diabetes Care. 2009;32:900-2.

86. Rydén M, Andersson DP, Bergström IB, Arner P. Adipose tissue and metabolic alterations: regional differences in fat cell size and number matter, but differently: a cross-sectional study. J Clin Endocrinol Metab. 2014;99:E1870-6.

87. van Tienen FHJ, van der Kallen CJH, Lindsey PJ, Wanders RJ, Van Greevenbroek MM, Smeets HJM. Preadipocytes of type 2 diabetes subjects display an intrinsic gene expression profile of decreased differentiation capacity. Int J Obes (Lond). 2011;35:1154-64.

88. Rydén M, Andersson DP, Bernard S, Spalding K, Arner P. Adipocyte triglyceride turnover and lipolysis in lean and overweight subjects. J Lipid Res. 2013;54:2909-13. 
89. Arner E, Westermark PO, Spalding KL, Britton T, Rydén M, Frisén J, et al. Adipocyte turnover: relevance to human adipose tissue morphology. Diabetes. 2010;59:105-9.

90. Rosen ED, Spiegelman BM. What We Talk About When We Talk About Fat. Cell. 2014;156:20-44.

91. Reilly SM, Saltiel AR. Adapting to obesity with adipose tissue inflammation. Nat Rev Endocrinol. 2017;13:633-43.

92. Blüher M. Adipose tissue inflammation: a cause or consequence of obesity-related insulin resistance? Clin Sci. 2016;130:1603-14.

93. Asghar A, Sheikh N. Role of immune cells in obesity induced low grade inflammation and insulin resistance. Cell Immunol. 2017;315:18-26.

94. Thomas D, Apovian C. Macrophage functions in lean and obese adipose tissue. Metab Clin Exp. 2017;72:120-43.

95. Castoldi A, Naffah de Souza C, Câmara NOS, Moraes-Vieira PM. The Macrophage Switch in Obesity Development. Front Immunol. 2015;6:637.

96. Haase J, Weyer U, Immig K, Klöting N, Blüher M, Eilers J, et al. Local proliferation of macrophages in adipose tissue during obesity-induced inflammation. Diabetologia. 2014;57:562-71.

97. Schipper HS, Prakken B, Kalkhoven E, Boes M. Adipose tissue-resident immune cells: key players in immunometabolism. Trends Endocrinol Metab. 2012;23:407-15.

98. Mathis D. Immunological goings-on in visceral adipose tissue. Cell Metab. 2013;17:851-9.

99. Souza SC, Palmer HJ, Kang YH, Yamamoto MT, Muliro KV, Eric Paulson K, et al. TNF- $\alpha$ induction of lipolysis is mediated through activation of the extracellular signal related kinase pathway in 3T3-L1 adipocytes. J Cell Biochem. 2003;89:1077-86.

100. Zhang HH, Halbleib M, Ahmad F, Manganiello VC, Greenberg AS. Tumor necrosis factor-alpha stimulates lipolysis in differentiated human adipocytes through activation of extracellular signal-related kinase and elevation of intracellular cAMP. Diabetes. 2002;51:2929-35.

101. van Hall G, Steensberg A, Sacchetti M, Fischer C, Keller C, Schjerling P, et al. Interleukin-6 stimulates lipolysis and fat oxidation in humans. J Clin Endocrinol Metab. 2003;88:3005-10.

102. Sopasakis VR, Sandqvist M, Gustafson B, Hammarstedt A, Schmelz M, Yang X, et al. High local concentrations and effects on differentiation implicate interleukin-6 as a paracrine regulator. Obes Res. 2004;12:454-60.

103. Petruschke T, Hauner H. Tumor necrosis factor-alpha prevents the differentiation of human adipocyte precursor cells and causes delipidation of newly developed fat cells. J Clin Endocrinol Metab. 1993;76:742-7.

104. Dyck DJ, Heigenhauer GJF, Bruce CR. The role of adipokines as regulators of skeletal muscle fatty acid metabolism and insulin sensitivity. Acta Physiol. 2005;:1-12.

105. Sell H, Eckel J, Dietze-Schroeder D. Pathways leading to muscle insulin resistance--the muscle--fat connection. Arch Physiol Biochem. 2006;112:105-13.

106. Lumeng CN, Saltiel AR. Inflammatory links between obesity and metabolic disease. J Clin Invest. 2011;121:2111-7.

107. Kwon H, Pessin JE. Adipokines Mediate Inflammation and Insulin Resistance. Front Endocrinol (Lausanne). 2013;4:1-13. 
108. Meex RCR, Watt MJ. Hepatokines: linking nonalcoholic fatty liver disease and insulin resistance. Nat Rev Endocrinol. 2017;:1-12.

109. Kabir M, Catalano KJ, Ananthnarayan S, Kim SP, Van Citters GW, Dea MK, et al. Molecular evidence supporting the portal theory: a causative link between visceral adiposity and hepatic insulin resistance. Am J Physiol Endocrinol Metab. 2005;288:E454-61.

110. Jensen MD. Role of body fat distribution and the metabolic complications of obesity. J Clin Endocrinol Metab. 2008;93:S57-63.

111. Vial G, Dubouchaud H, Leverve XM. Liver mitochondria and insulin resistance. Acta Biochim Pol. 2010;57:389-92.

112. Donnelly KL, Smith CI, Schwarzenberg SJ, Jessurun J, Boldt MD, Parks EJ. Sources of fatty acids stored in liver and secreted via lipoproteins in patients with nonalcoholic fatty liver disease. J Clin Invest. 2005;115:1343-51.

113. Barrows BR, Parks EJ. Contributions of different fatty acid sources to very low-density lipoproteintriacylglycerol in the fasted and fed states. J Clin Endocrinol Metab. 2006;91:1446-52.

114. Sparks JD, Sparks CE, Adeli K. Selective hepatic insulin resistance, VLDL overproduction, and hypertriglyceridemia. Arterioscler Thromb Vasc Biol. 2012;32:2104-12.

115. Titchenell PM, Lazar MA, Birnbaum MJ. Unraveling the Regulation of Hepatic Metabolism by Insulin. Trends Endocrinol Metab. 2017;28:497-505.

116. Bickerton AST, Roberts R, Fielding BA, Hodson L, Blaak EE, Wagenmakers AJM, et al. Preferential uptake of dietary Fatty acids in adipose tissue and muscle in the postprandial period. Diabetes. 2007;56:168-76.

117. Jaldin-Fincati JR, Pavarotti M, Frendo-Cumbo S, Bilan PJ, Klip A. Update on GLUT4 Vesicle Traffic: A Cornerstone of Insulin Action. Trends Endocrinol Metab. 2017;28:597-611.

118. Jocken JWE, Goossens GH, van Hees AMJ, Frayn KN, van Baak M, Stegen J, et al. Effect of betaadrenergic stimulation on whole-body and abdominal subcutaneous adipose tissue lipolysis in lean and obese men. Diabetologia. 2008;51:320-7.

119. Moors CCM, van der Zijl NJ, Diamant M, Blaak EE, Goossens GH. Impaired insulin sensitivity is accompanied by disturbances in skeletal muscle fatty acid handling in subjects with impaired glucose metabolism. Int J Obes (Lond). 2012;36:709-17.

120. Corpeleijn E, Mensink M, Kooi ME, Roekaerts PMHJ, Saris WHM, Blaak EE. Impaired skeletal muscle substrate oxidation in glucose-intolerant men improves after weight loss. Obesity (Silver Spring). 2008;16:1025-32.

121. Cohn JS, Johnson EJ, Millar JS, Cohn SD, Milne RW, Marcel YL, et al. Contribution of apoB-48 and apoB-100 triglyceride-rich lipoproteins (TRL) to postprandial increases in the plasma concentration of TRL triglycerides and retinyl esters. J Lipid Res. 1993;34:2033-40.

122. Evans K, Burdge GC, Wootton SA, Clark ML, Frayn KN. Regulation of dietary fatty acid entrapment in subcutaneous adipose tissue and skeletal muscle. Diabetes. 2002;51:2684-90.

123. Miles JM, Park YS, Walewicz D, Russell-Lopez C, Windsor S, Isley WL, et al. Systemic and forearm triglyceride metabolism: fate of lipoprotein lipase-generated glycerol and free fatty acids. Diabetes. 2004;53:521-7.

124. Teusink B, Voshol PJ, Dahlmans VEH, Rensen PCN, Pijl H, Romijn JA, et al. Contribution of Fatty Acids Released From Lipolysis of Plasma Triglycerides to Total Plasma Fatty Acid Flux and TissueSpecific Fatty Acid Uptake. Diabetes. 2003;52:614-20. 
125. Goossens G, Moors C, Jocken J, van der Zijl N, Jans A, Konings E, et al. Altered Skeletal Muscle Fatty Acid Handling in Subjects with Impaired Glucose Tolerance as Compared to Impaired Fasting Glucose. Nutrients. 2016;8:164-15.

126. van Hees AMJ, Jans A, Hul GB, Roche HM, Saris WHM, Blaak EE. Skeletal muscle fatty acid handling in insulin resistant men. Obesity. 2011;19:1350-9.

127. Andersen IR, Søndergaard E, Sørensen LP, Nellemann B, Gormsen LC, Jensen MD, et al. Increased VLDL-TG fatty acid storage in skeletal muscle in men with type 2 diabetes. J Clin Endocrinol Metab. 2016;:jc20162979.

128. Wang H, Knaub LA, Jensen DR, Young Jung D, Hong E-G, Ko H-J, et al. Skeletal muscle-specific deletion of lipoprotein lipase enhances insulin signaling in skeletal muscle but causes insulin resistance in liver and other tissues. Diabetes. 2009;58:116-24.

129. Kim JK, Fillmore JJ, Chen Y, Yu C, Moore IK, Pypaert M, et al. Tissue-specific overexpression of lipoprotein lipase causes tissue-specific insulin resistance. Proc Natl Acad Sci USA. 2001;98:7522-7.

130. Sugden MC, Holness MJ, Howard RM. Changes in lipoprotein lipase activities in adipose tissue, heart and skeletal muscle during continuous or interrupted feeding. Biochem J. 1993;292:113-9.

131. Greiwe JS, Holloszy JO, Semenkovich CF. Exercise induces lipoprotein lipase and GLUT-4 protein in muscle independent of adrenergic-receptor signaling. J Appl Physiol. 2000;89:176-81.

132. Farese RV, Yost TJ, Eckel RH. Tissue-Specific Regulation of Lipoprotein-Lipase Activity by Insulin Glucose in Normal-Weight Humans. Metab Clin Exp. 1991;40:214-6.

133. Staiger H, Haas C, Machann J, Werner R, Weisser M, Schick F, et al. Muscle-derived angiopoietinlike protein 4 is induced by fatty acids via peroxisome proliferator-activated receptor (PPAR)-delta and is of metabolic relevance in humans. Diabetes. 2009;58:579-89.

134. Bonen A, Chabowski A, Luiken JJFP, Glatz JFC. Is membrane transport of FFA mediated by lipid, protein, or both? Mechanisms and regulation of protein-mediated cellular fatty acid uptake: molecular, biochemical, and physiological evidence. Physiol. 2007;22:15-29.

135. Bonen A, Benton CR, Campbell SE, Chabowski A, Clarke DC, Han X-X, et al. Plasmalemmal fatty acid transport is regulated in heart and skeletal muscle by contraction, insulin and leptin, and in obesity and diabetes. Acta Physiol Scand. 2003;178:347-56.

136. Corpeleijn E, Pelsers MMAL, Soenen S, Mensink M, Bouwman FG, Kooi ME, et al. Insulin acutely upregulates protein expression of the fatty acid transporter CD36 in human skeletal muscle in vivo. J Physiol Pharmacol. 2008;59:77-83.

137. Bonen A, Parolin ML, Steinberg GR, Calles-Escandon J, Tandon NN, Glatz JFC, et al. Triacylglycerol accumulation in human obesity and type 2 diabetes is associated with increased rates of skeletal muscle fatty acid transport and increased sarcolemmal FAT/CD36. FASEB J. 2004;18:1144-6.

138. Glatz JFC, Luiken JJFP, van Bilsen M, van der Vusse GJ. Cellular lipid binding proteins as facilitators and regulators of lipid metabolism. Mol Cell Biochem. 2002;239:3-7.

139. Timmers S, Schrauwen P, de Vogel J. Muscular diacylglycerol metabolism and insulin resistance. Physiol Behav. 2008;94:242-51.

140. Timmers S, de Vogel-van den Bosch J, Hesselink MKC, van Beurden D, Schaart G, Ferraz MJ, et al. Paradoxical increase in TAG and DAG content parallel the insulin sensitizing effect of unilateral DGAT1 overexpression in rat skeletal muscle. PLoS ONE. 2011;6:e14503.

141. Bergman BC, Perreault L, Hunerdosse DM, Koehler MC, Samek AM, Eckel RH. Intramuscular lipid metabolism in the insulin resistance of smoking. Diabetes. 2009;58:2220-7. 
142. Perreault L, Bergman BC, Hunerdosse DM, Playdon MC, Eckel RH. Inflexibility in Intramuscular Triglyceride Fractional Synthesis Distinguishes Prediabetes From Obesity in Humans. Obesity. 2009;18:1524-31.

143. Perreault L, Bergman BC, Hunerdosse DM, Eckel RH. Altered Intramuscular Lipid Metabolism Relates to Diminished Insulin Action in Men, but Not Women, in Progression to Diabetes. Obesity. 2009;18:2093-100.

144. Hodson L, Fielding BA. Stearoyl-CoA desaturase: rogue or innocent bystander? Prog Lipid Res. 2013;52:15-42.

145. Coleman R. Enzymes of triacylglycerol synthesis and their regulation. Prog Lipid Res. 2004;43:134-76.

146. Pinnamaneni SK, Southgate RJ, Febbraio MA, Watt MJ. Stearoyl CoA desaturase 1 is elevated in obesity but protects against fatty acid-induced skeletal muscle insulin resistance in vitro. Diabetologia. 2006;49:3027-37.

147. Hulver MW, Berggren JR, Carper MJ, Miyazaki M, Ntambi JM, Hoffman EP, et al. Elevated stearoylCoA desaturase-1 expression in skeletal muscle contributes to abnormal fatty acid partitioning in obese humans. Cell Metab. 2005;2:251-61.

148. Jacob S, Hauer B, Becker R, Artzner S, Grauer P, Loblein K, et al. Lipolysis in skeletal muscle is rapidly regulated by low physiological doses of insulin. Diabetologia. 1999;42:1171-4.

149. Blaak EE, Schiffelers SL, Saris WH, Mensink M, Kooi ME. Impaired beta-adrenergically mediated lipolysis in skeletal muscle of obese subjects. Diabetologia. 2004;47:1462-8.

150. Jocken JWE, Moro C, Goossens GH, Hansen D, Mairal A, Hesselink MKC, et al. Skeletal Muscle Lipase Content and Activity in Obesity and Type 2 Diabetes. J Clin Endocrinol Metab. 2010;95:5449_ 53.

151. Jocken JWE, Roepstorff C, Goossens GH, van der Baan P, van Baak M, Saris WHM, et al. Hormonesensitive lipase serine phosphorylation and glycerol exchange across skeletal muscle in lean and obese subjects: effect of beta-adrenergic stimulation. Diabetes. 2008;57:1834-41.

152. Jocken JWE, Goossens GH, Boon H, Mason RR, Essers Y, Havekes B, et al. Insulin-mediated suppression of lipolysis in adipose tissue and skeletal muscle of obese type 2 diabetic men and men with normal glucose tolerance. Diabetologia. 2013;56:2255-65.

153. Rasmussen BB, Holmbäck UC, Volpi E, Morio-Liondore B, Paddon-Jones D, Wolfe RR. Malonyl coenzyme $\mathrm{A}$ and the regulation of functional carnitine palmitoyltransferase- 1 activity and fat oxidation in human skeletal muscle. J Clin Invest. 2002;110:1687-93.

154. Holloway GP, Bezaire V, Heigenhauser GJF, Tandon NN, Glatz JFC, Luiken JJFP, et al. Mitochondrial long chain fatty acid oxidation, fatty acid translocase/CD36 content and carnitine palmitoyltransferase I activity in human skeletal muscle during aerobic exercise. J Physiol. 2006;571:20110.

155. Corpeleijn E, Saris WHM, Blaak EE. Metabolic flexibility in the development of insulin resistance and type 2 diabetes: effects of lifestyle. Obes Rev. 2009;10:178-93.

156. Blaak EE, Wagenmakers AJ, Glatz JF, Wolffenbuttel BH, Kemerink GJ, Langenberg CJ, et al. Plasma FFA utilization and fatty acid-binding protein content are diminished in type 2 diabetic muscle. Am J Physiol Endocrinol Metab. 2000;279:E146-54.

157. Kelley DE. Skeletal muscle fat oxidation: timing and flexibility are everything. J Clin Invest. 2005;115:1699-702. 
158. Goodpaster BH, Sparks LM. Metabolic Flexibility in Health and Disease. Cell Metab. 2017;25:102736.

159. Kelley DE, Goodpaster B, Wing RR, Simoneau JA. Skeletal muscle fatty acid metabolism in association with insulin resistance, obesity, and weight loss. Am J Physiol. 1999;277:E1130-41.

160. Kelley DE, He J, Menshikova EV, Ritov VB. Dysfunction of Mitochondria in Human Skeletal Muscle in Type 2 Diabetes. Diabetes. 2002;51:2944-50.

161. Schrauwen-Hinderling VB, Kooi ME, Hesselink MKC, Jeneson JAL, Backes WH, van Echteld CJA, et al. Impaired in vivo mitochondrial function but similar intramyocellular lipid content in patients with type 2 diabetes mellitus and BMI-matched control subjects. Diabetologia. 2006;50:113-20.

162. Phielix E, Schrauwen-Hinderling VB, Mensink M, Lenaers E, Meex R, Hoeks J, et al. Lower intrinsic ADP-stimulated mitochondrial respiration underlies in vivo mitochondrial dysfunction in muscle of male type 2 diabetic patients. Diabetes. 2008;57:2943-9.

163. Boushel R, Gnaiger E, Schjerling P, Skovbro M, Kraunsøe R, Dela F. Patients with type 2 diabetes have normal mitochondrial function in skeletal muscle. Diabetologia. 2007;50:790-6.

164. Schrauwen P, Schrauwen-Hinderling V, Hoeks J, Hesselink MKC. Mitochondrial dysfunction and lipotoxicity. Biochim Biophys Acta. 2010;1801:266-71.

165. Krssak M, Falk Petersen K, Dresner A, DiPietro L, Vogel SM, Rothman DL, et al. Intramyocellular lipid concentrations are correlated with insulin sensitivity in humans: a 1H NMR spectroscopy study. Diabetologia. 1999;42:113-6.

166. Pan DA, Lillioja S, Kriketos AD, Milner MR, Baur LA, Bogardus C, et al. Skeletal muscle triglyceride levels are inversely related to insulin action. Diabetes. 1997;46:983-8.

167. Goodpaster BH, He J, Watkins S, Kelley DE. Skeletal muscle lipid content and insulin resistance: evidence for a paradox in endurance-trained athletes. J Clin Endocrinol Metab. 2001;86:5755-61.

168. Chalkley SM, Hettiarachchi M, Chisholm DJ, Kraegen EW. Five-hour fatty acid elevation increases muscle lipids and impairs glycogen synthesis in the rat. Metab Clin Exp. 1998;47:1121-6.

169. Ellis BA, Poynten A, Lowy AJ, Furler SM, Chisholm DJ, Kraegen EW, et al. Long-chain acyl-CoA esters as indicators of lipid metabolism and insulin sensitivity in rat and human muscle. Am J Physiol Endocrinol Metab. 2000;279:E554-60.

170. Houmard JA, Tanner CJ, Yu C, Cunningham PG, Pories WJ, MacDonald KG, et al. Effect of weight loss on insulin sensitivity and intramuscular long-chain fatty acyl-CoAs in morbidly obese subjects. Diabetes. 2002;51:2959-63.

171. Coen PM, Goodpaster BH. Role of intramyocelluar lipids in human health. Trends Endocrinol Metab. 2012;23:391-8.

172. Itani SI, Ruderman NB, Schmieder F, Boden G. Lipid-induced insulin resistance in human muscle is associated with changes in diacylglycerol, protein kinase C, and IkappaB-alpha. Diabetes. 2002;51:2005-11.

173. Dube JJ, Amati F, Toledo FGS, Stefanovic-Racic M, Rossi A, Coen P, et al. Effects of weight loss and exercise on insulin resistance, and intramyocellular triacylglycerol, diacylglycerol and ceramide. Diabetologia. 2011;54:1147-56.

174. Dubé JJ, Amati F, Stefanovic-Racic M, Toledo FGS, Sauers SE, Goodpaster BH. Exercise-induced alterations in intramyocellular lipids and insulin resistance: the athlete's paradox revisited. Am J Physiol Endocrinol Metab. 2008;294:E882-8. 
175. Amati F, Dubé JJ, Alvarez-Carnero E, Edreira MM, Chomentowski P, Coen PM, et al. Skeletal muscle triglycerides, diacylglycerols, and ceramides in insulin resistance: another paradox in endurance-trained athletes? Diabetes. 2011;60:2588-97.

176. Bergman BC, Perreault L, Hunerdosse DM, Koehler MC, Samek AM, Eckel RH. Increased intramuscular lipid synthesis and low saturation relate to insulin sensitivity in endurance-trained athletes. J Appl Physiol. 2010;108:1134-41.

177. Bergman BC, Hunerdosse DM, Kerege A, Playdon MC, Perreault L. Localisation and composition of skeletal muscle diacylglycerol predicts insulin resistance in humans. Diabetologia. 2012;55:1140-50.

178. Hassan RH. Defect of insulin signal in peripheral tissues: Important role of ceramide. WJD. 2014;5:244-15.

179. Moro C, Galgani JE, Luu L, Pasarica M, Mairal A, Bajpeyi S, et al. Influence of gender, obesity, and muscle lipase activity on intramyocellular lipids in sedentary individuals. J Clin Endocrinol Metab. 2009;94:3440-7.

180. Straczkowski M, Kowalska I, Baranowski M, Nikolajuk A, Otziomek E, Zabielski P, et al. Increased skeletal muscle ceramide level in men at risk of developing type 2 diabetes. Diabetologia. 2007;50:236673.

181. Thrush AB, Brindley DN, Chabowski A, Heigenhauser GJ, Dyck DJ. Skeletal muscle lipogenic protein expression is not different between lean and obese individuals: a potential factor in ceramide accumulation. J Clin Endocrinol Metab. 2009;94:5053-61.

182. Adams JM, Pratipanawatr T, Berria R, Wang E, DeFronzo RA, Sullards MC, et al. Ceramide Content Is Increased in Skeletal Muscle From Obese Insulin-Resistant Humans. Diabetes. 2004;53:25-31.

183. Serlie MJ, Meijer AJ, Groener JE, Duran M, Endert E, Fliers E, et al. Short-term manipulation of plasma free fatty acids does not change skeletal muscle concentrations of ceramide and glucosylceramide in lean and overweight subjects. J Clin Endocrinol Metab. 2007;92:1524-9.

184. Skovbro M, Baranowski M, Skov-Jensen C, Flint A, Dela F, Gorski J, et al. Human skeletal muscle ceramide content is not a major factor in muscle insulin sensitivity. Diabetologia. 2008;51:1253-60.

185. Ritter O, Jelenik T, Roden M. Lipid-mediated muscle insulin resistance: different fat, different pathways? J Mol Med. 2015;93:831-43.

186. Kitessa S, Abeywardena M. Lipid-Induced Insulin Resistance in Skeletal Muscle: The Chase for the Culprit Goes from Total Intramuscular Fat to Lipid Intermediates, and Finally to Species of Lipid Intermediates. Nutrients. 2016;8:466-14.

187. Chaurasia B, Summers SA. Ceramides - Lipotoxic Inducers of Metabolic Disorders. Trends Endocrinol Metab. 2015;26:538-50. 


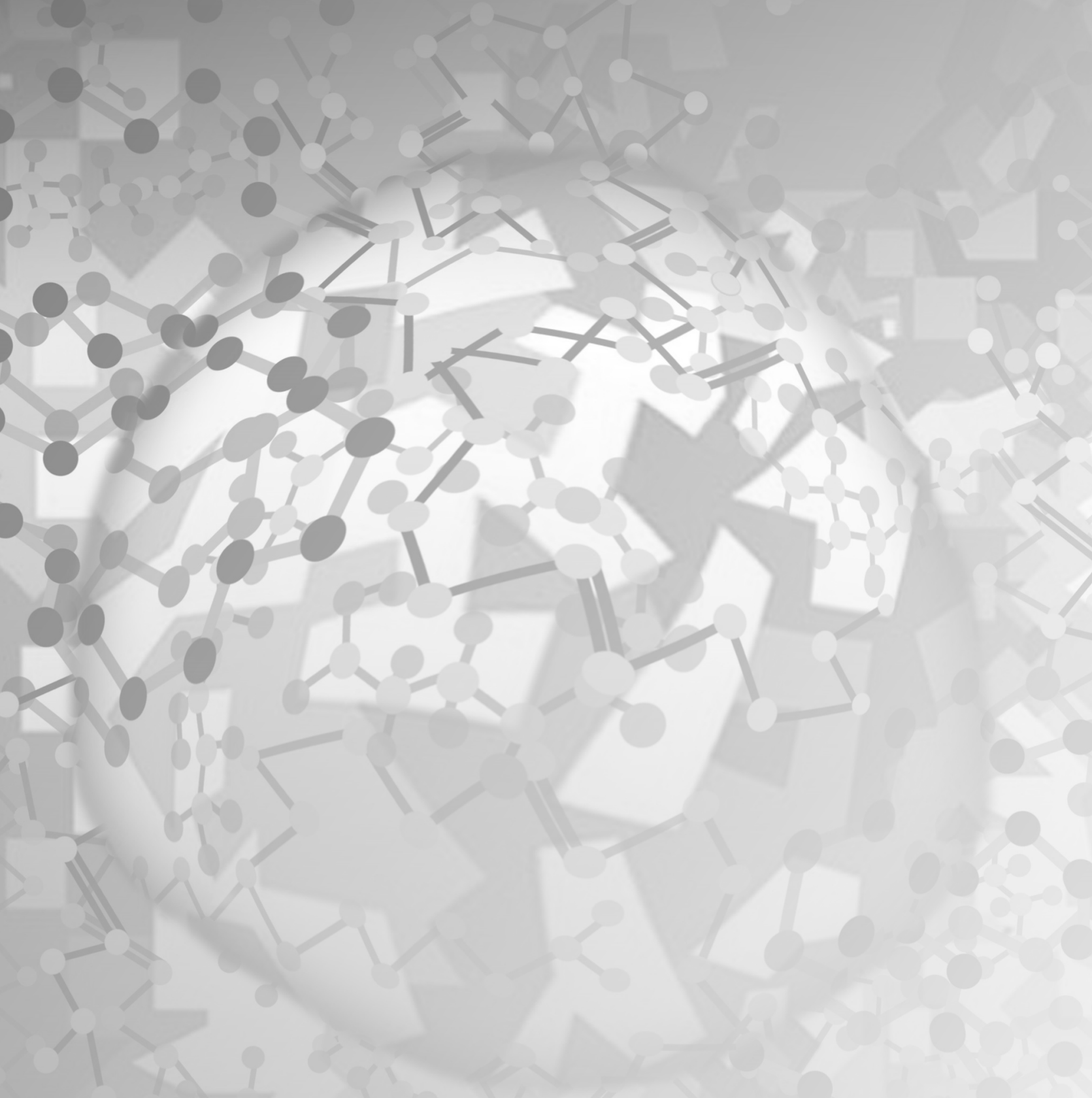




\section{Chapter 2}

\section{Altered skeletal muscle fatty acid handling is associated with the degree of insulin resistance in overweight and obese humans}

Birgitta W. van der Kolk ${ }^{1}$, Gijs H. Goossens ${ }^{1}$, Johan W. Jocken ${ }^{1}$, Ellen E. Blaak ${ }^{1}$

${ }^{1}$ Department of Human Biology, NUTRIM School of Nutrition and Translational Research in Metabolism, Maastricht University Medical Center ${ }^{+}$, the Netherlands 


\section{Abstract}

Introduction/ hypothesis Disturbances in skeletal muscle fatty acid (FA) handling may contribute to the development and progression of whole-body insulin resistance (IR). In this study, we compared fasting and postprandial skeletal muscle FA handling in individuals with varying degrees of IR.

Methods Seventy-four overweight/obese participants (62 men) were divided into two groups based on the HOMA-IR median (3.35). Fasting and postprandial skeletal muscle FA handling were determined by combining the forearm muscle balance technique with stable isotopes. $\left[{ }^{2} \mathrm{H}_{2}\right]$-palmitate was infused intravenously to label VLDL-triacylglycerol (VLDL-TAG) and NEFA in the circulation, whereas $\left[\mathrm{U}-{ }^{13} \mathrm{C}\right]$-palmitate was incorporated in a high-saturated FA mixed-meal labelling chylomicron-TAG. Skeletal muscle biopsies were taken to assess intramuscular lipid content, fractional synthetic rate (FSR) and the transcriptional regulation of FA metabolism.

Results Postprandial forearm muscle VLDL-TAG extraction was elevated in the high-IR vs the mild-IR group $\left(\mathrm{AUC}_{0-4 \mathrm{~h}}: 0.57 \pm 0.32\right.$ vs $-0.43 \pm 0.38 \mathrm{nmol}[100 \mathrm{~mL} \text { tissue }]^{-1} \mathrm{~min}^{-1}$, respectively, $p=0.045$ ). Although no differences in skeletal muscle TAG, diacylglycerol, NEFA content and FSR were present between groups, the high-IR group showed increased saturation of the intramuscular NEFA pool $(p=0.039)$. This was accompanied by lower muscle GPAT1 (also known as GPAM) expression $(p=0.050)$.

Conclusions/interpretation Participants with high-IR demonstrated increased postprandial skeletal muscle VLDL-TAG extraction and higher saturation of the intramuscular NEFA pool vs individuals with mild-IR. These data support the involvement of disturbances in skeletal muscle FA handling in the progression of whole-body IR. 


\section{Introduction}

Systemic lipid overflow, which is driven by adipose tissue dysfunction and impaired skeletal muscle lipid handling, is associated with insulin resistance (IR) (1). Increased circulating triacylglycerol (TAG) and NEFA concentrations are often found in IR because of impaired adipose tissue lipid handling (2-4). This results in an increased lipid supply to other nonadipose tissues, such as liver and skeletal muscle. Due to an impaired capacity to oxidise fatty acids (FAs) (5,6), these lipids may accumulate and interfere with insulin signalling in the liver and skeletal muscle $(7,8)$. Over the last decade, it has become clear that the amount of lipids per se does not determine IR. Rather, a complex interplay between FA supply, FA type, muscle lipid turnover, subcellular localisation and composition of specific bioactive lipid metabolites seems to determine skeletal muscle IR $(1,8,9)$.

The contribution of dietary fat (chylomicron-TAG) and endogenous fat (NEFA and VLDL-TAG) to skeletal muscle FA handling is not well understood. Elevated plasma NEFA concentrations may result from both expanded fat mass (2) and reduced peripheral clearance $(5,10)$. Despite a reduced lipolysis per unit fat mass because of hyperinsulinaemia $(11,12)$, the total amount of NEFA released from adipose tissue in the postprandial state seems to be elevated in the obese insulin resistant state (13). Furthermore, in situations with plasma insulin concentrations comparable to insulin levels achieved during a hyperinsulinaemiceuglycaemic clamp, the spillover from FAs derived from lipoprotein lipase (LPL)-mediated TAG hydrolysis in adipose tissue has been shown to be less suppressed in obese patients with type 2 diabetes than in non-obese healthy controls (14). This increase in adipose tissue NEFA output might lead to increased hepatic VLDL-TAG production and elevated plasma TAG concentrations $(15,16)$. Bickerton et al. (17) demonstrated that dietary FAs were preferentially taken up in adipose tissue and skeletal muscle in the postprandial state in healthy lean humans, even though VLDL particles were abundantly present after the meal (11).

Up to now, most studies investigating combined VLDL- and chylomicron-TAG metabolism have been performed in healthy, lean humans $(17,18)$. Bickerton et al. (11) have shown elevated postprandial plasma VLDL- and chylomicron-TAG concentrations in overweight men with IR (11). Moreover, we have recently demonstrated that an increased postprandial VLDL-TAG extraction was associated with IR in men with the metabolic syndrome (19). However, studies involving the combined assessment of human skeletal muscle VLDL- and chylomicron-TAG metabolism, and intramuscular lipid species are limited. In addition, previous studies have used a relatively small sample size due to 
methodological difficulties as well as the high costs associated with these measurements. Therefore, extensive human in vivo data on skeletal muscle FA handling in IR is currently lacking. The aim of this study was to investigate fasting and postprandial skeletal muscle FA handling in a large study cohort of overweight or obese participants with a wide range of IR. A dual stable isotope tracer technique using labelled palmitate in combination with measurements of differences in arteriovenous concentrations across forearm muscle and forearm blood flow was used in this study, as previously validated (17). This enabled us to differentiate between the metabolic fate of dietary and endogenous FA. In addition, skeletal muscle biopsies were taken to investigate skeletal muscle lipid metabolites, their fractional synthetic rates (FSRs) and the transcriptional regulation of FA metabolism.

\section{Methods}

\section{Study participants}

Seventy-four participants (62 men and 12 women) with the metabolic syndrome or impaired glucose metabolism were obtained from the Maastricht biobank. These participants (described elsewhere in more detail (19-21)) underwent a high-saturated FA (SFA) mixedmeal test. Participants were divided into two groups based on the median of HOMA-IR (3.35); participants below the median of HOMA-IR formed the 'mild-IR' group $(n=37)$ and participants above the median formed the 'high-IR' group $(n=37)$. The local Medical Ethical Committee of Maastricht University Medical Center ${ }^{+}$approved the study protocols. All participants gave their written informed consent before participation.

\section{High-fat mixed-meal test}

Participants were studied after an overnight fast and were asked to refrain from strenuous exercise and drinking alcohol for $24 \mathrm{~h}$ before the study day. In addition, they were asked to avoid food products naturally enriched with ${ }^{13} \mathrm{C}$ for 7 days before the study day. Forearm muscle metabolism was studied using arteriovenous concentration differences combined with measurements of forearm blood flow. Three catheters were inserted before the start of the experiment. One catheter was placed retrogradely into a superficial dorsal vein of a hand heated in a hot-box $\left(60^{\circ} \mathrm{C}\right)$ to obtain an arterialised blood sample. In the same arm another catheter was placed in an antecubital vein for the infusion of the $\left[{ }^{2} \mathrm{H}_{2}\right]$-palmitate tracer. A third catheter was placed retrogradely in a deep antecubital vein of the contralateral forearm to sample venous blood draining the forearm muscle. After taking an arterialised and 
deep-venous background sample at 90 min before meal ingestion, a continuous intravenously infusion of the stable isotope tracer, $\left[{ }^{2} \mathrm{H}_{2}\right]$-palmitate (97\% enrichment; Cambridge Isotope Laboratories, Andover, MA, USA) complexed to albumin was started $(0.035 \mu \mathrm{mol}[\mathrm{kg}$ body weight $]^{-1} \min ^{-1}$ ). Baseline blood sampling was started after $1 \mathrm{~h}$ of tracer infusion to allow for isotopic equilibration to occur. Blood samples were taken simultaneously from the dorsal hand vein and the deep muscle vein at three time points during fasting. Samples were also taken at six time points postprandially after consumption of a high-SFA mixed-meal (at ' 0 min') containing $200 \mathrm{mg}\left[\mathrm{U}-{ }^{13} \mathrm{C}\right]$-palmitate (98\% enrichment; Cambridge Isotope Laboratories). The liquid meal provided 2.6 MJ energy, consisting of 61 energy \% (E\%) fat (35.5 E\%, SFA; $18.8 \mathrm{E} \%$, monounsaturated FA [MUFA]; $1.7 \mathrm{E} \%$ polyunsaturated FA [PUFA]), $33 \mathrm{E} \%$ carbohydrates and $6.3 \mathrm{E} \%$ protein. Analysis of forearm blood flow before blood sampling and details of other biochemical analyses have been described previously (19).

\section{Skeletal muscle biopsies}

Skeletal muscle biopsies were obtained from the vastus lateralis muscle after local anaesthesia of the skin and fascia using the Bergström method with suction (22). Muscle biopsies were taken during fasting and at the end of the postprandial period $(240 \mathrm{~min})$. Muscle biopsies were lyophilised and dissected free of extramyocellular lipid, blood and connective tissue under a microscope. Details of lipid extraction and quantification have been described previously (19). Skeletal muscle expression of genes related to transcription factors, oxidative metabolism, lipid synthesis and lipolysis were analysed. Gene expression was normalised relative to the geometric mean of the internal reference genes ( $\beta$-actin, $\beta$-2-microglobulin and/or ribosomal protein L13a). Details of accession numbers, RNA primer sequences and RT-PCR analysis of these genes have been described previously $(19,20)$. Since limited muscle biopsy samples were available, not all genes have been measured in all individuals.

\section{Calculations}

Net fluxes of metabolites (labelled and unlabelled) across the forearm were calculated by multiplying the arteriovenous concentration difference by forearm plasma flow. Plasma flow was measured using plethysmography and calculated by multiplying forearm blood flow with ([1 - haematocrit (\%vol.)] / 100). A positive flux indicates net uptake across forearm muscle, whereas a negative flux indicates net release. Labelled NEFA and TAG concentrations were calculated as the product of tracer:tracee ratio (TTR) of $\left[{ }^{2} \mathrm{H}_{2}\right]$-palmitate and $\left[\mathrm{U}-{ }^{13} \mathrm{C}\right]-$ palmitate and the concentration of palmitate in NEFA and TAG, as reported previously (19). 
The degree of saturation of skeletal muscle TAG, diacylglycerol (DAG), phospholipid (PL) and NEFA (\%) was calculated by dividing the sum of unsaturated FAs by the total amount of FAs in a fraction multiplied by 100. The FSR of skeletal muscle NEFA, TAG, DAG and PL was calculated using skeletal muscle NEFA as the precursor pool for lipid synthesis. The increase in TTR of $\left[\mathrm{U}^{13} \mathrm{C}\right]$ from fasting to $4 \mathrm{~h}$ postprandial measures was divided by the enrichment of skeletal muscle NEFA and expressed as per cent per hour $(\% / \mathrm{h})$. Postprandial areas under the curve $\left(\mathrm{AUC}_{0-} \mathrm{h}^{\mathrm{h}}\right)$ of metabolites were calculated using the trapezium rule and in this study data are presented as $\mathrm{AUC}_{0-4 \mathrm{~h}} / \mathrm{min}$.

\section{Statistics}

In this study, all data are expressed as means \pm SEM. Participant characteristics and differences in skeletal muscle lipid handling during fasting and postprandial conditions of the mild-IR and high-IR group were compared using independent samples $t$ tests. A linear regression was performed with HOMA-IR and BMI and sex as co-variates. Variables were $\log _{\mathrm{e}}$-transformed if the assumption of normality was not met. The data were analysed using SPSS for Mac version 22.0 (SPSS, Chicago, IL, USA) and statistical significance was set at $p<0.05$.

\section{Results}

\section{Study population}

Participant characteristics are summarised in Table 1. Age, waist:hip ratio and blood pressure were comparable between groups, while BMI was significantly higher in the high-IR group $(p<0.002)$. By design, mean HOMA-IR was different between the two groups (mild-IR vs high-IR: $2.5 \pm 0.1$ vs $4.7 \pm 0.3$, respectively, $p<0.001$ ). 
Table 1. Characteristics of participants

\begin{tabular}{lccccc}
\hline Characteristic & $\begin{array}{c}\text { Mild-IR } \\
(\mathbf{n}=37)\end{array}$ & $\begin{array}{c}\text { High-IR } \\
(\mathbf{n}=37)\end{array}$ & $\begin{array}{c}\text { Total group } \\
(\mathbf{n}=74)\end{array}$ & $\begin{array}{c}\text { Range } \\
(\mathbf{n}=74)\end{array}$ & $p^{\text {value }^{\mathrm{a}}}$ \\
\hline Male $(\mathrm{n}) /$ Female $(\mathrm{n})$ & $33 / 4$ & $29 / 8$ & $62 / 12$ & & \\
Age $(\mathrm{y})$ & $58.0 \pm 1.4$ & $59.0 \pm 1.1$ & $58.5 \pm 0.9$ & $36-70$ & 0.582 \\
Body weight $(\mathrm{kg})$ & $89.8 \pm 1.9$ & $95.1 \pm 2.1$ & $92.5 \pm 1.4$ & $64.0-115.0$ & 0.064 \\
BMI $\left(\mathrm{kg} / \mathrm{m}^{2}\right)$ & $29.2 \pm 0.5$ & $31.7 \pm 0.6$ & $30.5 \pm 0.4$ & $22.7-39.5$ & 0.002 \\
Waist:hip ratio & $1.02 \pm 0.01$ & $1.03 \pm 0.01$ & $1.02 \pm 0.01$ & $0.89-1.17$ & 0.494 \\
Systolic blood pressure $(\mathrm{mmHg})$ & $135 \pm 2$ & $136 \pm 2$ & $135 \pm 2$ & $105-174$ & 0.636 \\
Diastolic blood pressure $(\mathrm{mmHg})$ & $84 \pm 2$ & $85 \pm 1$ & $85 \pm 1$ & $68-110$ & 0.944 \\
Fasting plasma glucose $(\mathrm{mmol} / \mathrm{L})$ & $5.4 \pm 0.1$ & $5.7 \pm 0.1$ & $5.5 \pm 0.1$ & $4.6-6.7$ & 0.002 \\
Fasting plasma insulin $(\mathrm{pmol} / \mathrm{L})$ & $72.3 \pm 2.4$ & $130.2 \pm 6.6$ & $101.2 \pm 4.9$ & $50-263.3$ & $<0.001$ \\
Fasting plasma NEFA $(\mu \mathrm{mol} / \mathrm{L})$ & $561 \pm 22$ & $598 \pm 26$ & $580 \pm 17$ & $296-1002$ & 0.287 \\
Fasting plasma TAG $(\mu \mathrm{mol} / \mathrm{L})$ & $1320 \pm 103$ & $1246 \pm 85$ & $1283 \pm 66$ & $415-3232$ & 0.582 \\
HOMA-IR & $2.5 \pm 0.1$ & $4.7 \pm 0.3$ & $3.6 \pm 0.2$ & $1.68-11.3$ & $<0.001$ \\
\hline
\end{tabular}

Values are means \pm SEM

${ }^{a} p$ value for difference between mild-IR and high-IR group, Student's $t$ test for unpaired samples

\section{Arterialised metabolites, forearm muscle metabolism and forearm blood flow}

Fasting arterialised plasma glucose (Figure 1A) and insulin (Figure 1B) concentrations were significantly higher in the high-IR group than in the mild-IR group $(p=0.002$ and $p<0.001$, respectively) and remained higher throughout the postprandial period $(p=0.035$ and $p<0.001$, respectively). Net glucose uptake across forearm muscle was similar in the high-IR and mild-IR groups under fasting conditions, but was significantly lower in the high-IR group than in the mild-IR group after meal ingestion $\left(\mathrm{AUC}_{0-4 \mathrm{~h}} 0.59 \pm 0.04\right.$ vs $0.76 \pm 0.07 \mu \mathrm{mol}$ [100 $\mathrm{ml}$ tissue $]^{-1} \mathrm{~min}^{-1}$, respectively, $\left.p=0.034\right)$, indicating a lower postprandial insulin sensitivity in the high-IR group (see Table 2 and Figure 1C). Arterialised fasting plasma glycerol concentrations $(p=0.006)$ and lactate concentrations were significantly higher $(p=0.006)$ in the high-IR group than in the mild-IR group (Table 2). Forearm blood flow and glycerol release were similar between the two IR groups, both during fasting and postprandial conditions. Moreover, fasting $(p=0.002)$ and postprandial $(p=0.048)$ lactate release was positively associated with IR (Table 2$)$. 
A

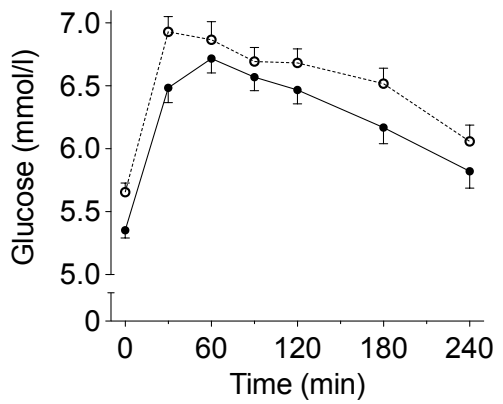

C

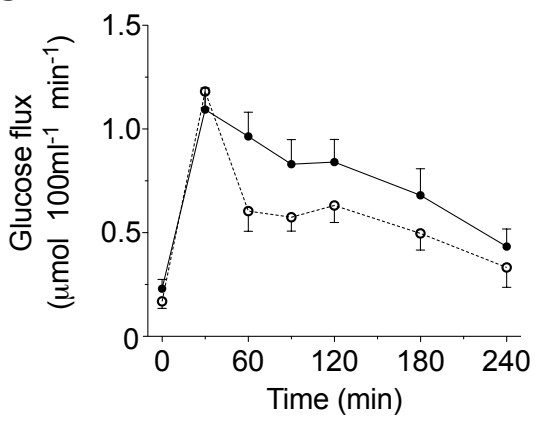

B

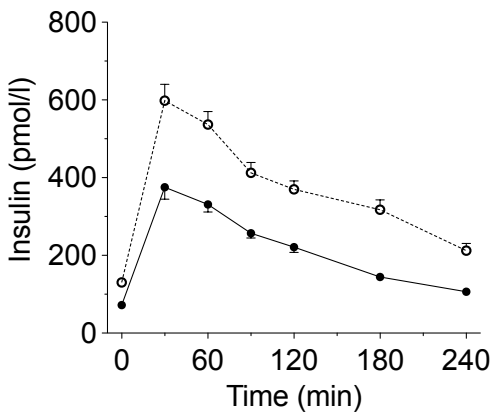

Figure 1. Arterialised plasma glucose (A) and insulin (B) concentrations and glucose flux (C) during fasting ( $0 \mathrm{~min})$ and after consumption of a high-SFA meal. Black circles, mild-IR group; white circles, high-IR group. Student's $t$ test for unpaired samples showed significant effect of group on fasting and postprandial plasma glucose $\left(p=0.002\right.$ and $\mathrm{AUC}_{0-4 \mathrm{~h}}: p=0.035$, respectively), fasting and postprandial plasma insulin $\left(p<0.001\right.$ and $\mathrm{AUC}_{0-4 h}: p<0.001$, respectively) and postprandial glucose flux $\left(\mathrm{AUC}_{0-4 \mathrm{~h}}: p=0.034\right)$. Values are presented as mean \pm SEM

\section{Whole-body and forearm muscle NEFA metabolism}

Fasting arterialised NEFA concentrations were similar in the high-IR and mild-IR groups (Figure 2A). After the high-SFA meal ingestion, arterialised NEFA concentrations decreased to the same extent in both groups and returned to near-baseline values at the end of the postprandial period, with no significant differences observed between the groups. $\left[{ }^{2} \mathrm{H}_{2}\right]$-palmitate was infused intravenously and was mixed with the plasma NEFA pool. The TTR reached steady state during fasting measurements (Figure $2 \mathrm{C}, \mathrm{D}$ ). Consistent with these findings, the rate of appearance of NEFA (RanEFA) decreased after the meal (Figure 2B), which is an indication of suppression of whole-body lipolysis. A reduction in postprandial 

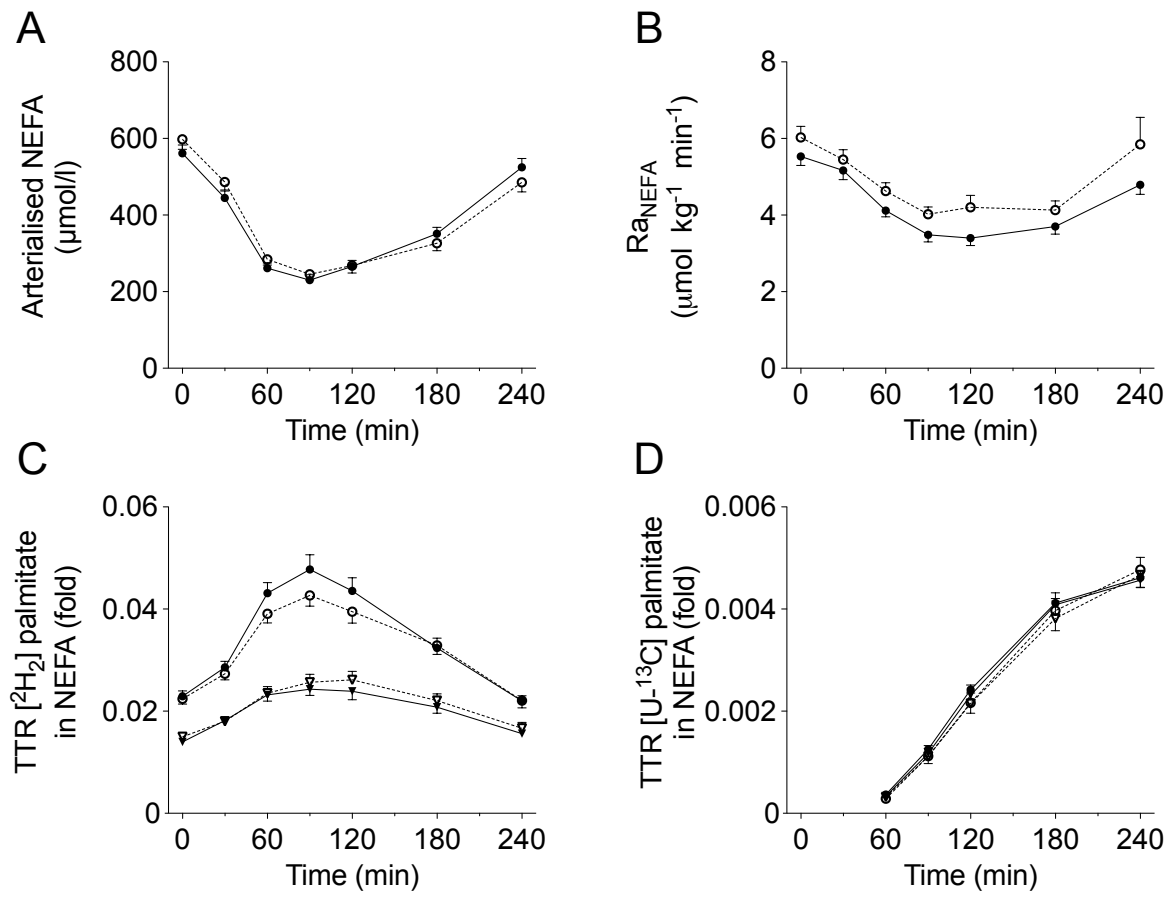

Figure 2. Postprandial whole-body NEFA metabolism. Arterialised plasma NEFA concentrations (A), RanEFA (B), and the TTR of $\left[{ }^{2} \mathrm{H}_{2}\right]$-palmitate $(\mathrm{C})$ and $\left[\mathrm{U}-{ }^{13} \mathrm{C}\right]$-palmitate (D) in the plasma NEFA fraction during fasting (0 min) and after consumption of a high-SFA meal. Black symbols, mild-IR group; white symbols, high-IR group; in (C) and (D) circles, arterialised plasma concentrations and triangles, forearm venous plasma concentrations. Values are presented as mean $\pm \mathrm{SEM}$

suppression of the RaNEFA was observed in the high-IR group compared with the mild-IR group, although the difference did not reach statistical significance $(p=0.079$, Figure $2 \mathrm{~B})$. There were no differences in arterialised concentrations of $\left[{ }^{2} \mathrm{H}_{2}\right]$-palmitate and $\left[\mathrm{U}-{ }^{13} \mathrm{C}\right]$-palmitate in NEFA between groups (data not shown).

The TTR of $\left[{ }^{2} \mathrm{H}_{2}\right]$-palmitate in NEFA was higher in arterialised vs deep-venous plasma at all time points in both groups. This reflects dilution of the ${ }^{2} \mathrm{H}_{2}$ tracer in the plasma NEFA pool across forearm muscle. The TTR of $\left[\mathrm{U}-{ }^{13} \mathrm{C}\right]$-palmitate in NEFA (resulting from spillover of FA derived from chylomicron-TAG hydrolysis) was not different in arterialised vs deep-venous plasma at all time points in both groups (Figure 2C,D). 
Table 2. Fasting and postprandial lipid metabolism

\begin{tabular}{|c|c|c|c|c|c|}
\hline Variable & Mild-IR & High-IR & $p$ value $^{\mathrm{a}}$ & $\mathrm{SE} \beta$ & $p$ value $^{\mathrm{b}}$ \\
\hline \multicolumn{6}{|c|}{ Forearm blood flow $\left(\mathrm{mL}[100 \mathrm{ml} \text { tissue }]^{-1} \mathrm{~min}^{-1}\right)$} \\
\hline Fasting & $2.5 \pm 0.2$ & $2.5 \pm 0.2$ & 0.896 & 0.054 & 0.682 \\
\hline Postprandial & $2.6 \pm 0.2$ & $2.8 \pm 0.2$ & 0.476 & 0.118 & 0.369 \\
\hline \multicolumn{6}{|l|}{ Glycerol $(\mu \mathrm{mol} / \mathrm{L})$} \\
\hline Fasting & $84.6 \pm 3.9$ & $118.5 \pm 11.1$ & 0.006 & 0.200 & 0.090 \\
\hline Postprandial & $64.9 \pm 3.6$ & $92.9 \pm 10.6$ & 0.016 & 0.278 & 0.025 \\
\hline \multicolumn{6}{|l|}{ Lactate $(\mu \mathrm{mol} / \mathrm{L})$} \\
\hline Fasting & $0.62 \pm 0.04$ & $0.79 \pm 0.05$ & 0.006 & 0.438 & $<0.001$ \\
\hline Postprandial & $0.98 \pm 0.05$ & $1.10 \pm 0.05$ & 0.081 & 0.224 & 0.087 \\
\hline \multicolumn{6}{|c|}{ Net flux across forearm muscle } \\
\hline \multicolumn{6}{|c|}{ Glucose $\left(\mu \mathrm{mol}[100 \mathrm{~mL} \text { tissue }]^{-1} \mathrm{~min}^{-1}\right)$} \\
\hline Fasting & $0.23 \pm 0.05$ & $0.17 \pm 0.03$ & 0.274 & -0.083 & 0.524 \\
\hline Postprandial & $0.76 \pm 0.07$ & $0.59 \pm 0.04$ & 0.034 & -0.147 & 0.226 \\
\hline \multicolumn{6}{|c|}{ Glycerol $\left(\mathrm{nmol}[100 \mathrm{~mL} \text { tissue }]^{-1} \mathrm{~min}^{-1}\right)$} \\
\hline Fasting & $-28.3 \pm 5.5$ & $-27.0 \pm 7.7$ & 0.883 & 0.224 & 0.092 \\
\hline Postprandial & $-20.4 \pm 4.5$ & $-25.2 \pm 6.5$ & 0.541 & 0.081 & 0.543 \\
\hline \multicolumn{6}{|c|}{ Lactate $\left(\mathrm{nmol}[100 \mathrm{~mL} \text { tissue }]^{-1} \mathrm{~min}^{-1}\right)$} \\
\hline Fasting & $-0.18 \pm 0.02$ & $-0.12 \pm 0.03$ & 0.123 & 0.384 & 0.002 \\
\hline Postprandial & $0.01 \pm 0.02$ & $0.04 \pm 0.03$ & 0.472 & 0.249 & 0.048 \\
\hline \multicolumn{6}{|c|}{ NEFA (nmol $\left.[100 \mathrm{~mL} \text { tissue }]^{-1} \mathrm{~min}^{-1}\right)$} \\
\hline Fasting & $-6.9 \pm 20.4$ & $26.6 \pm 24.6$ & 0.300 & 0.165 & 0.210 \\
\hline Postprandial & $-0.8 \pm 9.5$ & $8.7 \pm 13.4$ & 0.565 & 0.112 & 0.405 \\
\hline \multicolumn{6}{|c|}{$\left[{ }^{2} \mathrm{H}_{2}\right]$-palmitate NEFA (nmol $[100 \mathrm{~mL} \text { tissue }]^{-1} \mathrm{~min}^{-1}$ ) } \\
\hline Fasting & $1.69 \pm 0.12$ & $1.58 \pm 0.14$ & 0.539 & 0.017 & 0.902 \\
\hline Postprandial & $1.50 \pm 0.09$ & $1.53 \pm 0.14$ & 0.846 & 0.171 & 0.208 \\
\hline \multicolumn{6}{|c|}{ TAG $\left(\mathrm{nmol}[100 \mathrm{~mL} \text { tissue }]^{-1} \mathrm{~min}^{-1}\right)$} \\
\hline Fasting & $10.2 \pm 13.2$ & $45.5 \pm 12.1$ & 0.052 & 0.094 & 0.466 \\
\hline Postprandial & $53.9 \pm 17.2$ & $51.9 \pm 28.4$ & 0.954 & -0.105 & 0.422 \\
\hline
\end{tabular}


Table 2. Fasting and postprandial lipid metabolism (continued)

\begin{tabular}{|c|c|c|c|c|c|}
\hline Variable & Mild-IR & High-IR & $p$ value $^{\mathrm{a}}$ & $\operatorname{SE} \beta$ & $p$ value $^{\mathrm{b}}$ \\
\hline \multicolumn{6}{|c|}{ (Net flux across forearm muscle) } \\
\hline \multicolumn{6}{|c|}{$\left[{ }^{2} \mathrm{H}_{2}\right]$-palmitate TAG (nmol $\left.[100 \mathrm{~mL} \text { tissue }]^{-1} \mathrm{~min}^{-1}\right)$} \\
\hline Fasting & $-0.24 \pm 0.16$ & $0.56 \pm 0.41$ & 0.069 & 0.241 & 0.076 \\
\hline Postprandial & $-0.43 \pm 0.38$ & $0.57 \pm 0.32$ & 0.045 & 0.294 & 0.037 \\
\hline \multicolumn{6}{|c|}{$\left[\mathrm{U}-{ }^{13} \mathrm{C}\right]$-palmitate TAG $\left(\mathrm{nmol}[100 \mathrm{~mL} \text { tissue }]^{-1} \mathrm{~min}^{-1}\right)$} \\
\hline \multicolumn{6}{|l|}{ Fasting $^{c}$} \\
\hline Postprandial & $0.86 \pm 0.16$ & $0.66 \pm 0.16$ & 0.353 & -0.046 & 0.736 \\
\hline \multicolumn{6}{|c|}{$\begin{array}{l}\text { Values are means } \pm \text { SEM. Postprandial values are calculated from } \mathrm{AUC}_{0-4 h} \text {. A positive flux indicates net uptake } \\
\text { across forearm muscle, whereas a negative flux indicates net release. }\left[{ }^{2} \mathrm{H}_{2}\right] \text {-palmitate NEFA fasting and }{ }^{\mathrm{a}} p \text { value } \\
\text { for difference between mild-IR and high-IR group, Student's } t \text { test for unpaired samples. }{ }^{\mathrm{b}} p \text { value for multiple } \\
\text { linear regression. }{ }^{\mathrm{c}}\left[\mathrm{U}-{ }^{13} \mathrm{C}\right] \text {-palmitate was given with a meal, hence fasting data is not available. }\left[{ }^{2} \mathrm{H}_{2}\right] \text {-palmitate } \\
\text { TAG fasting, } \mathrm{n}=34 ;\left[{ }^{2} \mathrm{H}_{2}\right] \text {-palmitate NEFA postprandial and }\left[\mathrm{U}-{ }^{13} \mathrm{C}\right] \text {-palmitate TAG postprandial, } \mathrm{n}=33 \text {; } \\
{\left[{ }^{2} \mathrm{H}_{2}\right] \text {-palmitate TAG postprandial (mild-IR), } \mathrm{n}=29 ;\left[{ }^{2} \mathrm{H}_{2}\right] \text {-palmitate TAG postprandial (high-IR), } \mathrm{n}=32 . \mathrm{SE} \beta \text {, }} \\
\text { standardised } \beta \text { coefficient for total group for HOMA-IR, adjusted for sex and BMI }\end{array}$} \\
\hline
\end{tabular}

Fasting and postprandial net extraction of plasma NEFA across forearm muscle did not differ between groups. Furthermore, there was consistent uptake of $\left[{ }^{2} \mathrm{H}_{2}\right]$-palmitate across forearm muscle during the study period and this was similar in both groups (Table 2).

\section{Whole-body and forearm muscle TAG metabolism}

Comparable arterialised TAG concentrations between the high-IR and mild-IR groups were observed during fasting and postprandial conditions (Figure 3A). The $\left[{ }^{2} \mathrm{H}_{2}\right]$-palmitate tracer was measurable in plasma TAG from the first baseline sample onwards, reflecting incorporation of the intravenously infused tracer into VLDL-TAG (Figure 3B). The $\left[\mathrm{U}-{ }^{13} \mathrm{C}\right]$-palmitate tracer, which was given with the meal, appeared in plasma TAG from 60 min after meal ingestion, representing chylomicron-TAG in the circulation (Figure 3B). During the postprandial period both labelled TAG fractions increased without significant differences between groups.

Fasting net extraction of $\left[{ }^{2} \mathrm{H}_{2}\right]$-palmitate TAG across forearm muscle was higher in the high-IR group than in the mild-IR group, although the difference did not reach statistical significance $(p=0.069)$. Postprandial net extraction of $\left[{ }^{2} \mathrm{H}_{2}\right]$-palmitate TAG was significantly elevated in the high-IR group ws the mild-IR group $(p=0.045)$ (Figure 3C). In line with this, 
A
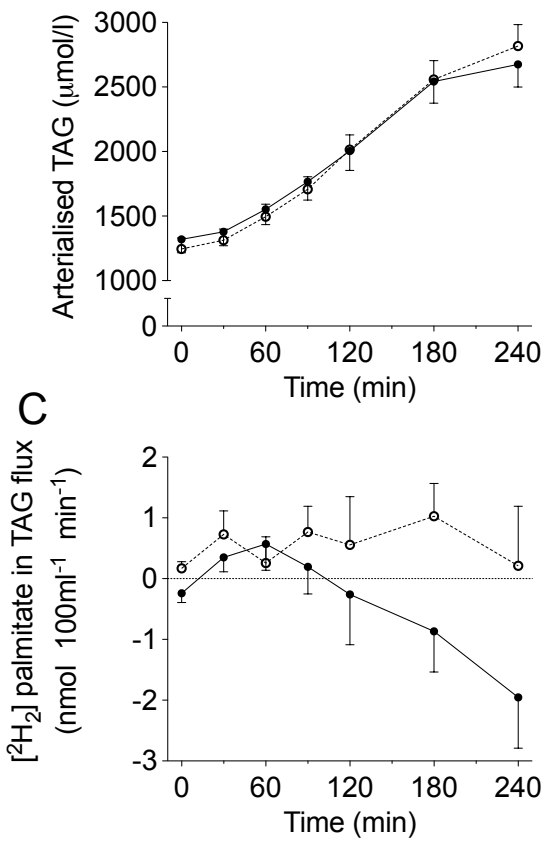

B
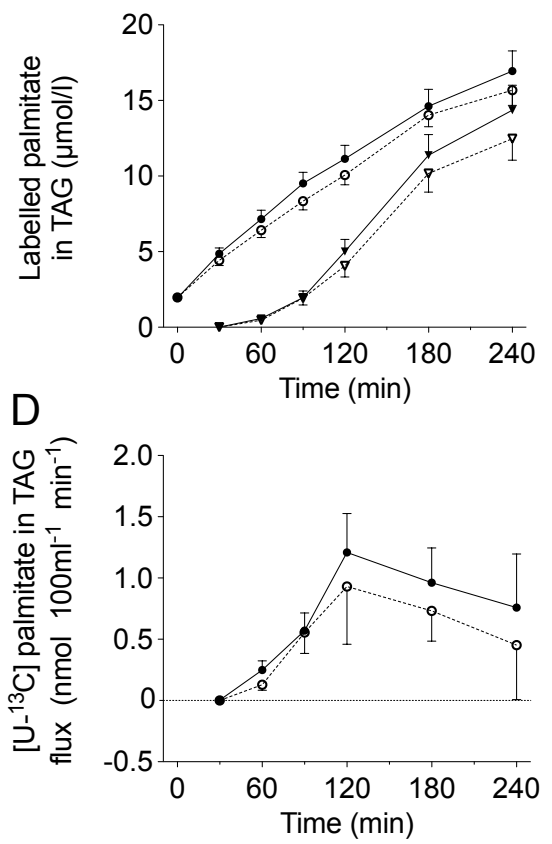

Figure 3. Postprandial whole-body and forearm muscle TAG metabolism. Arterialised plasma TAG concentrations (A), $\left[{ }^{2} \mathrm{H}_{2}\right]-$ and $\left[\mathrm{U}-{ }^{13} \mathrm{C}\right]$-palmitate concentrations in the plasma TAG fraction (B), and the net flux of $\left[{ }^{2} \mathrm{H}_{2}\right]$-palmitate TAG $(\mathbf{C})$ and $\left[\mathrm{U}-{ }^{13} \mathrm{C}\right]$-palmitate TAG (D) across forearm muscle during fasting $(0 \mathrm{~min})$ and after consumption of a high-SFA meal. A positive flux indicates net uptake across forearm muscle, whereas a negative flux indicates net release. Black symbols, mild-IR group; white symbols, high-IR group; in (B) circles, $\left[{ }^{2} \mathrm{H}_{2}\right]$-palmitate TAG and triangles, $\left[\mathrm{U}-{ }^{13} \mathrm{C}\right]$-palmitate TAG. Student's $t$ test for unpaired samples showed a significant effect of group on postprandial net flux of $\left[{ }^{2} \mathrm{H}_{2}\right]$-palmitate TAG $\left(\mathrm{AUC}_{0-4 h} ; p=0.045\right)$. Values are presented as mean $\pm \mathrm{SEM}$

we found a significant linear association between postprandial net extraction of $\left[{ }^{2} \mathrm{H}_{2}\right]$-palmitate TAG and HOMA-IR, even after adjustment for BMI and sex (standardised $\beta=0.294 ; p=0.037$; Table 2 ). The net extraction of [U- $\left.{ }^{13} \mathrm{C}\right]$-palmitate TAG across forearm muscle could be detected from 60 min onwards and did not differ significantly between groups (Table 2, Figure 3D). 


\section{Intramuscular lipid metabolism}

Skeletal muscle TAG, DAG and NEFA content were comparable between high-IR and mild-IR groups (Table 3). The PL content was lower in the high-IR group than in the mild-IR group, although the difference did not reach statistical significance $(60.5 \pm 3.2$ vs $70.2 \pm 3.6 \mu \mathrm{mol} /$ [g dry weight], respectively, $p=0.055$ ). However, there was no significant linear association between PL and measures of IR (Table 3). Intramuscular lipid composition was different between groups, with a significantly higher degree of saturation in the muscle NEFA pool in participants with high-IR compared with those with mild-IR $(51.8 \pm 2.8 \%$ vs $43.9 \pm 2.5 \%$, respectively, $p=0.039$ ), but there was no significant linear association with IR (Table 3). This difference was mainly explained by higher percentages of myristic acid (C14:0; $3.5 \pm 0.7 \%$ vs $2.1 \pm 0.4 \%, p=0.078)$, pentadecyclic acid (C15:0; $4.5 \pm 1.5 \%$ vs $1.2 \pm 0.3 \%$, $p=0.038)$ and tricosylic acid (C23:0; $3.0 \pm 1.1 \%$ vs $0.8 \pm 0.4 \%, p=0.064)$ in the high-IR group vs mild-IR group (Figure 4A). Furthermore, the percentage of PUFA in the NEFA pool was lower in the high-IR group than in the mild-IR group $(13.0 \pm 1.1 \%$ vs $17.0 \pm 1.4 \%$, $p=0.034$; Table 3). In addition, lipid composition in the intramuscular DAG pool differed between high-IR and mild-IR groups (Table 3): in the high-IR group, the percentage PUFA was significantly lower $(p=0.022)$. Linear regression showed a non-significant negative association between the percentage of PUFA in the DAG pool and HOMA-IR. Furthermore, a higher percentage of MUFA was observed in the DAG pool of the high-IR group compared with the mild-IR group ( $p=0.052$; Table 3 ). Although the total saturation of the lipid content in the DAG pool did not differ between groups (Table 3), the percentage of palmitate (C16:0) in the DAG pool of the high-IR group was significantly higher compared with that in the mild-IR group $(22.1 \pm 0.7 \%$ vs $24.6 \pm 0.8 \%$, respectively, $p=0.024$; Figure 4B).

The FSR of skeletal muscle TAG, DAG and PL was comparable between groups (Table 3), indicating that a similar proportion of palmitate from the intramuscular NEFA pool was directed towards storage after the high-SFA meal.

Fasting skeletal muscle mRNA expression of genes encoding proteins involved in oxidative metabolism, lipid synthesis and lipolysis is shown in Table 4. Skeletal muscle gene expression of GPAT1 (also known as GPAM), a gene involved in lipid synthesis, was significantly lower $(p=0.050)$ in the high-IR group than in the mild-IR group, even when adjusted for sex and BMI using linear regression analysis (standardised $\beta=-0.666 ; p=0.002$ ). Furthermore, the expression level of NDUFB5, encoding a subunit of complex I in the electron transport chain, tended to be lower in the high-IR $v$ s the mild-IR group $(p=0.062)$, 
Table 3. Skeletal muscle lipid content and composition during fasting and the FSR of the muscle lipid pools after a high-SFA meal

\begin{tabular}{|c|c|c|c|c|c|}
\hline Lipid & $\begin{array}{c}\text { Mild-IR } \\
(\mathrm{n}=35)\end{array}$ & $\begin{array}{c}\text { High-IR } \\
(\mathrm{n}=28)\end{array}$ & $p$ value $^{\mathrm{a}}$ & $\mathrm{SE} \beta$ & $p$ value \\
\hline \multicolumn{6}{|l|}{ NEFA } \\
\hline Total $(\mu \mathrm{mol} /[\mathrm{g}$ dry weight $])$ & $5.9 \pm 0.8$ & $4.9 \pm 0.8$ & 0.360 & -0.058 & 0.642 \\
\hline$\%$ SFA & $43.9 \pm 2.5$ & $51.8 \pm 2.8$ & 0.039 & 0.219 & 0.112 \\
\hline$\%$ MUFA & $39.1 \pm 1.9$ & $35.2 \pm 2.3$ & 0.183 & -0.183 & 0.162 \\
\hline$\%$ PUFA & $17.0 \pm 1.4$ & $13.0 \pm 1.1$ & 0.034 & -0.162 & 0.266 \\
\hline FSR $(\% / h)$ & $0.38 \pm 0.05$ & $0.36 \pm 0.07$ & 0.747 & -0.069 & 0.619 \\
\hline \multicolumn{6}{|l|}{ DAG } \\
\hline Total ( $\mu \mathrm{mol} /[\mathrm{g}$ dry weight $])$ & $10.8 \pm 2.8$ & $6.2 \pm 0.7$ & 0.151 & -0.195 & 0.160 \\
\hline$\%$ SFA & $37.8 \pm 1.9$ & $36.6 \pm 0.8$ & 0.594 & -0.093 & 0.535 \\
\hline$\%$ MUFA & $44.2 \pm 1.6$ & $47.6 \pm 0.6$ & 0.052 & 0.255 & 0.086 \\
\hline$\%$ PUFA & $18.0 \pm 0.8$ & $15.7 \pm 0.5$ & 0.022 & -0.271 & 0.059 \\
\hline $\operatorname{FSR}(\% / \mathrm{h})$ & $0.33 \pm 0.05$ & $0.29 \pm 0.05$ & 0.538 & -0.058 & 0.692 \\
\hline \multicolumn{6}{|l|}{ TAG } \\
\hline Total $(\mu \mathrm{mol} /[\mathrm{g}$ dry weight $])$ & $182.6 \pm 24.3$ & $232.1 \pm 42.5$ & 0.301 & 0.126 & 0.365 \\
\hline$\% \mathrm{SFA}$ & $36.7 \pm 0.9$ & $35.8 \pm 0.9$ & 0.477 & -0.157 & 0.273 \\
\hline$\%$ MUFA & $47.9 \pm 1.0$ & $50.1 \pm 0.7$ & 0.076 & 0.046 & 0.749 \\
\hline$\%$ PUFA & $15.3 \pm 0.8$ & $14.1 \pm 1.0$ & 0.325 & 0.112 & 0.444 \\
\hline FSR $(\% / h)$ & $0.28 \pm 0.05$ & $0.21 \pm 0.04$ & 0.325 & -0.186 & 0.209 \\
\hline \multicolumn{6}{|l|}{ PL } \\
\hline Total $(\mu \mathrm{mol} /[\mathrm{g}$ dry weight $])$ & $70.2 \pm 3.6$ & $60.5 \pm 3.2$ & 0.055 & -0.155 & 0.260 \\
\hline$\%$ SFA & $41.3 \pm 0.8$ & $40.4 \pm 0.6$ & 0.364 & -0.046 & 0.754 \\
\hline$\%$ MUFA & $11.3 \pm 0.3$ & $11.4 \pm 0.5$ & 0.903 & 0.017 & 0.909 \\
\hline$\%$ PUFA & $47.4 \pm 1.0$ & $48.2 \pm 0.7$ & 0.496 & 0.030 & 0.838 \\
\hline $\operatorname{FSR}(\% / h)$ & $0.10 \pm 0.01$ & $0.09 \pm 0.01$ & 0.486 & -0.006 & 0.966 \\
\hline
\end{tabular}

Values are means \pm SEM. ${ }^{a} p$ value for difference between mild-IR and high-IR group, Student's $t$ test for unpaired samples. ${ }^{\mathrm{b}} p$ value for multiple linear regression. SE $\beta$, standardised $\beta$ coefficient for total group for HOMA-IR, adjusted for sex and BMI

whilst the expression of the intracellular lipase gene $A T G L$ (also known as PNPLA2) tended to be higher in the high-IR group $(p=0.052)$. 

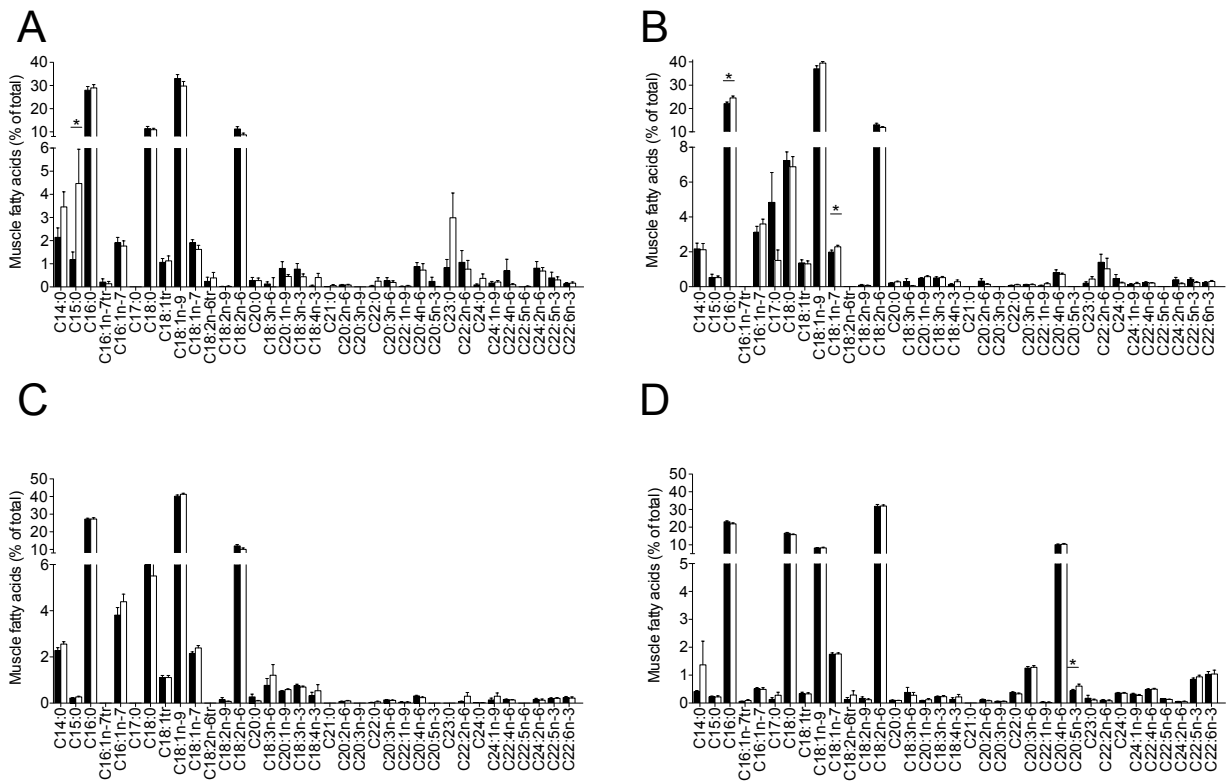

Figure 4. Intramuscular NEFA (A), DAG (B), TAG (C) and PL (D) composition under fasting conditions. Black bars, mild-IR group; white bars, high-IR group. ${ }^{*} p<0.05$, mild-IR vs highIR group, Student's $t$ test for unpaired samples. Values are presented as mean \pm SEM

\section{Discussion}

The present study demonstrated that postprandial forearm muscle VLDL-TAG extraction was elevated in individuals with high-IR compared with mild-IR. This elevation in VLDL-TAG extraction was accompanied by increased saturation of the intramuscular NEFA pool. Both effects were independent of BMI. These data support the notion of an important role for disturbances in skeletal muscle FA handling in the progression of wholebody IR.

Disturbances in skeletal muscle FA handling have been implicated in the aetiology of IR and type 2 diabetes $(1,23)$. Our group has recently demonstrated that higher postprandial plasma TAG concentrations and increased net TAG extraction across forearm muscle were accompanied by decreased postprandial insulin sensitivity in participants with impaired glucose metabolism compared with normal glucose tolerance (24). Furthermore, we showed a higher postprandial VLDL-TAG extraction by skeletal muscle in men with IR compared 
Table 4. Fasting skeletal muscle gene expression

\begin{tabular}{|c|c|c|c|c|c|}
\hline Gene & Mild-IR & High-IR & $p$ value $^{\mathrm{a}}$ & $\operatorname{SE} \beta$ & $p$ value $^{\mathrm{b}}$ \\
\hline Oxidative metabolism & $\mathrm{n}=32$ & $\mathrm{n}=30$ & & & \\
\hline$m C P T 1 B$ & $1.70 \pm 0.14$ & $1.74 \pm 0.13$ & 0.821 & 0.006 & 0.986 \\
\hline$P G C 1 \alpha(P P A R G C 1 A)$ & $0.51 \pm 0.05$ & $0.46 \pm 0.04$ & 0.428 & 0.027 & 0.847 \\
\hline$A C C 2$ & $1.52 \pm 0.14$ & $1.59 \pm 0.16$ & 0.741 & 0.020 & 0.891 \\
\hline$S D H B$ & $2.40 \pm 0.21$ & $1.97 \pm 0.22$ & 0.153 & -0.058 & 0.683 \\
\hline NDUFB5 & $2.67 \pm 0.17$ & $2.14 \pm 0.23$ & 0.062 & -0.243 & 0.076 \\
\hline Transcription factors & $\mathrm{n}=28$ & $\mathrm{n}=23$ & & & \\
\hline$P P A R \alpha(P P A R A)$ & $1.63 \pm 0.16$ & $1.56 \pm 0.11$ & 0.743 & 0.034 & 0.808 \\
\hline$P P A R \delta(P P A R D)$ & $0.36 \pm 0.04$ & $0.48 \pm 0.07$ & 0.114 & 0.175 & 0.259 \\
\hline$S R E B P 1 c(S R E B F 1)$ & $0.92 \pm 0.10$ & $1.12 \pm 0.14$ & 0.238 & 0.028 & 0.840 \\
\hline SREBP2 (SREBF2) & $1.43 \pm 0.15$ & $1.86 \pm 0.23$ & 0.127 & 0.266 & 0.216 \\
\hline$C h R E B P(C R E B B P)$ & $1.02 \pm 0.19$ & $0.99 \pm 0.15$ & 0.906 & -0.040 & 0.859 \\
\hline TAG synthesis & $\mathrm{n}=10$ & $\mathrm{n}=15$ & & & \\
\hline GPAT1 $(G P A M)$ & $2.55 \pm 0.23$ & $1.81 \pm 0.25$ & 0.050 & -0.666 & 0.002 \\
\hline$D G A T 1$ & $1.89 \pm 0.19$ & $1.77 \pm 0.20$ & 0.667 & 0.079 & 0.683 \\
\hline$D G A T 2$ & $0.31 \pm 0.05$ & $0.25 \pm 0.06$ & 0.509 & -0.103 & 0.671 \\
\hline TAG lipolysis & $\mathrm{n}=15$ & $\mathrm{n}=8$ & & & \\
\hline$L P L$ & $0.50 \pm 0.08$ & $0.62 \pm 0.11$ & 0.342 & 0.018 & 0.927 \\
\hline$A T G L(P N P L A 2)$ & $1.11 \pm 0.17$ & $2.52 \pm 0.60$ & 0.052 & 0.522 & 0.007 \\
\hline HSL (LIPE) & $0.44 \pm 0.19$ & $0.74 \pm 0.21$ & 0.329 & 0.130 & 0.515 \\
\hline
\end{tabular}

Values are means \pm SEM. ${ }^{a} p$ value for difference between mild-IR and high-IR group, Student's $t$ test for unpaired samples. ${ }^{\mathrm{b}} p$ value for multiple linear regression. $m \mathrm{CPT} 1 \mathrm{~b}$, muscle $C P T 1 B$; SE $\beta$, standardised $\beta$ coefficient for total group for HOMA-IR, adjusted for sex and BMI

with controls with the metabolic syndrome, matched for age and BMI, despite a similar TAG supply (19). More recently, we demonstrated that increased muscle VLDL-TAG extraction and reduced lipid turnover of SFA, rather than DAG content, accompany the more pronounced IR observed in humans with impaired glucose tolerance (IGT) compared with impaired fasting glucose (IFG) (20).

The present data extend our previous observations regarding FA handling by showing that postprandial forearm muscle VLDL-TAG extraction was elevated in participants with 
high-IR when compared with those with mild-IR. We included participants who encompassed the entire spectrum of insulin sensitivity, from insulin-sensitive to very-insulinresistant states (HOMA-IR, 1.7-11.3) and with a wide range of adiposity (BMI, $22.7-39.5 \mathrm{~kg} / \mathrm{m}^{2}$ ). This allowed us to differentiate between the effect of obesity and IR per se, and our present findings confirm those of previous studies that have suggested the existence of a relationship between impaired skeletal muscle FA handling and IR (1,8,25). Moreover, our data imply that IR is primarily responsible for increased postprandial forearm muscle VLDL-TAG extraction, since we observed a significant linear association between VLDLTAG extraction and IR. A potential mechanism for increased skeletal muscle VLDL-TAG extraction in participants with high-IR may involve differential apolipoprotein composition of the VLDL particles (16). For example, higher plasma apoCII:apoCIII ratios have been shown in diabetic individuals, compared with a control group (26). This variation in lipid composition might lead to higher a susceptibility for lipid degradation by in vivo skeletal muscle LPL (27). Of note, we did not perform measurements in the late postprandial phase. It has been shown that dietary FAs appear in VLDL-TAG from 2-3 $\mathrm{h}$ after meal ingestion, making it difficult to separate chylomicron- and VLDL-TAG in the late postprandial phase using the current dual isotope approach $(17,28,29)$. Therefore, we cannot exclude the possibility that the increased TAG extraction observed in high-IR participants may also extend to chylomicron-TAG. In this context, an impaired inhibitory effect of insulin on skeletal muscle LPL action in the high-IR group (30), or impaired FA uptake via membraneassociated carrier proteins like CD36 (31) might possibly explain the observed differences.

In addition to an increased skeletal muscle lipid uptake, we observed differences in the intramyocellular FA partitioning between groups. Reduced re-esterification of NEFA into TAG may expose muscle to excess NEFA concentrations and bioactive lipid metabolites that may interfere with insulin signalling (23). In line with this, a reduced incorporation of NEFA into TAG in primary myotubes from obese individuals with type 2 diabetes has previously been shown (32), indicating that the ability to incorporate FAs into TAG is an intrinsic feature of human muscle cells that is reduced in individuals with type 2 diabetes. Moreover, in vitro work has shown that muscle cells incubated with palmitate incorporated more FA towards the DAG pool, while the unsaturated FAs were diverted towards storage in the TAG pool (33). In the present study, an increased percentage of palmitate in the DAG pool in the participants with high-IR was observed. Together with the reduced expression of GPAT1, which is involved in the first step in TAG synthesis in muscle, this might indicate a retention of SFA in the NEFA pool and may explain the lower percentage of PUFA in the DAG pool 
in the individuals with high-IR vs mild-IR. More recently, we reported a reduced FSR of palmitate into intramuscular TAG and DAG in individuals with combined IGT and IFG compared with participants with isolated IFG (20). This has also been shown in obese humans with impaired glucose metabolism (34). However, in the present study we did not observe significant differences between the mild-IR and high-IR groups in the FSR of palmitate into intramuscular TAG and DAG. Nevertheless, these findings suggest that the postprandial incorporation of FAs in TAG or DAG is not affected by the degree of IR per se.

Strikingly, in this study the increased saturation in the NEFA pool was mainly confined to specific SFAs, namely myristic acid (C14:0), pentadecyclic acid (C15:0) and tricosylic acid (C23:0). Recently, plasma odd-chain SFAs were shown to be inversely associated with type 2 diabetes and coronary heart disease incidence in large epidemiological studies (35). Interestingly, dairy products are known to be the most important source for C15:0 (36). This would certainly suggest a contribution of dietary fat to the increased saturation of the NEFA pool, since it has been shown that FA composition of skeletal muscle reflects dietary FA composition (37). However, data related to odd-chain FA metabolism in skeletal muscle is currently lacking and more research is needed to unravel the role of odd-chain FAs in intramyocellular lipid turnover and skeletal muscle IR. Moreover, it is important to note that the increased content of SFA in the high-IR group might be linked to an increased ceramide content and higher saturation in the long-chain fatty acyl-CoA. It has been shown that increased levels of the SFA palmitate drive ceramide synthesis (38). However, we did not measure skeletal muscle ceramide levels or expression of related genes in the present study. Finally, previous studies have shown that lower percentages of PUFA in the plasma membrane are associated with IR $(39,40)$. However, in this study the percentages of total PUFAs in the muscle PL pool were comparable between groups. It is important to note that we have not specifically measured muscle membrane PL content but rather total muscle PL content. Since most PLs are located mainly in the plasma membrane, the reduced total PL content might reflect a lower absolute amount of PUFA in the muscle membrane fraction and might therefore contribute to the worsening of IR in individuals with high-IR.

A limitation of the present study is that we did not perform a hyperinsulinaemiceuglycaemic clamp test to assess insulin sensitivity. Rather, we divided groups based on a surrogate marker of whole-body insulin sensitivity, namely HOMA-IR. Nevertheless, previous studies have shown strong correlations between HOMA-IR and peripheral insulin sensitivity, as measured by the gold-standard hyperinsulinaemic-euglycaemic clamp (41). Importantly, in this study individuals in the high-IR group had a significantly lower 
postprandial net glucose uptake across forearm muscle as compared with the individuals with mild-IR, despite having significantly higher postprandial plasma insulin concentrations. Since skeletal muscle accounts for approximately $80 \%$ of insulin-mediated glucose uptake in humans (42), these data clearly indicate a more pronounced skeletal muscle IR in the individuals with high-IR as compared with those with mild-IR.

In conclusion, increased skeletal muscle VLDL-TAG extraction in the postprandial state and higher saturation of the intramuscular NEFA pool are associated with more pronounced IR. These data support an important role for disturbances in skeletal muscle FA handling in the progression of whole-body IR. 


\section{References}

1. Stinkens R, Goossens GH, Jocken JWE, Blaak EE. Targeting fatty acid metabolism to improve glucose metabolism. Obes Rev. 2015;16:715-57.

2. Goossens GH. The role of adipose tissue dysfunction in the pathogenesis of obesity-related insulin resistance. Physiol Behav. 2008;94:206-18.

3. Ebbert J, Jensen M. Fat Depots, Free Fatty Acids, and Dyslipidemia. Nutrients. 2013;5:498-508.

4. Mittendorfer B. Origins of metabolic complications in obesity: adipose tissue and free fatty acid trafficking. Curr Opin Clin Nutr Metab Care. 2011;14:535-41.

5. Mensink M, Blaak EE, van Baak MA, Wagenmakers AJ, Saris WH. Plasma free Fatty Acid uptake and oxidation are already diminished in subjects at high risk for developing type 2 diabetes. Diabetes. 2001;50:2548-54.

6. Dubé JJ, Coen PM, DiStefano G, Chacon AC, Helbling NL, Desimone ME, et al. Effects of acute lipid overload on skeletal muscle insulin resistance, metabolic flexibility, and mitochondrial performance. Am J Physiol Endocrinol Metab. 2014;307:E1117-24.

7. Schrauwen P, Schrauwen-Hinderling V, Hoeks J, Hesselink MKC. Mitochondrial dysfunction and lipotoxicity. Biochim Biophys Acta. 2010;1801:266-71.

8. Coen PM, Goodpaster BH. Role of intramyocelluar lipids in human health. Trends Endocrinol Metab. 2012;23:391-8.

9. Samuel VT, Shulman GI. Mechanisms for Insulin Resistance: Common Threads and Missing Links. Cell. 2012;148:852-71.

10. Blaak EE, Wagenmakers AJ, Glatz JF, Wolffenbuttel BH, Kemerink GJ, Langenberg CJ, et al. Plasma FFA utilization and fatty acid-binding protein content are diminished in type 2 diabetic muscle. Am J Physiol Endocrinol Metab. 2000;279:E146-54.

11. Bickerton AST, Roberts R, Fielding BA, Tornqvist H, Blaak EE, Wagenmakers AJM, et al. Adipose tissue fatty acid metabolism in insulin-resistant men. Diabetologia. 2008;51:1466-74.

12. Jocken JWE, Goossens GH, van Hees AMJ, Frayn KN, van Baak M, Stegen J, et al. Effect of betaadrenergic stimulation on whole-body and abdominal subcutaneous adipose tissue lipolysis in lean and obese men. Diabetologia. 2008;51:320-7.

13. Hodson L, Bickerton AST, McQuaid SE, Roberts R, Karpe F, Frayn KN, et al. The contribution of splanchnic fat to VLDL triglyceride is greater in insulin-resistant than insulin-sensitive men and women: studies in the postprandial state. Diabetes. 2007;56:2433-41.

14. Riemens SC, Sluiter WJ, Dullaart RP. Enhanced escape of non-esterified fatty acids from tissue uptake: its role in impaired insulin-induced lowering of total rate of appearance in obesity and Type II diabetes mellitus. Diabetologia. 2000;43:416-26.

15. Nielsen S, Karpe F. Determinants of VLDL-triglycerides production. Curr Opin Lipidol. 2012;23:321-6.

16. Choi SH, Ginsberg HN. Increased very low density lipoprotein (VLDL) secretion, hepatic steatosis, and insulin resistance. Trends Endocrinol Metab. 2011;22:353-63.

17. Bickerton AST, Roberts R, Fielding BA, Hodson L, Blaak EE, Wagenmakers AJM, et al. Preferential uptake of dietary Fatty acids in adipose tissue and muscle in the postprandial period. Diabetes. 2007;56:168-76. 
18. Ruge T, Hodson L, Cheeseman J, Dennis AL, Fielding BA, Humphreys SM, et al. Fasted to Fed Trafficking of Fatty Acids in Human Adipose Tissue Reveals a Novel Regulatory Step for Enhanced Fat Storage. J Clin Endocrinol Metab. 2009;94:1781-8.

19. van Hees AMJ, Jans A, Hul GB, Roche HM, Saris WHM, Blaak EE. Skeletal muscle fatty acid handling in insulin resistant men. Obesity. 2011;19:1350-9.

20. Goossens G, Moors C, Jocken J, van der Zijl N, Jans A, Konings E, et al. Altered Skeletal Muscle Fatty Acid Handling in Subjects with Impaired Glucose Tolerance as Compared to Impaired Fasting Glucose. Nutrients. 2016;8:164-15.

21. Jans A, Konings E, Goossens GH, Bouwman FG, Moors CC, Boekschoten MV, et al. PUFAs acutely affect triacylglycerol-derived skeletal muscle fatty acid uptake and increase postprandial insulin sensitivity. Am J Clin Nutr. 2012;95:825-36.

22. Bergström J, Hermansen L, Hultman E, Saltin B. Diet, muscle glycogen and physical performance. Acta Physiol Scand. 1967;71:140-50.

23. Bosma M, Kersten S, Hesselink MKC, Schrauwen P. Re-evaluating lipotoxic triggers in skeletal muscle: relating intramyocellular lipid metabolism to insulin sensitivity. Prog Lipid Res. 2012;51:36-49.

24. Moors CCM, van der Zijl NJ, Diamant M, Blaak EE, Goossens GH. Impaired insulin sensitivity is accompanied by disturbances in skeletal muscle fatty acid handling in subjects with impaired glucose metabolism. Int J Obes (Lond). 2012;36:709-17.

25. Samuel VT, Petersen KF, Shulman GI. Lipid-induced insulin resistance: unravelling the mechanism. Lancet. 2010;375:2267-77.

26. Hiukka A, Fruchart-Najib J, Leinonen E, Hilden H, Fruchart J-C, Taskinen M-R. Alterations of lipids and apolipoprotein CIII in very low density lipoprotein subspecies in type 2 diabetes. Diabetologia. $2005 ; 48: 1207-15$.

27. Kersten S. Physiological regulation of lipoprotein lipase. Biochim Biophys Acta. 2014;1841:919-33.

28. Heath RB, Karpe F, Milne RW, Burdge GC, Wootton SA, Frayn KN. Selective partitioning of dietary fatty acids into the VLDL TG pool in the early postprandial period. J Lipid Res. 2003;44:2065-72.

29. Heath RB, Karpe F, Milne RW, Burdge GC, Wootton SA, Frayn KN. Dietary fatty acids make a rapid and substantial contribution to VLDL-triacylglycerol in the fed state. Am J Physiol Endocrinol Metab. 2007;292:E732-9.

30. Yost TJ, Jensen DR, Haugen BR, Eckel RH. Effect of dietary macronutrient composition on tissue-specific lipoprotein lipase activity and insulin action in normal-weight subjects. Am J Clin Nutr. 1998;68:296-302.

31. Goldberg IJ, Eckel RH, Abumrad NA. Regulation of fatty acid uptake into tissues: lipoprotein lipase- and CD36-mediated pathways. J Lipid Res. 2009;50 Suppl:S86-90.

32. Sparks LM, Bosma M, Brouwers B, van de Weijer T, Bilet L, Schaart G, et al. Reduced Incorporation of Fatty Acids Into Triacylglycerol in Myotubes From Obese Individuals With Type 2 Diabetes. Diabetes. 2014;63:1583-93.

33. Montell E, Turini M, Marotta M, Roberts M, Noé V, Ciudad CJ, et al. DAG accumulation from saturated fatty acids desensitizes insulin stimulation of glucose uptake in muscle cells. Am J Physiol Endocrinol Metab. 2001;280:E229-37.

34. Perreault L, Bergman BC, Hunerdosse DM, Playdon MC, Eckel RH. Inflexibility in Intramuscular Triglyceride Fractional Synthesis Distinguishes Prediabetes From Obesity in Humans. Obesity. 2009;18:1524-31. 
35. Forouhi NG, Koulman A, Sharp SJ, Imamura F. Differences in the prospective association between individual plasma phospholipid saturated fatty acids and incident type 2 diabetes: the EPIC-InterAct casecohort study. Lancet Diabetes Endocrinol. 2014;2:810-8.

36. Jenkins B, West J, Koulman A. A Review of Odd-Chain Fatty Acid Metabolism and the Role of Pentadecanoic Acid (C15:0) and Heptadecanoic Acid (C17:0) in Health and Disease. Molecules. 2015;20:2425-44.

37. Andersson A, Nälsén C, Tengblad S, Vessby B. Fatty acid composition of skeletal muscle reflects dietary fat composition in humans. Am J Clin Nutr. 2002;76:1222-9.

38. Chaurasia B, Summers SA. Ceramides - Lipotoxic Inducers of Metabolic Disorders. Trends Endocrinol Metab. 2015;26:538-50.

39. Borkman M, Storlien LH, Pan DA, Jenkins AB, Chisholm DJ, Campbell LV. The relation between insulin sensitivity and the fatty-acid composition of skeletal-muscle phospholipids. N Engl J Med. 1993;328:238-44.

40. Baur LA, O'Connor J, Pan DA, Kriketos AD, Storlien LH. The fatty acid composition of skeletal muscle membrane phospholipid: its relationship with the type of feeding and plasma glucose levels in young children. Metabolism. 1998;47:106-12.

41. Bonora E, Targher G, Alberiche M, Bonadonna RC, Saggiani F, Zenere MB, et al. Homeostasis model assessment closely mirrors the glucose clamp technique in the assessment of insulin sensitivity: studies in subjects with various degrees of glucose tolerance and insulin sensitivity. Diabetes Care. 2000;23:57-63.

42. DeFronzo RA, Jacot E, Jequier E, Maeder E, Wahren J, Felber JP. The effect of insulin on the disposal of intravenous glucose. Results from indirect calorimetry and hepatic and femoral venous catheterization. Diabetes. 1981;30:1000-7. 
Skeletal muscle fatty acid handling in IR | 63 


\section{Chapter 3}

\section{Angiopoietin-like protein 4 and postprandial skeletal muscle lipid metabolism in overweight and obese prediabetics}

Birgitta W. van der Kolk ${ }^{1}$, Gijs H. Goossens ${ }^{1}$, Johan W. Jocken ${ }^{1}$, Sander Kersten ${ }^{2}$, Ellen E. Blaak ${ }^{1}$

${ }^{1}$ Department of Human Biology, NUTRIM School of Nutrition and Translational Research in Metabolism, Maastricht University Medical Center ${ }^{+}$, the Netherlands ${ }^{2}$ Nutrition, Metabolism and Genomics Group, Division of Human Nutrition, Wageningen University, the Netherlands 


\section{Abstract}

Context: Angiopoietin-like protein 4 (ANGPTL4) decreases plasma triacylglycerol (TAG) clearance by inhibiting lipoprotein lipase (LPL) and may contribute to impairments in lipid metabolism under compromised metabolic conditions.

Objectives: To investigate the effects of a high-saturated fatty acid (SFA) mixed meal on plasma ANGPTL4 concentrations in relation to in vivo muscle LPL activity, to study the effects of dietary fat quality, and to examine skeletal muscle ANGPTL4 release.

Design, Participants, Setting, and Interventions: We used a dual stable-isotope tracer technique in combination with measurements of arteriovenous concentration differences across forearm muscle to investigate muscle ANGPTL4 secretion and fatty acid handling under fasting conditions and after a high-SFA mixed meal in 73 overweight and obese humans at the Metabolic Research Unit of Maastricht University. The effect of dietary fat quality manipulation on plasma ANGPTL4 was investigated in 10 obese insulin-resistant participants.

Results: The high-SFA meal decreased circulating ANGPTL4 concentrations (fasting, $5.2 \mathrm{ng} / \mathrm{ml}$ vs 4 hours postprandial, $4.0 \mathrm{ng} / \mathrm{mL} ; p<0.001)$. Furthermore, skeletal muscle ANGPTL4 secretion into the circulation was observed $\left(\mathrm{AUC}_{0-4 \mathrm{~h}}, p=0.048\right)$. However, no association was observed between plasma ANGPTL4 and skeletal muscle very low-density lipoprotein or dietary (chylomicron) TAG extraction $\left(\mathrm{AUC}_{0-4 \mathrm{~h}}, p=0.372\right.$ and $p=0.139$, respectively). In contrast to a high-SFA or high-monounsaturated fat meal, plasma ANGPTL4 remained unchanged after a high-polyunsaturated fat meal.

Conclusions: ANGPTL4 is secreted by human forearm muscle in postprandial conditions after a high-SFA meal. Plasma ANGPTL4 concentrations were not associated with in vivo skeletal muscle LPL activity after a high-SFA meal. Dietary fat quality affects plasma ANGPTL4, but it remains to be elucidated whether this influences short-term skeletal muscle lipid handling. 


\section{Introduction}

Systemic lipid overflow, driven by adipose tissue dysfunction and an impaired skeletal muscle lipid handling, may contribute to insulin resistance (1). Lipoprotein lipase (LPL) plays a central role in the clearance of triacylglycerol (TAG)-rich plasma lipoproteins (2). LPL is located at the capillary endothelium, where it catalyzes the hydrolysis of endogenous very lowdensity lipoprotein (VLDL)-TAG and exogenous chylomicron-TAG to glycerol and free fatty acids (FFAs) (3). The resulting FFAs are then taken up by the tissues and will be directed toward oxidation or storage or will be spilled over into the circulation (4,5). The activity of LPL is under tight nutritional and hormonal control. For instance, insulin is a major activator of LPL activity (6). Furthermore, angiopoietinlike protein 4 (ANGPTL4) has emerged as an important inhibitor of LPL activity, likely by inducing dissociation of catalytically active LPL dimers into inactive LPL monomers (7-9).

The regulation of ANGPTL4 under fasting and postprandial conditions in humans and its contribution to human tissue lipid handling is not well understood. Insulin reduces circulating ANGPTL4, as revealed by hyperinsulinemic-euglycemic clamps in humans (1013). Interestingly, concomitant intravenous infusion of a lipid emulsion high in polyunsaturated fatty acids (PUFAs) blunted this insulin-mediated ANGPTL4 decrease. This suggests that dietary fat quality might be an important regulator of plasma ANGPTL4 (10). Furthermore, in vitro studies using human myotubes and adipocytes have shown that ANGPTL4 expression and secretion are stimulated by dietary fatty acid quality in a peroxisomal proliferator activator receptor-dependent manner (12,14-17). Interestingly, we have reported that dietary fat quality affects in vivo skeletal muscle fatty acid handling with an increased TAG extraction in obese insulin-resistant humans (18). However, it remains to be elucidated whether ANGPTL4 is involved in interindividual differences in skeletal muscle lipid metabolism.

ANGPTL4 is expressed and secreted by numerous cell types, and its expression is dependent on nutritional status (19). Human plasma ANGPTL4 concentrations are relatively stable, although plasma ANGPTL4 increases after long-term fasting $(12,20)$ and chronic caloric restriction (12), as well as following physical activity $(12,16,21)$. These conditions are characterized by elevated plasma FFA concentrations. However, the origin of circulating ANGPTL4 is currently unknown. Based on human ANGPTL4 mRNA expression and ANGPTL4 overexpression studies in mice, it has been postulated that the liver is the main contributor to systemic ANGPTL4 concentrations $(12,22)$. In addition, adipose tissue and 
intestine might also be important contributors to circulating ANGPTL4 concentrations $(23,24)$. Interestingly, it has recently been shown that acute exercise induced gene and protein expression of ANGPTL4 in skeletal muscle and increased plasma ANGPTL4 concentrations $(16,21)$. These data suggest that skeletal muscle might also contribute to plasma ANGPTL4 $(16,21)$. However, data on in vivo ANGPTL4 secretion by skeletal muscle in humans are still lacking.

The aims of the present study were to investigate the determinants and postprandial regulation of plasma ANGPTL4 in overweight and obese prediabetic humans after the intake of a high saturated fatty acid (SFA) meal. Secondly, the relationship between plasma ANGPTL4 concentration and in vivo skeletal muscle LPL activity was studied. Moreover, we addressed the impact of dietary fat quality on plasma ANGPTL4 concentrations and examined whether human forearm muscle secretes ANGPTL4 under fasting conditions and after the intake of a high-SFA meal.

\section{Subjects and methods}

\section{Study participants}

In 150 participants (138 men and 12 women), fasting plasma ANGPTL4 concentrations were measured. Participants' characteristics are summarized in Table 1. From this cohort, 73 participants (61 men and 12 women) with metabolic syndrome or impaired glucose metabolism had a high-SFA mixed-meal test. These participants have been described elsewhere in more detail $(18,25,26)$. From these participants, 10 obese insulin-resistant men also consumed two additional high-fat mixed meals, high in either monounsaturated fat (MUFA) or in PUFA (18). The local Medical Ethical Committee of Maastricht University Medical Center ${ }^{+}$approved the study protocols. All participants gave written informed consent before participation.

\section{High-fat mixed-meal test}

Participants were studied after an overnight fast and were asked to refrain from strenuous exercise and drinking alcohol 24 hours before the study day. In addition, they were asked to avoid food products naturally enriched with $\left[{ }^{13} \mathrm{C}\right]$ for 7 days before the study day. Forearm muscle metabolism was calculated using arteriovenous concentration differences combined with measurements of forearm blood flow. Three catheters were inserted before the start of 
the experiment. One catheter was placed retrogradely into a superficial dorsal hand vein, which was heated in a hot-box $\left(60^{\circ} \mathrm{C}\right)$ to obtain an arterialized blood sample. In the same arm, another catheter was placed in an antecubital vein for the infusion of the $\left[{ }^{2} \mathrm{H}_{2}\right]$-palmitate tracer. A third catheter was placed retrogradely in a deep antecubital vein of the contralateral forearm to sample venous blood draining the forearm muscle. After taking an arterial and deep venous background sample at 90 minutes before meal ingestion ( $t-90)$, a continuous intravenous infusion of the stable isotope tracer $\left[{ }^{2} \mathrm{H}_{2}\right]$-palmitate $(97 \%$ enrichment; Cambridge Isotope Laboratories) complexed to albumin was started $\left(0.035 \mu \mathrm{mol} \cdot \mathrm{kg}\right.$ body weight ${ }^{-1} \cdot \mathrm{min}^{-}$ ${ }^{1}$ ). Baseline blood sampling was started after 1 hour of tracer infusion to allow isotopic equilibration to occur. Blood samples were taken simultaneously from the dorsal hand vein and the deep muscle vein at three time points during fasting: $\mathrm{t}-30, \mathrm{t}-15$, at meal ingestion

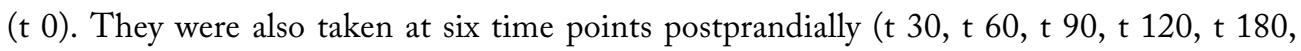
$\mathrm{t}$ 240) after consumption of a high-SFA mixed meal ( $\mathrm{t} 0$ ) containing $200 \mathrm{mg}$ $\left[\mathrm{U}-{ }^{13} \mathrm{C}\right]$-palmitate (98\% enrichment; Cambridge Isotope Laboratories). The liquid meal test provided 2.6 MJ, consisting of 61 Energy \% (E\%) fat (35.5 E\% SFA, $18.8 \mathrm{E} \% \mathrm{MUFA}$, and 1.7 E\% PUFA), $33 \mathrm{E} \%$ carbohydrates, and $6.3 \mathrm{E} \%$ protein. Ten obese insulin-resistant participants also consumed in a randomized order a liquid high-fat mixed meal (2.6 MJ; $61 \mathrm{E} \%$ fat), which was high in MUFA (42.2 E\%) or PUFA (34.8 E\%) in a single-blinded randomized crossover design (18). Forearm blood flow was measured before each blood sampling and has been described previously (27).

\section{Plasma ANGPTL4 concentration}

ANGPTL4 was measured by ELISA, as described previously (12). Briefly, 96-well plates were coated with antihuman ANGPTL4 polyclonal goat IgG antibody (AF3485; R\&D Systems) and incubated overnight at $4^{\circ} \mathrm{C}$. Plates were washed extensively between each step. After blocking, $100 \mu \mathrm{L}$ of 20 -fold diluted human plasma was added, followed by 2 -hour incubation at room temperature. A standard curve was prepared using recombinant ANGPTL4 (3485-AN; R\&D Systems) at 0.3-2.1 ng/well. Next, $100 \mu \mathrm{L}$ of diluted biotinylated antihuman ANGPTL4 polyclonal goat IgG antibody (BAF3485; R\&D Systems) was added for 2 hours, followed by the addition of streptavidin-conjugated horseradish peroxidase for 20 minutes and tetramethyl benzidine substrate for 6 minutes. The reaction was stopped by the addition of $50 \mu \mathrm{L}$ of $10 \% \mathrm{H}_{2} \mathrm{SO}_{4}$, and the absorbance was measured at $450 \mathrm{~nm}$. Details on other biochemical analyses have previously been reported (25). 


\section{Skeletal muscle ANGPTL4 release and muscle lipid handling}

Net fluxes of ANGPTL4 and metabolites (labeled and unlabeled) across the forearm were calculated by multiplying the arteriovenous concentration difference by forearm plasma flow. Plasma flow was measured using plethysmography and calculated by multiplying forearm blood flow with (1 - hematocrit/ 100). A positive flux indicates net uptake across forearm muscle, whereas a negative flux indicates net release. Labeled FFA and TAG concentrations were calculated as the product of the tracer-tracee ratio of $\left[{ }^{2} \mathrm{H}_{2}\right]-$ and $\left[\mathrm{U}-{ }^{13} \mathrm{C}\right]$-labeled palmitate and the concentration of palmitate in FFA and TAG, as reported before (25). In vivo LPL activity was based on net fluxes of $\left[{ }^{2} \mathrm{H}_{2}\right]-$ and $\left[\mathrm{U}-{ }^{13} \mathrm{C}\right]$-labeled palmitate. Postprandial areas under the curve (AUCs) of metabolites were calculated using the trapezium rule. Besides the total AUC (0-4 hours after meal ingestion), the "early" (0-2 hours) and "mid" (2-4 hours) AUCs were also calculated to obtain more detailed information on the time course of the postprandial responses. Likewise, ANGPTL4 changes from baseline $(\Delta)$ to the "total" (0-4 hours), "early" (0-2 hours), and "mid" (2-4 hours) postprandial phases were calculated.

\section{Statistics}

Correlations between clinical characteristics or postprandial responses and plasma ANGPTL4 concentrations were tested by Pearson's correlation coefficients, partial regression analyses, and with multiple linear regression analyses. Repeated-measures ANOVA with time as within-subject and dietary fat quality as between-subject factors was performed to identify the effects of dietary fat quality on plasma ANGPTL4 concentrations. Student's unpaired $t$ test was used to examine whether ANGPTL4 was released from skeletal muscle into the circulation (ANGPTL4 flux vs "zero" flux). The data were analyzed using SPSS for Mac version 22.0 (SPSS Inc). Statistical significance was set at $p<0.05$, and all data in this study are expressed as means \pm SEM.

\section{Results}

\section{Determinants of fasting ANGPTL4 concentration}

First, we investigated determinants of fasting plasma ANGPTL4 concentration in a crosssectional study cohort of 150 participants (characteristics in Table 1). Participants had a wide range in body mass index (BMI; $20.8-49.3 \mathrm{~kg} / \mathrm{m}^{2}$ ) and insulin resistance (homeostasis model of assessment for insulin resistance [HOMA-IR], 0.5-11.3). Plasma ANGPTL4 showed a 
Table 1. Participants' characteristics

\begin{tabular}{|c|c|c|c|}
\hline & Fasting & Meal test & Dietary fat quality \\
\hline No. of participants & 150 & 73 & 10 \\
\hline Male (n) / Female (n) & $138 / 12$ & $61 / 12$ & $10 / 0$ \\
\hline Age (y) & $55.5 \pm 0.8(23-70)$ & $58.6 \pm 0.9(36-70)$ & $61.5 \pm 1.6(54-70)$ \\
\hline BMI $\left(\mathrm{kg} / \mathrm{m}^{2}\right)$ & $30.8 \pm 0.4(20.8-49.8)$ & $30.5 \pm 0.4(22.7-39.5)$ & $33.8 \pm 3.8(28.6-38.6)$ \\
\hline Waist-hip ratio & $1.03 \pm 0.01(0.89-1.22)$ & $1.02 \pm 0.01(0.89-1.17)$ & $1.04 \pm 0.01(1.00-1.10)$ \\
\hline $\begin{array}{l}\text { Fasting plasma glucose } \\
(\mathrm{mmol} / \mathrm{L})\end{array}$ & $5.7 \pm 0.1(4.4-8.4)$ & $5.5 \pm 0.1(4.6-6.7)$ & $5.6 \pm 0.1(4.8-5.6)$ \\
\hline $\begin{array}{l}\text { Fasting plasma insulin } \\
(\mathrm{mU} / \mathrm{L})\end{array}$ & $14.9 \pm 0.5(2.1-38.0)$ & $14.6 \pm 0.7(7.2-38.0)$ & $13.7 \pm 1.3(7.8-24.1)$ \\
\hline $\begin{array}{l}\text { Fasting plasma FFA } \\
(\mu \mathrm{mol} / \mathrm{L})\end{array}$ & $615 \pm 16(127-1265)$ & $578 \pm 17(296-1002)$ & $652 \pm 47(415-846)$ \\
\hline $\begin{array}{l}\text { Fasting plasma TAG } \\
(\mu \mathrm{mol} / \mathrm{L})\end{array}$ & $1299 \pm 53(415-4571)$ & $1276 \pm 67(415-3232)$ & $1204 \pm 154(690-2481)$ \\
\hline HOMA-IR & $3.7 \pm 0.2(0.5-11.3)$ & $3.6 \pm 0.2(1.7-11.3)$ & $3.5 \pm 0.4(1.7-5.4)$ \\
\hline $\begin{array}{l}\text { Fasting plasma } \\
\text { ANGPTL4 }(\mathrm{ng} / \mathrm{mL})\end{array}$ & $5.7 \pm 0.2(1.2-16.4)$ & $5.2 \pm 0.2(2.4-11.1)$ & $5.4 \pm 0.6(2.5-8.9)$ \\
\hline
\end{tabular}

Values are expressed as mean \pm SEM (range) unless specified otherwise.

positive correlation with circulating FFA, fasting insulin, and markers of adiposity, including BMI and waist-hip ratio (Table 2). Plasma ANGPTL4 was inversely associated with age and fasting glucose. No significant relationship was observed between plasma ANGPTL4 and circulating TAG concentrations. A partial regression analysis demonstrated that these variables together accounted for $32.7 \%$ of the variance in fasting ANGPTL4 (adjusted $\mathrm{R}^{2}$, 0.327). These results might point toward higher ANGPTL4 concentrations when metabolic health is attenuated (Table 2). 
Table 2. Pearson and partial regression coefficients between fasting plasma ANGPTL4, anthropometric and clinical characteristics

\begin{tabular}{lcccc}
\hline & $R$ & $p$-value & $\begin{array}{c}\text { Partial } \\
\text { regression } \\
\text { coefficients }\end{array}$ & $p$-value \\
\hline Age $(\mathrm{y})$ & -0.214 & 0.009 & -0.200 & 0.016 \\
BMI $\left(\mathrm{kg} / \mathrm{m}^{2}\right)$ & 0.420 & $<0.001$ & 0.137 & 0.103 \\
Waist-hip ratio & 0.292 & $<0.001$ & 0.167 & 0.045 \\
Fasting plasma glucose $(\mathrm{mmol} / \mathrm{L})$ & -0.185 & 0.023 & -0.318 & $<0.001$ \\
Fasting plasma insulin $(\mathrm{mU} / \mathrm{L})$ & 0.208 & 0.011 & 0.149 & 0.074 \\
Fasting FFA $(\mu \mathrm{mol} / \mathrm{L})$ & 0.355 & $<0.001$ & 0.334 & $<0.001$ \\
Fasting TAG $(\mu \mathrm{mol} / \mathrm{L})$ & -0.041 & 0.617 & -0.202 & 0.015 \\
HOMA-IR & 0.126 & 0.123 & & \\
\hline
\end{tabular}

\section{High-fat meal intake alters postprandial plasma ANGPTL4}

Next, we investigated the postprandial response of ANGPTL4 in 73 overweight or obese participants (characteristics can be found in Table 1), after consumption of a high-SFA meal. Arterialized ANGPTL4 concentrations significantly decreased during the postprandial phase (baseline, $5.2 \pm 0.2 \mathrm{ng} / \mathrm{mL}$, vs 4 hours after meal intake, $4.0 \pm 0.2 \mathrm{ng} / \mathrm{mL}$; ANOVA time $p<0.001$ ) (Figure 1A). In the present study, fasting plasma FFAs, TAG, insulin, and glucose concentrations correlated with fasting plasma ANGPTL4. Therefore we investigated the relationship between the postprandial decline in ANGPTL4 concentrations and postprandial responses of these circulating factors after a high-SFA meal. Multiple regression analysis revealed that postprandial FFA concentration decline ( $\mathrm{iAUC}_{0-4 \mathrm{~h}}$ ) was positively associated with the decline in ANGPTL4 $\left(\Delta_{0-4 h}\right)$ after a high-SFA meal $(\beta=0.002 ; p=0.028)$. This was independent from postprandial changes in plasma insulin, glucose, and TAG concentrations.

\section{Plasma ANGPTL4 does not correlate with muscle LPL activity}

Next, we examined whether fasting plasma ANGPTL4 concentrations or the postprandial (changes in) plasma ANGPTL4 concentrations after a high-SFA meal were associated with skeletal muscle LPL activity. Using a dual stable isotope methodology, we were able to determine forearm muscle TAG extraction from endogenous VLDL-TAG (TAG labeled with $\left[{ }^{2} \mathrm{H}_{2}\right]$-palmitate) and from chylomicron TAG (TAG labeled with [U- $\left.{ }^{13} \mathrm{C}\right]$-palmitate), as previously reported $(5,25)$. As expected, from the first fasting sample onward, the 
A

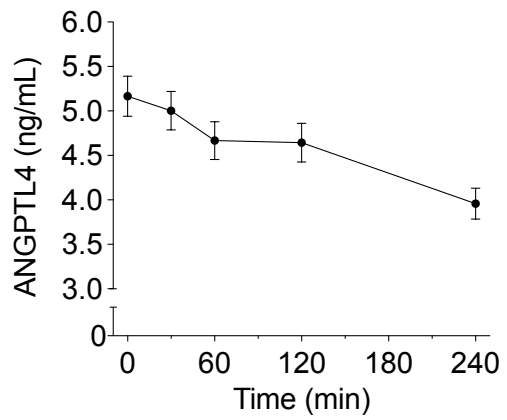

$\mathrm{B}$

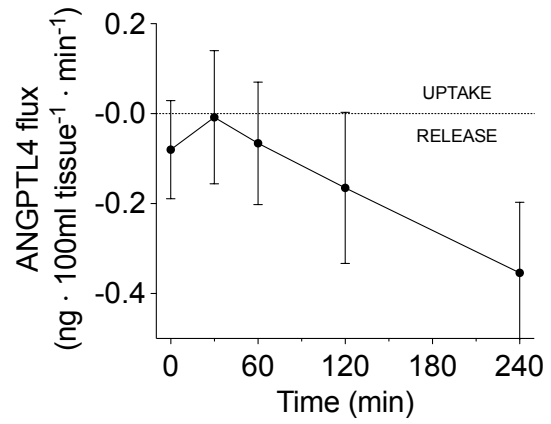

Figure 1. (A) Plasma ANGPTL4 concentrations (B) Net forearm muscle ANGPTL4 flux before and after a high-saturated fatty acid (SFA) meal. Values are mean \pm SEM; $n=73$.

$\left[{ }^{2} \mathrm{H}_{2}\right]$-palmitate tracer could be measured in plasma TAG pool. This reflects the incorporation of the intravenously infused tracer into hepatically derived VLDL-TAG. The $\left[\mathrm{U}-{ }^{13} \mathrm{C}\right]$-palmitate tracer (ingested together with the meal), representing exogenous chylomicron-TAG, appeared in the plasma TAG fraction 60 minutes after meal ingestion (Figure 2A). The net flux of $\left[\mathrm{U}-{ }^{13} \mathrm{C}\right]$-palmitate in TAG, which reflects LPL-mediated hydrolysis of chylomicron-TAG, could be measured from 60 minutes onward until the end of the postprandial period (Figure 2B). This was greater than the net flux of $\left[{ }^{2} \mathrm{H}_{2}\right]$-palmitate in TAG, reflecting VLDL-TAG extraction. There was no relationship between fasting plasma ANGPTL4 and baseline VLDL-TAG flux $(\mathrm{r}=-0.045 ; p=0.717)$ or the postprandial plasma ANGPTL4 concentrations and the SFA meal-induced VLDL-TAG flux ( $\mathrm{AUC}_{0-4 \mathrm{~h}}$, $\mathrm{r}=0.117 ; p=0.373)$ and chylomicron-TAG flux $\left(\mathrm{AUC}_{0-4 \mathrm{~h}}, \mathrm{r}=-0.186 ; p=0.139\right)$. No genderrelated differences were observed in plasma ANGPTL4 concentrations, VLDL-TAG flux, and chylomicron-TAG flux or in the associations between plasma ANGPTL4 and skeletal muscle lipid handling. Moreover, when we divided the group into tertiles of $\left[{ }^{2} \mathrm{H}_{2}\right]$-palmitate and $\left[\mathrm{U}-{ }^{13} \mathrm{C}\right]$-palmitate skeletal muscle TAG extraction, no differences were observed between postprandial plasma ANGPTL4 concentrations (ANOVA $p=0.484$ and $p=0.393$, respectively). These data suggest that plasma ANGPTL4 concentration does not play a major role in skeletal muscle fatty acid handling in humans. 
A

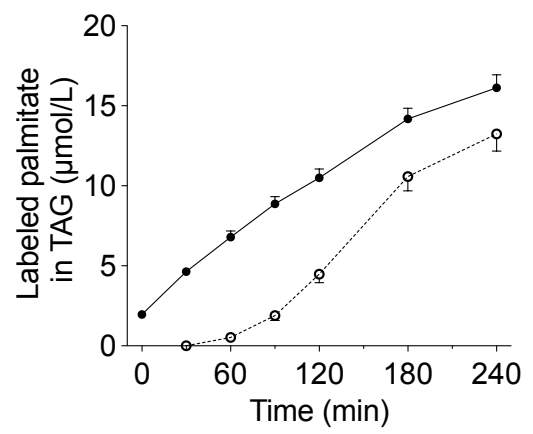

$\mathrm{B}$

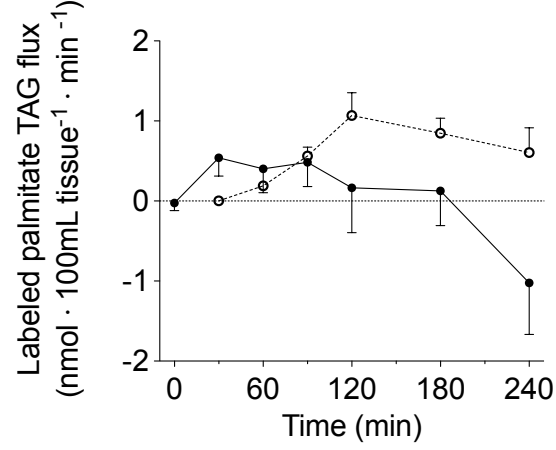

Figure 2. (A) $\left[{ }^{2} \mathrm{H}_{2}\right]-$ and $\left[\mathrm{U}-{ }^{13} \mathrm{C}\right]$-palmitate concentrations in the plasma TAG fraction (B) Net flux of $\left[{ }^{2} \mathrm{H}_{2}\right]$ - and $\left[\mathrm{U}-{ }^{13} \mathrm{C}\right]$-palmitate TAG across forearm muscle during fasting $(\mathrm{t}=0)$ and after consumption of a high-SFA meal. Black symbols, $\left[{ }^{2} \mathrm{H}_{2}\right]$-palmitate, $\mathrm{n}=61$; white symbols, dotted line $\left[\mathrm{U}-{ }^{13} \mathrm{C}\right]$-palmitate, $\mathrm{n}=66$. Values are mean \pm SEM.

\section{Dietary fat quality affects plasma ANGPTL4}

Next, we investigated the effect of dietary fat quality on fasting and postprandial ANGPTL4 concentrations and examined postprandial fatty acid handling after meals varying in dietary fat quality (18). In 10 obese insulin-resistant participants (characteristics can be found in Table 1), plasma ANGPTL4 concentrations decreased after intake of the high-SFA meal (baseline, $5.6 \pm 0.6 \mathrm{ng} / \mathrm{mL}$; vs 4 hours after meal intake, $4.3 \pm 0.4 \mathrm{ng} / \mathrm{mL}$ ). This decrease was also evident after the high-MUFA meal $(5.4 \pm 0.8$ vs $4.8 \pm 0.6 \mathrm{ng} / \mathrm{mL})$ but not after a high-PUFA meal in the mid postprandial phase $\left(5.1 \pm 0.7\right.$ vs $\left.5.3 \pm 0.6 \mathrm{ng} / \mathrm{mL} ; \Delta_{2-4 \mathrm{~h}} p=0.035\right)$ (Figure 3). Strikingly, the blunted decrease in plasma ANGPTL4 after the high-PUFA meal was accompanied by a lower TAG-derived fatty acid uptake (18).

\section{ANGPTL4 is released from human skeletal muscle}

Finally, it has been postulated that skeletal muscle may be a source of plasma ANGPTL4 in humans (21). In the present study, no significant release of ANGPTL4 from skeletal muscle after an overnight fast was found. Importantly, however, significant ANGPTL4 release from skeletal muscle was detectable after a high-SFA meal $\left(\mathrm{AUC}_{0-4 \mathrm{~h}} ;-0.17 \pm 0.09 \mathrm{ng} \cdot 100 \mathrm{~mL}\right.$ tissue $^{-1} \cdot \min ^{-1}$ vs zero flux; $p=0.048$ ) (Figure $1 \mathrm{~B}$ ), with the highest release observed in the mid postprandial phase $\left(\mathrm{AUC}_{2-4 \mathrm{~h}} ;-0.26 \pm 0.13 \mathrm{ng} \cdot 100 \mathrm{~mL}\right.$ tissue- ${ }^{1} \cdot \mathrm{min}^{-1}$ vs zero flux; $p=0.045)$ (Figure 1B). No relationship was found between skeletal muscle ANGPTL4 release 


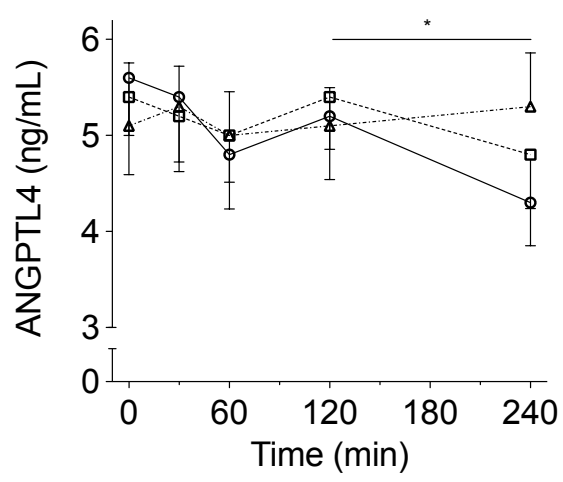

Figure 3. ANGPTL4 concentrations during fasting $(t=0)$ and after consumption of three highfat mixed meals. Circles, SFA; squares, MUFA; triangles, PUFA. Values are mean \pm SEM, $\mathrm{n}=10 .{ }^{*}, \Delta 2-4 \mathrm{~h} ; p<0.05$.

and postprandial insulin sensitivity $\left(\mathrm{AUC}_{\text {glucose }} \cdot \mathrm{AUC}_{\text {insulin }} \cdot 10^{-6}\right)(p=0.127), \mathrm{BMI}(p=0.568)$, or waist-hip ratio $(p=0.484)$. Similarly, when we divided the group into tertiles of $\left[{ }^{2} \mathrm{H}_{2}\right]$-palmitate and $\left[\mathrm{U}-{ }^{13} \mathrm{C}\right]$-palmitate TAG extraction, no differences were observed in skeletal muscle ANGPTL4 release (ANOVA $p=0.944$ and $p=0.895$, respectively).

\section{Discussion}

This study demonstrates that during fasting conditions and after intake of the high-SFA meal, plasma ANGPTL4 concentrations were not associated with in vivo skeletal muscle LPL activity. Moreover, under physiological postprandial conditions, we found that plasma ANGPTL4 was markedly decreased after a high-SFA and high-MUFA meal, but not after a high-PUFA meal. Strikingly, this was accompanied by a differential skeletal muscle fatty acid handling, with a reduced TAG extraction after the high-PUFA meal compared with the high-SFA meal, as reported previously (18). Finally, we demonstrate for the first time that ANGPTL4 was released from skeletal muscle into the circulation after high-SFA meal ingestion in humans.

Little is known about the determinants of plasma ANGPTL4. So far, a clear, positive relationship with plasma FFA has been shown $(12,14,15,20)$. Here, we demonstrate in a group of participants with a broad range in BMI and insulin sensitivity that fasting plasma ANGPTL4 is positively related to waist-hip ratio and circulating FFA concentrations. 
Furthermore, it is negatively related to circulating TAG and glucose concentrations. Overall, our data indicate that plasma ANGPTL4 is increased in participants with an attenuated metabolic health profile. Indeed, the progression of the metabolic syndrome toward type 2 diabetes mellitus has also been shown to increase plasma ANGPTL4 (28). Strikingly, after a high-SFA meal, plasma FFAs are the main determinants of circulating ANGPTL4 independently of insulin, glucose, and TAG, suggesting that FFAs are a key regulator of plasma ANGPTL4 in the postprandial state.

Our current understanding of the physiological role of ANGPTL4 indicates an important role in tissue-specific LPL inhibition (19). Nevertheless, we could not show a relationship between circulating ANGPTL4 and in vivo skeletal muscle LPL activity during fasting conditions and after a high-SFA meal. Importantly, these findings do not exclude the possibility that ANGPTL4 is a local regulator of LPL activity via autocrine and paracrine actions and that plasma ANGPTL4 does not reflect local effects in skeletal muscle on LPL activity. Indeed, tissue-specific LPL activity regulation by ANGPTL4 has been shown to take place in the subendothelial space rather than at the endothelium $(7,29)$. In line with these findings, it was proposed that newly synthesized and locally produced ANGPTL4 might have more pronounced effects on LPL activity than circulating ANGPTL4 (30). Furthermore, data from a genetic study with carriers of a rare plasma TAG-lowering genetic variant of ANGPTL4, T266M, also suggest that ANGPTL4 at the cell surface rather than circulating ANGPTL4 might play a role in LPL inhibition (31). T266M carriers have significantly higher plasma ANGPTL4 concentrations compared with T266 carriers, and in vitro studies with cultured human cells have shown higher secretion of ANGPTL4 T266M compared with wild type. Nevertheless, this ANGPTL4 variant was not associated with plasma TAG (31). These data suggest that locally produced ANGPTL4 rather than plasma ANGPTL4 may mediate LPL inhibition after a high-SFA meal. Moreover, it is important to note that additional factors are involved in functional ANGPTL4 activity. For instance, it has been suggested that the locally produced glycosylphosphatidylinositol-anchored high-density lipoprotein-binding protein might compete with ANGPTL4 for LPL binding at either the interstitial space or capillary lumen (19). This indicates that there is a complex regulation of in vivo LPL activity with many factors involved. However, the exact inter-relationships remain unclear and need to be investigated in more detail in future research.

In addition to plasma FFA, dietary fat quality might be an important determinant of circulating ANGPTL4. Indeed, the present study found that a high-PUFA meal blunted the postprandial ANGPTL4 decline that was observed after a meal rich in SFAs or MUFAs. 
This was accompanied by a reduced muscle TAG-derived fatty acid uptake (18). It is tempting to speculate from these data that ANGPTL4 may play a role in the reduced muscle LPL activity after a high-PUFA meal. For instance, it has been shown that incubation of murine $\mathrm{C} 2 \mathrm{C} 12$ myocytes and human myotubes with long-chain fatty acids induced ANGPTL4 expression in a peroxisomal proliferator activator receptor- $\delta$-dependent manner $(14,16)$. Furthermore, infusion of lipid emulsions high in MUFA or PUFA under hyperinsulinemic conditions blunted the insulin-mediated ANGPTL4 decrease in vivo in humans (10). Our findings, together with earlier observations, indicate that meal fatty acid composition affects plasma ANGPTL4. However, it remains to be elucidated whether or not this finding is important in the previously reported differential effect of dietary fat quality on TAG-derived fatty acid uptake in skeletal muscle in vivo.

The contribution of different tissues to circulating ANGPTL4 concentration remains to be established. In the present study, we provide for the first time direct in vivo evidence that skeletal muscle contributes to plasma ANGPTL4 in humans. Furthermore, it has been shown that basal in vitro ANGPTL4 expression in human myotubes correlated positively with plasma ANGPTL4 of the donors (14). Moreover, increased skeletal muscle ANGPTL4 mRNA and protein expression and plasma ANGPTL4 have been shown after acute exercise in humans, indirectly suggesting the contribution of skeletal muscle to circulating ANGPTL4 $(16,21)$. In our study, the relative muscle-derived contribution to circulating concentrations is difficult to estimate because information on ANGPTL4 half-life is lacking. The fact that plasma ANGPTL4 concentrations decline postprandially might indicate that skeletal muscle is not the major organ regulating postprandial plasma ANGPTL4 concentrations. In addition, we could not detect a significant release under fasting conditions, suggesting that other tissues such as adipose tissue, liver, and intestine contribute more to fasting plasma ANGPTL4 concentrations $(16,19)$.

This study had some limitations. First, mainly overweight and obese people and/or subjects with impaired glucose metabolism were included. Therefore, we cannot exclude that the lack of association between in vivo LPL activity and plasma ANGPTL4 may have been be due to the absence of a healthy, lean, normoglycemic group. Nevertheless, the participants covered a broad range in insulin sensitivity (HOMA-IR, 1.7 - 11.3) and adiposity (BMI, $22.7-39.5 \mathrm{~kg} / \mathrm{m}^{2}$ ). Consequently, the present analyses do not support a major contribution of plasma ANGPTL4 concentration in the regulation of in vivo skeletal muscle LPL activity in humans. Secondly, we cannot exclude that plasma ANGPTL4 does not accurately reflect functional ANGPTL4. Moreover, we have measured full-length ANGPTL4 and the 
C-terminal truncated fragment, but not the N-terminal truncated fragment of ANGPTL4 (20). However, both the full-length and the N-terminal fragment ANGPTL4 may influence plasma lipid concentration (32). Therefore, it remains to be established whether the results from the ANGPTL4 ELISA provide accurate reflection of functional ANGPTL4. Finally, in our forearm model, we cannot exclude the possibility that inter- and intramuscular fat contamination may have contributed to muscle-derived ANGPTL4 release in this study population (33) or the contribution of other cell types such as endothelial cells (34) and macrophages (28). However, previous data indicate that adipose tissue contribution is minor (27).

In conclusion, we provide in vivo evidence that ANGPTL4 is secreted from the human skeletal muscle after a high-SFA meal. Furthermore, our data indicate that plasma ANGPTL4 concentrations do not relate to in vivo muscle LPL activity after a high-SFA meal. However, we cannot exclude the possibility that ANGPTL4 could play a local role in skeletal muscle lipid metabolism in insulin resistant conditions after a high-SFA meal. Finally, we show a postprandial decline in plasma ANGPTL4 after a high-SFA and high-MUFA meal, but not after a high-PUFA meal, suggesting that dietary fat quality might regulate short-term muscle lipid handling via ANGPTL4. However, the mechanisms involved in the regulation of in vivo skeletal muscle LPL activity need to be investigated in more detail in future studies. 


\section{References}

1. Stinkens R, Goossens GH, Jocken JWE, Blaak EE. Targeting fatty acid metabolism to improve glucose metabolism. Obes Rev. 2015;16:715-57.

2. Wang H, Eckel RH. Lipoprotein lipase: from gene to obesity. Am J Physiol Endocrinol Metab. 2009;297:E271-88.

3. Goldberg IJ, Merkel M. Lipoprotein lipase: physiology, biochemistry, and molecular biology. Front Biosci. 2001;6:D388-405.

4. Miles JM, Park YS, Walewicz D, Russell-Lopez C, Windsor S, Isley WL, et al. Systemic and forearm triglyceride metabolism: fate of lipoprotein lipase-generated glycerol and free fatty acids. Diabetes. 2004;53:521-7.

5. Bickerton AST, Roberts R, Fielding BA, Hodson L, Blaak EE, Wagenmakers AJM, et al. Preferential uptake of dietary Fatty acids in adipose tissue and muscle in the postprandial period. Diabetes. 2007;56:168-76.

6. Kersten S. Physiological regulation of lipoprotein lipase. Biochim Biophys Acta. 2014;1841:919-33.

7. Sukonina V, Lookene A, Olivecrona T, Olivecrona G. Angiopoietin-like protein 4 converts lipoprotein lipase to inactive monomers and modulates lipase activity in adipose tissue. Proc Natl Acad Sci USA. 2006;103:17450-5.

8. Yau M-H, Wang Y, Lam KSL, Zhang J, Wu D, Xu A. A highly conserved motif within the NH2-terminal coiled-coil domain of angiopoietin-like protein 4 confers its inhibitory effects on lipoprotein lipase by disrupting the enzyme dimerization. J Biol Chem. 2009;284:11942-52.

9. Lichtenstein L, Mattijssen F, de Wit NJ, Georgiadi A, Hooiveld GJ, van der Meer R, et al. Angptl4 protects against severe proinflammatory effects of saturated fat by inhibiting fatty acid uptake into mesenteric lymph node macrophages. Cell Metab. 2010;12:580-92.

10. Brands M, Sauerwein HP, Ackermans MT, Kersten S, Serlie MJ. Omega-3 long-chain fatty acids strongly induce angiopoietin-like 4 in humans. J Lipid Res. 2013;54:615-21.

11. Ruge T, Sukonina V, Kroupa O, Makoveichuk E, Lundgren M, Svensson MK, et al. Effects of hyperinsulinemia on lipoprotein lipase, angiopoietin-like protein 4, and glycosylphosphatidylinositolanchored high-density lipoprotein binding protein 1 in subjects with and without type 2 diabetes mellitus. Metab Clin Exp. 2012;61:652-60.

12. Kersten S, Lichtenstein L, Steenbergen E, Mudde K, Hendriks HFJ, Hesselink MK, et al. Caloric restriction and exercise increase plasma ANGPTL4 levels in humans via elevated free fatty acids. Arterioscler Thromb Vasc Biol. 2009;29:969-74.

13. van Raalte DH, Brands M, Serlie MJ, Mudde K, Stienstra R, Sauerwein HP, et al. Angiopoietin-like protein 4 is differentially regulated by glucocorticoids and insulin in vitro and in vivo in healthy humans. Exp Clin Endocrinol Diabetes. 2012;120:598-603.

14. Staiger H, Haas C, Machann J, Werner R, Weisser M, Schick F, et al. Muscle-derived angiopoietin-like protein 4 is induced by fatty acids via peroxisome proliferator-activated receptor (PPAR)-delta and is of metabolic relevance in humans. Diabetes. 2009;58:579-89.

15. Robciuc MR, Skrobuk P, Anisimov A, Olkkonen VM, Alitalo K, Eckel RH, et al. Angiopoietin-Like 4 Mediates PPAR Delta Effect on Lipoprotein Lipase-Dependent Fatty Acid Uptake but Not on BetaOxidation in Myotubes. Müller M, editor. PLoS ONE. 2012;7:e46212. 
16. Norheim F, Hjorth M, Langleite TM, Lee S, Holen T, Bindesbøll C, et al. Regulation of angiopoietinlike protein 4 production during and after exercise. Physiol Rep. 2014;2.

17. González-Muniesa P, de Oliveira C, Pérez de Heredia F, Thompson MP, Trayhurn P. Fatty Acids and Hypoxia Stimulate the Expression and Secretion of the Adipokine ANGPTL4 (Angiopoietin-Like Protein 4/ Fasting-Induced Adipose Factor) by Human Adipocytes. J Nutrigenet Nutrigenomics. 2011;4:146-53.

18. Jans A, Konings E, Goossens GH, Bouwman FG, Moors CC, Boekschoten MV, et al. PUFAs acutely affect triacylglycerol-derived skeletal muscle fatty acid uptake and increase postprandial insulin sensitivity. Am J Clin Nutr. 2012;95:825-36.

19. Dijk W, Kersten S. Regulation of lipoprotein lipase by Angptl4. Trends Endocrinol Metab. 2014;25:14655 .

20. Jonker JT, Smit JW, Hammer S, Snel M, van der Meer RW, Lamb HJ, et al. Dietary modulation of plasma angiopoietin-like protein 4 concentrations in healthy volunteers and in patients with type 2 diabetes. Am J Clin Nutr. 2013;97:255-60.

21. Catoire M, Alex S, Paraskevopulos N, Mattijssen F, Evers-van Gogh I, Schaart G, et al. Fatty acidinducible ANGPTL4 governs lipid metabolic response to exercise. Proc Natl Acad Sci USA. 2014;111:E1043-52.

22. Köster A, Chao YB, Mosior M, Ford A, Gonzalez-DeWhitt PA, Hale JE, et al. Transgenic angiopoietinlike (angptl)4 overexpression and targeted disruption of angptl4 and angptl3: regulation of triglyceride metabolism. Endocrinology. 2005;146:4943-50.

23. Kersten S, Mandard S, Tan NS, Escher P, Metzger D, Chambon P, et al. Characterization of the fastinginduced adipose factor FIAF, a novel peroxisome proliferator-activated receptor target gene. J Biol Chem. 2000;275:28488-93.

24. Alex S, Lichtenstein L, Dijk W, Mensink RP, Tan NS, Kersten S. ANGPTL4 is produced by enteroendocrine cells in the human intestinal tract. Histochem Cell Biol. 2013;141:383-91.

25. van Hees AMJ, Jans A, Hul GB, Roche HM, Saris WHM, Blaak EE. Skeletal muscle fatty acid handling in insulin resistant men. Obesity. 2011;19:1350-9.

26. Moors CCM, van der Zijl NJ, Diamant M, Blaak EE, Goossens GH. Impaired insulin sensitivity is accompanied by disturbances in skeletal muscle fatty acid handling in subjects with impaired glucose metabolism. Int J Obes (Lond). 2012;36:709-17.

27. Blaak EE, van Baak MA, Kemerink GJ. Beta-adrenergic stimulation of energy expenditure and forearm skeletal muscle metabolism in lean and obese men. 1994.

28. Tjeerdema N, Georgiadi A, Jonker JT, van Glabbeek M, Alizadeh Dehnavi R, Tamsma JT, et al. Inflammation increases plasma angiopoietin-like protein 4 in patients with the metabolic syndrome and type 2 diabetes. BMJ Open Diabetes Res Care. 2014;2:e00034-4.

29. Makoveichuk E, Vorrsjö E, Olivecrona T, Olivecrona G. Inactivation of lipoprotein lipase in 3T3-L1 adipocytes by angiopoietin-like protein 4 requires that both proteins have reached the cell surface. Biochim Biophys Acta. 2013;441:941-6.

30. Nilsson SK, Anderson F, Ericsson M, Larsson M, Makoveichuk E, Lookene A, et al. Triacylglycerol-rich lipoproteins protect lipoprotein lipase from inactivation by ANGPTL3 and ANGPTL4. Biochim Biophys Acta. 2012;1821:1370-8.

31. Smart-Halajko MC, Robciuc MR, Cooper JA, Jauhiainen M, Kumari M, Kivimaki M, et al. The relationship between plasma angiopoietin-like protein 4 levels, angiopoietin-like protein 4 genotype, and coronary heart disease risk. Arterioscler Thromb Vasc Biol. 2010;30:2277-82. 
32. Yin W, Romeo S, Chang S, Grishin NV, Hobbs HH, Cohen JC. Genetic variation in ANGPTL4 provides insights into protein processing and function. J Biol Chem. 2009;284:13213-22.

33. Guo Z, Jensen MD. Arterio-venous balance studies of skeletal muscle fatty acid metabolism: what can we believe? Am J Physiol Endocrinol Metab. 2013;305:E925-30.

34. Zheng Z, Cheng C, Dong R, Li M, Xiong Z, Qian X, et al. Advanced glycation end products upregulate angiopoietin-like protein 4 expression by activating the renin-angiotensin system in endothelial cells. Biomed Rep. 2015;:1-5. 


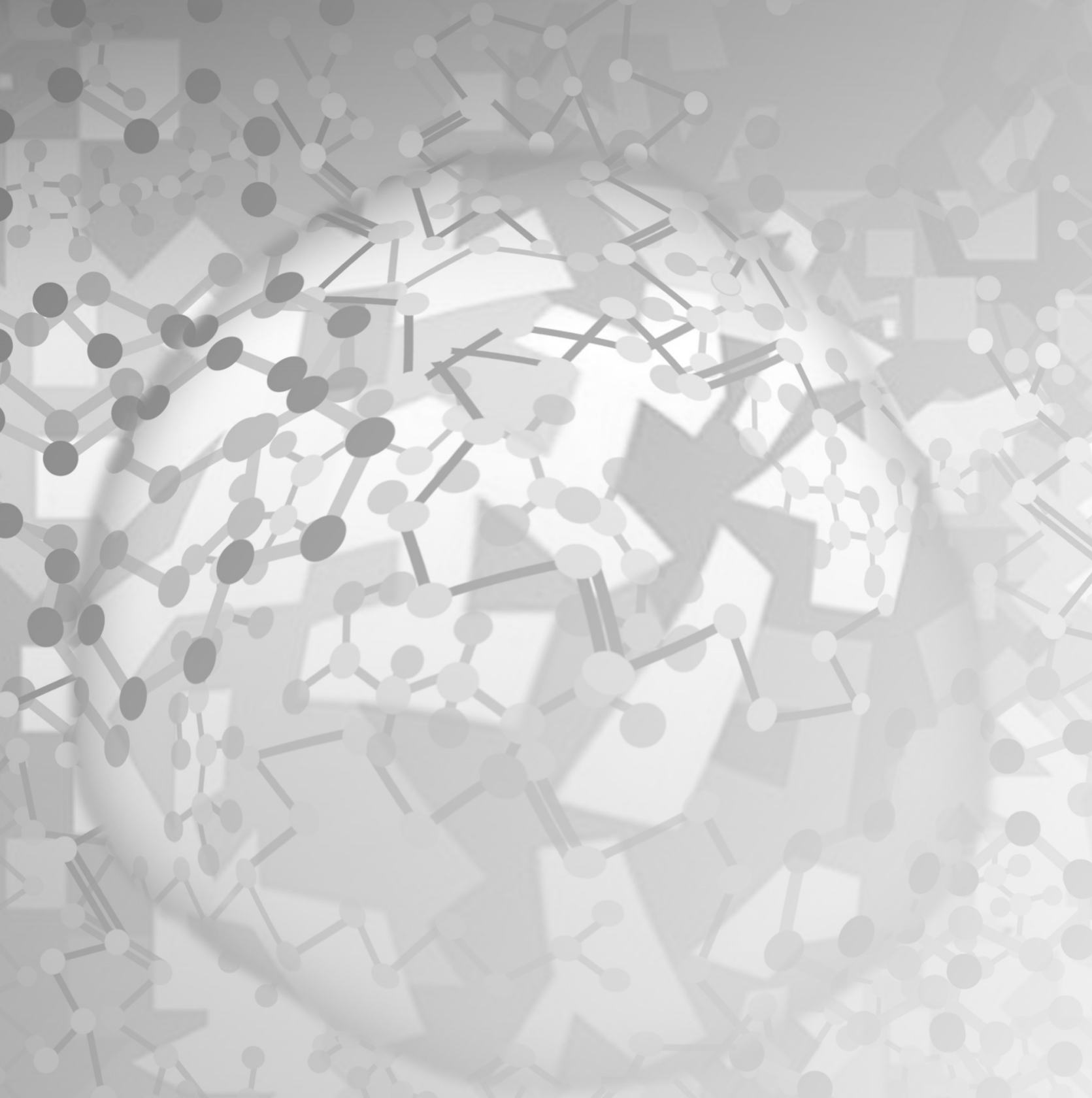




\section{Chapter 4}

\section{Effect of diet-induced weight loss on Angiopoietin-like protein 4 and adipose tissue lipid metabolism in overweight and obese humans}

Birgitta W. van der Kolk ${ }^{1}$, Roel G. Vink ${ }^{1}$, Johan W.E. Jocken ${ }^{1}$, Nadia J.T. Roumans ${ }^{1}$, Gijs H. Goossens ${ }^{1}$, Edwin C.M. Mariman ${ }^{1}$, Marleen A. van Baak ${ }^{1}$, Ellen E. Blaak ${ }^{1}$

${ }^{1}$ Department of Human Biology, NUTRIM School of Nutrition and Translational Research in Metabolism, Maastricht University Medical Center ${ }^{+}$, the Netherlands 


\section{Abstract}

Background Angiopoietin-like protein 4 (ANGPTL4) plays a role in lipid partitioning by inhibiting lipoprotein lipase (LPL)-dependent plasma clearance of triacylglycerol in adipose tissue. We investigated the effects of diet-induced weight loss on plasma ANGPTL4 concentrations in relation to in vivo adipose tissue LPL activity and lipolysis and adipose tissue ANGPTL4 release in overweight/obese participants.

Methods Sixteen individuals (BMI: $28-35 \mathrm{~kg} / \mathrm{m}^{2} ; 10$ women) were randomized to a dietary intervention composed of either a low-calorie diet $(1250 \mathrm{kcal} / \mathrm{d})$ for 12 weeks $(\mathrm{n}=9)$ or a very-low-calorie diet $(500 \mathrm{kcal} / \mathrm{d})$ for 5 weeks, followed by a 4 -week weight stable period. Before and after the intervention, arteriovenous concentration differences were measured in combination with adipose tissue blood flow before and after intake of a high-fat mixed-meal with $\left[\mathrm{U}-{ }^{13} \mathrm{C}\right]$-palmitate to assess in vivo adipose tissue LPL activity and lipolysis.

Results The intervention significantly reduced body weight $(-8.6 \pm 0.6 \mathrm{~kg}, p<0.001)$, but plasma ANGPTL4 concentrations were unaffected. Significant postprandial adipose tissue ANGPTL4 release into the circulation was observed $(p<0.01)$. No association was observed between plasma ANGPTL4 and in vivo LPL activity. After intervention, fasting and postprandial plasma ANGPTL4 concentrations were positively associated with adipose tissue non-esterified fatty acid (NEFA) and glycerol release, reflecting in vivo adipose tissue lipolysis (fasting NEFA: $p=0.039$ and postprandial NEFA: $p=0.003$ ).

Conclusions Plasma ANGPTL4 is unaffected by weight loss and is secreted from human adipose tissue after a high-fat meal in overweight/obese individuals. Plasma ANGPTL4 concentration was not related to in vivo adipose tissue LPL activity, but was positively associated with in vivo adipose tissue lipolysis after weight loss. 


\section{Introduction}

Multiple physiological and environmental factors are known to interact in the energy intake regulation and fuel metabolism to maintain energy homeostasis in humans. Among them, the enzyme lipoprotein lipase (LPL) plays an important role in fasting and postprandial lipid fuel partitioning in humans (1). LPL is located at the capillary endothelium where it catalyzes the hydrolysis of triacylglycerol (TAG)-rich plasma lipoproteins to glycerol and non-esterified fatty acids (NEFAs) (2). The resulting NEFAs are then taken up by the peripheral tissues via passive diffusion or specialized transport proteins (e.g. FAT/CD36) and will be directed towards oxidation or storage, or spilled over into the circulation $(3,4)$.

The activity of LPL is under tight tissue-specific nutritional and hormonal control. For instance, insulin is a major activator of adipose tissue LPL activity. This results in postprandial (chylomicron)-TAG storage (1), while in skeletal muscle insulin may suppress LPL activity in healthy humans (5). In obesity, a diminished lipid buffering capacity of the adipose tissue might lead to ectopic lipid deposition in skeletal muscle, liver and heart and has been linked to insulin resistance in these tissues (6). Next to insulin, angiopoietin-like protein 4 (ANGPTL4) has emerged as an important regulator of in vivo LPL activity in adipose tissue and skeletal muscle, and thereby as a potent modulator of lipid metabolism (7).

ANGPTL4 is a central factor of a feedback mechanism that regulates plasma TAG hydrolysis during various physiological conditions (8). ANGPTL4 is expressed and secreted by numerous cell types, including human adipocytes. Tissue-specific expression of ANGPTL4 is induced by fatty acids via Peroxisome Proliferator-Activated Receptors (PPARs) in response to changes in lipid availability and cellular fuel demand (8). It has been shown that during long-term fasting (9) and after acute physical activity (9-11) skeletal muscle ANGPTL4 expression and plasma ANGPTL4 concentration is increased in humans.

In rodent adipose tissue studies, increased ANGPTL4 concentrations inhibit adipose tissue LPL activity and might therefore lead to inhibited plasma TAG clearance by adipose tissue under fasting conditions. This effect was blunted in ANGPTL4 knockout mice (12). Moreover, it has been shown that ANGPTL4 promotes intracellular degradation of LPL (13) and intracellular lipolysis (14) in murine cell studies. Subsequently, ANGPTL4 is hypothesized to play a role in lipid partitioning to other tissues (e.g. muscle and liver) under conditions with increased energy demand, like fasting and exercise (8). However, up to now data on circulating ANGPTL4 in relation to in vivo adipose tissue fatty acid metabolism in humans are missing. 
In addition, no information is available on the role of ANGPTL4 in the impaired adipose tissue TAG extraction as observed under obese conditions. After short-term and chronic caloric restriction, circulating ANGPTL4 concentrations were increased $(9,15)$, indicating a role in fuel partitioning also in humans. Importantly, in these studies, participants were in a negative energy balance when plasma ANGPTL4 was measured. Therefore, the distinction between acute energy restriction and the effect of weight loss per se on plasma ANGPTL4 cannot be made.

The origin of plasma ANGPTL4 is currently unknown. Based on human ANGPTL4 mRNA expression studies (9) and ANGPTL4 overexpression studies in mice (16), it has been postulated that the liver is the main contributor to systemic ANGPTL4 concentrations. Intestine and skeletal muscle might also contribute to circulating ANGPTL4 concentrations $(17,18)$. Nevertheless, ANGPTL4 was originally discovered as fasting induced adipose factor (FIAF), which suggests that adipose tissue might also be an important contributor to circulating ANGPTL4 concentrations (19). However, data on the in vivo contribution of adipose tissue to circulating ANGPTL4 levels in humans is still missing.

The aim of the present study was to investigate fasting and postprandial plasma ANGPTL4 concentrations and their relationship with in vivo adipose tissue LPL activity and adipose tissue lipolysis in overweight and obese humans before and after diet-induced weight loss. Secondly, we examined whether human adipose tissue secretes ANGPTL4 into the circulation under fasting conditions and after the intake of a high-fat mixed-meal and if this is affected by significant weight loss. In addition, adipose tissue biopsies were taken to assess transcriptional changes in fatty acid metabolism before and after weight loss.

\section{Materials and Methods}

\section{Study participants}

Sixteen individuals with overweight and obesity (BMI $28-35 \mathrm{~kg} / \mathrm{m}^{2}$ ), 10 women and 6 men were included in the present study, as reported previously (20). Participants had to remain weight stable (weight change $<3.0 \mathrm{~kg}$ ) two months prior to the start of the study. All participants gave their written informed consent before participation in the study. The study was performed according to the declaration of Helsinki and was approved by the Medical Ethics Committee of Maastricht University Medical Centre. 


\section{Study design}

The present study was performed in a sub-cohort of a larger clinical trial. As described previously (21), participants followed a dietary intervention program that was divided in three periods: i) a 12-week low-calorie diet (LCD-period) or a 5-week very low-calorie diet (VLCD) weight loss period, ii) a 4-week weight stable period and iii) a 9-month follow-up period. The weight loss period and weight stable period taken together was named the dietary intervention (DI) period. Fasting and postprandial fatty acid metabolism and ANGPTL4 measurements were studied before and after the DI-period. Participants were randomly assigned to either the $\operatorname{LCD}(n=9)$ or $\operatorname{VLCD}(n=7)$ group and both interventions aimed at a weight loss of approximately $10 \%$. In the 12 -week program, participants followed a LCD providing $1250 \mathrm{kcal} /$ day designed by the dietician. The participants could consume one meal that was replaced by meal replacements (Modifast; Nutrition et Santé Benelux, Breda, The Netherlands), two meals that were prepared by the participants themselves and three inbetween meal snacks. In the VLCD group participants followed a 5-week diet in which three meals per day were replaced by meal replacements, providing $500 \mathrm{kcal} /$ day. During this period, participants could consume an unrestricted amount of low-calorie vegetables. The detailed composition of the diets has been described previously (21). Both groups subsequently underwent a 4-week weight stable period with a diet based on the energy requirements of the participants. This allowed us to investigate the effect of weight loss, without the interfering effect of a negative energy balance. The study dietician provided dietary advice to both groups to assist with losing weight during the weight loss period (five meetings) and in remaining weight stable throughout the weight stable period (four meetings). The researchers, study participants and dietician were not blinded to the intervention. This trial is registered with www.clinicaltrials.gov: as NCT01559415.

\section{High-fat mixed-meal test}

Participants were studied after an overnight fast and were asked to refrain from strenuous exercise and drinking alcohol $24 \mathrm{~h}$ before the study day. In addition, they were asked to avoid consuming food products naturally enriched with $\left[{ }^{13} \mathrm{C}\right]$ for 7 days before the study day. Adipose tissue metabolism was studied using arteriovenous concentration differences combined with measurements of adipose tissue blood flow (ATBF). Two catheters were inserted before the start of the experiment. One catheter was placed retrogradely into a superficial dorsal hand vein, which was heated in a hot-box $\left(60{ }^{\circ} \mathrm{C}\right)$ to obtain arterialized blood. To sample blood from the venous effluent of subcutaneous abdominal adipose tissue, another catheter was placed in a superficial epigastric vein (22). This catheter was kept patent 
by continuous saline infusion. Blood samples were obtained from both sites simultaneously. Blood samples were taken at two time points during fasting: $\mathrm{t}-30 \mathrm{~min}$ and just before meal ingestion ( $\mathrm{t}$ 0). Postprandial blood samples were taken at five time points ( $\mathrm{t} 60$, t 120, t 180, t 240, t $300 \mathrm{~min}$ ) after consumption of a high-saturated fatty acid (SFA) mixed-meal (t 0) containing $200 \mathrm{mg}\left[\mathrm{U}-^{13} \mathrm{C}\right]$-palmitate (98\% enrichment, Cambridge Isotope Laboratories). The liquid meal provided 2.6 MJ, consisting of 61 Energy \% (E\%) fat (35.5 E\% SFA, 18.8 E\% monounsaturated fatty acid, and $1.7 \mathrm{E} \%$ polyunsaturated fatty acid), $33 \mathrm{E} \%$ carbohydrates and $6.3 \mathrm{E} \%$ protein. The participants were asked to drink the milkshake within 10 minutes.

Abdominal subcutaneous ATBF was measured on the contralateral side of the abdomen, at the same level where the epigastric vein was cannulated. Fasting and postprandial ATBF was determined using the ${ }^{133} \mathrm{Xe}$ washout technique (22).

\section{Plasma ANGPTL4 and metabolite concentrations}

ANGPTL4 was measured in EDTA plasma before and after the DI-period during the high-fat mixed-meal test by ELISA, as described previously (18). Briefly, 96-well plates were coated with antihuman ANGPTL4 polyclonal goat IgG antibody (AF3485, R\&D Systems) and incubated overnight at $4^{\circ} \mathrm{C}$. Plates were washed extensively between each step. After blocking, $100 \mu \mathrm{L}$ of 20 -fold diluted human plasma was added, followed by $2 \mathrm{~h}$ incubation at room temperature. A standard curve was prepared using recombinant ANGPTL4 (3485-AN, R\&D Systems) at 0.3-2.1 ng/well. Next, $100 \mu \mathrm{L}$ of diluted biotinylated antihuman ANGPTL4 polyclonal goat IgG antibody (BAF3485, R\&D Systems) was added for $2 \mathrm{~h}$, followed by addition of streptavidin-conjugated horseradish peroxidase for $20 \mathrm{~min}$ and tetramethyl benzidine substrate for $6 \mathrm{~min}$. The reaction was stopped by addition of $50 \mu \mathrm{L}$ of $10 \% \mathrm{H}_{2} \mathrm{SO}_{4}$, and the absorbance was measured at $450 \mathrm{~nm}$. Details on other biochemical analyses and hematocrit have previously been reported (20).

\section{Adipose tissue biopsy}

Before and after the DI-period abdominal subcutaneous adipose tissue needle biopsies $(\approx 1 \mathrm{~g})$ were collected $6-8 \mathrm{~cm}$ lateral from the umbilicus under local anesthesia ( $2 \%$ lidocaine) by needle biopsy. Biopsies were immediately rinsed with sterile saline and visible blood vessels were removed with sterile tweezers. Adipose tissue biopsies were snap-frozen in liquid nitrogen and stored at $-80^{\circ} \mathrm{C}$ for further analysis. 


\section{Adipose tissue microarray analysis}

RNA was extracted from frozen adipose tissue ( $150 \mathrm{mg})$ using Trizol chloroform extraction (Invitrogen, Breda, The Netherlands). Next, total RNA (100 ng per sample) was labeled by Whole-Transcript Sense Target Assay and hybridized to human whole-genome Affymetrix Gene 1.1 ST arrays targeting 19,654 unique genes (Affymetrix, Santa Clara, CA, USA). Quality control and data analysis have been described in detail previously (20). We performed a supervised gene expression analysis focusing on 22 genes important for uptake, storage and release of fatty acids by adipose tissue (Supplementary Table 1) and analyzed gene expression before and after DI-period. Changes in mRNA levels were defined as significantly different when the $q$-value was $<0.05$ in a paired $t$ test with Bayesian correction (Limma). Array data have been submitted to the Gene Expression Omnibus (number GSE77962).

\section{Calculations}

Plasma tracer concentrations were calculated by multiplying the TTRs of $\left[\mathrm{U}-{ }^{13} \mathrm{C}\right]$-palmitate with the corresponding palmitate-NEFA or palmitate-TAG concentrations. To calculate the net fluxes of metabolites across subcutaneous abdominal AT, the arteriovenous concentration difference was multiplied by adipose tissue plasma flow. Plasma flow was calculated by multiplying ATBF with: 1 - (hematocrit / 100). A positive flux indicates net uptake across adipose tissue, whereas a negative flux indicates net release. In vivo LPL activity was based on net fluxes of $\left[\mathrm{U}-{ }^{13} \mathrm{C}\right]$-labeled palmitate $(4,23)$. Postprandial areas under the curve (AUC) of metabolites were calculated using the trapezium rule.

\section{Statistics}

Data are presented as mean \pm SEM. Comparisons of variables between time-points within groups were made with the Students' paired-sample $t$ test. Between-group comparisons were made with the independent-samples $t$ test. Variables were evaluated for residual normality and logarithmic transformations were performed when appropriate. For non-normally distributed variables the logarithmic transformed $p$-values are shown, whereas values of concentrations are presented as non-adjusted. Statistical calculations were performed with SPSS for Macintosh, Version 22 (Chicago, IL). $p<0.05$ was considered statistically significant. 


\section{Results}

\section{Study population}

Participant characteristics are summarized in Table 1. The present study included participants that lost weight either by a LCD $(n=9)$ or VLCD diet $(n=7)$. Similar weight loss was achieved by both diets (LCD: $-8.6 \pm 0.9 \mathrm{~kg}$ and VLCD: $-8.7 \pm 0.9 \mathrm{~kg} ; p=0.927$ ) and no significant differences between diet groups were observed for the fatty acid metabolism parameters (data not shown). Therefore we analyzed both diet groups as a single group (21). Significant improvements in body fat percentage, waist-hip ratio and fat cell size were observed, as reported previously (20) (Table 1).

Table 1. Characteristics of participants

\begin{tabular}{lccc}
\hline & Study Start & End of DI-period & $p$-value \\
\hline Diet $(\mathrm{LCD} /$ VLCD) & $9 / 7$ & & \\
Female $(\mathrm{n}) /$ Male $(\mathrm{n})$ & $10 / 6$ & & \\
Age $(\mathrm{y})$ & $48.8 \pm 1.8$ & & $<0.001$ \\
Weight $(\mathrm{kg})$ & $96.0 \pm 2.4$ & $29.6 \pm 0.6$ & $<0.001$ \\
BMI $\left(\mathrm{kg} / \mathrm{m}^{2}\right)$ & $32.4 \pm 0.6$ & $96.0 \pm 1.8$ & $<0.001$ \\
Waist circumference $(\mathrm{cm})$ & $103.3 \pm 2.5$ & $38.1 \pm 2.8$ & $<0.001$ \\
Fat mass $(\%)$ & $43.2 \pm 2.3$ & $118.9 \pm 2.8$ & $<0.001$ \\
Systolic blood pressure $(\mathrm{mmHg})$ & $123.7 \pm 3.0$ & $79.2 \pm 1.8$ & $<0.001$ \\
Diastolic blood pressure $(\mathrm{mmHg})$ & $84.9 \pm 1.8$ & $5.2 \pm 0.1$ & 0.005 \\
Glucose $(\mathrm{mmol} / \mathrm{L})$ & $5.3 \pm 0.1$ & $13.8 \pm 1.5$ & 0.248 \\
Insulin $(\mathrm{mU} / \mathrm{L})$ & $16.3 \pm 1.1$ & $3.2 \pm 0.4$ & 0.113 \\
HOMA-IR & $3.8 \pm 0.4$ & $521 \pm 70$ & 0.440 \\
NEFA $(\mu \mathrm{mol} / \mathrm{L})$ & $460 \pm 51$ & $972 \pm 109$ & 0.001 \\
TAG $(\mu \mathrm{mol} / \mathrm{L})$ & $1375 \pm 143$ & $5.9 \pm 0.2$ & 0.017 \\
Total cholesterol $(\mathrm{mmol} / \mathrm{L})$ & $6.3 \pm 0.2$ & $64.7 \pm 1.3$ & 0.005 \\
Adipocyte size $(\mu \mathrm{m})$ & $68.9 \pm 1.2$ & & \\
\hline Val & & & \\
\hline
\end{tabular}

Values are mean \pm SEM. $p$-value for difference between start study and after DI-period, student's $t$ test for paired samples. 
A

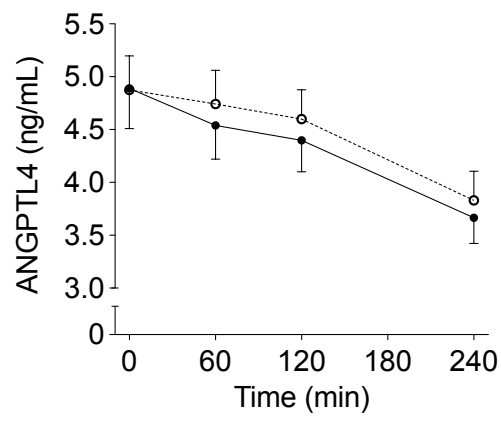

B

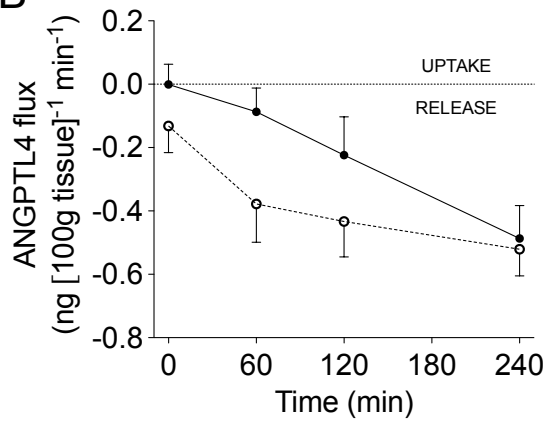

Figure 1. (A) Arterialized plasma ANGPTL4 concentrations (B) Net ANGPTL4 flux across adipose tissue during fasting $(t=0)$ and after consumption of a high-SFA meal. Black symbols; baseline measurements, White symbols; after DI-period. Values are mean \pm SEM.

\section{Weight loss does not alter ANGPTL4 response to high-fat meal}

We investigated fasting and postprandial plasma ANGPTL4 concentrations after consumption of a high-SFA meal. Arterialized ANGPTL4 concentrations during fasting and the postprandial decrease in arterialized ANGPTL4 concentrations were comparable before and after DI-period (Figure 1A). This indicates that weight loss per se does not alter fasting and postprandial plasma ANGPTL4 responses.

\section{ANGPTL4 is released from adipose tissue}

Next, it has been postulated that adipose tissue may be a source of plasma ANGPTL4 in humans (7). In the present study, no significant release of ANGPTL4 from adipose tissue during fasting conditions was observed before and after the DI-period. However, significant postprandial ANGPTL4 release from adipose tissue was detectable following a high-SFA meal before (AUC ${ }_{0-4 \mathrm{~h}}-0.23 \pm 0.08 \mathrm{ng} \cdot 100 \mathrm{~g}$ tissue ${ }^{-1} \cdot \mathrm{min}^{-1}$ vs zero flux; $p=0.011$ ) and after the DI-period ( AUC $_{0-4 h}-0.39 \pm 0.07 \mathrm{ng} \cdot 100 \mathrm{~g}$ tissue $^{-1} \cdot \mathrm{min}^{-1}$ ws zero flux; $p<0.001$ ) (Figure 1B). After the DI-period, this postprandial ANGPTL4 release tended to be higher when compared with before weight loss $(p=0.072)$. 
A

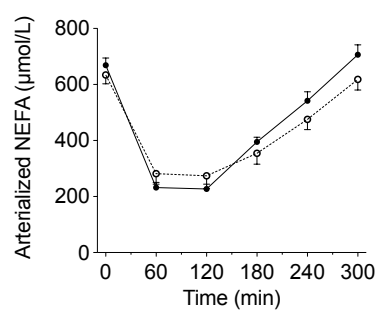

C

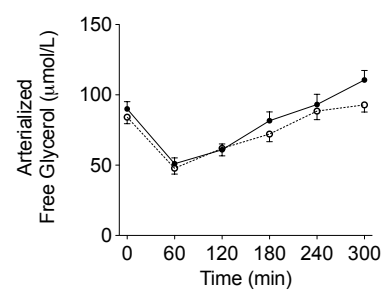

$E$

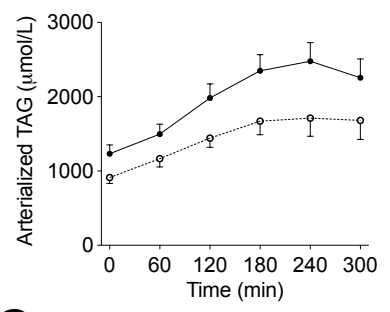

G

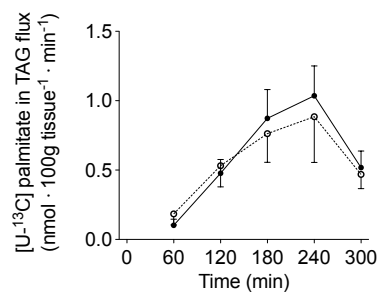

B

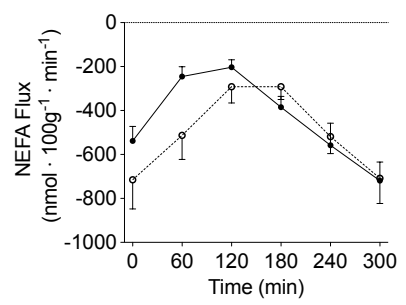

D

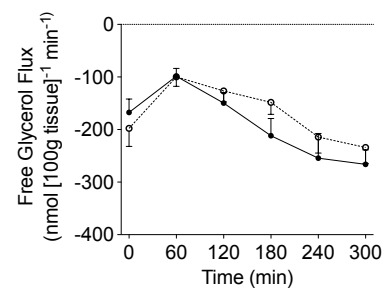

$\mathrm{F}$

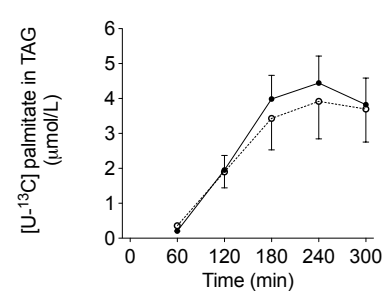

Figure 2. Postprandial lipid metabolism. (A) Arterialized plasma NEFA concentrations, (B) net flux of NEFA across adipose tissue, (C) arterialized plasma glycerol concentrations, (D) net flux of glycerol across adipose tissue, (E) arterialized plasma TAG concentrations, (F) [U- $\left.{ }^{13} \mathrm{C}\right]-$ palmitate concentrations in the plasma TAG fraction, $(\mathrm{G})$ net flux of $\left[\mathrm{U}-{ }^{13} \mathrm{C}\right]$-palmitate TAG across adipose tissue during fasting $(t=0)$ and after consumption of a high-SFA meal. Black symbols; baseline measurements, White symbols; after DI-period. Values are mean \pm SEM. 


\section{Systemic responses and adipose tissue fatty acid metabolism after a high-SFA meal}

As reported previously, fasting and postprandial NEFA and glycerol concentrations were similar before and after DI-period (Figure 2A, C) (20). Furthermore, net fasting and postprandial adipose tissue NEFA and glycerol adipose tissue release were not altered by the DI-period (Figure 2B, D). Fasting and postprandial plasma TAG concentrations significantly decreased after the DI-period ( $p=0.007$ and $p=0.001$, respectively) (Figure 2E) (20). Using a stable isotope tracer methodology, we were able to determine adipose tissue meal-derived TAG extraction (TAG labeled with $\left[\mathrm{U}-{ }^{13} \mathrm{C}\right]$-palmitate) (4). At baseline and after the DIperiod, the $\left[\mathrm{U}-{ }^{13} \mathrm{C}\right]$-palmitate tracer appeared in the plasma TAG fraction 60 min after meal ingestion (Figure $2 \mathrm{~F}$ ). The net flux of $\left[\mathrm{U}-{ }^{13} \mathrm{C}\right]$-palmitate in TAG, which reflects LPL-mediated hydrolysis of meal-derived TAG, was not affected by the DI-period (Figure 2G) (20).

\section{Plasma ANGPTL4 and in vivo markers for adipose tissue lipid metabolism}

Next, we examined whether the fasting and postprandial plasma ANGPTL4 concentrations were associated with in vivo markers of adipose tissue lipid metabolism before and after weight loss. First, we examined whether postprandial (changes in) plasma ANGPTL4 concentrations after a high-SFA meal were associated with in vivo adipose tissue LPL activity. There was no relationship between postprandial plasma ANGPTL4 concentrations and the SFA meal-derived TAG flux, a marker for LPL activity, before and after DI-period (before: $\mathrm{AUC}_{0-5 \mathrm{~h}} \mathrm{r}=0.163 ; p=0.546$; after DI-period: $\mathrm{AUC}_{0-5 \mathrm{~h}} \mathrm{r}=-0.192 ; p=0.477$ ). Moreover, weight loss induced changes in ANGPTL4 concentrations were not related to the changes in SFA meal-derived TAG fluxes.

Secondly, ANGPTL4 has been reported to stimulate fasting-induced intracellular lipolysis in adipocytes (14). Therefore, we correlated fasting and postprandial plasma ANGPTL4 concentrations with adipose tissue NEFA and adipose tissue glycerol flux under fasting and postprandial conditions. Before the DI-period, there was no relationship between circulating ANGPTL4 and adipose tissue NEFA release or adipose tissue glycerol release. Moreover, the DI-period induced plasma ANGPTL4 changes and DI-period induced adipose tissue NEFA release changes were not associated. However, after weight loss, plasma ANGPTL4 was positively associated with fasting and postprandial adipose tissue NEFA release (fasting $\mathrm{r}=0.520 ; p=0.039$ and $\mathrm{AUC}_{0-5 \mathrm{~h}} \mathrm{r}=0.690 ; p=0.003$ ). Comparable results 
were observed for the relation between plasma ANGPTL4 and adipose tissue glycerol release after the DI-period (fasting $\mathrm{r}=0.503 ; p=0.047$ and $\mathrm{AUC}_{0-5 \mathrm{~h}} \mathrm{r}=0.597 ; p=0.015$ ). This indicates that higher plasma ANGPTL4 concentrations were associated with higher adipose tissue NEFA and glycerol release after weight loss.

\section{ANGPTL4 gene expression}

To obtain further insight into the relationship between ANGPTL4 and adipose tissue lipid metabolism, a targeted microarray analysis was performed. We selected genes directly involved in adipose tissue fatty acid uptake, lipid synthesis, lipid droplet formation and lipolysis (Table S1). In accordance with unchanged adipose tissue fatty acid metabolism after weight loss, this targeted microarray approach revealed no significant changes in mRNA levels related to adipose tissue lipid metabolism after the DI-period as compared to baseline values (20). mRNA levels of LPL and ANGPTL4 were also comparable before and after the DI-period (Table S1) (20). No associations were found between adipose tissue ANGPTL4 mRNA levels and markers of lipolysis (including LPL, LIPE, MGLL and PNPLA2) before and after the DI-period. In addition, no associations were found between adipose tissue ANGPTL4 mRNA levels and in vivo adipose tissue LPL activity and the net adipose tissue NEFA and glycerol release at both time points (data not shown).

\section{Discussion}

This study demonstrated that fasting and postprandial plasma ANGPTL4 concentrations were unaffected by weight loss in overweight and obese humans. Furthermore, we found that ANGPTL4 was released from adipose tissue into the circulation after a high-SFA meal in humans, and this release tended to increase after weight loss. There was no association between plasma ANGPTL4 and in vivo adipose tissue LPL activity, neither before nor after weight loss. However, after weight loss, plasma ANGPTL4 was positively associated with fasting and postprandial adipose tissue NEFA and glycerol release, reflecting adipose tissue lipolysis.

Circulating ANGPTL4 concentrations have been shown to increase after prolonged fasting and short-term and chronic caloric restriction $(9,15)$. Importantly, in these studies, participants were still in a negative energy balance when plasma ANGPTL4 was measured. The present study demonstrated that weight loss per se does not affect fasting and postprandial plasma ANGPTL4 concentrations and adipose tissue ANGPTL4 gene expression. This is 
contradictory to a study by Cullberg et al. (24). They showed that after 8 weeks of VLCD and 4 weeks of weight maintenance diet, plasma ANGPTL4 concentrations increased in obese male and female individuals, while adipose tissue ANGPTL4 mRNA expression was decreased (24). However, their study population was younger, had a different sex distribution and their participants lost on average $12 \%$, while the average weight loss was $9 \%$ in the present study. These factors might partly explain the observed differences. We observed no differences between diets (VLCD and LCD) with respect to changes in circulating ANGPTL4 concentrations.

We provide the first direct evidence that adipose tissue contributes to plasma ANGPTL4 in vivo in humans. After weight loss, the ANGPTL4 secretion from adipose tissue tended to be elevated, although plasma ANGPTL4 concentrations were not affected. After weight loss, reduced adipose tissue mass together with a higher net adipose tissue ANGPTL4 release per unit adipose tissue might explain comparable circulating ANGPTL4 concentrations before and after the DI-period. The relative adipose tissue-derived contribution to circulating concentrations is difficult to estimate as information on ANGPTL4 half-life is lacking. The fact that plasma ANGPTL4 concentrations decline after the high-fat meal, despite the increase in ANGPTL4 release from adipose tissue, might indicate that adipose tissue is not the major organ regulating postprandial plasma ANGPTL4 concentrations. Furthermore, we could not detect significant adipose tissue release under fasting conditions before and after weight loss, which suggests that release from other tissues than adipose tissue, such as liver or intestines, determines plasma ANGPTL4 concentrations in humans.

ANGPTL4 plays an important role in tissue-specific LPL inhibition (7). However, in this study we could not show a relationship between circulating ANGPTL4 and in vivo adipose tissue LPL activity before and after weight loss in humans. Recently, we have also shown that plasma ANGPTL4 was not related to skeletal muscle LPL activity in overweight and obese humans with impaired glucose homeostasis (18). These results suggest that circulating ANGPTL4 is not a regulator of LPL activity during postprandial conditions in key metabolic organs. However, ANGPTL4 might be a local regulator of LPL activity via autocrine and paracrine actions and plasma ANGPTL4 might not reflect local effects on adipose tissue LPL activity. Indeed, tissue-specific LPL activity regulation by ANGPTL4 has been shown to take place in the sub-endothelial space rather than at the endothelium $(25,26)$. It has been proposed that newly synthesized and locally produced ANGPTL4 might have more pronounced effects on LPL activity than circulating ANGPTL4 (27). Recently, Dijk et al. (13) has shown that locally produced ANGPTL4 promotes intracellular 
degradation of LPL in murine adipocytes. Additionally, more factors are involved in functional ANGPTL4 activity regarding LPL inhibition. It has been suggested that the locally produced glycosylphosphatidylinositol-anchored high-density lipoprotein-binding protein 1 (GPIHBP1) might compete with ANGPTL4 for LPL binding at either the interstitial space or capillary lumen (8). This indicates that there is a complex regulation of in vivo LPL activity with many factors involved.

Next to LPL inhibition, it has been suggested that ANGPTL4 stimulates intracellular lipolysis in adipocytes in the fasted state, thereby favoring the use of NEFAs as fuel by other tissues (8). In the present study, after weight loss, plasma ANGPTL4 was positively associated with estimates of adipose tissue lipolysis (i.e. adipose tissue NEFA and glycerol release) under fasting and postprandial conditions. It is tempting to speculate that weight loss might improve post-translational ANGPTL4 signaling in adipose tissue, which might be reflected in the observed association. So far, plasma ANGPTL4 has been positively associated with plasma NEFA concentrations during an oral glucose drink, another estimate of adipose tissue lipolysis (28). In transgenic ANGPTL4 mice models, an altered release of NEFA and glycerol from adipose tissue explants was observed (29) and in ANGPTL4 knockout mice, a lack of NEFA increase during the fasted state was observed (29). Furthermore, in vitro studies have shown that ANGPTL4 markedly induced glycerol release from 3T3-L1 adipocytes (29) and that ANGPTL4 is a glucocorticoid-responsive mediator which stimulates fasting-induced intracellular lipolysis by enhancing cAMP signaling in adipocytes (14). Finally, it has been shown that adipose tissue ANGPTL4 mRNA expression was positively correlated with Hormone sensitive lipase $(L I P E)$ and Lipid droplet-binding protein CGI-58 (ABHD5/CGI-58) gene expression in the Finnish Twin cohort (30). However, in the present study adipose tissue expression of ANGPTL4 was not associated with markers of lipolysis in overweight and obese individuals. Together, these results suggest that plasma ANGPTL4 might play a role in adipose tissue lipolysis and possibly may play a role in lipid partitioning after weight loss.

The present study had some limitations. First, we have measured full-length ANGPTL4 and the $\mathrm{C}$-terminal truncated fragment, but not the $\mathrm{N}$-terminal truncated fragment of ANGPTL4 (15). However, both the full-length and the N-terminal fragment ANGPTL4 may influence plasma lipid concentration (31). Therefore, it remains to be established whether the results from the ANGPTL4 ELISA provide an accurate reflection of functional ANGPTL4. Secondly, we cannot exclude the possibility that the participants were still in a negative energy balance after the 4-week weight stable period (32). This might have partly 
impacted the observed ANGPTL4 effects after weight loss. Moreover, an intervention with more pronounced effects of weight loss on LPL activity, might also show a different effect on ANGPTL4 expression and plasma concentrations (24). Finally, it has been shown that sex differences can be important in fatty acid handling in humans (33). However, the present study was not powered to take these differences into account.

In conclusion, we provide in vivo evidence that ANGPTL4 is secreted from human abdominal subcutaneous adipose tissue after a high-SFA meal, which tended to be elevated after weight loss. Furthermore, our data indicate that plasma ANGPTL4 concentrations do not relate to in vivo adipose tissue LPL activity. However, after weight loss, there was a positive association between plasma ANGPTL4 and fasting and postprandial abdominal subcutaneous adipose tissue NEFA and glycerol release, partly reflecting adipose tissue lipolysis. Therefore, the role of ANGPTL4 in human adipose tissue lipolysis needs to be investigated in more detail in future research. 


\section{References}

1. Kersten S. Physiological regulation of lipoprotein lipase. Biochim Biophys Acta. 2014;1841:919-33.

2. Goldberg IJ, Eckel RH, Abumrad NA. Regulation of fatty acid uptake into tissues: lipoprotein lipase- and CD36-mediated pathways. J Lipid Res. 2009;50 Suppl:S86-90.

3. Miles JM, Park YS, Walewicz D, Russell-Lopez C, Windsor S, Isley WL, et al. Systemic and forearm triglyceride metabolism: fate of lipoprotein lipase-generated glycerol and free fatty acids. Diabetes. 2004;53:521-7.

4. Bickerton AST, Roberts R, Fielding BA, Hodson L, Blaak EE, Wagenmakers AJM, et al. Preferential uptake of dietary Fatty acids in adipose tissue and muscle in the postprandial period. Diabetes. 2007;56:168-76.

5. Farese RV, Yost TJ, Eckel RH. Tissue-Specific Regulation of Lipoprotein-Lipase Activity by Insulin Glucose in Normal-Weight Humans. Metab Clin Exp. 1991;40:214-6.

6. Stinkens R, Goossens GH, Jocken JWE, Blaak EE. Targeting fatty acid metabolism to improve glucose metabolism. Obes Rev. 2015;16:715-57.

7. Dijk W, Kersten S. Regulation of lipoprotein lipase by Angptl4. Trends Endocrinol Metab. 2014;25:14655 .

8. Dijk W, Kersten S. Regulation of lipid metabolism by angiopoietin-like proteins. Curr Opin Lipidol. 2016;27:249-56.

9. Kersten S, Lichtenstein L, Steenbergen E, Mudde K, Hendriks HFJ, Hesselink MK, et al. Caloric restriction and exercise increase plasma ANGPTL4 levels in humans via elevated free fatty acids. Arterioscler Thromb Vasc Biol. 2009;29:969-74.

10. Norheim F, Hjorth M, Langleite TM, Lee S, Holen T, Bindesbøll C, et al. Regulation of angiopoietinlike protein 4 production during and after exercise. Physiol Rep. 2014;2.

11. Catoire M, Alex S, Paraskevopulos N, Mattijssen F, Evers-van Gogh I, Schaart G, et al. Fatty acidinducible ANGPTL4 governs lipid metabolic response to exercise. Proc Natl Acad Sci USA. 2014;111:E1043-52.

12. Kroupa O, Vorrsj E, Stienstra R, Mattijssen F, Nilsson SK, Sukonina V, et al. Linking nutritional regulation of Angpt14, Gpihbp1, and Lmf1 to lipoprotein lipase activity in rodent adipose tissue. BMC Physiol. 2012;12:1-1.

13. Dijk W, Beigneux AP, Larsson M, Bensadoun A, Young SG, Kersten S. Angiopoietin-like 4 promotes intracellular degradation of lipoprotein lipase in adipocytes. J Lipid Res. 2016;57:1670-83.

14. Gray NE, Lam LN, Yang K, Zhou AY, Koliwad S, Wang J-C. Angiopoietin-like 4 (Angpt14) protein is a physiological mediator of intracellular lipolysis in murine adipocytes. J Biol Chem. 2012;287:8444-56.

15. Jonker JT, Smit JW, Hammer S, Snel M, van der Meer RW, Lamb HJ, et al. Dietary modulation of plasma angiopoietin-like protein 4 concentrations in healthy volunteers and in patients with type 2 diabetes. Am J Clin Nutr. 2013;97:255-60.

16. Köster A, Chao YB, Mosior M, Ford A, Gonzalez-DeWhitt PA, Hale JE, et al. Transgenic angiopoietinlike (angptl)4 overexpression and targeted disruption of angpt14 and angptl3: regulation of triglyceride metabolism. Endocrinology. 2005;146:4943-50.

17. Alex S, Lichtenstein L, Dijk W, Mensink RP, Tan NS, Kersten S. ANGPTL4 is produced by enteroendocrine cells in the human intestinal tract. Histochem Cell Biol. 2013;141:383-91. 
18. van der Kolk BW, Goossens GH, Jocken JW, Kersten S, Blaak EE. Angiopoietin-Like Protein 4 and Postprandial Skeletal Muscle Lipid Metabolism in Overweight and Obese Prediabetics. J Clin Endocrinol Metab. 2016;101:2332-9.

19. Kersten S, Mandard S, Tan NS, Escher P, Metzger D, Chambon P, et al. Characterization of the fastinginduced adipose factor FIAF, a novel peroxisome proliferator-activated receptor target gene. J Biol Chem. 2000;275:28488-93.

20. Vink RG, Roumans NJ, van der Kolk BW, Fazelzadeh P, Boekschoten MV, Mariman EC, et al. Adipose tissue meal-derived fatty acid uptake before and after diet-induced weight loss in adults with overweight and obesity. Obesity. 2017.

21. Vink RG, Roumans NJT, Arkenbosch LAJ, Mariman ECM, van Baak MA. The effect of rate of weight loss on long-term weight regain in adults with overweight and obesity. Obesity. 2016;24:321-7.

22. Jocken JWE, Goossens GH, van Hees AMJ, Frayn KN, van Baak M, Stegen J, et al. Effect of betaadrenergic stimulation on whole-body and abdominal subcutaneous adipose tissue lipolysis in lean and obese men. Diabetologia. 2008;51:320-7.

23. van der Kolk BW, Goossens GH, Jocken JW, Blaak EE. Altered skeletal muscle fatty acid handling is associated with the degree of insulin resistance in overweight and obese humans. Diabetologia. 2016;59:2686-96.

24. Cullberg KB, Christiansen T, Paulsen SK, Bruun JM, Pedersen SB, Richelsen B. Effect of weight loss and exercise on angiogenic factors in the circulation and in adipose tissue in obese subjects. Obesity. 2013;21:454-60.

25. Sukonina V, Lookene A, Olivecrona T, Olivecrona G. Angiopoietin-like protein 4 converts lipoprotein lipase to inactive monomers and modulates lipase activity in adipose tissue. Proc Natl Acad Sci USA. 2006;103:17450-5.

26. Makoveichuk E, Vorrsjö E, Olivecrona T, Olivecrona G. Inactivation of lipoprotein lipase in 3T3-L1 adipocytes by angiopoietin-like protein 4 requires that both proteins have reached the cell surface. Biochim Biophys Acta. 2013;441:941-6.

27. Nilsson SK, Anderson F, Ericsson M, Larsson M, Makoveichuk E, Lookene A, et al. Triacylglycerol-rich lipoproteins protect lipoprotein lipase from inactivation by ANGPTL3 and ANGPTL4. Biochim Biophys Acta. 2012;1821:1370-8.

28. Staiger H, Haas C, Machann J, Werner R, Weisser M, Schick F, et al. Muscle-derived angiopoietin-like protein 4 is induced by fatty acids via peroxisome proliferator-activated receptor (PPAR)-delta and is of metabolic relevance in humans. Diabetes. 2009;58:579-89.

29. Sanderson LM, Degenhardt T, Koppen A, Kalkhoven E, Desvergne B, Müller M, et al. Peroxisome proliferator-activated receptor beta/delta (PPARbeta/delta) but not PPARalpha serves as a plasma free fatty acid sensor in liver. Mol Cell Biol. 2009;29:6257-67.

30. Robciuc MR, Skrobuk P, Anisimov A, Olkkonen VM, Alitalo K, Eckel RH, et al. Angiopoietin-Like 4 Mediates PPAR Delta Effect on Lipoprotein Lipase-Dependent Fatty Acid Uptake but Not on BetaOxidation in Myotubes. Müller M, editor. PLoS ONE. 2012;7:e46212.

31. Yin W, Romeo S, Chang S, Grishin NV, Hobbs HH, Cohen JC. Genetic variation in ANGPTL4 provides insights into protein processing and function. J Biol Chem. 2009;284:13213-22.

32. Vink RG, Roumans NJ, Fazelzadeh P, Tareen SHK, Boekschoten MV, van Baak MA, et al. Adipose tissue gene expression is differentially regulated with different rates of weight loss in overweight and obese humans. Int J Obes (Lond). 2017;41:309-16.

33. Varlamov O, Bethea CL, Roberts CT. Sex-specific differences in lipid and glucose metabolism. Front Endocrinol (Lausanne). 2014;5:241. 


\section{Supplementary data}

Table S1. List of selected genes important for adipose tissue fatty acid handling in humans from the microarray analysis and their $\log _{2}$ expression values

\begin{tabular}{|c|c|c|}
\hline & T1 ( $\log _{2}$ expression) & T3 ( $\log _{2}$ expression) \\
\hline \multicolumn{3}{|c|}{ Fatty acid uptake } \\
\hline$L P L$ & $11.18 \pm 0.27$ & $11.12 \pm 0.17$ \\
\hline ANGPTL4 & $7.52 \pm 0.40$ & $7.40 \pm 0.33$ \\
\hline$P P A R \gamma$ & $9.37 \pm 0.23$ & $9.38 \pm 0.25$ \\
\hline SREBF1 & $6.65 \pm 0.49$ & $6.76 \pm 0.48$ \\
\hline \multicolumn{3}{|c|}{ Fatty acid synthesis } \\
\hline$F A S N$ & $9.37 \pm 0.57$ & $9.10 \pm 0.50$ \\
\hline$A C A C A$ & $7.07 \pm 0.40$ & $6.94 \pm 0.35$ \\
\hline$S C D$ & $11.02 \pm 0.87$ & $10.67 \pm 0.65$ \\
\hline \multicolumn{3}{|c|}{ TAG synthesis } \\
\hline$G P A M$ & $11.29 \pm 0.53$ & $11.10 \pm 0.39$ \\
\hline AGPAT9 & $4.97 \pm 0.59$ & $5.08 \pm 0.61$ \\
\hline$D G A T 1$ & $7.86 \pm 0.28$ & $7.84 \pm 0.21$ \\
\hline$D G A T 2$ & $9.75 \pm 0.54$ & $9.48 \pm 0.62$ \\
\hline$A Q P 7$ & $10.24 \pm 0.25$ & $10.31 \pm 0.20$ \\
\hline \multicolumn{3}{|c|}{ Lipid droplet formation } \\
\hline FITM2 & $6.80 \pm 0.22$ & $7.02 \pm 0.26^{*}$ \\
\hline CIDEC & $10.23 \pm 0.30$ & $10.33 \pm 0.21$ \\
\hline PLIN1 & $11.58 \pm 0.20$ & $11.58 \pm 0.21$ \\
\hline \multicolumn{3}{|c|}{ Intracellular lipolysis } \\
\hline PNPLA2 & $10.40 \pm 0.31$ & $10.30 \pm 0.16$ \\
\hline LIPE & $9.41 \pm 0.24$ & $9.25 \pm 0.24$ \\
\hline CGI-58 & $8.28 \pm 0.38$ & $8.33 \pm 0.38$ \\
\hline$M G L L$ & $9.64 \pm 0.28$ & $9.48 \pm 0.25$ \\
\hline$A D R B 2$ & $7.17 \pm 0.28$ & $7.28 \pm 0.35$ \\
\hline CIDEA & $7.66 \pm 0.60$ & $7.86 \pm 0.67$ \\
\hline$G O / S 2$ & $11.12 \pm 0.19$ & $11.13 \pm 0.24$ \\
\hline
\end{tabular}

Genes not meeting filter critera: NPRA, FABP4, CD36, FATP, ANP, BNP. Values are mean \pm SD. ${ }^{*} p<0.05$ for difference between start study and after DI-period, student's $t$-test for paired samples 


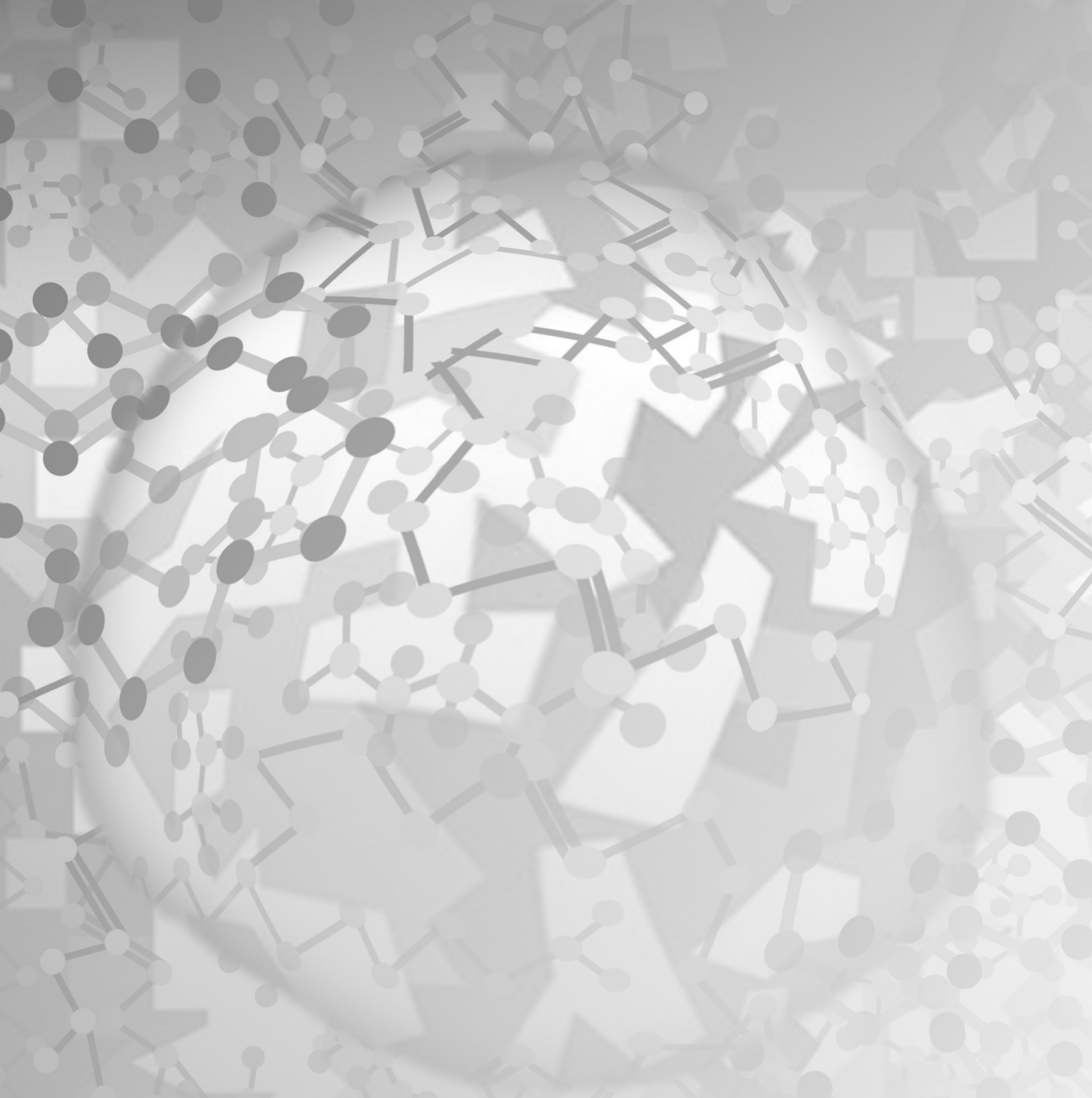




\title{
Chapter 5
}

\section{Plasma lipid profiling of tissue-specific insulin resistance in human obesity}

\author{
Birgitta W. van der Kolk ${ }^{1}$, Nicole Vogelzangs ${ }^{1,2,3}$, Johan W.E. Jocken ${ }^{1}$, Armand \\ Valsesia $^{4}$, Thomas Hankemeier ${ }^{5}$, Arne Astrup ${ }^{6}$, Wim H.M. Saris ${ }^{1}$, Ilja C.W. Arts ${ }^{2,3}$, \\ Marleen M.J. van Greevenbroek ${ }^{7}$, Ellen E. Blaak ${ }^{1}$ and the DiOGenes consortium
}

\footnotetext{
${ }^{1}$ Department of Human Biology and Movement Sciences, Maastricht University, Maastricht, The Netherlands; ${ }^{2}$ Department of Epidemiology, Maastricht University, Maastricht, The Netherlands; ${ }^{3}$ Maastricht Centre for Systems Biology (MaCSBio), Maastricht University, Maastricht, The Netherlands; ${ }^{4}$ Nestlé Institute of Health Sciences, Lausanne, Switzerland; ${ }^{5}$ Netherlands Metabolomics Centre, Leiden, The Netherlands; ${ }^{6}$ Department of Nutrition, Exercise and Sports, Faculty of Science, University of Copenhagen, Copenhagen, Denmark; ${ }^{7}$ Department of Internal Medicine, $\mathrm{MUMC}^{+}$, Maastricht, The Netherlands
} 


\section{Abstract}

Objective: Obesity-associated insulin resistance (IR) may develop in multiple organs, representing different etiologies towards cardiometabolic diseases. This study aimed to identify distinct plasma lipid profiles in overweight/obese individuals who show muscle-IR and/or liver-IR.

Research design and methods: Baseline data of the European multicenter DiOGenes project were used ( $\mathrm{n}=640 ; 401$ women, non-diabetic BMI: $\left.27-45 \mathrm{~kg} / \mathrm{m}^{2}\right)$. Muscle insulin sensitivity index (MISI) and hepatic insulin resistance index (HIRI) were derived from a 5-point oral glucose tolerance test. 140 plasma lipids were quantified by liquid chromatography-mass spectrometry. Linear mixed models were used to evaluate associations between MISI, HIRI and plasma lipids.

Results: MISI was comparable between sexes while HIRI and triacylglycerol (TAG) levels were lower in women than in men. MISI was associated with higher lysophosphatidylcholine (LPC) levels (standardized (std) $\beta=0.126$; FDR $p=0.032$ ). Sex interactions were observed for associations between HIRI, TAG and diacylglycerol (DAG) lipid classes. In women, but not in men, HIRI was associated with higher levels of TAG (44 out of 55 species) and both DAG (stdßs: 0.139 - 0.313; FDR $p<0.05$ ), a lower odd-chain/even-chain TAG ratio $(\operatorname{std} \beta=-0.182 ;$ FDR $p=0.005)$, and a lower very-long-chain/long-chain TAG ratio $(\operatorname{std} \beta=-0.156 ;$ FDR $p=0.037)$.

Conclusions: In overweight/obese individuals, muscle insulin sensitivity is associated with higher plasma LPC concentrations. Women have less hepatic IR and lower TAG than men. Nevertheless, hepatic IR is associated with higher plasma TAG and DAG concentrations and a lower abundance of odd-chain and very-long-chain TAG in women, but not in men. This suggests a more pronounced worsening of plasma lipid profile in women with the progression of hepatic IR. 


\section{Introduction}

Worldwide over 2.1 billion people were overweight or obese in 2013 (1). Overweight and obesity are major risk factors for a number of disorders including cardiovascular disease and type 2 diabetes (2). Excess fat mass and lipid abnormalities are frequently associated with insulin resistance (IR) (3), but the relationship between obesity, IR and lipid metabolism is complex (4).

In the overweight/obese IR state, an impaired adipose tissue lipid buffering capacity may lead to an elevated lipid supply (increased non-esterified fatty acids and triacylglycerol (TAG) to non-adipose tissues, for instance skeletal muscle and the liver (5). This lipid overflow, in combination with an impaired capacity to adjust fat oxidation to the increased supply (metabolic inflexibility), leads to ectopic lipid accumulation in peripheral tissues (5). In these organs, the accumulated lipids and lipid intermediates may interfere with insulin signaling through various mechanisms (6), which eventually are thought to contribute to the development or worsening of IR in skeletal muscle and liver.

In recent years, the plasma lipidome has gained special interest because it may reflect organ composition and metabolism. Circulating lipid species represent a read-out of different tissues, particularly the liver, but may also reflect muscle or adipose tissue lipid composition or metabolism (7). Previous studies have identified lipid (sub)classes and species that are associated with obesity (8), IR (9) and type 2 diabetes (10-12). In the San Antonio Family Heart Study the plasma lipid profile could explain a substantial part of the variability in glucose homeostasis (13) and specific lipid species have been identified as potential biomarkers of glucose intolerance and type 2 diabetes (10). In the Framingham Heart study with a 12 year follow-up, plasma TAG species with a low number of carbon atoms and double bonds were associated with the development of type 2 diabetes and whole-body IR (12). Several studies also report that higher levels of lysophosphatidylcholines (LPC) are associated with a decreased risk of developing type 2 diabetes $(7,14,15)$, but results are not fully consistent (16).

Whole-body IR reflects defective insulin action in major metabolic insulin sensitive organs, such as skeletal muscle, liver and adipose tissue and has long been known to precede the development of type 2 diabetes and cardiovascular disease (5). IR can develop simultaneously in multiple organs, but severity may vary between different organs. It has been suggested that impaired fasting glucose (IFG) and impaired glucose tolerance (IGT) represent distinct pathways towards type 2 diabetes. However, impaired hepatic and peripheral (muscle) 
insulin sensitivity might be the underlying disorders in IFG and IGT individuals, respectively (17). IFG and IGT have been associated with different metabolic profiles. For instance, an altered skeletal muscle fatty acid handling is observed in IGT individuals when compared to IFG individuals (18). These observations support the notion that the metabolic phenotype and disease risk are directly related to the severity of IR in different organs. In addition, there is evidence that interventions that increase insulin sensitivity are organ specific, at least for a part of their effects. For instance, physical activity was shown to mainly target muscle insulin sensitivity (19), while metformin treatment might have major effects on hepatic insulin sensitivity (20). Moreover, a low-fat diet may be more beneficial for prediabetic individuals with hepatic IR, while the Mediterranean diet may target more specifically muscle insulin sensitivity (21).

The information presented above emphasizes the relevance of tissue-specific IR in the development and treatment of cardiometabolic diseases. Thus far, lipidome analyses in large cohort studies have shown to be a powerful tool for identification of potential lipid contributors to endpoint type 2 diabetes (10-12). However, studies that focus on early stages of disease, including development of IR in different tissues prior to type 2 diabetes development are currently missing. Therefore, we investigated in healthy overweight/obese non-diabetic individuals who are at risk for developing cardiometabolic diseases, whether distinct plasma lipid profiles can be identified that are associated with muscle insulin sensitivity or with hepatic IR. Quantification and identification of metabolic anomalies in organ-specific IR may provide directions for more personalized lifestyle or pharmacological interventions in the prevention and control of cardiometabolic diseases.

\section{Material and Methods}

\section{Study Design}

The DiOGenes study was a multicenter, randomized, controlled dietary intervention study that involved 8 European countries. In total, 938 overweight or obese, nondiabetic adults free of cardiovascular disease [age 18-65 years, body mass index (BMI) $27-45 \mathrm{~kg} / \mathrm{m}^{2}$ and fasting blood glucose concentrations $<6.1 \mathrm{mmol} / \mathrm{L}]$ were recruited. More details on recruitment, inclusion and exclusion criteria, design and study procedures have been described previously (22). The analyses described here include baseline data of 640 participants, prior to 
any intervention, for whom plasma lipidomics data and information of tissue-specific IR were available.

Local ethics committees approved the study and all participants gave written informed consent. The study was carried out in accordance with the principles of the Declaration of Helsinki.

\section{Estimates of tissue-specific IR}

Participants underwent a standard 5-point oral glucose tolerance test (OGTT) at baseline. In short, after an overnight fast, venous blood was sampled before ( 0 ) and after a $75 \mathrm{~g}$ glucose load was ingested. Blood samples were taken at t 0 , t 30, t 60, t 90 and t 120 min to determine glucose and insulin concentrations (22). Muscle insulin sensitivity and hepatic IR were estimated using the methods of Abdul-Ghani et al. Both indexes were developed and validated against gold standard hyperinsulinemic-euglycemic clamp studies (23).

The muscle insulin sensitivity index (MISI) was calculated according to the following formula: $\mathrm{MISI}=(\mathrm{dG} / \mathrm{dt}) /$ mean plasma insulin concentration during OGTT. Here, $\mathrm{dG} / \mathrm{dt}$ is the rate of decay of plasma glucose concentration during the OGTT, calculated as the slope of the least square fit to the decline in plasma glucose concentration from peak to nadir (23). The decline in plasma glucose concentration after $60 \mathrm{~min}$ primarily reflects glucose uptake by peripheral tissues, mainly skeletal muscle.

The hepatic IR index (HIRI) was calculated using the square root of the product of the area under curves (AUCs) for glucose and insulin during the first $30 \mathrm{~min}$ of the OGTT - i.e., SQRT (glucose $e_{0-30}[$ AUC in $\mathrm{mg} / \mathrm{d} \cdot \mathrm{h}] \cdot$ insulin $_{0-30}[\mathrm{AUC}$ in $\mu \mathrm{U} / \mathrm{mL} \cdot \mathrm{h}$ ). This index has been developed and validated against the product of fasting plasma insulin and endogenous glucose production in clamp studies (23).

Other indices of whole-body IR were: Matsuda insulin sensitivity index $(\mathrm{ISI})=10,000 / \sqrt{ }[($ fasting insulin $[\mathrm{pmol} / \mathrm{L}] \cdot$ fasting glucose $[\mathrm{mmol} / \mathrm{L}]) \cdot($ mean OGTT insulin $[\mathrm{pmol} / \mathrm{L}]) \cdot($ mean OGTT glucose $[\mathrm{mmol} / \mathrm{L}])]$ and HOMA-IR calculated as fasting insulin $[\mu \mathrm{U} / \mathrm{L}] \cdot$ fasting glucose $[\mathrm{mmol} / \mathrm{L}] / 22.5$.

\section{Classification of participants into muscle-IR and liver-IR}

For descriptive reasons, participants were divided into tertiles according to HIRI and MISI scores (21). The lowest tertile of MISI represented individuals with muscle IR; the highest 
tertile of HIRI represented individuals with hepatic IR. Accordingly, participants were categorized in one of four groups: (1) no IR, (2) IR primarily in muscle (muscle-IR), (3) IR primarily in liver (liver-IR) and (4) IR in both muscle and liver (muscle/liver-IR).

\section{Plasma lipidomics}

Fasting plasma lipidome analysis was done using liquid chromatography-mass spectrometry as described previously (4). Briefly, a mixture of internal standards and calibration standards was added to each sample and was followed by liquid-liquid extraction with a (2:1) mixture of dichloromethane and methanol (4). The organic phase that contained most of the lipids was removed and prepared for further analysis. Extracted lipids were separated on a Ascentis Express C8 2.19 150-mm (2.7-mm particle size) column (Sigma-Aldrich) with the use of an Acquity UPLC system (Waters) and analyzed with the use of quadrupole time-of-flight mass spectrometry (Agilent Technologies). Experimental conditions during the chromatographic analysis and detection by mass spectrometry were similar to Valsesia et al. (4).

Names and abbreviations were assigned to the identified lipids according to Lipid Maps nomenclature (http://www.lipidmaps.org). In total, 140 intact lipid species within 11 classes were measured: triacylglycerols (TAG; $n=55$ ), diacylglycerols (DAG; $n=2$ ), cholesterol esters (CE; $n=3)$, sphingomyelins (SM; $n=20)$, phosphatidylcholine (PC; $n=25)$, alkylphosphatidylcholine ( $\mathrm{PC}(\mathrm{O}-) ; \mathrm{n}=15)$, lysoalkylphosphatidylcholine ( $\mathrm{LPC}(\mathrm{O}-) ; \mathrm{n}=2)$, lysophosphatidylcholine (LPC; $\mathrm{n}=11$ ), phosphatidylethanolamine (PE; $\mathrm{n}=3$ ), alkylphosphatidylethanolamine $(\mathrm{PE}(\mathrm{O}-) ; \mathrm{n}=3)$ and lysophosphatidylethanolamine (LPE; $\mathrm{n}=1)$. Lipids were denoted by headgroup and total acyl-carbon and double-bond content. A detailed list of measured lipids, including within-class abundance in plasma, can be found in supplementary Table S1.

Sum scores (e.g. sum of all TAG) were calculated per lipid (sub)class. In addition, as saturation and chain length of fatty acids have been widely shown to be related to cardiometabolic risk factors $(12,24)$, sum scores were calculated for saturated TAG (TAG with 0 double bonds), unsaturated TAG (TAG with 1-3 double bonds), and polyunsaturated TAG (TAG with $\geq 4$ double bonds). Moreover, ratios for TAG composition were calculated, i.e., ratio of the sum of all odd-chain TAG to the sum of all even-chain TAG and ratio of the sum of all very-long-chain ( $\geq 56$ carbon atoms) TAG to the sum of all long-chain $(<56$ carbon atoms) TAG. 


\section{Statistical analyses}

Differences in characteristics between tissue-specific IR groups and between sexes were assessed using one-way ANOVAs and Bonferroni post hoc tests.

HIRI, MISI and most lipid species showed a right-skewed distribution, therefore, nonnormal data were logarithmically transformed to approximate normality. To allow for direct comparison of the effect sizes, we additionally standardized HIRI, MISI and lipids by calculating $Z$-scores for each variable. Linear mixed model analyses were performed with plasma lipid species as the dependent variable (per-lipid analyses), HIRI or MISI (continuous variables) as fixed effect and study center as random effect. In the adjusted analyses, sex, BMI and waist-to-hip ratio were included as covariates, because body composition is an important determinant in the development of obesity-related IR (25). In the fully adjusted models, HIRI was included as a covariate in analyses on MISI and MISI was included in analyses on HIRI to assess the independent effects of tissue-specific IR. Benjamini \& Hochberg false discovery rate (FDR)-correction was applied to adjust for multiple testing. Since sex differences in lipid metabolism are well established (26), we also evaluated sex interactions in each comparison by including interaction terms for sex and HIRI or sex and MISI, as applicable. As similar associations were found in all models, only the results of the fully adjusted models are shown. The data were analyzed using SPSS for Mac version 22.0 (SPSS, Chicago, IL, USA) and R statistical programming system (http://www.r-project.org/). The statistical significance was set at (FDR-adjusted) $p<0.05$.

\section{Results}

\section{Clinical characteristics of study population}

The group with no IR consisted of 325 participants, 108 participants were in the group with muscle-IR, 99 participants in the group with liver-IR, and 108 participants in the group with muscle/liver-IR. Compared to the group with no IR $(67.4 \%$ women), participants with liver-IR and muscle/liver-IR were more often men $(59.6 \%$ and $47.3 \%$ respectively) while participants with mainly muscle-IR were more often women $(78.7 \%, p<0.001)$ (Table S2). Table 1 shows the demographic and metabolic characteristics of the participants according to their sex and IR phenotype. 
Table 1. Clinical characteristics of tissue-specific IR groups stratified by sex

\begin{tabular}{|c|c|c|c|c|c|}
\hline & \multicolumn{5}{|c|}{ Women } \\
\hline & $\begin{array}{l}\text { No IR } \\
(\mathrm{n}=219)\end{array}$ & $\begin{array}{c}\text { Muscle-IR } \\
(\mathrm{n}=85)\end{array}$ & $\begin{array}{c}\text { Liver-IR } \\
(\mathrm{n}=40)\end{array}$ & $\begin{array}{c}\text { Muscle/liverIR } \\
(\mathrm{n}=57)\end{array}$ & $p$ \\
\hline Age (y) & $41 \pm 6$ & $41 \pm 6$ & $42 \pm 7$ & $40 \pm 6$ & 0.832 \\
\hline BMI $\left(\mathrm{kg} / \mathrm{m}^{2}\right)$ & $34.1 \pm 4.8$ & $34.6 \pm 4.5$ & $35.5 \pm 5.2$ & $35.4 \pm 4.9$ & 0.143 \\
\hline Waist-to-hip ratio & $0.87 \pm 0.07$ & $0.87 \pm 0.06$ & $0.89 \pm 0.06$ & $0.92 \pm 0.08^{*} \dagger$ & $<0.001$ \\
\hline Weight $(\mathrm{kg})$ & $94.3 \pm 14.8$ & $94.7 \pm 15.1$ & $100.0 \pm 15.7$ & $97.1 \pm 17.4$ & 0.144 \\
\hline Waist $(\mathrm{cm})$ & $102.3 \pm 10.9$ & $104.1 \pm 11.1$ & $107.8 \pm 11.3^{*}$ & $109.2 \pm 13.4^{*}$ & $<0.001$ \\
\hline Systolic BP (mmHg) & $121 \pm 15$ & $123 \pm 12$ & $125 \pm 16$ & $126 \pm 13$ & 0.111 \\
\hline Diastolic BP (mmHg) & $75 \pm 12$ & $77 \pm 9$ & $79 \pm 10$ & $76 \pm 10$ & 0.223 \\
\hline Fat Free Mass (kg) & $54.2 \pm 7.0$ & $53.3 \pm 7.1$ & $56.0 \pm 9.9$ & $54.7 \pm 8.2$ & 0.491 \\
\hline Fat Mass (kg) & $38.6 \pm 12.1$ & $38.4 \pm 14.0$ & $38.1 \pm 12.2$ & $43.6 \pm 11.1$ & 0.212 \\
\hline Body Fat (\%) & $42.9 \pm 5.4$ & $42.9 \pm 5.3$ & $43.4 \pm 5.2$ & $44.0 \pm 5.1$ & 0.729 \\
\hline Cholesterol $(\mathrm{mmol} / \mathrm{L})$ & $4.8 \pm 0.9$ & $4.7 \pm 1.0$ & $5.1 \pm 0.8$ & $4.8 \pm 0.9$ & 0.232 \\
\hline TAG $(\mathrm{mmol} / \mathrm{L})$ & $1.1 \pm 0.5$ & $1.3 \pm 0.5$ & $1.5 \pm 0.6^{*}$ & $1.5 \pm 0.7^{*}$ & $<0.001$ \\
\hline $\mathrm{HDL}(\mathrm{mmol} / \mathrm{L})$ & $1.3 \pm 0.3$ & $1.3 \pm 0.3$ & $1.3 \pm 0.3$ & $1.1 \pm 0.4^{*}$ & 0.004 \\
\hline $\mathrm{LDL}(\mathrm{mmol} / \mathrm{L})$ & $3.0 \pm 0.9$ & $2.9 \pm 0.8$ & $3.1 \pm 0.6$ & $2.9 \pm 0.8$ & 0.496 \\
\hline NEFA $(\mu \mathrm{mol} / \mathrm{L})$ & $706 \pm 335$ & $703 \pm 329$ & $778 \pm 420$ & $691 \pm 320$ & 0.692 \\
\hline $\mathrm{CRP}(\mathrm{mg} / \mathrm{L})$ & $3.7 \pm 3.6$ & $4.7 \pm 3.4$ & $6.0 \pm 5.1^{*}$ & $6.2 \pm 4.7^{*}$ & $<0.001$ \\
\hline Glucose $(\mathrm{mmol} / \mathrm{L})$ & $5.0 \pm 0.6$ & $5.0 \pm 0.6$ & $5.2 \pm 0.5$ & $5.2 \pm 0.7^{*}$ & 0.021 \\
\hline Insulin (mU/L) & $7.6 \pm 4.0$ & $10.0 \pm 3.5^{*}$ & $12.7 \pm 4.3^{*} \dagger$ & $18.7 \pm 10.0^{*} \dagger \neq$ & $<0.001$ \\
\hline HOMA-IR (AU) & $2.0 \pm 1.2$ & $2.6 \pm 1.1^{*}$ & $3.4 \pm 1.3^{*} \dagger$ & $5.0 \pm 2.7^{*} \dagger \ddagger$ & $<0.001$ \\
\hline MISI (AU) & $0.08 \pm 0.06$ & $0.02 \pm 0.01^{*}$ & $0.06 \pm 0.03^{*} \dagger$ & $0.02 \pm 0.01^{*} \ddagger$ & $<0.001$ \\
\hline HIRI (AU) & $25.4 \pm 5.4$ & $28.0 \pm 4.6^{*}$ & $41.5 \pm 6.8^{*} \dagger$ & $45.3 \pm 8.6^{*} \dagger \neq$ & $<0.001$ \\
\hline ISI (AU) & $7.2 \pm 3.3$ & $5.0 \pm 2.1^{*}$ & $3.7 \pm 1.3^{*} \dagger$ & $2.4 \pm 1.0^{*} \dagger \ddagger$ & $<0.001$ \\
\hline NGT / IGM / T2D (\%) & $85 / 14 / 1$ & $54 / 41 / 5$ & $80 / 18 / 2$ & $55 / 33 / 12$ & $<0.001$ \\
\hline Oral anticonception (\%) & 11.6 & 19.3 & 12.5 & 23.2 & 0.096 \\
\hline
\end{tabular}

Data are mean \pm SD unless otherwise indicated. Differences between tissue-specific IR groups within sex were assessed using one-way ANOVAs and Bonferroni post hoc tests. ${ }^{*} p<0.05$ for the difference with no IR group; $\dagger p<0.05$ for the difference with muscle-IR group. $\neq p<0.05$ for difference with liver-IR group. BMI: body mass index; BP: blood pressure; HDL: high-density lipoprotein; LDL: low-density lipoprotein; NEFA: non-esterified fatty acids; CRP: C-reactive protein; HOMA-IR: homeostatic model for assessment of insulin resistance; MISI: muscle insulin sensitivity index; HIRI: hepatic insulin resistance index; ISI: (Matsuda) insulin sensitivity index; NGT: normal glucose tolerance; IGM: impaired glucose metabolism; T2D: type 2 diabetes. 


\begin{tabular}{|c|c|c|c|c|}
\hline \multicolumn{5}{|c|}{ Men } \\
\hline $\begin{array}{c}\text { No IR } \\
(n=106)\end{array}$ & $\begin{array}{c}\text { Muscle-IR } \\
(\mathrm{n}=23)\end{array}$ & $\begin{array}{c}\text { Liver-IR } \\
(\mathrm{n}=59)\end{array}$ & $\begin{array}{c}\text { Muscle/liverIR } \\
(\mathrm{n}=51)\end{array}$ & $p$ \\
\hline $43 \pm 6$ & $44 \pm 5$ & $41 \pm 6$ & $43 \pm 6$ & 0.138 \\
\hline $33.9 \pm 4.8$ & $34.8 \pm 5.0$ & $34.4 \pm 4.2$ & $35.1 \pm 4.5$ & 0.440 \\
\hline $1.00 \pm 0.06$ & $1.02 \pm 0.06$ & $1.01 \pm 0.05$ & $1.03 \pm 0.05$ & 0.080 \\
\hline $108.2 \pm 17.6$ & $112.9 \pm 17.2$ & $108.6 \pm 15.1$ & $110.0 \pm 17.7$ & 0.671 \\
\hline $112.1 \pm 12.3$ & $116.4 \pm 13.2$ & $114.5 \pm 10.6$ & $116.6 \pm 12.3$ & 0.119 \\
\hline $132 \pm 13$ & $131 \pm 11$ & $132 \pm 12$ & $131 \pm 13$ & 0.907 \\
\hline $81 \pm 10$ & $82 \pm 10$ & $82 \pm 11$ & $80 \pm 11$ & 0.924 \\
\hline $73.6 \pm 12.8$ & $75.2 \pm 9.5$ & $72.3 \pm 10.9$ & $71.9 \pm 9.4$ & 0.798 \\
\hline $39.2 \pm 12.6$ & $38.3 \pm 14.7$ & $36.6 \pm 11.2$ & $41.9 \pm 13.2$ & 0.486 \\
\hline $31.2 \pm 8.5$ & $33.3 \pm 6.8$ & $32.0 \pm 6.8$ & $30.8 \pm 5.1$ & 0.741 \\
\hline $5.0 \pm 1.1$ & $5.0 \pm 1.2$ & $5.2 \pm 1.1$ & $4.9 \pm 1.1$ & 0.575 \\
\hline $1.6 \pm 0.8$ & $1.6 \pm 0.7$ & $1.6 \pm 0.7$ & $1.7 \pm 0.6$ & 0.803 \\
\hline $1.1 \pm 0.3$ & $1.0 \pm 0.3$ & $1.1 \pm 0.3$ & $1.0 \pm 0.2$ & 0.193 \\
\hline $3.2 \pm 1.0$ & $3.2 \pm 1.0$ & $3.3 \pm 1.0$ & $3.1 \pm 1.0$ & 0.785 \\
\hline $519 \pm 206$ & $538 \pm 178$ & $603 \pm 384$ & $570 \pm 363$ & 0.343 \\
\hline $3.0 \pm 2.6$ & $4.0 \pm 3.5$ & $3.4 \pm 3.9$ & $3.2 \pm 2.4$ & 0.512 \\
\hline $5.2 \pm 0.5$ & $5.3 \pm 0.7$ & $5.5 \pm 0.6^{*}$ & $5.3 \pm 0.6$ & 0.017 \\
\hline $9.5 \pm 4.7$ & $13.7 \pm 5.7$ & $15.7 \pm 8.5^{*}$ & $18.1 \pm 8.9^{*}$ & $<0.001$ \\
\hline $2.6 \pm 1.3$ & $3.8 \pm 1.9$ & $4.5 \pm 2.7^{*}$ & $5.0 \pm 2.8^{*}$ & $<0.001$ \\
\hline $0.09 \pm 0.06$ & $0.02 \pm 0.01^{*}$ & $0.06 \pm 0.04^{*} \dagger$ & $0.02 \pm 0.01 * \neq$ & $<0.001$ \\
\hline $27.6 \pm 4.8$ & $30.3 \pm 4.8$ & $44.9 \pm 9.5^{* \dagger} \dagger$ & $47.1 \pm 9.9^{*} \dagger$ & $<0.001$ \\
\hline $5.7 \pm 2.7$ & $3.7 \pm 1.9^{*}$ & $3.1 \pm 1.4^{*}$ & $2.4 \pm 1.0^{*}$ & $<0.001$ \\
\hline $81 / 17 / 2$ & $48 / 39 / 13$ & $70 / 27 / 3$ & $67 / 22 / 11$ & $<0.001$ \\
\hline
\end{tabular}


Overall, in women, plasma TAG concentrations were lower $(p<0.001)$ and HDL cholesterol $(p<0.001)$ and CRP $(p<0.001)$ were higher than in men. Furthermore, MISI was not different between sexes $(p=0.154)$, but HIRI was higher in men than in women $(p<0.001)$.

In both sexes, age and BMI did not differ significantly between the groups. In women, but not in men, waist circumference and waist-to-hip ratio were significantly larger in the liver-IR and muscle/liver-IR groups compared to the no IR group. In addition, in women, but not in men, plasma TAG and CRP levels were significantly higher in the liver-IR and muscle/liver-IR groups than in the no IR group while HDL-cholesterol was lowest in the muscle/liver-IR group. In both sexes, muscle-IR, liver-IR and muscle/liver-IR groups all showed significantly higher fasting glucose and fasting insulin concentrations, higher levels of HOMA-IR, and lower levels of ISI than those with no IR.

\section{Muscle insulin sensitivity is associated with higher lysophosphatidylcholine concentrations}

No significant sex interactions were observed for the associations between MISI and lipid classes and species (Table S3). Therefore, associations between MISI and lipids were assessed in men and women combined.

MISI was positively associated with the sum score for LPC $(\operatorname{std} \beta=0.126$; $\operatorname{FDR} p<0.032$ ), but not with any of the other lipid classes after correction for multiple testing (Figure 1A/ Table S4). This indicates that higher levels of LPC were associated with better muscle insulin sensitivity. MISI showed a positive and nominal significant association with six out of the 11 individual LPC species, of which $\operatorname{LPC}(18: 1)(\operatorname{std} \beta=0.172 ; \operatorname{FDR} p=0.008)$ and $\operatorname{LPC}(18: 2)\left(\operatorname{std} \beta=0.148 ; \operatorname{FDR}_{p}=0.025\right)$ remained statistically significant after correction for multiple testing (Figure 1B). MISI was not associated with any other individual lipid species (Table S4).

\section{Hepatic IR is associated with TAG and DAG levels in women, but not in men}

Significant sex-interactions were observed in the associations between HIRI and the lipid classes TAG and DAG (Table S3). Therefore, all statistical analyses for associations between HIRI and TAG or DAG were stratified by sex (Table S5). 

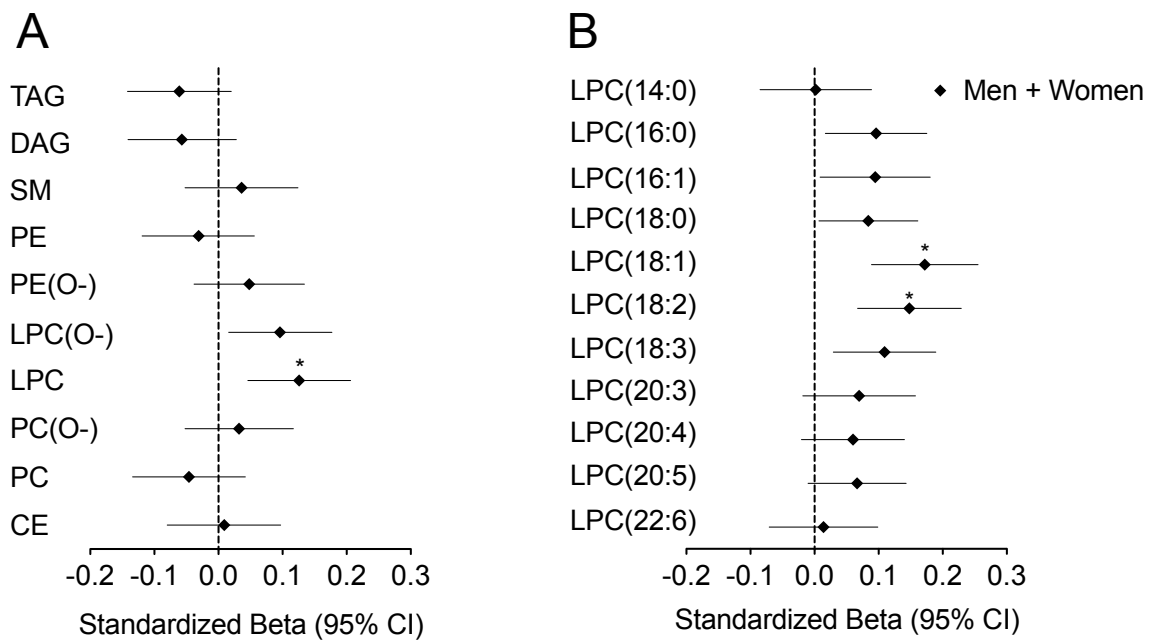

Figure 1. Associations of MISI with plasma lipid (sub-)classes and individual lysophosphatidylcholine lipid species. (A) Standardized coefficients ( $\beta \mathrm{s}$ ) in linear mixed models with the sum scores of plasma lipid (sub-)classes as dependent variable, MISI as fixed effect, study center as random effect, adjusted for sex, BMI, waist-to-hip ratio and HIRI; (B) Standardized coefficients $(\beta s)$ in linear mixed models with the individual LPC lipid species as dependent variable, MISI as fixed effect, study center as random effect, adjusted for sex, BMI, waist-to-hip ratio and HIRI. No significant sex interactions were observed in the associations between MISI and lipids, therefore squares represent all individuals ( $n=640)$. Error bars denote 95\% confidence intervals. Asterisks indicate a significant association after Benjamini \& Hochberg FDR corrections for multiple testing ( $\operatorname{FDR} p<0.05)$.

In women, HIRI was significantly associated with the sum score for TAG $(\operatorname{std} \beta=0.273$; FDR $p<0.001)$ and DAG $(\operatorname{std} \beta=0.212$; FDR $p<0.001)$ (Figure $2 \mathrm{~A})$. The positive associations of HIRI with total TAG and DAG indicate that higher plasma TAG and DAG levels were associated with a more severe hepatic IR. Importantly, both DAG species and 44 out of 55 TAG species contributed significantly to this effect $(\operatorname{std} \beta s: 0.139$ to 0.313 ; FDR $p<0.05$, Table S5). In men, no associations of HIRI with TAG and DAG were found (Figure 2A, Table S5).

Next, TAG composition was analyzed in more detail. Associations between HIRI and variables that reflect TAG composition, i.e. fatty acid saturation and chain length (Table S3), were statistically significant in women but not in men, even though the interaction term for 
sex and HIRI did not reach statistical significance. In women, HIRI was inversely associated with the odd-to-even-chain TAG ratio $(\operatorname{std} \beta=-0.182 ; \operatorname{FDR} p=0.005)$ as well as with the very-long-chain to long-chain TAG ratio $(\operatorname{std} \beta=-0.156 ; \operatorname{FDR} p=0.037)$. This indicates that TAG with a relative lower abundance of odd-chain and very-long-chain fatty acids were associated with worse hepatic IR (Figure 2B, Table S5). In men, no association between HIRI and TAG composition was found (Figure 2B, Table S5).

\section{Hepatic IR and other lipid (sub-)classes}

Sex-interactions were significant in the association between HIRI and the lipid class PE, but not with the other lipid classes (Table S3). Likewise, we performed sex-stratified analyses (Table S5).

A trend for a positive association of HIRI with $P E$ was observed in women $(\operatorname{std} \beta=0.120$; FDR $p=0.070)$, but not in $\operatorname{men}(\operatorname{std} \beta=-0.092 ; \mathrm{FDR} p=0.780)$. The association between HIRI and the sum score for PC was significant in women ( $\operatorname{std} \beta=0.166 ; \mathrm{FDR} p=0.028)$, but not in men $(\operatorname{std} \beta=0.007 ;$ FDR $p=0.927)$, although the interaction term for sex and HIRI was not significant in these analyses $(p=0.226)$. Likewise, in men and women combined, HIRI was significantly associated with nine out of the 28 individual PC species ( $\operatorname{std} \beta$ s: 0.098 to 0.195 ; FDR $p<0.05$ ), but stratified analyses showed that, again, these were primarily driven by the associations in women (Table S5). Lastly, in men and women combined, significant associations were observed between HIRI and four individual lipid species from the other lipid classes, i.e. a positive association for $\operatorname{LPC}(14: 0)(\operatorname{std} \beta=0.157$; $\operatorname{FDR} p=0.003)$, and inverse associations for $\operatorname{PCO}(42: 6)(\operatorname{std} \beta=-0.110 ; \operatorname{FDR} p=0.015)$, $\mathrm{PCO}(44: 5)(\operatorname{std} \beta=0.110 ;$ FDR $p=0.033)$, and $\operatorname{SM}(\mathrm{d} 18: 0 / 24: 2) \quad(\operatorname{std} \beta=-0.156$; $\operatorname{FDR} p=0.002)$.

\section{Discussion}

The role of the plasma lipidome in IR and type 2 diabetes has been subject of intense research in recent years. The present study focused on the relationship between the plasma lipidome and tissue-specific IR. In a cross-sectional evaluation of overweight and obese individuals without cardiometabolic disorders we showed that a higher muscle insulin sensitivity was associated with higher plasma LPC concentrations. Furthermore, in women, but not in men, we observed positive associations between hepatic IR and several lipid classes including TAG and DAG, whilst a similar tendency was observed for PC and PE. 

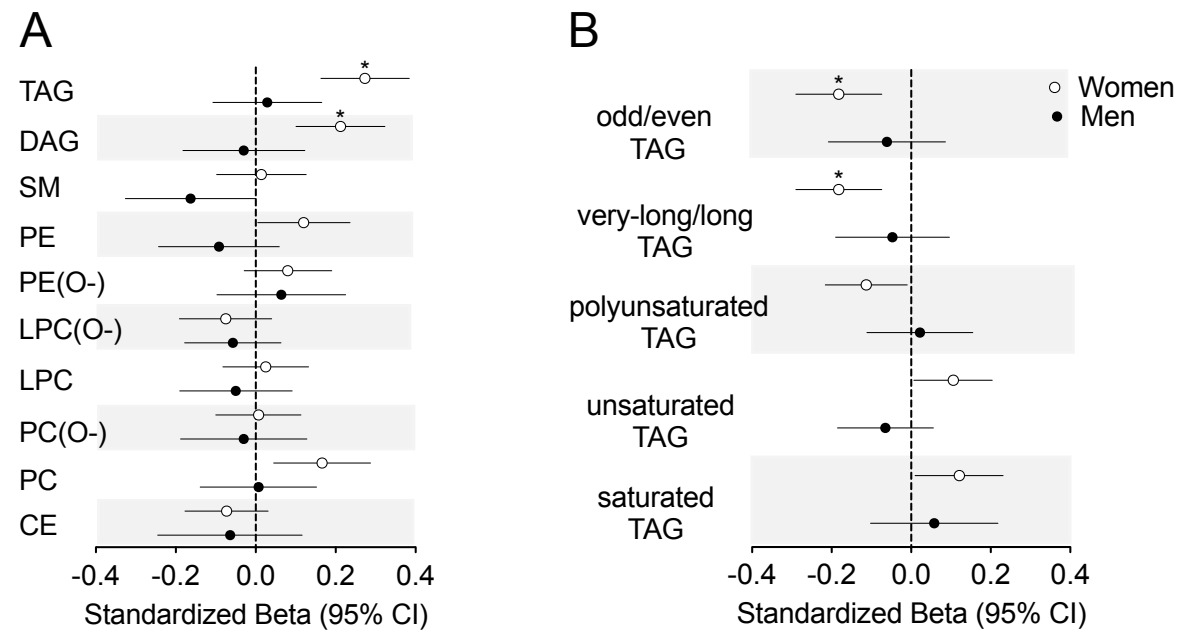

Figure 2. Associations of HIRI with plasma lipid (sub-)classes and TAG composition. Significant sex interactions were observed in the associations between HIRI and TAG, DAG, and PE; therefore, all analyses presented are stratified by sex. (A) Standardized coefficients ( $\beta \mathrm{s}$ ) in linear mixed models with the sum scores of plasma lipid (sub-)classes as dependent variable, HIRI as fixed effect, study center as random effect, adjusted for BMI, waist-to-hip ratio and MISI; (B) Standardized $\beta$ s in linear mixed models with TAG composition as dependent variable, HIRI as fixed effect, study center as random effect, adjusted for BMI, waist-to-hip ratio and MISI. White circles represent women $(n=401)$ and black circles represent men $(\mathrm{n}=239)$. Error bars denote $95 \%$ confidence intervals. Asterisks indicate a significant association after Benjamini \& Hochberg FDR corrections for multiple testing (FDR $p<0.05$ ). Saturated TAG: 0 double bonds; unsaturated TAG: $1-3$ double bonds, polyunsaturated TAG: $\geq 4$ double bonds; Odd/even TAG: odd-chain to even-chain TAG ratio; Very-long/long TAG: very-longchain ( $\geq 56$ carbon atoms) to long-chain ( $<56$ carbon atoms) TAG ratio.

Our current analyses showed that muscle insulin sensitivity (as reflected by a higher MISI) was positively associated with the sum score for plasma LPC. Moreover, muscle insulin sensitivity showed strong and positive associations with two individual LPC species, LPC(18:1) and LPC(18:2). Several previous studies showed associations between LPC and general indices of insulin sensitivity. For instance, lower plasma concentrations of numerous individual LPC species have been reported in human obesity $(9,14)$, IR $(7,27)$, and have also been associated with an increased risk of type 2 diabetes $(15,27,28)$. Floegel et al. identified LPC(18:2) to be positively associated with the Matsuda insulin sensitivity index (ISI) in the 
Tübingen Family study for type 2 diabetes (15), while Barber et al. (14) reported lower LPC(18:1) and LPC(18:2) in obesity. The latter study suggested that obesity-related factors, such as diet and adiposity, rather than IR and diabetes per se, contributed to the changes in the LPC profile. Notably, in our study, adjustment for body composition (i.e. BMI and waist-to-hip ratio) did not affect the positive association between muscle insulin sensitivity and LPCs. This might imply that IR, and more specifically muscle insulin resistance, rather than obesity per se is associated with lower plasma LPC levels. In addition, it was recently shown that fasting plasma levels of several LPCs, including LPC(18:1) and LPC(18:2), were increased in healthy male participants after completion of a ten-week exercise program (29). Furthermore, in human myotubes, it was shown that extracellular LPC(16:0) and LPC(18:1) can act as lipid signaling molecules and, as such, activate PPAR $\delta$-dependent gene expression and reduce lipid-induced inflammation and IR (30). These in vivo and in vitro results are in line with our current findings and imply that LPCs may indeed be specifically related to muscle insulin sensitivity.

In contrast to the other LPCs, LPC(14:0) was the only LPC that was positively and significantly associated with hepatic IR (as reflected by HIRI), while it was not associated with muscle insulin sensitivity. Several reports showed associations of LPC(14:0) with general markers of whole body IR. Rauschert et al. reported that increased LPC(14:0) was significantly associated with high HOMA-IR in normal-weight young adults (9). Another study in infants found elevated LPC(14:0) levels to be predictive of obesity onset at early school age (31). Moreover, obese men had lower levels of LPC(18:1) and higher levels of LPC(14:0) than normal-weight controls (32). In our study, adjustment for body composition did not affect the positive association between hepatic IR and LPC(14:0). This suggests that LPC(14:0) might be specifically associated with hepatic IR, independent of obesity. However, more research is needed to further unravel the potential role of LPC(14:0) in hepatic IR.

In women, hepatic IR was positively associated with the sum of plasma TAG, DAG, with a similar tendency for PC and PE. These associations were not observed in men. Importantly, the associations between hepatic IR and TAG/DAG species were not affected by adjustments for body composition and body fat distribution. Thus, these observed differences between men and women were unlikely to result from the known differences in body composition. Healthy, premenopausal women generally have a more favorable cardiometabolic plasma lipid profile than men (26). In our current evaluations we indeed observed that, in general, women had less hepatic IR, lower plasma TAG and higher HDL concentrations as compared to men. However, our data also suggest that in women, the 
presence of hepatic IR is prominently related to a more pronounced worsening of lipid profile. A potential mechanism might be related to very-low-density-lipoprotein (VLDL) production in the liver. Women have lower plasma TAG concentrations, and produce fewer, but larger, TAG-rich VLDL particles than men (33). Previous studies have shown that IR attenuates insulin-mediated hepatic suppression of VLDL production and insulin-mediated hepatic de novo lipogenesis and thereby enhancing total VLDL production (34). Notably, these studies did not differentiate between sexes. Given our current observations, it is tempting to speculate that under hepatic IR conditions, VLDL production might be differentially affected in men and women, leading to an accelerated VLDL production in women. Furthermore, sex hormones are known to influence VLDL production in women (26). For instance, VLDL-TAG turnover is faster in postmenopausal women compared with well-matched premenopausal women despite similar plasma (VLDL)-TAG concentrations (35). In the current study, we could not directly explain our observations by hormonal state, as most women were most likely in a premenopausal status. There may be more subtle effects of sex hormones in the context of hepatic IR, but we could not address that point as no information was available on sex hormones nor phase in menstrual cycle. Together, these associations between hepatic IR and TAG species are intriguing findings and might imply that women with hepatic IR 'catch-up' with men with respect to cardiovascular disease risk.

TAG composition was also analyzed in more detail, including saturation and chain length of TAGs. Here, we show that hepatic IR, rather than muscle insulin sensitivity, was associated with a relatively lower abundance of odd-chain fatty acids in plasma TAGs. In line, in the EPIC (European Prospective Investigation into Cancer and Nutrition) study a relatively lower abundance of odd-chain fatty acids in plasma phospholipids were shown to be inversely associated with incidence of type 2 diabetes and coronary heart disease (24). Moreover, the odd-chain fatty acid C15:0 was positively associated with insulin sensitivity and $\beta$-cell function, as measured by an intravenous glucose tolerance test, as well as with a $27 \%$ decreased risk of incident diabetes after 5 years (36). The biological mechanisms underlying the associations between hepatic IR and individual odd-chain fatty acids have not yet been elucidated, but some pathways can be suggested. Enhanced de novo lipogenesis in hepatic IR increases levels of even-chain saturated fatty acids and may, as such, contribute to a lower ratio of odd-to-even chain saturated fatty acids in the liver. Eventually this novo lipogenesis might increase hepatic steatosis and hepatic IR (37). Lastly, alterations in membrane fluidity have previously been linked to insulin sensitivity (38). Odd-chain fatty acids might have a lower melting point than their next lower even-numbered homolog, which 
may affect fluidity (39). In addition, the fatty acid composition of circulating TAG might also represent fatty acid composition of, for example, glycerophospholipids in cell membranes (40). However, how these TAG characteristics specifically attribute to hepatic IR remains to be studied.

The major strength of our study is the availability of a 5-point OGTT in a large and well-phenotyped cohort to estimate muscle sensitivity as well as hepatic IR in each participant. Importantly, the calculated MISI and HIRI represent different responses to the OGTT and they have been validated against the gold standard hyperinsulinemic-euglycemic clamp studies (23). For the first time, information on tissue-specific IR was combined with comprehensive plasma lipidome analysis, hence adding novel information to deepen our understanding of the etiology of tissue-specific IR. Furthermore, these data were generated in healthy overweight and obese individuals without cardiometabolic diseases, thus representing early events in the progression towards these diseases. The main limitation of our study is its cross-sectional design which prohibits causal inferences. Therefore, experimental studies should follow up on these outcomes to fully elucidate biological mechanisms.

In conclusion, we showed that the previously reported positive associations between LPC levels and whole-body insulin sensitivity were related to muscle insulin sensitivity, rather than hepatic IR. Furthermore, we identified sex differences in the associations between hepatic IR and the plasma lipidome. In men, the degree of hepatic IR did not relate to alterations in the plasma lipidome. In contrast, in women, worse hepatic IR was associated with higher levels of plasma TAG, DAG, with a similar tendency for PC and PE. In addition, a lower abundance of odd-chain and very-long-chain TAG was observed in worse hepatic IR in women. Combined with the observation that overweight/obese women had less hepatic IR and lower TAG levels than men, this suggests that, in women, the plasma lipidome may be more responsive to worsening of hepatic IR, or vice versa. Notably, such an effect was not observed for muscle insulin sensitivity. These distinct plasma lipid profiles in tissue-specific IR may provide directions for more personalized lifestyle or pharmacological interventions in the prevention of cardiometabolic disease that can, at least at the group level, be tailored towards a specific sex, or a specific type of insulin resistance. Notwithstanding, the underlying mechanisms that drive the observed differences require further study. 


\section{References}

1. Ng M, Fleming T, Robinson M, Thomson B, Graetz N, Margono C, et al. Global, regional, and national prevalence of overweight and obesity in children and adults during 1980-2013: a systematic analysis for the Global Burden of Disease Study 2013. Lancet. 2014;384:766-81.

2. Kahn SE, Hull RL, Utzschneider KM. Mechanisms linking obesity to insulin resistance and type 2 diabetes. Nature. 2006;444:840-6.

3. Samuel VT, Petersen KF, Shulman GI. Lipid-induced insulin resistance: unravelling the mechanism. Lancet. 2010;375:2267-77.

4. Valsesia A, Saris WH, Astrup A, Hager J, Masoodi M. Distinct lipid profiles predict improved glycemic control in obese, nondiabetic patients after a low-caloric diet intervention: the Diet, Obesity and Genes randomized trial. Am J Clin Nutr. 2016;104:566-75.

5. Stinkens R, Goossens GH, Jocken JWE, Blaak EE. Targeting fatty acid metabolism to improve glucose metabolism. Obes Rev. 2015;16:715-57.

6. Coen PM, Goodpaster BH. Role of intramyocelluar lipids in human health. Trends Endocrinol Metab. 2012;23:391-8.

7. Tonks KT, Coster AC, Christopher MJ, Chaudhuri R, Xu A, Gagnon-Bartsch J, et al. Skeletal muscle and plasma lipidomic signatures of insulin resistance and overweight/obesity in humans. Obesity. 2016;24:908-16.

8. Mika A, Sledzinski T. Alterations of specific lipid groups in serum of obese humans: a review. Obes Rev. $2016 ;: 1-26$.

9. Rauschert S, Uhl O, Koletzko B, Kirchberg F, Mori TA, Huang R-C, et al. Lipidomics Reveals Associations of Phospholipids With Obesity and Insulin Resistance in Young Adults. J Clin Endocrinol Metab. 2016;101:871-9.

10. Meikle PJ, Wong G, Barlow CK, Weir JM, Greeve MA, MacIntosh GL, et al. Plasma Lipid Profiling Shows Similar Associations with Prediabetes and Type 2 Diabetes. Maya-Monteiro CM, editor. PLoS ONE. 2013;8:e74341-11.

11. Weir JM, Wong G, Barlow CK, Greeve MA, Kowalczyk A, Almasy L, et al. Plasma lipid profiling in a large population-based cohort. J Lipid Res. 2013;54:2898-908.

12. Rhee EP, Cheng S, Larson MG, Walford GA, Lewis GD, McCabe E, et al. Lipid profiling identifies a triacylglycerol signature of insulin resistance and improves diabetes prediction in humans. J Clin Invest. 2011;121:1402-11.

13. Kulkarni H, Meikle PJ, Mamtani M, Weir JM, Almeida M, Diego V, et al. Plasma lipidome is independently associated with variability in metabolic syndrome in Mexican American families. J Lipid Res. 2014;55:939-46.

14. Barber MN, Risis S, Yang C, Meikle PJ, Staples M, Febbraio MA, et al. Plasma Lysophosphatidylcholine Levels Are Reduced in Obesity and Type 2 Diabetes. Waki H, editor. PLoS ONE. 2012;7:e41456-12.

15. Floegel A, Stefan N, Yu Z, Mühlenbruch K, Drogan D, Joost H-G, et al. Identification of serum metabolites associated with risk of type 2 diabetes using a targeted metabolomic approach. Diabetes. 2013;62:639-48. 
16. Pietiläinen KH, Sysi-Aho M, Rissanen A, Seppänen-Laakso T, Yki-Jarvinen H, Kaprio J, et al. Acquired Obesity Is Associated with Changes in the Serum Lipidomic Profile Independent of Genetic Effects - A Monozygotic Twin Study. PLoS ONE. 2007;2:e218-14.

17. Stefan N, Fritsche A, Schick F, Häring H-U. Phenotypes of prediabetes and stratification of cardiometabolic risk. Lancet Diabetes Endocrinol. 2016;4:789-98.

18. Goossens G, Moors C, Jocken J, van der Zijl N, Jans A, Konings E, et al. Altered Skeletal Muscle Fatty Acid Handling in Subjects with Impaired Glucose Tolerance as Compared to Impaired Fasting Glucose. Nutrients. 2016;8:164-15.

19. Bird SR, Hawley JA. Update on the effects of physical activity on insulin sensitivity in humans. BMJ Open Sport Exerc Med. 2016;2:e000143.

20. Zheng J, Woo S-L, Hu X, Botchlett R, Chen L, Huo Y, et al. Metformin and metabolic diseases: a focus on hepatic aspects. Front Med. 2015;9:173-86.

21. Blanco-Rojo R, Alcala-Diaz JF, Wopereis S, Perez-Martinez P, Quintana-Navarro GM, Marin C, et al. The insulin resistance phenotype (muscle or liver) interacts with the type of diet to determine changes in disposition index after 2 years of intervention: the CORDIOPREV-DIAB randomised clinical trial. Diabetologia. 2016;59:67-76.

22. Larsen TM, Dalskov S-M, van Baak M, Jebb SA, Papadaki A, Pfeiffer AFH, et al. Diets with high or low protein content and glycemic index for weight-loss maintenance. N Engl J Med. 2010;363:2102-13.

23. Abdul-Ghani MA, Matsuda M, Balas B, DeFronzo RA. Muscle and liver insulin resistance indexes derived from the oral glucose tolerance test. Diabetes Care. 2007;30:89-94.

24. Forouhi NG, Koulman A, Sharp SJ, Imamura F. Differences in the prospective association between individual plasma phospholipid saturated fatty acids and incident type 2 diabetes: the EPIC-InterAct casecohort study. Lancet Diabetes Endocrinol. 2014;2:810-8.

25. Goossens GH. The Metabolic Phenotype in Obesity: Fat Mass, Body Fat Distribution, and Adipose Tissue Function. Obes Facts. 2017;10:207-15.

26. Wang X, Magkos F, Mittendorfer B. Sex Differences in Lipid and Lipoprotein Metabolism: It's Not Just about Sex Hormones. J Clin Endocrinol Metab. 2011;96:885-93.

27. Ferrannini E, Natali A, Camastra S, Nannipieri M, Mari A, Adam K-P, et al. Early metabolic markers of the development of dysglycemia and type 2 diabetes and their physiological significance. Diabetes. 2013;62:1730-7.

28. Wang-Sattler R, Yu Z, Herder C, Messias AC, Floegel A, He Y, et al. Novel biomarkers for pre-diabetes identified by metabolomics. Mol Syst Biol. 2012;8:615-11.

29. Felder TK, Ring-Dimitriou S, Auer S, Soyal SM, Kedenko L, Rinnerthaler M, et al. Specific circulating phospholipids, acylcarnitines, amino acids and biogenic amines are aerobic exercise markers. J Sci Med Sport. 2017;20:700-5.

30. Klingler C, Zhao X, Adhikary T, Li J, Xu G, Häring H-U, et al. Lysophosphatidylcholines activate PPAR $\delta$ and protect human skeletal muscle cells from lipotoxicity. Biochim Biophys Acta. 2016;1861:1980-92.

31. Rzehak P, Hellmuth C, Uhl O, Kirchberg FF, Peissner W, Harder U, et al. Rapid Growth and Childhood Obesity Are Strongly Associated with LysoPC(14:0). Ann Nutr Metab. 2014;64:294-303.

32. Kim JY, Park JY, Kim OY, Ham BM, Kim H-J, Kwon DY, et al. Metabolic profiling of plasma in overweight/obese and lean men using ultra performance liquid chromatography and Q-TOF mass spectrometry (UPLC-Q-TOF MS). J Proteome Res. 2010;9:4368-75. 
33. Magkos F, Patterson BW, Mohammed BS, Klein S, Mittendorfer B. Women produce fewer but triglyceride-richer very low-density lipoproteins than men. J Clin Endocrinol Metab. 2007;92:1311-8.

34. Sparks JD, Sparks CE, Adeli K. Selective hepatic insulin resistance, VLDL overproduction, and hypertriglyceridemia. Arterioscler Thromb Vasc Biol. 2012;32:2104-12.

35. Magkos F, Fabbrini E, Mohammed BS, Patterson BW, Klein S, Mittendorfer B. Estrogen Deficiency after Menopause Does Not Result in Male Very-Low-Density Lipoprotein Metabolism Phenotype. J Clin Endocrinol Metab. 2010;95:3377-84.

36. Santaren ID, Watkins SM, Liese AD, Wagenknecht LE, Rewers MJ, Haffner SM, et al. Serum pentadecanoic acid (15:0), a short-term marker of dairy food intake, is inversely associated with incident type 2 diabetes and its underlying disorders. Am J Clin Nutr. 2014;100:1532-40.

37. Yilmaz M, Claiborn KC, Hotamisligil GS. De Novo Lipogenesis Products and Endogenous Lipokines. Diabetes. 2016;65:1800-7.

38. Weijers RNM. Lipid composition of cell membranes and its relevance in type 2 diabetes mellitus. Curr Diabetes Rev. 2012;8:390-400.

39. Holman RT, Adams CE, Nelson RA, GRATER S, JASKIEWICZ JA, JOHNSON SB, et al. Patients with Anorexia-Nervosa Demonstrate Deficiencies of Selected Essential Fatty-Acids, Compensatory Changes in Nonessential Fatty-Acids and Decreased Fluidity of Plasma-Lipids. J Nutr. 1995;125:901-7.

40. Andersson A, Nälsén C, Tengblad S, Vessby B. Fatty acid composition of skeletal muscle reflects dietary fat composition in humans. Am J Clin Nutr. 2002;76:1222-9. 


\section{Supplementary Data}

Table S1. Overview of measured lipid species and within lipid class abundance.

\begin{tabular}{|c|c|}
\hline Lipid species & Abundance (\%) \\
\hline \multicolumn{2}{|l|}{ Triacylglycerol } \\
\hline$\%$ TAG (46:2) & $0.19 \pm 0.13$ \\
\hline \% TAG (48:0) & $1.18 \pm 0.59$ \\
\hline$\%$ TAG (48:1) & $2.21 \pm 1.19$ \\
\hline \% TAG (48:2) & $1.27 \pm 0.63$ \\
\hline$\%$ TAG (48:3) & $0.28 \pm 0.14$ \\
\hline \% TAG (48:4) & $0.08 \pm 0.04$ \\
\hline \% TAG (50:0) & $0.92 \pm 0.46$ \\
\hline$\%$ TAG $(50: 1)$ & $6.86 \pm 2.03$ \\
\hline$\%$ TAG $(50: 2)$ & $7.66 \pm 1.87$ \\
\hline \% TAG (50:3) & $2.76 \pm 0.83$ \\
\hline \% TAG (50:4) & $0.42 \pm 0.17$ \\
\hline \% TAG (50:5) & $0.16 \pm 0.06$ \\
\hline \% TAG (51:1) & $0.45 \pm 0.19$ \\
\hline$\%$ TAG (51:2) & $0.17 \pm 0.07$ \\
\hline \% TAG (51:3) & $0.29 \pm 0.08$ \\
\hline \% TAG (51:4) & $0.10 \pm 0.03$ \\
\hline$\%$ TAG $(52: 0)$ & $0.16 \pm 0.08$ \\
\hline \% TAG (52:1) & $3.23 \pm 1.20$ \\
\hline$\%$ TAG (52:2) & $18.64 \pm 3.20$ \\
\hline$\%$ TAG (52:3) & $16.95 \pm 2.83$ \\
\hline \% TAG (52:4) & $6.37 \pm 2.57$ \\
\hline \% TAG (52:5) & $0.91 \pm 0.35$ \\
\hline \% TAG (52:6) & $0.13 \pm 0.05$ \\
\hline$\%$ TAG (53:1) & $0.63 \pm 0.21$ \\
\hline$\%$ TAG (54:0) & $0.06 \pm 0.03$ \\
\hline \% TAG (54:0) & $0.10 \pm 0.05$ \\
\hline$\%$ TAG $(54: 1)$ & $0.22 \pm 0.14$ \\
\hline$\%$ TAG (54:2) & $2.88 \pm 0.75$ \\
\hline \% TAG (54:3) & $6.57 \pm 1.59$ \\
\hline \% TAG (54:4) & $5.22 \pm 1.46$ \\
\hline$\%$ TAG (54:5) & $3.03 \pm 1.14$ \\
\hline$\%$ TAG (54:6) & $1.09 \pm 0.46$ \\
\hline$\%$ TAG (54:7) & $0.28 \pm 0.15$ \\
\hline \% TAG (55:1) & $0.13 \pm 0.06$ \\
\hline \% TAG (55:2) & $2.11 \pm 0.63$ \\
\hline$\%$ TAG (55:3) & $2.12 \pm 0.62$ \\
\hline$\%$ TAG $(56: 1)$ & $0.04 \pm 0.02$ \\
\hline \% TAG (56:2) & $0.09 \pm 0.05$ \\
\hline$\%$ TAG (56:3) & $0.25 \pm 0.09$ \\
\hline
\end{tabular}

\begin{tabular}{|c|c|}
\hline Lipid species & Abundance (\%) \\
\hline \% TAG (56:4) & $0.15 \pm 0.05$ \\
\hline$\%$ TAG (56:5) & $0.33 \pm 0.10$ \\
\hline$\%$ TAG $(56: 6)$ & $1.15 \pm 0.27$ \\
\hline$\%$ TAG $(56: 7)$ & $1.08 \pm 0.47$ \\
\hline \% TAG (56:8) & $0.41 \pm 0.28$ \\
\hline$\%$ TAG $(57: 1)$ & $0.03 \pm 0.02$ \\
\hline$\%$ TAG $(57: 2)$ & $0.11 \pm 0.04$ \\
\hline$\%$ TAG $(58: 1)$ & $0.03 \pm 0.02$ \\
\hline$\%$ TAG $(58: 2)$ & $0.03 \pm 0.02$ \\
\hline$\%$ TAG $(58: 3)$ & $0.03 \pm 0.03$ \\
\hline$\%$ TAG $(58: 6)$ & $0.12 \pm 0.04$ \\
\hline \% TAG (58:8) & $0.16 \pm 0.12$ \\
\hline \% TAG (58:9) & $0.11 \pm 0.10$ \\
\hline$\%$ TAG $(58: 10)$ & $0.05 \pm 0.05$ \\
\hline \% TAG (59:0) & $0.01 \pm 0.01$ \\
\hline$\%$ TAG $(60: 2)$ & $0.01 \pm 0.01$ \\
\hline \multicolumn{2}{|l|}{ Diacylglycerol } \\
\hline \% DAG (36:2) & $55.87 \pm 8.35$ \\
\hline \% DAG (36:3) & $44.13 \pm 8.35$ \\
\hline \multicolumn{2}{|l|}{ Sphingomyelin } \\
\hline$\%$ SM (d18:1/14:0) & $2.07 \pm 0.39$ \\
\hline$\%$ SM (d18:1/15:0) & $1.05 \pm 0.19$ \\
\hline \% SM (d18:1/16:0) & $26.75 \pm 1.65$ \\
\hline$\%$ SM (d18:1/16:1) & $3.45 \pm 0.42$ \\
\hline \% SM (d18:1/17:0) & $0.70 \pm 0.13$ \\
\hline \% SM (d18:1/18:0) & $5.27 \pm 0.76$ \\
\hline \% SM (d18:1/18:1) & $2.30 \pm 0.41$ \\
\hline \% SM (d18:1/18:2) & $0.32 \pm 0.06$ \\
\hline \% SM (d18:1/20:0) & $2.28 \pm 0.52$ \\
\hline$\% \mathrm{SM}(\mathrm{d} 18: 1 / 20: 1)$ & $1.20 \pm 0.20$ \\
\hline \% SM (d18:1/21:0) & $1.27 \pm 0.23$ \\
\hline$\% \mathrm{SM}(\mathrm{d} 18: 1 / 22: 0)$ & $9.91 \pm 1.21$ \\
\hline$\%$ SM (d18:1/22:1) & $5.79 \pm 0.53$ \\
\hline \% SM (d18:1/23:0) & $4.04 \pm 0.58$ \\
\hline$\% \mathrm{SM}(\mathrm{d} 18: 1 / 23: 1)$ & $2.44 \pm 0.34$ \\
\hline$\%$ SM (d18:0/24:0) & $5.92 \pm 1.08$ \\
\hline \% SM (d18:0/24:1) & $17.81 \pm 1.88$ \\
\hline$\%$ SM (d18:0/24:2) & $6.85 \pm 0.96$ \\
\hline \% SM (d18:0/25:0) & $0.17 \pm 0.05$ \\
\hline \% SM (d18:0/25:1) & $0.44 \pm 0.16$ \\
\hline
\end{tabular}


Table S1. Continued

\begin{tabular}{|c|c|}
\hline Lipid species & Abundance (\%) \\
\hline \multicolumn{2}{|c|}{ Phosphatidylethanolamine } \\
\hline$\% \operatorname{PE}(38: 2)$ & $72.63 \pm 10.55$ \\
\hline$\% \operatorname{PE}(38: 4)$ & $7.24 \pm 2.84$ \\
\hline$\% \operatorname{PE}(38: 6)$ & $20.13 \pm 8.75$ \\
\hline \multicolumn{2}{|c|}{ Alkyl-phosphatidylethanolamine } \\
\hline$\% \mathrm{PE}(\mathrm{O}-36: 5)$ & $33.52 \pm 3.51$ \\
\hline$\% \mathrm{PE}(\mathrm{O}-38: 5)$ & $45.52 \pm 5.08$ \\
\hline$\% \mathrm{PE}(\mathrm{O}-38: 7)$ & $20.96 \pm 4.91$ \\
\hline \multicolumn{2}{|c|}{ Alkyl-lysophosphatidylcholine } \\
\hline$\% \operatorname{LPC}(\mathrm{O}-16: 1 / 0: 0)$ & $59.91 \pm 4.99$ \\
\hline$\% \operatorname{LPC}(\mathrm{O}-18: 1 / 0: 0)$ & $40.09 \pm 4.99$ \\
\hline \multicolumn{2}{|c|}{ Lysophosphatidylcholine } \\
\hline$\% \operatorname{LPC}(14: 0 / 0: 0)$ & $0.39 \pm 0.14$ \\
\hline$\% \operatorname{LPC}(16: 0 / 0: 0)$ & $49.27 \pm 3.36$ \\
\hline$\% \operatorname{LPC}(16: 1 / 0: 0)$ & $0.82 \pm 0.23$ \\
\hline$\% \operatorname{LPC}(18: 0 / 0: 0)$ & $20.92 \pm 2.54$ \\
\hline$\% \operatorname{LPC}(18: 1 / 0: 0)$ & $9.94 \pm 1.64$ \\
\hline$\% \operatorname{LPC}(18: 2 / 0: 0)$ & $13.49 \pm 2.85$ \\
\hline$\% \operatorname{LPC}(18: 3 / 0: 0)$ & $0.22 \pm 0.09$ \\
\hline$\% \operatorname{LPC}(20: 3 / 0: 0)$ & $0.84 \pm 0.24$ \\
\hline$\% \operatorname{LPC}(20: 4 / 0: 0)$ & $3.07 \pm 0.65$ \\
\hline$\% \operatorname{LPC}(20: 5 / 0: 0)$ & $0.28 \pm 0.20$ \\
\hline$\% \operatorname{LPC}(22: 6 / 0: 0)$ & $0.77 \pm 0.25$ \\
\hline \multicolumn{2}{|l|}{ Phosphatidylcholine } \\
\hline$\% \operatorname{PC}(32: 0)$ & $0.78 \pm 0.10$ \\
\hline$\% \mathrm{PC}(32: 1)$ & $0.91 \pm 0.45$ \\
\hline$\% \mathrm{PC}(32: 2)$ & $0.22 \pm 0.07$ \\
\hline$\% \mathrm{PC}(34: 0)$ & $0.73 \pm 0.12$ \\
\hline$\% \mathrm{PC}(34: 1)$ & $13.74 \pm 2.45$ \\
\hline$\%$ PC (34:2) & $25.32 \pm 3.03$ \\
\hline$\%$ PC (34:3) & $0.73 \pm 0.19$ \\
\hline$\%$ PC (34:4) & $0.06 \pm 0.02$ \\
\hline$\% \operatorname{PC}(36: 1)$ & $2.59 \pm 0.68$ \\
\hline$\%$ PC (36:2) & $14.35 \pm 2.25$ \\
\hline$\% \operatorname{PC}(36: 3)$ & $8.58 \pm 1.20$ \\
\hline$\% \mathrm{PC}(36: 4)$ & $12.42 \pm 2.09$ \\
\hline
\end{tabular}

\begin{tabular}{ll}
\hline Lipid species & Abundance (\%) \\
\hline \% PC (36:5) & $1.14 \pm 0.73$ \\
\% PC (36:6) & $0.02 \pm 0.01$ \\
\% PC (38:2) & $0.22 \pm 0.04$ \\
\% PC (38:3) & $2.68 \pm 0.68$ \\
\% PC (38:4) & $6.37 \pm 1.49$ \\
\% PC (38:5) & $2.72 \pm 0.50$ \\
\% PC (38:6) & $4.21 \pm 1.26$ \\
\% PC (38:7) & $0.02 \pm 0.02$ \\
\% PC (40:4) & $0.13 \pm 0.05$ \\
\% PC (40:5) & $0.38 \pm 0.10$ \\
\% PC (40:6) & $1.52 \pm 0.50$ \\
\% PC (40:7) & $0.13 \pm 0.04$ \\
\% PC (40:8) & $0.04 \pm 0.01$ \\
\hline Alkyl-phosphatidylcholine & \\
\% PC (O-34:1) & $7.01 \pm 1.32$ \\
\% PC (O-34:2) & $4.5 \pm 1.10$ \\
\% PC (O-34:3) & $10.79 \pm 2.37$ \\
\% PC (O-36:2) & $2.41 \pm 0.54$ \\
\% PC (O-36:3) & $6.06 \pm 1.23$ \\
\% PC (O-36:4) & $20.27 \pm 2.73$ \\
\% PC (O-36:5) & $14.97 \pm 2.35$ \\
\% PC (O-36:6) & $0.71 \pm 0.48$ \\
\% PC (O-38:4) & $7.36 \pm 1.30$ \\
\% PC (O-38:5) & $16.29 \pm 2.09$ \\
\% PC (O-38:6) & $3.35 \pm 0.56$ \\
\% PC (O-38:7) & $1.82 \pm 0.56$ \\
\% PC (O-40:6) & $1.00 \pm 0.34$ \\
\% PC (O-42:6) (O-44:5) & $0.48 \pm 0.22$ \\
\hline Cholesterol ester & $2.96 \pm 0.73$ \\
\% CholE02 & \\
\% CholE05 & $56.84 \pm 6.45$ \\
\hline LPE (18:0/0:0) & $25.75 \pm 4.45$ \\
\hline
\end{tabular}

Data are mean $\pm \mathrm{SD}$ 
Table S2. Participants' characteristics of tissue-specific IR groups

\begin{tabular}{lccccc}
\hline & no IR & muscle-IR \\
$\mathbf{n = 3 2 5}$ & $\mathbf{n}=\mathbf{1 0 8}$ & $\begin{array}{c}\text { Liver-IR } \\
\mathbf{n}=\mathbf{9 9}\end{array}$ & $\begin{array}{c}\text { muscle/liver-IR } \\
\mathbf{n = 1 0 8}\end{array}$ & $p$ \\
\hline Age (y) & $41 \pm 6$ & $41 \pm 6$ & $41 \pm 6$ & $42 \pm 6$ & 0.990 \\
Sex $(\%$ women) & 67.4 & 78.7 & 40.4 & 52.8 & $<0.001$ \\
BMI $\left(\mathrm{kg} / \mathrm{m}^{2}\right)$ & $34.0 \pm 4.8$ & $34.6 \pm 4.6$ & $34.9 \pm 4.7$ & $35.3 \pm 4.7$ & 0.078 \\
Waist-hip ratio & $0.91 \pm 0.09$ & $0.91 \pm 0.09$ & $0.96 \pm 0.08$ & $0.97 \pm 0.09$ & $<0.001$ \\
TAG $(\mathrm{mmol} / \mathrm{l})$ & $1.27 \pm 0.62$ & $1.33 \pm 0.60$ & $1.54 \pm 0.66$ & $1.59 \pm 0.65$ & $<0.001$ \\
NEFA $(\mu \mathrm{mol} / \mathrm{l})$ & $635 \pm 306$ & $658 \pm 303$ & $664 \pm 403$ & $627 \pm 345$ & 0.818 \\
Glucose $(\mathrm{mmol} / \mathrm{l})$ & $5.0 \pm 0.6$ & $5.1 \pm 0.6$ & $5.3 \pm 0.6$ & $5.3 \pm 0.6$ & $<0.001$ \\
Insulin $(\mathrm{mU} / \mathrm{L})$ & $8.3 \pm 4.5$ & $11.0 \pm 4.4$ & $13.6 \pm 5.5$ & $18.5 \pm 9.6$ & $<0.001$ \\
HOMA-IR $(\mathrm{AU})$ & $2.2 \pm 1.3$ & $2.9 \pm 1.4$ & $4.1 \pm 2.3$ & $5.0 \pm 2.7$ & $<0.001$ \\
MISI (AU) & $0.08 \pm 0.06$ & $0.02 \pm 0.01$ & $0.06 \pm 0.03$ & $0.02 \pm 0.01$ & $<0.001$ \\
HIRI (AU) & $26.1 \pm 5.3$ & $28.5 \pm 4.7$ & $43.6 \pm 8.6$ & $46.2 \pm 9.3$ & $<0.001$ \\
\hline
\end{tabular}

Data are mean \pm SD unless otherwise indicated. Differences between tissue-specific IR groups were assessed using one-way ANOVA. HDL: high-density lipoprotein; LDL: low-density lipoprotein; NEFA: non-esterified fatty acids; MISI: muscle insulin sensitivity index; HIRI: hepatic insulin resistance index;

Table S3. $p$-values of sex interactions of MISI and HIRI with sum scores, TAG composition and individual lipid species

\begin{tabular}{lll}
\hline Lipid species & MISI $p$ & HIRI $p$ \\
\hline Sum Scores & & \\
TAG & 0.440 & 0.006 \\
DAG & 0.781 & 0.019 \\
SM & 0.689 & 0.332 \\
PE & 0.209 & 0.042 \\
PE(O-) & 0.528 & 0.691 \\
LPC(O-) & 0.315 & 0.597 \\
LPC & 0.498 & 0.648 \\
PC & 0.829 & 0.226 \\
PC(O-) & 0.865 & 0.773 \\
CE & 0.329 & 0.704 \\
\hline TAG composition & & \\
odd/even TAG ratio & 0.855 & 0.283 \\
very-long/long TAG ratio & 0.138 & 0.156 \\
saturated TAG & 0.237 & 0.355 \\
unsaturated TAG & 0.138 & 0.026 \\
polyunsaturated TAG & 0.146 & 0.092 \\
\hline Individual lipid species & & \\
TAG (46:2) & 0.068 & 0.007 \\
TAG (48:0) & 0.115 & 0.006 \\
TAG (48:1) & 0.304 & 0.005 \\
TAG (48:2) & 0.366 & 0.013 \\
TAG (48:3) & 0.315 & 0.024 \\
TAG (48:4) & 0.129 & 0.150 \\
TAG (50:0) & 0.243 & 0.008 \\
TAG (50:1) & 0.251 & 0.001 \\
\hline
\end{tabular}

\begin{tabular}{lcc}
\hline Lipid species & MISI $p$ & HIRI $p$ \\
\hline TAG (50:2) & 0.536 & 0.009 \\
TAG (50:3) & 0.757 & 0.046 \\
TAG (50:4) & 0.813 & 0.114 \\
TAG (50:5) & 0.359 & 0.101 \\
TAG (51:1) & 0.313 & 0.002 \\
TAG (51:2) & 0.374 & 0.011 \\
TAG (51:3) & 0.729 & 0.020 \\
TAG (51:4) & 0.899 & 0.054 \\
TAG (52:0) & 0.384 & 0.052 \\
TAG (52:1) & 0.309 & 0.002 \\
TAG (52:2) & 0.327 & 0.001 \\
TAG (52:3) & 0.440 & 0.009 \\
TAG (52:4) & 0.957 & 0.197 \\
TAG (52:5) & 0.970 & 0.293 \\
TAG (52:6) & 0.734 & 0.508 \\
TAG (53:1) & 0.132 & 0.002 \\
TAG (54:0) & 0.277 & 0.599 \\
TAG (54:0) & 0.914 & 0.911 \\
TAG (54:1) & 0.468 & 0.019 \\
TAG (54:2) & 0.503 & 0.005 \\
TAG (54:3) & 0.876 & 0.018 \\
TAG (54:4) & 0.883 & 0.129 \\
TAG (54:5) & 0.726 & 0.373 \\
TAG (54:6) & 0.726 & 0.429 \\
TAG (54:7) & 0.529 & 0.541 \\
TAG (55:1) & 0.164 & 0.011 \\
\hline
\end{tabular}


Table S3. Continued

\begin{tabular}{|c|c|c|}
\hline Lipid species & MISI $p$ & HIRI $p$ \\
\hline TAG (55:2) & 0.325 & 0.001 \\
\hline TAG (55:3) & 0.552 & 0.021 \\
\hline TAG $(56: 1)$ & 0.392 & 0.067 \\
\hline TAG $(56: 2)$ & 0.531 & 0.051 \\
\hline TAG $(56: 3)$ & 0.993 & 0.067 \\
\hline TAG (56:4) & 0.580 & 0.203 \\
\hline TAG (56:5) & 0.547 & 0.018 \\
\hline TAG $(56: 6)$ & 0.787 & 0.154 \\
\hline TAG (56:7) & 0.771 & 0.114 \\
\hline TAG $(56: 8)$ & 0.737 & 0.193 \\
\hline TAG $(57: 1)$ & 0.668 & 0.563 \\
\hline TAG $(57: 2)$ & 0.676 & 0.975 \\
\hline TAG $(58: 1)$ & 0.344 & 0.004 \\
\hline TAG $(58: 2)$ & 0.375 & 0.044 \\
\hline TAG (58:3) & 0.663 & 0.616 \\
\hline TAG (58:6) & 0.306 & 0.101 \\
\hline TAG (58:8) & 0.634 & 0.296 \\
\hline TAG (58:9) & 0.793 & 0.116 \\
\hline TAG $(58: 10)$ & 0.493 & 0.429 \\
\hline TAG (59:0) & 0.426 & 0.774 \\
\hline TAG $(60: 2)$ & 0.135 & 0.105 \\
\hline DAG (36:2) & 0.605 & 0.005 \\
\hline DAG (36:3) & 0.889 & 0.069 \\
\hline SM (d18:1/14:0) & 0.982 & 0.026 \\
\hline $\mathrm{SM}(\mathrm{d} 18: 1 / 15: 0)$ & 0.907 & 0.048 \\
\hline $\mathrm{SM}(\mathrm{d} 18: 1 / 16: 0)$ & 0.836 & 0.492 \\
\hline $\mathrm{SM}(\mathrm{d} 18: 1 / 16: 1)$ & 0.451 & 0.901 \\
\hline $\mathrm{SM}(\mathrm{d} 18: 1 / 17: 0)$ & 0.556 & 0.304 \\
\hline $\mathrm{SM}(\mathrm{d} 18: 1 / 18: 0)$ & 0.209 & 0.643 \\
\hline $\mathrm{SM}(\mathrm{d} 18: 1 / 18: 1)$ & 0.091 & 0.640 \\
\hline $\mathrm{SM}(\mathrm{d} 18: 1 / 18: 2)$ & 0.875 & 0.691 \\
\hline $\mathrm{SM}(\mathrm{d} 18: 1 / 20: 0)$ & 0.612 & 0.033 \\
\hline $\mathrm{SM}(\mathrm{d} 18: 1 / 20: 1)$ & 0.022 & 0.141 \\
\hline $\mathrm{SM}(\mathrm{d} 18: 1 / 21: 0)$ & 0.926 & 0.007 \\
\hline $\mathrm{SM}(\mathrm{d} 18: 1 / 22: 0)$ & 0.949 & 0.030 \\
\hline $\mathrm{SM}(\mathrm{d} 18: 1 / 22: 1)$ & 0.424 & 0.542 \\
\hline $\mathrm{SM}(\mathrm{d} 18: 1 / 23: 0)$ & 0.539 & 0.004 \\
\hline $\mathrm{SM}(\mathrm{d} 18: 1 / 23: 1)$ & 0.862 & 0.272 \\
\hline $\mathrm{SM}(\mathrm{d} 18: 0 / 24: 0)$ & 0.665 & 0.098 \\
\hline $\mathrm{SM}(\mathrm{d} 18: 0 / 24: 1)$ & 0.808 & 0.804 \\
\hline $\mathrm{SM}(\mathrm{d} 18: 0 / 24: 2)$ & 0.424 & 0.200 \\
\hline $\mathrm{SM}(\mathrm{d} 18: 0 / 25: 0)$ & 0.421 & 0.072 \\
\hline $\mathrm{SM}(\mathrm{d} 18: 0 / 25: 1)$ & 0.257 & 0.551 \\
\hline $\mathrm{PE}(38: 2)$ & 0.595 & 0.479 \\
\hline PE (38:4) & 0.495 & 0.086 \\
\hline PE (38:6) & 0.247 & 0.011 \\
\hline $\mathrm{PE}(\mathrm{O}-36: 5)$ & 0.795 & 0.612 \\
\hline $\mathrm{PE}(\mathrm{O}-38: 5)$ & 0.336 & 0.652 \\
\hline
\end{tabular}

\begin{tabular}{|c|c|c|}
\hline Lipid species & MISI $p$ & HIRI $p$ \\
\hline $\mathrm{PE}(\mathrm{O}-38: 7)$ & 0.830 & 0.684 \\
\hline LPC (O-16:1/0:0) & 0.307 & 0.405 \\
\hline LPC (O-18:1/0:0) & 0.330 & 0.832 \\
\hline LPC (14:0/0:0) & 0.968 & 0.266 \\
\hline LPC (16:0/0:0) & 0.886 & 0.235 \\
\hline LPC (16:1/0:0) & 0.470 & 0.670 \\
\hline LPC (18:0/0:0) & 0.305 & 0.801 \\
\hline LPC (18:1/0:0) & 0.339 & 0.791 \\
\hline LPC (18:2/0:0) & 0.528 & 0.468 \\
\hline LPC (18:3/0:0) & 0.870 & 0.995 \\
\hline LPC (20:3/0:0) & 0.854 & 0.579 \\
\hline $\operatorname{LPC}(20: 4 / 0: 0)$ & 0.328 & 0.747 \\
\hline $\operatorname{LPC}(20: 5 / 0: 0)$ & 0.224 & 0.617 \\
\hline $\operatorname{LPC}(22: 6 / 0: 0)$ & 0.672 & 0.574 \\
\hline $\mathrm{PC}(32: 0)$ & 0.912 & 0.232 \\
\hline PC (32:1) & 0.736 & 0.328 \\
\hline PC (32:2) & 0.644 & 0.289 \\
\hline PC (34:0) & 0.823 & 0.610 \\
\hline PC (34:1) & 0.627 & 0.127 \\
\hline PC (34:2) & 0.232 & 0.328 \\
\hline PC (34:3) & 0.476 & 0.440 \\
\hline PC (34:4) & 0.480 & 0.310 \\
\hline PC (36:1) & 0.511 & 0.556 \\
\hline PC (36:2) & 0.896 & 0.915 \\
\hline PC (36:3) & 0.460 & 0.086 \\
\hline PC (36:4) & 0.898 & 0.316 \\
\hline $\mathrm{PC}(36: 5)$ & 0.568 & 0.165 \\
\hline PC (36:6) & 0.995 & 0.234 \\
\hline PC (38:2) & 0.963 & 0.193 \\
\hline PC (38:3) & 0.917 & 0.019 \\
\hline PC (38:4) & 0.129 & 0.604 \\
\hline PC (38:5) & 0.378 & 0.881 \\
\hline PC (38:6) & 0.763 & 0.230 \\
\hline PC (38:7) & 0.719 & 0.522 \\
\hline PC (40:4) & 0.457 & 0.676 \\
\hline PC (40:5) & 0.131 & 0.637 \\
\hline PC (40:6) & 0.476 & 0.411 \\
\hline PC (40:7) & 0.743 & 0.784 \\
\hline PC (40:8) & 0.285 & 0.103 \\
\hline$\overline{\mathrm{PC}}(\mathrm{O}-34: 1)$ & 0.356 & 0.734 \\
\hline $\mathrm{PC}(\mathrm{O}-34: 2)$ & 0.915 & 0.452 \\
\hline $\mathrm{PC}(\mathrm{O}-34: 3)$ & 0.138 & 0.839 \\
\hline $\mathrm{PC}(\mathrm{O}-36: 2)$ & 0.925 & 0.824 \\
\hline $\mathrm{PC}(\mathrm{O}-36: 3)$ & 0.964 & 0.839 \\
\hline $\mathrm{PC}(\mathrm{O}-36: 4)$ & 0.604 & 0.895 \\
\hline $\mathrm{PC}(\mathrm{O}-36: 5)$ & 0.350 & 0.846 \\
\hline PC (O-36:6) & 0.326 & 0.310 \\
\hline $\mathrm{PC}(\mathrm{O}-38: 4)$ & 0.223 & 0.611 \\
\hline
\end{tabular}


Table S3. Continued

\begin{tabular}{ccc}
\hline Lipid species & MISI $p$ & HIRI $p$ \\
\hline PC (O-38:5) & 0.341 & 0.583 \\
PC (O-38:6) & 0.707 & 0.321 \\
PC (O-38:7) & 0.221 & 0.361 \\
PC (O-40:6) & 0.847 & 0.349 \\
PC (O-42:6) & 0.192 & 0.351
\end{tabular}

\begin{tabular}{lcc}
\hline Lipid species & MISI $p$ & HIRI $p$ \\
\hline PC (O-44:5) & 0.074 & 0.069 \\
\hline CholE02 & 0.668 & 0.787 \\
CholE05 & 0.224 & 0.625 \\
CholE06 & 0.524 & 0.979 \\
\hline LPE (18:0/0:0) & 0.308 & 0.054
\end{tabular}

Linear mixed model analyses were performed with plasma lipid species as the dependent variable (per-lipid analyses), MISI or HIRI, sex, and sex $\cdot$ MISI or sex $\cdot$ HIRI as fixed effect and study center as random effect. BMI, waist-to-hip ratio, and HIRI or MISI (as applicable) were included as covariates. Nominal $p<0.05$ was considered significant.

Table S4. Associations of MISI with individual lipid species

\begin{tabular}{|c|c|c|c|}
\hline Lipid species & Std $-\beta \pm S E$ & $p$ & FDR $p$ \\
\hline \multicolumn{4}{|l|}{ Sum Scores } \\
\hline TAG & $-0.061 \pm 0.041$ & 0.143 & 0.561 \\
\hline DAG & $-0.057 \pm 0.043$ & 0.192 & 0.561 \\
\hline SM & $0.036 \pm 0.045$ & 0.427 & 0.561 \\
\hline $\mathrm{PE}$ & $-0.031 \pm 0.045$ & 0.486 & 0.561 \\
\hline $\mathrm{PE}(\mathrm{O}-)$ & $0.048 \pm 0.044$ & 0.273 & 0.561 \\
\hline $\mathrm{LPC}(\mathrm{O}-)$ & $0.096 \pm 0.041$ & 0.019 & 0.142 \\
\hline LPC & $0.126 \pm 0.041$ & 0.002 & 0.032 \\
\hline PC & $-0.046 \pm 0.045$ & 0.303 & 0.561 \\
\hline $\mathrm{PC}(\mathrm{O}-)$ & $0.032 \pm 0.043$ & 0.451 & 0.561 \\
\hline $\mathrm{CE}$ & $0.009 \pm 0.045$ & 0.846 & 0.846 \\
\hline \multicolumn{4}{|l|}{ TAG composition } \\
\hline odd/even TAG ratio & $0.043 \pm 0.042$ & 0.306 & 0.561 \\
\hline very-long/long TAG ratio & $-0.053 \pm 0.045$ & 0.241 & 0.561 \\
\hline saturated TAG & $-0.009 \pm 0.044$ & 0.843 & 0.846 \\
\hline unsaturated TAG & $0.030 \pm 0.037$ & 0.417 & 0.561 \\
\hline polyunsaturated TAG & $-0.031 \pm 0.039$ & 0.438 & 0.561 \\
\hline \multicolumn{4}{|l|}{ Individual lipids } \\
\hline TAG (46:2) & $-0.033 \pm 0.042$ & 0.435 & 0.700 \\
\hline TAG (48:0) & $-0.052 \pm 0.041$ & 0.206 & 0.458 \\
\hline TAG (48:1) & $-0.066 \pm 0.040$ & 0.098 & 0.365 \\
\hline TAG (48:2) & $-0.061 \pm 0.041$ & 0.140 & 0.378 \\
\hline TAG (48:3) & $-0.051 \pm 0.042$ & 0.217 & 0.473 \\
\hline TAG (48:4) & $-0.006 \pm 0.046$ & 0.889 & 0.965 \\
\hline TAG (50:0) & $-0.042 \pm 0.040$ & 0.293 & 0.556 \\
\hline TAG (50:1) & $-0.060 \pm 0.039$ & 0.121 & 0.365 \\
\hline TAG (50:2) & $-0.057 \pm 0.041$ & 0.162 & 0.398 \\
\hline TAG (50:3) & $-0.075 \pm 0.042$ & 0.074 & 0.365 \\
\hline TAG (50:4) & $-0.071 \pm 0.041$ & 0.084 & 0.365 \\
\hline TAG (50:5) & $-0.038 \pm 0.042$ & 0.367 & 0.656 \\
\hline TAG (51:1) & $-0.062 \pm 0.039$ & 0.112 & 0.365 \\
\hline TAG (51:2) & $-0.062 \pm 0.041$ & 0.134 & 0.376 \\
\hline TAG (51:3) & $-0.069 \pm 0.042$ & 0.105 & 0.365 \\
\hline TAG (51:4) & $-0.077 \pm 0.043$ & 0.070 & 0.365 \\
\hline
\end{tabular}

\begin{tabular}{|c|c|c|c|}
\hline Lipid species & Std $-\beta \pm S E$ & $p$ & FDR $p$ \\
\hline TAG (52:0) & $-0.013 \pm 0.040$ & 0.740 & 0.901 \\
\hline TAG $(52: 1)$ & $-0.060 \pm 0.038$ & 0.113 & 0.365 \\
\hline TAG $(52: 2)$ & $-0.028 \pm 0.039$ & 0.468 & 0.725 \\
\hline TAG $(52: 3)$ & $-0.048 \pm 0.043$ & 0.264 & 0.536 \\
\hline TAG $(52: 4)$ & $-0.078 \pm 0.041$ & 0.059 & 0.365 \\
\hline TAG (52:5) & $-0.081 \pm 0.041$ & 0.051 & 0.365 \\
\hline TAG (52:6) & $-0.061 \pm 0.041$ & 0.140 & 0.378 \\
\hline TAG $(53: 1)$ & $-0.065 \pm 0.040$ & 0.109 & 0.365 \\
\hline TAG $(54: 0)$ & $0.039 \pm 0.045$ & 0.387 & 0.657 \\
\hline TAG $(54: 0)$ & $0.041 \pm 0.044$ & 0.352 & 0.641 \\
\hline TAG $(54: 1)$ & $-0.040 \pm 0.038$ & 0.294 & 0.556 \\
\hline TAG $(54: 2)$ & $-0.033 \pm 0.038$ & 0.386 & 0.657 \\
\hline TAG $(54: 3)$ & $-0.003 \pm 0.041$ & 0.946 & 0.978 \\
\hline TAG $(54: 4)$ & $-0.016 \pm 0.043$ & 0.706 & 0.901 \\
\hline TAG $(54: 5)$ & $-0.054 \pm 0.042$ & 0.196 & 0.443 \\
\hline TAG (54:6) & $-0.081 \pm 0.042$ & 0.052 & 0.365 \\
\hline TAG $(54: 7)$ & $-0.075 \pm 0.042$ & 0.079 & 0.365 \\
\hline TAG $(55: 1)$ & $-0.071 \pm 0.037$ & 0.058 & 0.365 \\
\hline TAG $(55: 2)$ & $-0.014 \pm 0.042$ & 0.738 & 0.901 \\
\hline TAG $(55: 3)$ & $-0.046 \pm 0.045$ & 0.304 & 0.560 \\
\hline TAG $(56: 1)$ & $-0.027 \pm 0.041$ & 0.511 & 0.770 \\
\hline TAG $(56: 2)$ & $-0.015 \pm 0.039$ & 0.704 & 0.901 \\
\hline TAG $(56: 3)$ & $-0.004 \pm 0.041$ & 0.914 & 0.971 \\
\hline TAG $(56: 4)$ & $-0.032 \pm 0.042$ & 0.443 & 0.706 \\
\hline TAG (56:5) & $-0.068 \pm 0.041$ & 0.097 & 0.365 \\
\hline TAG $(56: 6)$ & $-0.059 \pm 0.042$ & 0.158 & 0.398 \\
\hline TAG $(56: 7)$ & $-0.097 \pm 0.042$ & 0.022 & 0.329 \\
\hline TAG (56:8) & $-0.110 \pm 0.044$ & 0.012 & 0.329 \\
\hline TAG $(57: 1)$ & $-0.080 \pm 0.045$ & 0.074 & 0.365 \\
\hline TAG $(57: 2)$ & $-0.089 \pm 0.045$ & 0.048 & 0.365 \\
\hline TAG (58:1) & $-0.042 \pm 0.039$ & 0.272 & 0.537 \\
\hline TAG (58:2) & $-0.046 \pm 0.038$ & 0.232 & 0.484 \\
\hline TAG (58:3) & $-0.038 \pm 0.042$ & 0.370 & 0.656 \\
\hline TAG $(58: 6)$ & $-0.021 \pm 0.041$ & 0.599 & 0.839 \\
\hline
\end{tabular}


Table S4. Continued

\begin{tabular}{|c|c|c|c|c|c|c|c|}
\hline Lipid species & Std $-\beta \pm S E$ & $p$ & FDR $p$ & Lipid species & Std $-\beta \pm S E$ & $p$ & FDR $p$ \\
\hline TAG (58:8) & $-0.003 \pm 0.042$ & 0.945 & 0.978 & LPC $(22: 6 / 0: 0)$ & $0.014 \pm 0.043$ & 0.746 & 0.901 \\
\hline TAG (58:9) & $-0.073 \pm 0.041$ & 0.072 & 0.365 & $\mathrm{PC}(32: 0)$ & $-0.015 \pm 0.045$ & 0.733 & 0.901 \\
\hline TAG (58:10) & $-0.072 \pm 0.044$ & 0.099 & 0.365 & $\mathrm{PC}(32: 1)$ & $-0.030 \pm 0.042$ & 0.476 & 0.725 \\
\hline TAG (59:0) & $0.009 \pm 0.043$ & 0.837 & 0.961 & $\mathrm{PC}(32: 2)$ & $-0.057 \pm 0.043$ & 0.189 & 0.441 \\
\hline TAG (60:2) & $-0.007 \pm 0.041$ & 0.872 & 0.961 & PC (34:0) & $-0.082 \pm 0.045$ & 0.066 & 0.365 \\
\hline DAG (36:2) & $-0.047 \pm 0.043$ & 0.270 & 0.537 & $\mathrm{PC}(34: 1)$ & $0.014 \pm 0.038$ & 0.716 & 0.901 \\
\hline DAG $(36: 3$ & $-0.062 \pm 0.043$ & 0.154 & 0.398 & $\mathrm{PC}(34: 2)$ & $-0.026 \pm 0.043$ & 0.542 & 0.799 \\
\hline $\mathrm{SM}$ (d18:1/14:0) & $-0.006 \pm 0.043$ & 0.885 & 0.965 & PC (34:3) & $-0.008 \pm 0.039$ & 0.840 & 0.961 \\
\hline $\mathrm{SM}(\mathrm{d} 18: 1 / 15: 0)$ & $-0.009 \pm 0.043$ & 0.826 & 0.961 & $\mathrm{PC}(34: 4)$ & $-0.070 \pm 0.045$ & 0.117 & 0.365 \\
\hline $\mathrm{SM}(\mathrm{d} 18: 1 / 16: 0)$ & $0.067 \pm 0.045$ & 0.133 & 0.376 & $\mathrm{PC}(36: 1)$ & $0.046 \pm 0.038$ & 0.226 & 0.480 \\
\hline $\mathrm{SM}(\mathrm{d} 18: 1 / 16: 1)$ & $-0.001 \pm 0.041$ & 0.982 & 0.996 & $\mathrm{PC}(36: 2)$ & $0.008 \pm 0.045$ & 0.863 & 0.961 \\
\hline $\mathrm{SM}(\mathrm{d} 18: 1 / 17: 0)$ & $0.010 \pm 0.044$ & 0.825 & 0.961 & $\mathrm{PC}(36: 3)$ & $-0.025 \pm 0.044$ & 0.564 & 0.806 \\
\hline SM (d18:1/18:0) & $-0.012 \pm 0.044$ & 0.779 & 0.924 & PC (36:4) & $-0.059 \pm 0.045$ & 0.186 & 0.441 \\
\hline $\mathrm{SM}(\mathrm{d} 18: 1 / 18: 1)$ & $-0.016 \pm 0.044$ & 0.718 & 0.901 & $\mathrm{PC}(36: 5)$ & $0.007 \pm 0.035$ & 0.851 & 0.961 \\
\hline $\mathrm{SM}(\mathrm{d} 18: 1 / 18: 2)$ & $0.073 \pm 0.044$ & 0.099 & 0.365 & PC (36:6) & $-0.093 \pm 0.043$ & 0.029 & 0.361 \\
\hline SM (d18:1/20:0) & $-0.050 \pm 0.045$ & 0.263 & 0.536 & $\mathrm{PC}(38: 2)$ & $-0.054 \pm 0.044$ & 0.219 & 0.473 \\
\hline $\mathrm{SM}(\mathrm{d} 18: 1 / 20: 1)$ & $-0.005 \pm 0.043$ & 0.911 & 0.971 & $\mathrm{PC}(38: 3)$ & $-0.094 \pm 0.041$ & 0.023 & 0.329 \\
\hline $\mathrm{SM}(\mathrm{d} 18: 1 / 21: 0)$ & $-0.032 \pm 0.044$ & 0.477 & 0.725 & PC (38:4) & $-0.070 \pm 0.043$ & 0.108 & 0.365 \\
\hline $\mathrm{SM}(\mathrm{d} 18: 1 / 22: 0)$ & $-0.015 \pm 0.044$ & 0.737 & 0.901 & $\mathrm{PC}(38: 5)$ & $0.016 \pm 0.041$ & 0.687 & 0.901 \\
\hline $\mathrm{SM}(\mathrm{d} 18: 1 / 22: 1)$ & $0.008 \pm 0.043$ & 0.859 & 0.961 & $\mathrm{PC}(38: 6)$ & $-0.079 \pm 0.042$ & 0.062 & 0.365 \\
\hline $\mathrm{SM}(\mathrm{d} 18: 1 / 23: 0)$ & $0.004 \pm 0.043$ & 0.923 & 0.971 & $\mathrm{PC}(38: 7)$ & $0.066 \pm 0.038$ & 0.081 & 0.365 \\
\hline $\mathrm{SM}(\mathrm{d} 18: 1 / 23: 1)$ & $0.033 \pm 0.041$ & 0.420 & 0.693 & $\mathrm{PC}(40: 4)$ & $-0.065 \pm 0.042$ & 0.124 & 0.365 \\
\hline $\mathrm{SM}(\mathrm{d} 18: 0 / 24: 0)$ & $0.022 \pm 0.042$ & 0.591 & 0.836 & PC (40:5) & $-0.065 \pm 0.042$ & 0.125 & 0.365 \\
\hline $\mathrm{SM}(\mathrm{d} 18: 0 / 24: 1)$ & $0.071 \pm 0.043$ & 0.103 & 0.365 & PC (40:6) & $-0.096 \pm 0.042$ & 0.024 & 0.329 \\
\hline $\mathrm{SM}(\mathrm{d} 18: 0 / 24: 2)$ & $0.054 \pm 0.041$ & 0.195 & 0.443 & $\mathrm{PC}(40: 7)$ & $0.007 \pm 0.041$ & 0.866 & 0.961 \\
\hline $\mathrm{SM}(\mathrm{d} 18: 0 / 25: 0)$ & $-0.022 \pm 0.045$ & 0.622 & 0.862 & PC (40:8) & $0.039 \pm 0.045$ & 0.389 & 0.657 \\
\hline $\mathrm{SM}(\mathrm{d} 18: 0 / 25: 1)$ & $0.003 \pm 0.042$ & 0.950 & 0.978 & $\mathrm{PC}(\mathrm{O}-34: 1)$ & $0.032 \pm 0.04$ & 0.427 & 0.695 \\
\hline $\mathrm{PE}(38: 2)$ & $0.012 \pm 0.044$ & 0.777 & 0.924 & $\mathrm{PC}(\mathrm{O}-34: 2)$ & $0.066 \pm 0.043$ & 0.123 & 0.365 \\
\hline PE (38:4) & $-0.040 \pm 0.045$ & 0.377 & 0.657 & $\mathrm{PC}(\mathrm{O}-34: 3)$ & $0.072 \pm 0.042$ & 0.086 & 0.365 \\
\hline PE (38:6) & $-0.058 \pm 0.044$ & 0.186 & 0.441 & $\mathrm{PC}(\mathrm{O}-36: 2)$ & $0.100 \pm 0.042$ & 0.017 & 0.329 \\
\hline $\mathrm{PE}(\mathrm{O}-36: 5)$ & $0.037 \pm 0.043$ & 0.397 & 0.661 & $\mathrm{PC}(\mathrm{O}-36: 3)$ & $0.046 \pm 0.044$ & 0.303 & 0.560 \\
\hline $\mathrm{PE}(\mathrm{O}-38: 5)$ & $0.048 \pm 0.044$ & 0.276 & 0.537 & $\mathrm{PC}(\mathrm{O}-36: 4)$ & $0.000 \pm 0.043$ & 0.991 & 0.998 \\
\hline $\mathrm{PE}(\mathrm{O}-38: 7)$ & $-0.016 \pm 0.044$ & 0.723 & 0.901 & $\mathrm{PC}(\mathrm{O}-36: 5)$ & $0.028 \pm 0.044$ & 0.526 & 0.783 \\
\hline LPC (O-16:1/0:0) & $0.106 \pm 0.042$ & 0.012 & 0.329 & $\mathrm{PC}(\mathrm{O}-36: 6)$ & $0.058 \pm 0.037$ & 0.119 & 0.365 \\
\hline LPC (O-18:1/0:0) & $0.071 \pm 0.04$ & 0.072 & 0.365 & $\mathrm{PC}(\mathrm{O}-38: 4)$ & $-0.019 \pm 0.044$ & 0.664 & 0.901 \\
\hline LPC (14:0/0:0) & $0.002 \pm 0.044$ & 0.966 & 0.987 & $\mathrm{PC}(\mathrm{O}-38: 5)$ & $0.000 \pm 0.040$ & 0.998 & 0.998 \\
\hline LPC (16:0/0:0) & $0.096 \pm 0.04$ & 0.018 & 0.329 & $\mathrm{PC}(\mathrm{O}-38: 6)$ & $0.014 \pm 0.044$ & 0.746 & 0.901 \\
\hline LPC (16:1/0:0) & $0.095 \pm 0.044$ & 0.031 & 0.361 & $\mathrm{PC}(\mathrm{O}-38: 7)$ & $-0.017 \pm 0.042$ & 0.680 & 0.901 \\
\hline LPC (18:0/0:0) & $0.084 \pm 0.039$ & 0.034 & 0.361 & $\mathrm{PC}(\mathrm{O}-40: 6)$ & $-0.057 \pm 0.04$ & 0.160 & 0.398 \\
\hline LPC (18:1/0:0) & $0.172 \pm 0.042$ & 0.000 & 0.008 & $\mathrm{PC}(\mathrm{O}-42: 6)$ & $-0.027 \pm 0.037$ & 0.469 & 0.725 \\
\hline LPC (18:2/0:0) & $0.148 \pm 0.041$ & 0.000 & 0.025 & $\mathrm{PC}(\mathrm{O}-44: 5)$ & $0.075 \pm 0.042$ & 0.080 & 0.365 \\
\hline LPC (18:3/0:0) & $0.109 \pm 0.041$ & 0.008 & 0.329 & CholE02 & $0.025 \pm 0.044$ & 0.564 & 0.806 \\
\hline LPC (20:3/0:0) & $0.070 \pm 0.045$ & 0.121 & 0.365 & CholE05 & $0.005 \pm 0.045$ & 0.919 & 0.971 \\
\hline LPC (20:4/0:0) & $0.060 \pm 0.041$ & 0.144 & 0.380 & CholE06 & $-0.019 \pm 0.043$ & 0.667 & 0.901 \\
\hline LPC (20:5/0:0) & $0.066 \pm 0.039$ & 0.090 & 0.365 & LPE (18:0/0:0) & $0.026 \pm 0.043$ & 0.550 & 0.802 \\
\hline
\end{tabular}

Standardized $\beta \pm$ standard error in linear mixed models with the individual plasma lipid species as dependent variable, MISI as fixed effect, study center as random effect, adjusted for sex, BMI, waist-to-hip ratio and HIRI. No significant sex interactions were observed in the associations between MISI and lipids, therefore shown data represent all individuals $(\mathrm{n}=640)$ 


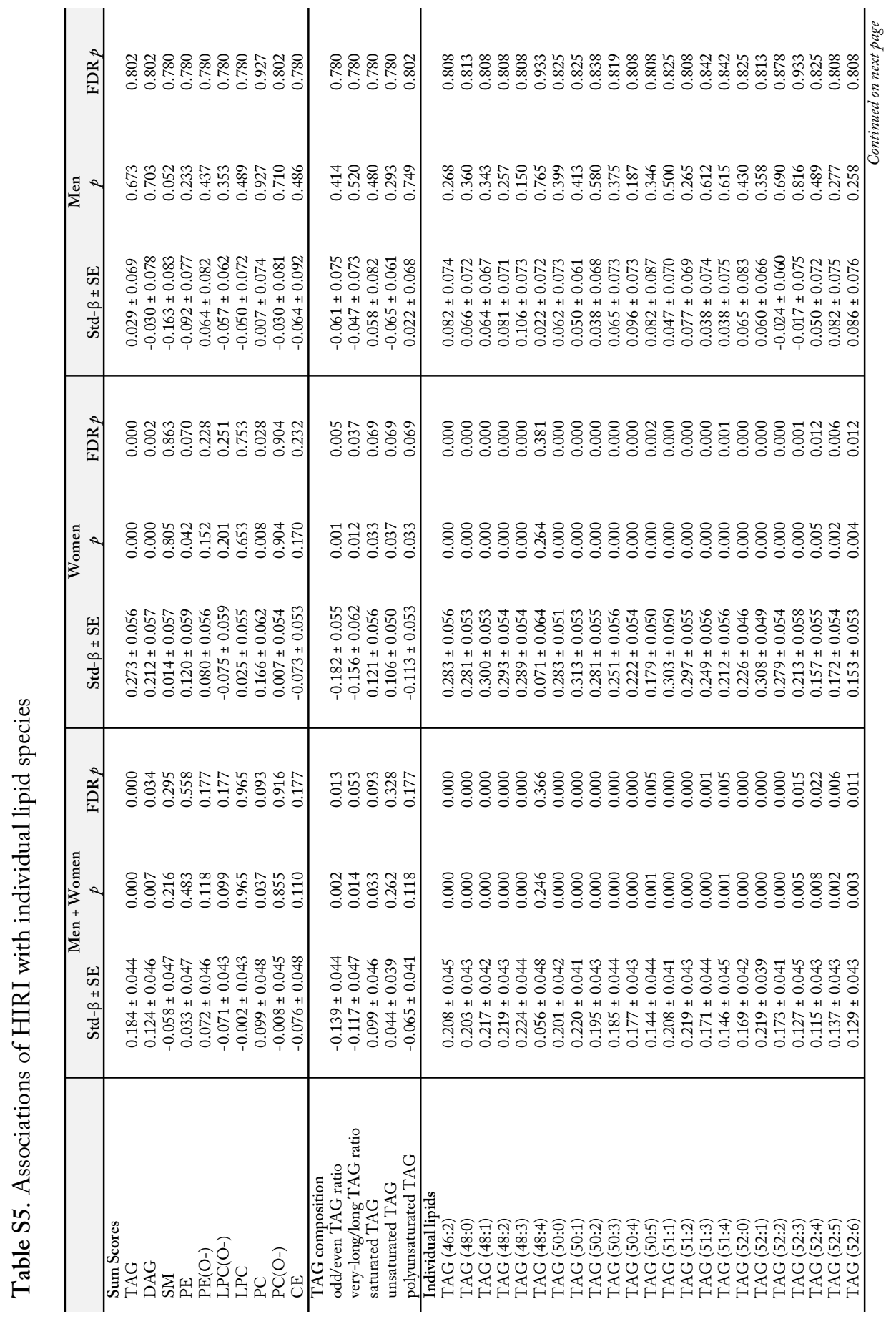




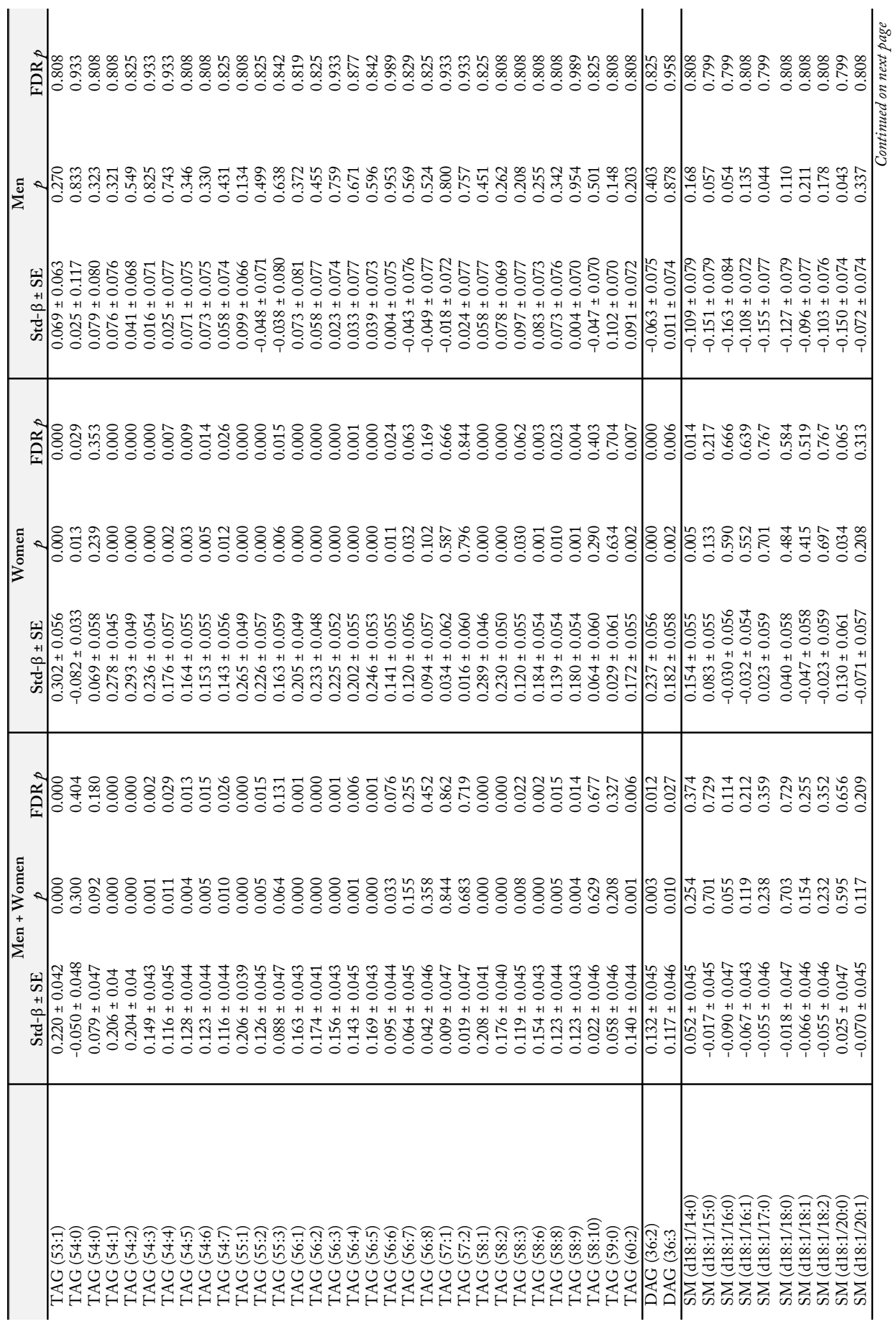




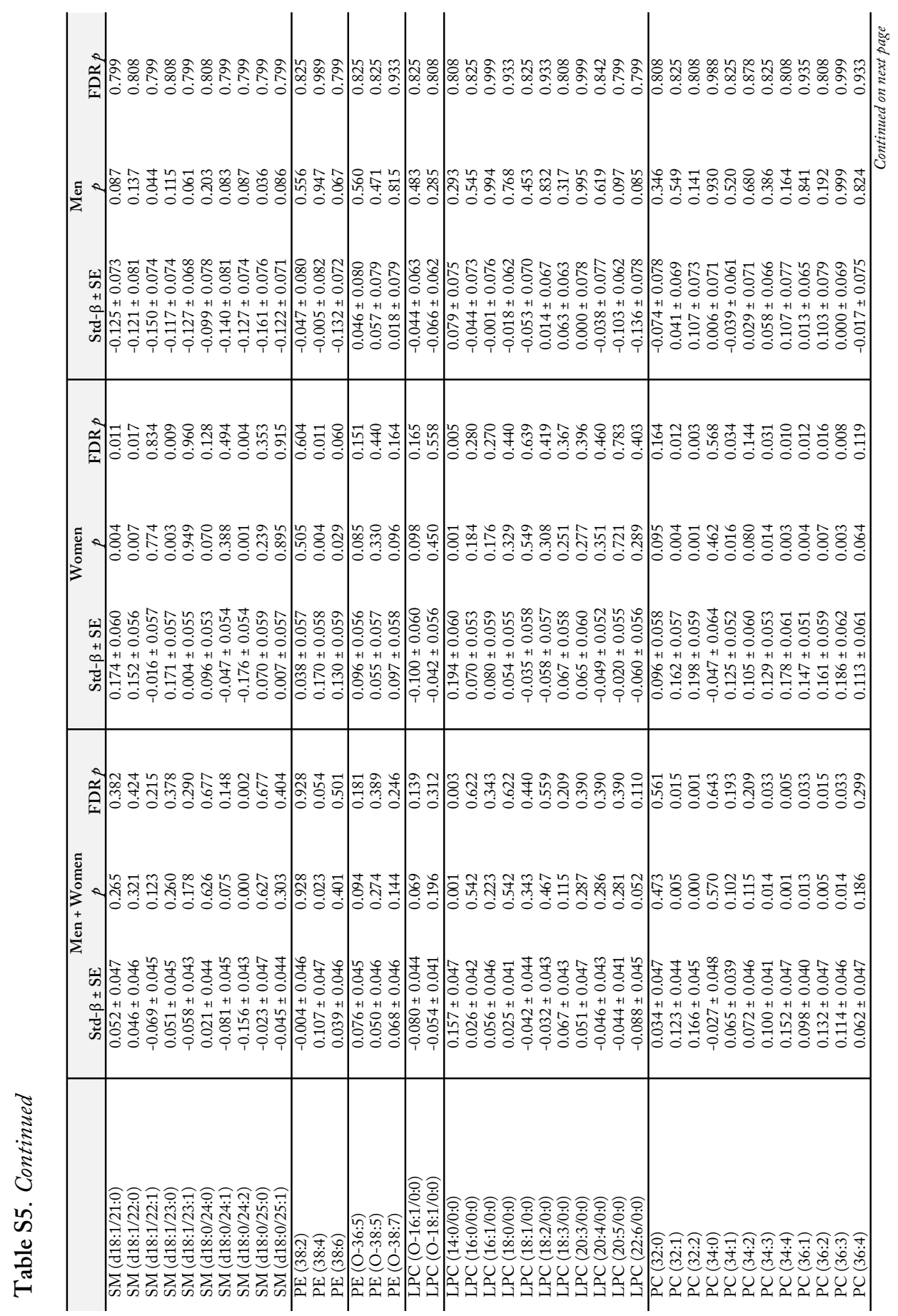




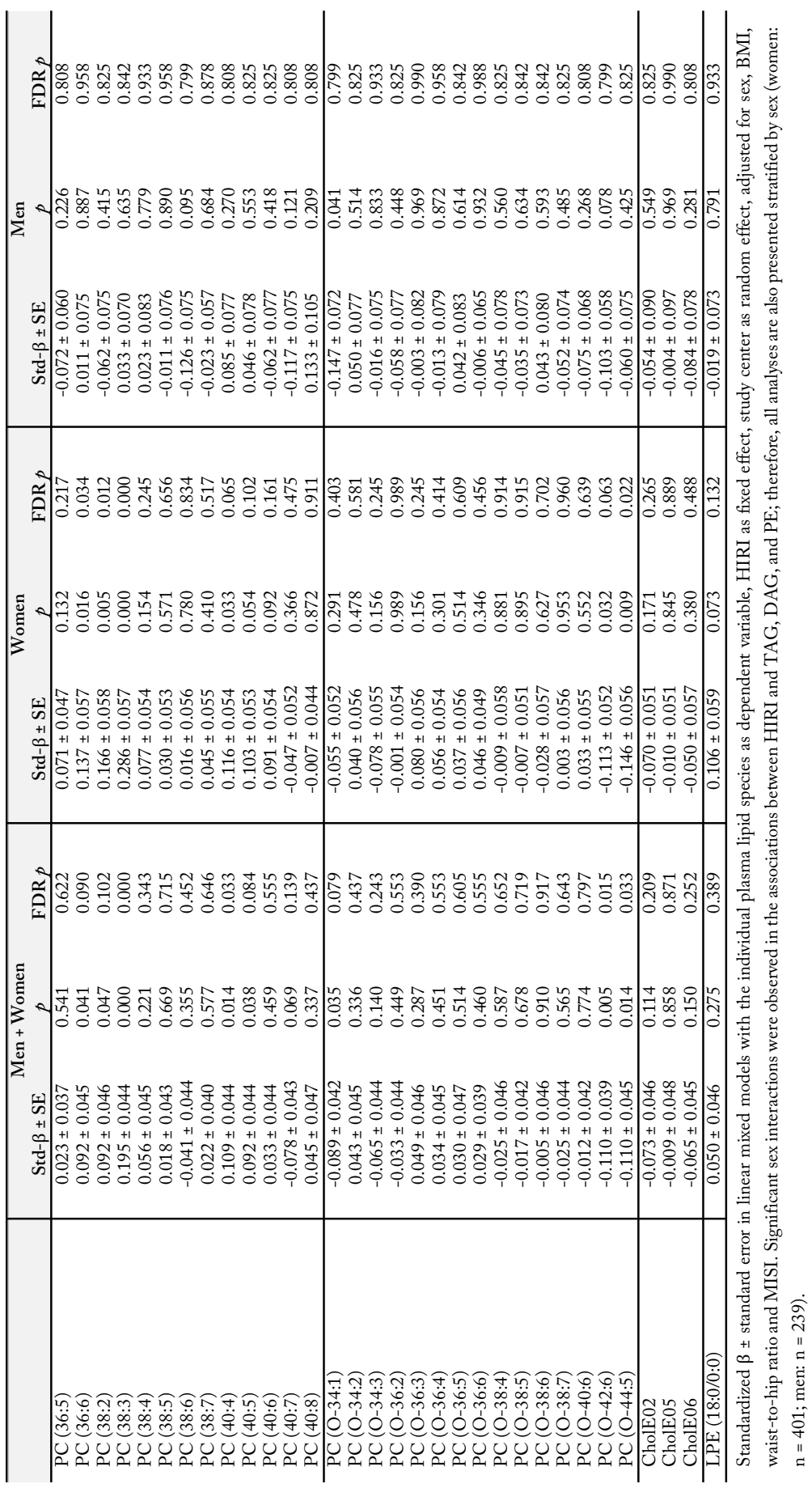




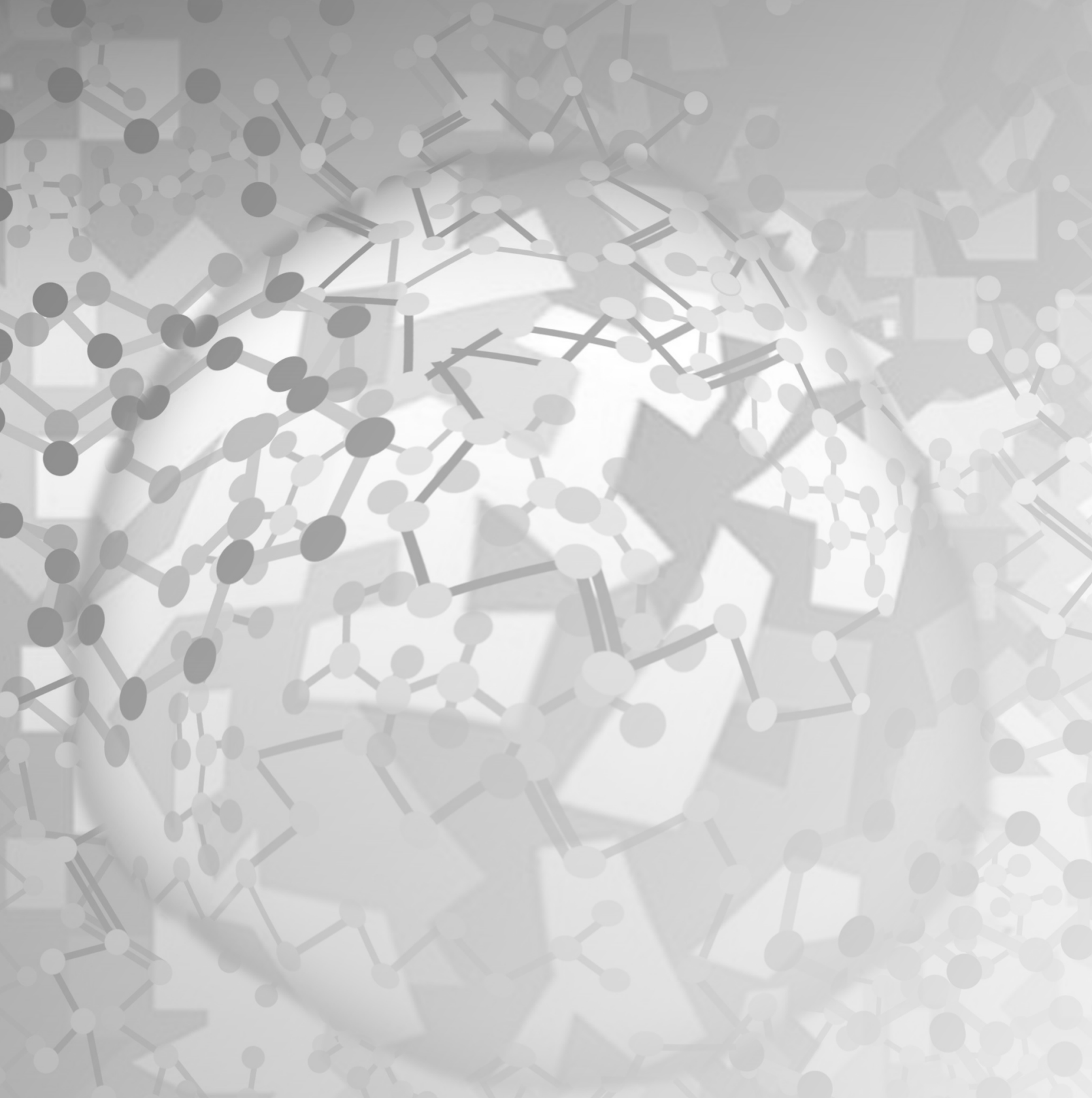




\title{
Chapter 6
}

\section{Abdominal subcutaneous adipose tissue gene expression in relation to tissue-specific insulin resistance in human obesity}

\begin{abstract}
Birgitta W. van der Kolk ${ }^{1^{*}}$, Marianthi Kalafati ${ }^{2,3^{*}}$, Michiel Adriaens ${ }^{3}$, Marleen M.J. van Greevenbroek ${ }^{4}$, Wim H.M. Saris ${ }^{1}$, Arne Astrup ${ }^{5}$, Armand Valsesia ${ }^{6}$, Dominique Langin $^{7}$, Carla J.H. van der Kallen ${ }^{4}$, Casper G. Schalkwijk ${ }^{4}$, Coen D.A. Stehouwer ${ }^{4}$, Gijs. H. Goossens ${ }^{1}$, Ilja C.W. Arts ${ }^{3,8}$, Johan W.E. Jocken ${ }^{1}$, Chris T. Evelo ${ }^{1 \S}$, Ellen E. Blaak ${ }^{1 \S}$ and the DiOGenes Consortium
\end{abstract}

"Shared first authors; ${ }^{\S}$ Shared last authors

\footnotetext{
${ }^{1}$ Department of Human Biology, Maastricht University, Maastricht, The Netherlands; ${ }^{2}$ Department of Bioinformatics-BiGCaT, Maastricht University, Mastricht, The Netherlands; ${ }^{3}$ Maastricht Centre for Systems Biology (MaCSBio), Maastricht University, The Netherlands; ${ }^{4}$ Department of Internal Medicine, Maastricht University, The Netherlands; ${ }^{5}$ Department of Nutrition, Exercise and Sports, Faculty of Science, University of Copenhagen, Copenhagen, Denmark; ${ }^{6}$ Nestlé Institute of Health Sciences, Lausanne, Switzerland; ${ }^{7}$ Obesity Research Laboratory, Paul Sabatier University, Toulouse, France; ${ }^{8}$ Department of Epidemiology, Maastricht University, Maastricht, The Netherlands
} 


\section{Abstract}

Introduction: Obesity-related insulin resistance (IR) may develop in multiple organs (e.g. liver and skeletal muscle), representing different etiologies towards cardiometabolic diseases. This study aimed to identify distinct abdominal subcutaneous adipose tissue (ScAT) transcriptome profiles in relation to muscle or liver IR.

Methods: Overweight/obese participants without diabetes $(n=368)$ of the European DiOGenes project were classified at baseline into 4 groups: i) no-IR ( $n=186)$, ii) muscle-IR $(\mathrm{n}=69)$, iii) liver-IR ( $=53)$, iv) muscle/liver-IR ( $=60)$. The IR phenotype was derived from a 5-point oral glucose tolerance test and based on tertiles of the muscle insulin sensitivity index (MISI) and the hepatic IR index (HIRI). ScAT RNA sequencing data between groups were analyzed using DESeq2 with adjustments for study center, sex, BMI and waist-to-hip ratio. Gene Ontology and WikiPathway enrichment analyses were performed with significant genes $(p<0.05)$. Based on DiOGenes outcomes, additional analyses were performed in 420 non-diabetic individuals of the Cohort on Diabetes and Atherosclerosis Maastricht (CODAM), relating low-grade inflammation and IR phenotype.

Results: In DiOGenes, ScAT extracellular matrix organization genes (e.g. collagens) were significantly upregulated in the liver-IR vs no-IR comparison. In muscle-IR vs no-IR comparison, pathways related to inflammation were significantly upregulated with pronounced upregulation of chemokine and complement genes. In CODAM, low-grade inflammation was inversely associated with MISI (standardized- $\beta$ : $-0.125 ; p=0.004$ ), independent of HIRI, but not vice versa (standardized- $\beta$ : $0.045, p=0.316$ ).

Conclusions: Muscle and hepatic IR are characterized by distinct transcriptome profiles in abdominal ScAT. Genes related to inflammation were significantly upregulated in individuals with primarily muscle IR, whilst genes related to extracellular remodeling were upregulated in individuals with primarily hepatic IR. Subsequent CODAM analyses showed that an increased systemic inflammatory profile may be specifically related to muscle IR. We propose that increased ScAT inflammatory gene expression in the muscle IR phenotype may translate into an increased systemic inflammatory profile, putatively linking ScAT inflammation to peripheral IR. 


\section{Introduction}

Worldwide over 2.1 billion people were overweight or obese in 2013 (1). Overweight and obesity are major risk factors for a number of diseases including cardiovascular disease and type 2 diabetes (2,3). Adipose tissue dysfunction, rather than excess fat mass per se, is frequently associated with the progression towards skeletal muscle, liver and whole-body insulin resistance (IR) $(4,5)$.

Adipose tissue dysfunction is characterized by increased adipocyte size (hypertrophy) rather than increased adipocyte number (hyperplasia) and this associates with impairments in adipose tissue lipid buffering capacity (6). In addition, expanded adipose tissue mass is accompanied by an increased production and secretion of pro-inflammatory cytokines, chemokines and adipokines $(7,8)$. Both systemic lipid overflow and systemic low-grade inflammation are thought to contribute to the development of IR in skeletal muscle and liver (9).

Whole-body IR reflects defective insulin action in major metabolic organs, such as skeletal muscle, liver, brain and adipose tissue, and has long been known to precede the development of cardiometabolic diseases (9). IR can develop simultaneously in multiple organs, but the severity may vary between organs. For instance, impaired fasting glucose (IFG) and impaired glucose tolerance (IGT) may represent distinct pathways towards type 2 diabetes. Likewise, IFG and IGT have been associated with different metabolic profiles. For instance, an altered skeletal muscle fatty acid handling as well as a more pronounced peripheral IR is observed in IGT as compared to IFG individuals $(10,11)$. Notably, impaired hepatic and peripheral (muscle) insulin sensitivity may be the underlying disorders in IFG and IGT individuals, respectively (12). These observations support the notion that the metabolic phenotype and disease risk are directly related to the severity of IR in different organs. In addition, there is evidence that variation in IR phenotype, e.g. being more insulin resistant at the level of the liver or skeletal muscle, may contribute to the differential response to lifestyle and pharmacological interventions. Indeed, physical activity has been shown to mainly target skeletal muscle insulin sensitivity (13), while metformin treatment might have more pronounced effects on hepatic insulin sensitivity (14). Moreover, a low-fat, high complex carbohydrate diet may result in a more pronounced increase in the disposition index (the product of first phase insulin secretion and insulin sensitivity) in prediabetic individuals with hepatic IR, while a Mediterranean diet may have more beneficial effects in individuals with muscle IR (15). 
Analysis of gene expression in subcutaneous adipose tissue (ScAT) may help to elucidate the pathways and mechanisms in adipose tissue that are linked to tissue-specific IR. Previous studies have shown significant dysregulation in the ScAT transcriptome with obesity and IR (16). For instance, Elbein et al. (17) found that ScAT inflammatory pathways and cell-cycle regulation pathways were upregulated in individuals with whole-body IR compared to insulin-sensitive BMI-matched individuals, while lipid metabolism pathways were downregulated. In addition, Soronen et al. (18) observed an upregulation of inflammatory and a downregulation of mitochondrial respiratory and lipid metabolism pathways in obese women with whole-body IR. In addition, recent DiOGenes transcriptome analyses from abdominal ScAT during weight loss highlighted the link between lipid metabolism pathways and glycemic improvement (19).

Studies that focus on detailed characterization of IR phenotypes are scarce, and it is currently not known whether differential ScAT transcriptome profiles are related to either more pronounced muscle IR or hepatic IR. Quantification and identification of metabolic anomalies in different IR phenotypes may provide directions for more personalized lifestyle or pharmacological interventions in the prevention and control of cardiometabolic diseases. In this report, we studied the ScAT transcriptome of overweight and obese, nondiabetic participants, from the DiOGenes study (20). We analyzed a large RNA sequencing (RNA-seq) dataset derived from abdominal ScAT biopsies, and identified genes that were associated with muscle or hepatic IR. We investigated whether we could confirm putative mechanisms suggested by our ScAT transcriptome findings in tissue-specific IR by performing a complementary analysis on inflammatory profile in an independent cohort (21).

\section{Material and Methods}

\section{Study Design}

\section{DiOGenes}

The ScAT gene expression profiling analyses were done in the DiOGenes study. DiOGenes is a multicenter, randomized, controlled dietary intervention study that involved 8 European countries. Briefly, 938 overweight or obese, nondiabetic adults [age between 18 and 65 years, body mass index (BMI) between 27 and $45 \mathrm{~kg} / \mathrm{m}^{2}$ and blood fasting glucose concentrations $<6.1 \mathrm{mmol} / \mathrm{L}]$ were included. Participants with heart or coronary diseases, kidney or liver diseases, thyroid diseases, psychiatric illnesses, systemic infections, endocrine diseases, or 
cancer were excluded. More details on recruitment, inclusion and exclusion criteria, design and study procedures have been described previously (20). For current analyses, baseline data were used of 368 participants for whom abdominal ScAT RNA sequencing and oral glucose tolerance test (OGTT) data were available.

\section{CODAM}

In DiOGenes, no information on systemic inflammation is available, therefore the Cohort on Diabetes and Atherosclerosis Maastricht (CODAM) was used to analyze the systemic lowgrade inflammation profile. CODAM is a prospective, observational study on, among others, the natural progression of IR and glucose tolerance. A total of 574 individuals were included from a large population-based cohort as described in detail elsewhere (21). The analyses described here include baseline data of 420 non-diabetic participants for whom data on OGTT and systemic low-grade inflammation were available.

Local ethics committees approved both studies and all participants gave written informed consent. These studies were carried out in accordance with the principles of the Declaration of Helsinki.

\section{Estimates of tissue-specific IR and classification of IR subgroups}

DiOGenes participants underwent a standard 5-point OGTT at baseline. In short, after an overnight fast, venous blood was sampled at baseline and after a $75 \mathrm{~g}$ flavored glucose load was ingested. Blood samples were taken at $\mathrm{t}=0$, 30, 60, 90 and 120 minutes to determine glucose and insulin concentrations (20). CODAM participants underwent a 4-point OGTT with blood samples taken at $\mathrm{t}=0$, 30, 60 and 120 minutes. Muscle insulin sensitivity and hepatic IR were estimated using the methods of Abdul-Ghani et al. (22).

Briefly, the muscle insulin sensitivity index (MISI) was calculated according to the following formula: MISI $=(\mathrm{dG} / \mathrm{dt}) /$ mean plasma insulin concentration during OGTT. Here, $\mathrm{dG} / \mathrm{dt}$ is the rate of decay of plasma glucose concentration during the OGTT, calculated as the slope of the least square fit to the decline in plasma glucose concentration from peak to nadir (22). The decline in plasma glucose concentration in the second part of the OGTT primarily reflects glucose uptake by peripheral tissues, mainly skeletal muscle. This index has been developed and validated against measures of peripheral insulin sensitivity as assessed during a hyperinsulinemic euglycemic clamp using a stable isotope glucose tracer (22). 
The hepatic IR index (HIRI) was calculated using the square root of the product of the area under curves (AUCs) for glucose and insulin during the first 30 minutes of the OGTT i.e., SQRT (glucose ${ }_{0-30}[$ AUC in $\mathrm{mg} / \mathrm{d} \cdot \mathrm{h}] \cdot$ insulin $_{0-30}[\mathrm{AUC}$ in $\mu \mathrm{U} / \mathrm{mL} \cdot \mathrm{h}]$ ). This index has been developed and validated against the product of fasting plasma insulin and endogenous glucose production during a hyperinsulinemic euglycemic clamp using a stable isotope glucose tracer (22).

DiOGenes and CODAM participants were each divided into four groups according to the presence or absence of muscle insulin sensitivity and/or hepatic IR. This was based on the tertiles of the HIRI and MISI scores of each cohort (15). The lowest tertile of MISI represented individuals with muscle IR; the highest tertile of HIRI represented individuals with hepatic IR. Accordingly, participants were categorized in one of four groups: i) no-IR, ii) IR primarily in muscle (muscle-IR), iii) IR primarily in liver (liver-IR) and iv) IR in both muscle and liver (muscle/liver-IR).

\section{Adipose tissue biopsy, RNA preparation and RNA sequencing}

In DiOGenes, abdominal ScAT needle biopsies $(\approx 1 \mathrm{~g})$ were collected $6-8 \mathrm{~cm}$ lateral from the umbilicus under local anesthesia ( $2 \%$ lidocaine) by needle biopsy. Biopsies were immediately rinsed with sterile saline, and visible blood vessels were removed with sterile tweezers. Thereafter, biopsies were snap-frozen in liquid nitrogen and stored at $-80{ }^{\circ} \mathrm{C}$ until further analysis.

Total RNA was extracted from abdominal ScAT needle biopsies as previously described (19). Briefly, gene expression was determined by using paired-end RNA sequencing (100 bp) with an Illumina HiSeq 2000. Libraries were prepared by using the Illumina TruSeq kit in accordance with the manufacturer's protocol. Sequences were mapped onto the human genome (GRCh37 assembly) with STAR (23) using default settings. Sequencing quality was evaluated by using FastQC and mapping quality was assessed by using Rsamtools (24). Non-unique reads, reads with > 5 mismatches, as well as PCR duplicates, were subsequently discarded.

For each sample, the number of reads mapping onto 53,343 genes (GRCh37 assembly) was retrieved by using GenomicAlignments. Only reads with both ends mapping onto a single gene were considered. 


\section{Statistical analyses}

\section{Clinical outcomes}

In DiOGenes and CODAM, variables with a skewed distribution were $\log _{\mathrm{e}}$-transformed before further analyses. The phenotypic differences between tissue-specific IR groups were assessed using one-way ANOVA for continuous variables with Bonferroni post hoc tests and $\chi^{2}$ test for categorical variables. Data shown are mean \pm SD (normally distributed variables), median [interquartile range] (skewed variables) or proportion (categorical variables). The threshold for statistical significance was set at $p<0.05$.

\section{RNA sequencing data pre-processing}

In DiOGenes, after alignment and transcript abundance, estimation raw count data for 53,343 genes and 368 samples was further analyzed within the statistical programming language R (version 3.3.3). Differential expression analysis was performed in the DESeq2 package (version 1.12.4) using default settings (25). Pre-filtering of genes with low counts was applied by removing genes with a total of 0 or 1 reads. The standard differential expression analysis steps are wrapped into a single function, DESeq. The estimation steps performed by this function are described in the Methods section of the DESeq2 publication (25). The differential expression analysis in DESeq2 implements a negative binomial generalized linear model with the tissue-specific IR phenotypes (muscle-IR, liver-IR and no-IR), study center, $\mathrm{BMI}$ and waist-to-hip ratio as covariates; two additional analyses were run next to the tissuespecific IR phenotypes: i) only study center and ii) study center and sex were taken along as covariates, respectively. The DESeq2 model internally corrects for library size; no additional data normalization was applied.

The DESeq2 package performs an additional step in the differential expression analysis referred to as independent filtering, using the mean of the normalized counts as a filter statistic for each gene. A threshold on the filter statistic is found which optimizes the number of adjusted $p$-values lower than a set significance level alpha $(\alpha=0.05)$. The adjusted $p$-values for the genes that do not pass the filter threshold were set to Not Applicable (NA). The result tables were generated using the function results comparing the tissue-specific IR phenotypes (liver-IR vs no-IR and muscle-IR vs no-IR) and returning base means across samples, $\log _{2}$ fold changes, standard errors, test statistics, $p$-values and adjusted $p$-values. 


\section{Gene ontology analysis}

Gene ontology (GO) analyses was performed using Gorilla (26), a tool for identifying and visualizing enriched GO terms in ranked lists of genes. The settings that were applied were i) organism: Homo Sapiens, ii) running mode: two unranked list of genes (target and background lists) iii) ontology: process and iv) $p<0.05$. All significant genes $(p<0.05)$ were included (Table S1 and S8), divided into up- and downregulated genes to provide direction for the involved biological processes. Therefore, the GO analysis resulted in four different set of results (liver-IR vs no-IR up- and downregulated and muscle-IR vs no-IR up- and downregulated). For each result, based on Benjamini \& Hochberg false discovery rate (FDR) $p$-values, the top five biological processes were selected.

\section{Pathway and network analysis}

Pathway analysis was performed with PathVisio 3.2.1, a free, open-source software for pathway analysis and pathway drawing. The curated human pathway collections were obtained from WikiPathways (version 20171116) (27), containing 344 pathways. An overrepresentation analysis was performed with the RNA sequencing data set. The pathways were then ranked based on a standardized difference score ( $z$-score). Pathways were considered significantly changed when i) Z-score $>1.96$, ii) permuted $p<0.05$ and iii) the number of significantly different genes $(p<0.05)$ in the pathway is $\geq 3$.

Cytoscape (28) was used for integrating and visualizing the pathways into one combined network. The WikiPathways app for Cytoscape (29) was firstly used to load the pathways. Secondly, an identifier mapping step was performed using the BridgeDb app for Cytoscape to unify the gene products to Ensembl and the metabolites to HMDB and in a third step all the pathways were merged into one large network using Cytoscape's merge function. Finally, selected genes had to fulfill two criteria: i) $p<0.05$ and ii) $\mid$ fold change $\mid>1.1$ for either of the comparisons liver-IR vs no-IR and muscle-IR vs no-IR.

\section{Association with low grade inflammation score}

In CODAM, linear regression analyses were performed with a low-grade inflammation score as the independent variable and HIRI or MISI (continuous variables) as dependent variable (outcome). The low-grade inflammation score was calculated by averaging the $Z$-scores (i.e., [individual's observed values - population mean] / SD) of eight inflammatory markers (C-reactive protein (CRP), interleukin-6 (IL-6), interleukin-8 (IL-8), serum amyloid A (SAA), soluble intercellular adhesion molecule 1 (sICAM-1), tumor necrosis factor $\alpha$ (TNF- $\alpha$ ), ceruloplasmin and haptoglobin). Averaging eight markers of low-grade 
inflammation produces a robust estimate of the overall inflammatory state with minimization of random error (30). Skewed variables were logarithmically transformed to approximate normality. To allow for direct comparison of the effect sizes, we additionally standardized HIRI and MISI by calculating their Z-scores. HIRI was included as a covariate in analyses on MISI, and vice versa, to assess the independent effects of tissue-specific IR. In additional analyses, sex, BMI and waist-to-hip ratio were included as covariates. All data were analyzed using SPSS for Mac version 23.0 (SPSS, Chicago, IL, USA) and R statistical programming language (version 3.3.3).

\section{Results}

\section{Clinical characteristics of DiOGenes population}

Table 1 shows the demographic and metabolic characteristics of the DiOGenes participants according to IR phenotype. A group of 186 participants presented no-IR, 69 individuals were in the group with primarily muscle-IR, 53 participants in the group with primarily liver-IR, and 60 participants in the group with combined muscle/liver-IR.

Compared to the no-IR group (68\% women), participants with liver-IR were more often men (47\% women) while participants with muscle-IR were more often women ( $82 \%)$. This sex distribution was also reflected in the body fat distribution and body composition of the participants in each tissue-specific IR group. More specific, liver-IR and muscle/liver-IR groups had significantly greater waist circumference and waist-to-hip ratio than those with no-IR. Moreover, the muscle/liver-IR group showed significantly greater waist circumference, waist-to-hip ratio and systolic blood pressure compared to the muscle-IR group. Participants in liver-IR group had significantly higher fat free mass and a lower body fat percentage compared to the no-IR and muscle-IR groups. Plasma TAG concentrations were significantly higher in liver-IR and muscle/liver-IR groups than in those with no-IR. Cholesterol concentrations were highest in participants in the liver-IR group, while HDL-cholesterol was lowest in muscle/liver-IR group compared with no-IR group. The liver-IR group showed significantly greater fasting glucose concentrations compared to the other groups, while insulin concentrations were significantly higher in the liver-IR and muscle/liver-IR groups compared to no-IR (Table 1). 
Table 1. Participants characteristics of DiOGenes

\begin{tabular}{|c|c|c|c|c|c|}
\hline & $\begin{array}{c}\text { No-IR } \\
(n=186)\end{array}$ & $\begin{array}{l}\text { Muscle-IR } \\
\quad(n=69)\end{array}$ & $\begin{array}{c}\text { Liver-IR } \\
(\mathrm{n}=53)\end{array}$ & $\begin{array}{c}\text { Muscle/liver-IR } \\
(\mathrm{n}=60)\end{array}$ & $p$ \\
\hline Female sex (\%) & 68 & 82 & 47 & 61 & $<0.001$ \\
\hline Age (y) & $42 \pm 7$ & $41 \pm 6$ & $42 \pm 6$ & $41 \pm 6$ & 0.554 \\
\hline $\operatorname{BMI}\left(\mathrm{kg} / \mathrm{m}^{2}\right)$ & $33.9 \pm 4.6$ & $35.0 \pm 4.3$ & $34.7 \pm 4.8$ & $35.7 \pm 4.4^{*}$ & 0.030 \\
\hline Waist $(\mathrm{cm})$ & $104.9 \pm 12.2$ & $105.6 \pm 11.5$ & $111.3 \pm 11.4^{*}$ & $112.6 \pm 14.1^{\# \#}$ & $<0.001$ \\
\hline Waist-to-hip ratio & $0.91 \pm 0.09$ & $0.90 \pm 0.08$ & $0.96 \pm 0.08^{* *}$ & $0.96 \pm 0.10^{* \#}$ & $<0.001$ \\
\hline $\mathrm{SBP}(\mathrm{mmHg})$ & $123 \pm 15$ & $123 \pm 12$ & $128 \pm 14$ & $130 \pm 11^{* \#}$ & 0.004 \\
\hline $\mathrm{DBP}(\mathrm{mmHg})$ & $76 \pm 11$ & $77 \pm 10$ & $80 \pm 9$ & $79 \pm 11$ & 0.182 \\
\hline Fat free mass $(\mathrm{kg})$ & $57.9 \pm 13.7$ & $56.3 \pm 10.8$ & $66.3 \pm 13.9^{* \#}$ & $61.8 \pm 10.8$ & 0.001 \\
\hline Body fat (\%) & $39.1 \pm 8.8$ & $42.0 \pm 6.3$ & $36.3 \pm 8.1^{\#}$ & $39.9 \pm 8.0$ & 0.011 \\
\hline TAG $(\mathrm{mmol} / \mathrm{L})$ & $1.2 \pm 0.5$ & $1.4 \pm 0.6$ & $1.6 \pm 0.7^{*}$ & $1.5 \pm 0.6^{*}$ & $<0.001$ \\
\hline Cholesterol $(\mathrm{mmol} / \mathrm{L})$ & $4.8 \pm 1.0$ & $4.8 \pm 0.9$ & $5.2 \pm 1.0^{*}$ & $5.0 \pm 0.9$ & 0.035 \\
\hline $\mathrm{HDL}(\mathrm{mmol} / \mathrm{L})$ & $1.3 \pm 0.3$ & $1.2 \pm 0.3$ & $1.2 \pm 0.2$ & $1.1 \pm 0.3^{*}$ & 0.002 \\
\hline $\mathrm{LDL}(\mathrm{mmol} / \mathrm{L})$ & $3.0 \pm 0.9$ & $2.9 \pm 0.8$ & $3.3 \pm 0.8$ & $3.2 \pm 0.8$ & 0.035 \\
\hline $\mathrm{NEFA}(\mu \mathrm{mol} / \mathrm{L})$ & $656 \pm 309$ & $739 \pm 415$ & $734 \pm 474$ & $657 \pm 318$ & 0.327 \\
\hline Glucose (mmol/L) & $5.0 \pm 0.6$ & $5.0 \pm 0.6$ & $5.3 \pm 0.5^{*}$ & $5.2 \pm 0.7$ & 0.010 \\
\hline Insulin (mU/L) & $\begin{array}{c}6.8 \\
{[4.9-9.8]}\end{array}$ & $\begin{array}{c}9.4 \\
{[7.5-14.0]^{*}}\end{array}$ & $\begin{array}{c}12.4 \\
{[9.8-17.2]^{*}}\end{array}$ & $\begin{array}{c}17.1 \\
{[12.1-23.5]^{* \# \S}}\end{array}$ & $<0.001$ \\
\hline MISI (AU) & $\begin{array}{c}0.07 \\
{[0.05-0.11]}\end{array}$ & $\begin{array}{c}0.02 \\
{[0.00-0.03]^{*}}\end{array}$ & $\begin{array}{c}0.05 \\
{[0.04-0.08]^{\#}}\end{array}$ & $\begin{array}{c}0.02 \\
{[0.01-0.02]^{*} \sharp \S}\end{array}$ & $<0.001$ \\
\hline HIRI (AU) & $26.0 \pm 5.5$ & $28.5 \pm 5.0$ & $43.2 \pm 8.7^{* \#}$ & $46.8 \pm 12.0^{* \#}$ & $<0.001$ \\
\hline \multicolumn{6}{|c|}{$\begin{array}{l}\text { Data are mean } \pm \mathrm{SD} \text { (normally distributed variables), median [interquartile range] (skewed variables) or } \\
\text { proportion (\%, categorical variables). } p \text {-values were obtained by ANOVA, ANOVA of } \log _{\mathrm{e}} \text {-transformed variables } \\
\text { or Pearson } \mathrm{Chi}^{2} . \text { In addition, Bonferroni post hoc tests were performed. } p<0.05 \text { vs no-IR group; }{ }^{\#} p<0.05 v \\
\text { muscle-IR group; }{ }^{\S} p<0.05 \text { vs liver-IR group. HDL: high-density lipoprotein; LDL: low-density lipoprotein } \\
\text { NEFA: non-esterified fatty acids; HOMA-IR: homeostatic model for assessment of insulin resistance; MISI } \\
\text { muscle insulin sensitivity index; HIRI: hepatic insulin resistance index. }\end{array}$} \\
\hline
\end{tabular}

By definition, MISI was lower in the muscle-IR and muscle/liver-IR groups compared with those with liver-IR and no-IR. HIRI was highest in the muscle/liver-IR and liver-IR groups as compared to those with muscle-IR and no-IR (Table 1). 
A.

$\uparrow$ liver-IR vs no-IR $\uparrow$ muscle-IR vs no-IR

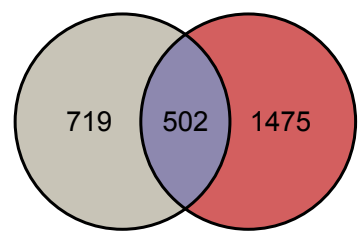

B. $\downarrow$ liver-IR vs no-IR $\downarrow$ muscle-IR vs no-IR

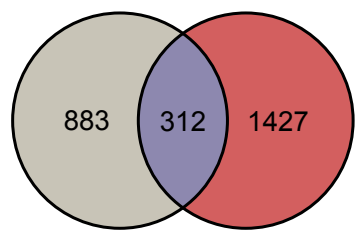

Figure 1. (A) Venn diagram of significantly upregulated genes in liver-IR vs no-IR and muscleIR $v s$ no-IR comparisons (B) Venn diagram of significantly downregulated genes in liver-IR vs no-IR and muscle-IR vs no-IR comparisons.

\section{Differential expression analysis for tissue-specific IR groups in DiOGenes}

We performed RNA sequencing on the abdominal ScAT to assess transcriptome differences in adipose tissue with liver-IR and muscle-IR. The no-IR group was used as reference. We identified 2416 genes differentially expressed in the liver-IR vs no-IR comparison $(p<0.05)$ with in total 1221 upregulated (Figure 1A)and 1195 downregulated genes (Figure 1B). For the muscle-IR vs no-IR comparison, 3716 genes were differentially expressed $(p<0.05)$ with 1977 upregulated (Figure 1A) and 1739 downregulated genes (Figure 1B).

\section{Extracellular structure organization is differentially regulated in liver- IR vs no-IR}

To gain further insight into the differentially expressed transcriptome in the tissue-specific IR phenotypes, Gene Ontology (GO) analyses were performed, focusing on biological processes in combination with enrichment analyses. All significantly differentially expressed genes were included (Table S1) and were divided into up- and downregulated genes. In the liver-IR vs no-IR comparison, 1221 differentially upregulated genes were represented in 45 GO terms (FDR $p<0.05$ ) (Table S2), whilst 1195 downregulated genes were represented in 54 GO terms (Table S5). The GO classification with the highest enrichment was 'extracellular structure organization' (40 genes related to e.g. collagens, integrins, laminins and thrombospondins (Table 2 and S3). In addition, the GO term 'mitotic cell cycle process' was enriched (57 genes related to e.g. cell division cycle and kinesins) (Table 2 and S4). Furthermore, 'Regulation of RNA metabolic process' was the most significant GO term with the highest number of downregulated genes (235 genes including zinc finger proteins) (Table 2 and S6). Together, expression of genes related to cell division and ECM remodeling 
Table 2. Gene Ontology analyses of differentially expressed genes in liver-IR vs no-IR and muscle-IR vs no-IR comparisons in DiOGenes

\begin{tabular}{|c|c|c|c|c|c|}
\hline Comparison & GO Term & Description & FDR- $p$ & $\begin{array}{c}\text { Enrich- } \\
\text { ment }\end{array}$ & $\begin{array}{c}\text { \# Genes } \\
(\mathrm{b} / \mathrm{B})\end{array}$ \\
\hline \multirow{5}{*}{$\begin{array}{l}\text { Liver-IR } \\
\text { vs no-IR } \\
\uparrow \text { genes }\end{array}$} & GO:0043062 & extracellular structure organization & $1.30 \mathrm{E}-07$ & 3.34 & $40 / 270$ \\
\hline & GO:0030198 & extracellular matrix organization & $2.31 \mathrm{E}-07$ & 3.36 & $40 / 269$ \\
\hline & GO:0007059 & chromosome segregation & $2.07 \mathrm{E}-06$ & 5.15 & $21 / 92$ \\
\hline & GO:0051276 & chromosome organization & $1.27 \mathrm{E}-04$ & 2.52 & $41 / 367$ \\
\hline & GO:1903047 & mitotic cell cycle process & $1.46 \mathrm{E}-04$ & 2.14 & $57 / 601$ \\
\hline \multirow{6}{*}{$\begin{array}{l}\text { Liver-IR } \\
\text { vs no-IR } \\
\downarrow \text { genes }\end{array}$} & GO:0051252 & regulation of RNA metabolic process & $1.26 \mathrm{E}-11$ & 1.61 & $233 / 3442$ \\
\hline & GO:0016070 & RNA metabolic process & $1.54 \mathrm{E}-11$ & 1.66 & $215 / 3072$ \\
\hline & GO:0006355 & regulation of transcription, & $1.80 \mathrm{E}-11$ & 1.62 & $222 / 3245$ \\
\hline & & DNA-templated & & & \\
\hline & GO:2001141 & regulation of RNA biosynthetic process & $2.56 \mathrm{E}-11$ & 1.61 & $222 / 3270$ \\
\hline & GO:1903506 & $\begin{array}{l}\text { regulation of nucleic acid-templated } \\
\text { transcription }\end{array}$ & $2.60 \mathrm{E}-11$ & 1.62 & $222 / 3264$ \\
\hline \multirow{5}{*}{$\begin{array}{l}\text { Muscle-IR } \\
\text { vs no-IR } \\
\uparrow \text { genes }\end{array}$} & GO:1903047 & mitotic cell cycle process & $4.04 \mathrm{E}-14$ & 2.36 & $111 / 601$ \\
\hline & GO:0002376 & immune system process & $4.73 \mathrm{E}-14$ & 1.73 & $236 / 1747$ \\
\hline & GO:0019882 & antigen processing and presentation & $3.73 \mathrm{E}-12$ & 3.68 & $48 / 167$ \\
\hline & GO:0022402 & cell cycle process & $5.00 \mathrm{E}-12$ & 1.95 & $145 / 949$ \\
\hline & GO:0002478 & $\begin{array}{l}\text { antigen processing and presentation of } \\
\text { exogenous peptide antigen }\end{array}$ & $2.72 \mathrm{E}-11$ & 3.91 & $41 / 134$ \\
\hline \multirow{5}{*}{$\begin{array}{l}\text { Muscle-IR } \\
\text { vs no-IR } \\
\downarrow \text { genes }\end{array}$} & GO:0032774 & RNA biosynthetic process & $1.29 \mathrm{E}-15$ & 1.73 & $251 / 2349$ \\
\hline & GO:0044260 & $\begin{array}{l}\text { cellular macromolecule metabolic } \\
\text { process }\end{array}$ & $1.76 \mathrm{E}-15$ & 1.36 & $518 / 6161$ \\
\hline & GO:0097659 & nucleic acid-templated transcription & $2.89 \mathrm{E}-15$ & 1.74 & $234 / 2170$ \\
\hline & GO:0006351 & transcription, DNA-templated & $3.64 \mathrm{E}-15$ & 1.74 & $234 / 2169$ \\
\hline & GO:0051252 & regulation of RNA metabolic process & $7.35 \mathrm{E}-15$ & 1.54 & $328 / 3442$ \\
\hline
\end{tabular}

The top five most significant and biologically relevant Gene Ontology (GO): Biological processes are listed for the genes identified in Figure1A and 1B. FDR-p-values are presented for the GO analysis. Enrichment is defined as follows: $(\mathrm{b} / \mathrm{n}) /(\mathrm{B} / \mathrm{N}) . \mathrm{N}$ - is total number of identified genes; $\mathrm{B}$ - is total number of genes associated with a specific GO term; $\mathrm{n}$ - is number of significant genes added to the GO analysis; $\mathrm{b}$ - is number of significant genes in a specific GO term. The number of genes (\# Genes) represent the number of significant genes in a specific GO term (b) compared to the total number of genes associated with a specific GO term (B).

were elevated in ScAT in participants with hepatic IR, while expression of genes related to RNA metabolism might be downregulated. 


\section{Inflammatory pathways are differentially regulated in muscle-IR vs no-IR}

In the muscle-IR ws no-IR comparison, GO enrichment analysis of 1977 upregulated genes identified $338 \mathrm{GO}$ terms (FDR $p<0.05$ ) (Table S9) and the 1739 downregulated genes identified $123 \mathrm{GO}$ terms (Table S13). The GO term with the highest enrichment in ScAT was 'mitotic cell cycle process' (119 genes related to e.g. cell division cycle and kinesins) (Table 2). In addition, 'immune system response' was enriched (237 genes related to e.g. complement (fold change > 1.2: Complement $\mathrm{C} 1 \mathrm{q}$ binding protein $(C 1 Q B P)$, Complement $\mathrm{C} 3 \mathrm{a}$ receptor 1 (C3AR1), Complement component 4 binding protein beta $(C A B P B)$ and chemokines (fold change > 1.2: Chemokine (C-C motif) ligand $(C C L)-2,-8$, $-19,-21$ ) (Table 2 and S11). The activated immune response could be subdivided into 'antigen processing and presentation' (48 genes, related to e.g. proteasome degradation and lysosomal cathepsins) (Table 2 and S12). Furthermore, 'RNA biosynthetic process' was the most significant GO term with the highest number of downregulated genes (251 genes, related to e.g. zinc finger proteins) (Table 2 and S14). Together, these data point towards an increased expression of genes related to cell division and inflammation in ScAT in participants with muscle IR, while expression of genes related to RNA metabolism may be downregulated.

\section{Distinct pathway enrichment in tissue-specific IR}

In addition to the $\mathrm{GO}$ enrichment analyses, a pathway enrichment analysis was included using the WikiPathways human collection of curated pathways. This showed a distinct expression pattern in the muscle-IR and liver-IR groups as compared to no-IR (Figure 2). Eight pathways were overrepresented in the liver-IR vs no-IR groups and 16 pathways in the muscle-IR vs no-IR comparison with at least one gene $\mid$ fold change $\mid>1.2$ and $p<0.05$ respectively (Table S7 and S15). Like the GO enrichment analyses, pathways related to mitotic cell cycle (e.g. cell cycle) were present in both comparisons. In line with the GO enrichment analyses, WikiPathways related to extracellular matrix (ECM) organization were more prominent in the comparison of liver-IR vs no-IR (e.g. Focal adhesion pathway), while inflammatory pathways were predominant in the comparison between the muscle-IR vs no-IR group (pathways e.g. Microglia pathogen phagocytosis, IL-1 and megakaryocytes in obesity pathway and Complement activation pathway) (Table S7 and S15).

To visualize which genes contributed significantly to the observed distinct transcriptome profiles as presented above, four large WikiPathways with comprehensive information on inflammation and ECM remodeling were selected: Toll-like receptor signaling pathway, 

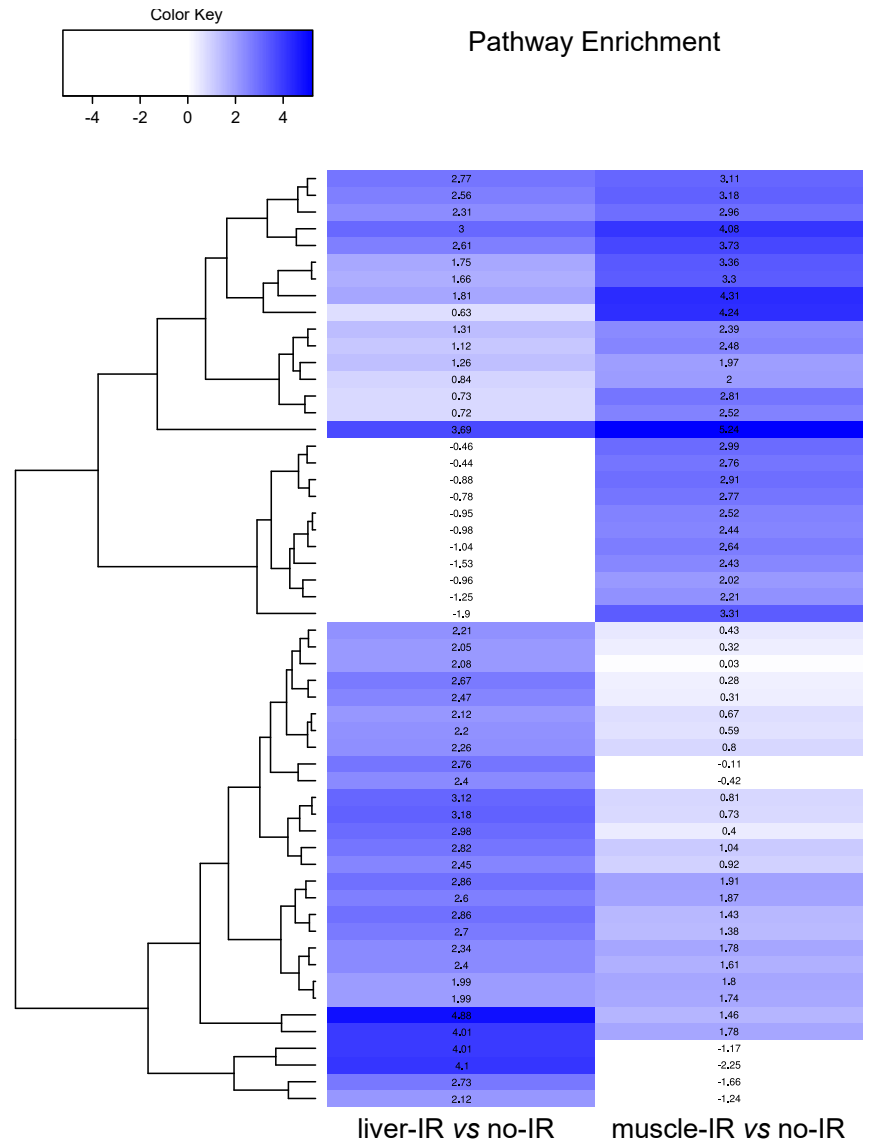

Apopitosis-related network due to al
Transcriptional activation by NRF2

Photodynamic therapy-induced NFE2L2 (NRF2) survival signaling

Cell Cycle

Retinoblastoma (RB) in Cancer

TGF-betta Receptor Signaling

Gastric Cancer Network 1

Gastric Cancer Network 1

Androgen recepplor signaling pathway

DNA IR-Double Strand Breaks (DSBs) and cellular response via ATM

Aryl Hydrocarbon Receptor Pathway

IL1 and megakaryocytes in obesity
Integrated Breast Cancer Pathway

Pathogenic Escherichia coll intection

Regulation of Microtubule

Photodynamic therapy-ind

Oxidative Damage

TYROBP Causal Network
Proteasome Degradation

Pathways Attected in Adenoid Cystic Carcinoma

Type Ill interferon signaling

G13 Signaling Pathway

sis Pattway

EirB Signaling Pathway

Apoptosis Modulation and Signalin

Alpha 6 Beta 4 signaling pathway

Trans-sulfuration pathway

Simplified Int:raction Map Between LoXL4 and Oxidative Stress Pathway

Angiogenesis

Sultation Biotranstormation Reaccion

Inflammatory Response Pathway

Bone Morphogegeric Protein (BMP) Signalling and Regula

Fas Ligand (FasL) pattway and Stress induction of Heat Shock Proteins (HSP) regulation

Hypothesized Palthways in Pathogenesis of Cardovasuascular Disease

Primary Focal S
Bladder Cancer

Senescence and Autophagy in Cancer

Gastric Cancer Network 2

Interentukin-T Induced Aetivation of NF-kappa-B

NRF2 pathway

Osteoclast Signaling
Serotonin Receptor 4 /67 and NR3c Signaling

Human Thyroid Stimulating Hormone (TSH) s

Canonical and Non-Canonical TGF-B signaling

Focal Adhesion

miR-509-3p a aleration of YAP1ECM axis

miRNA targets in ECM

liver-IR vs no-IR muscle-IR vs no-IR

Figure 2. A heatmap representing the pathway enrichment analysis using the WikiPathways curated collection of human pathways. The pathways are ranked based on a standardized difference score $(Z$-score). $Z$-scores $>0$ are indicative of enrichment for significantly different genes, indicated by gradients of a blue color. $Z$-scores $<0$ are indicative of absence of enrichment for significantly different genes, indicated by a white color. Pathways were considered significantly different when i) $\mathrm{Z}$-score $>1.96$, ii) permuted $p<0.05$ and iii) the number of significantly different genes $(p<0.05)$ in the pathway $\geq 3$.

Chemokine signaling pathway, Oxidative damage pathway and Focal adhesion pathway (Figure 3). In the liver-IR vs no-IR comparison, mainly genes related to ECM remodeling were upregulated and the genes with a $\mid$ fold change $\mid>1.2$ were the collagen genes Collagen type IV alpha 4 chain (COL4A4) and Collagen type $\mathrm{V}$ alpha 1 chain (COL5A1), integrin gene Integrin subunit alpha D (ITGAD), and glycoprotein gene Tenascin $\mathrm{C}(T N C)$ (Figure 3a). 
A.

liver-IR vs no-IR

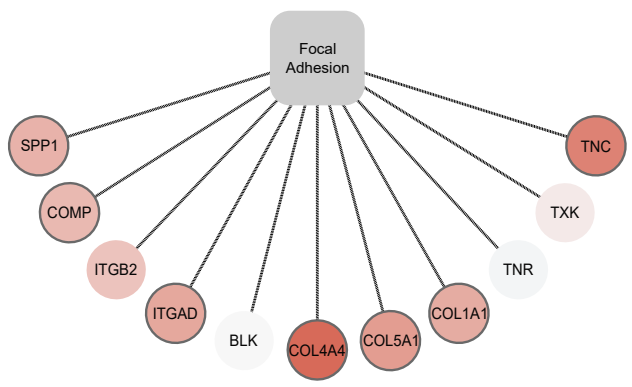

C.

liver-IR vs no-IR

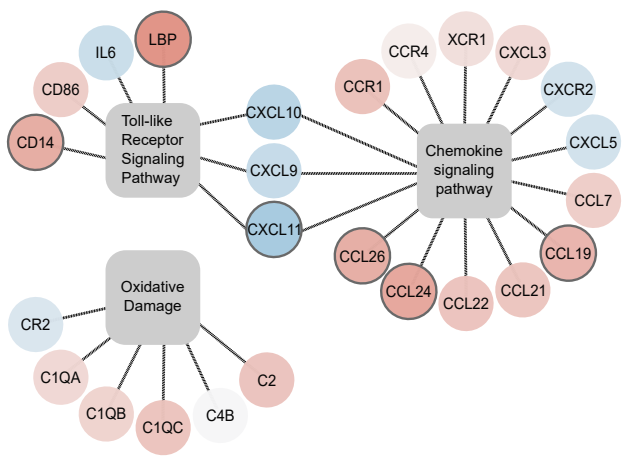

B. muscle-IR vs no-IR

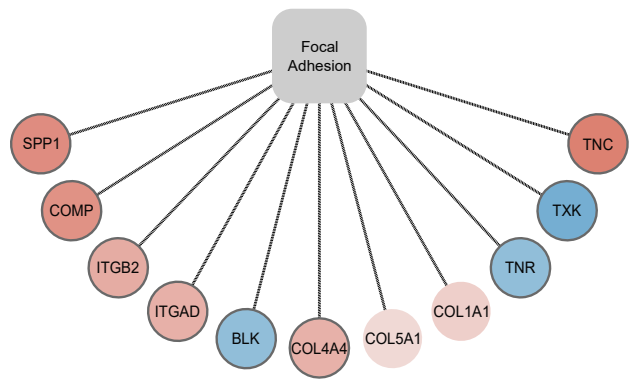

D. muscle-IR vs no-IR

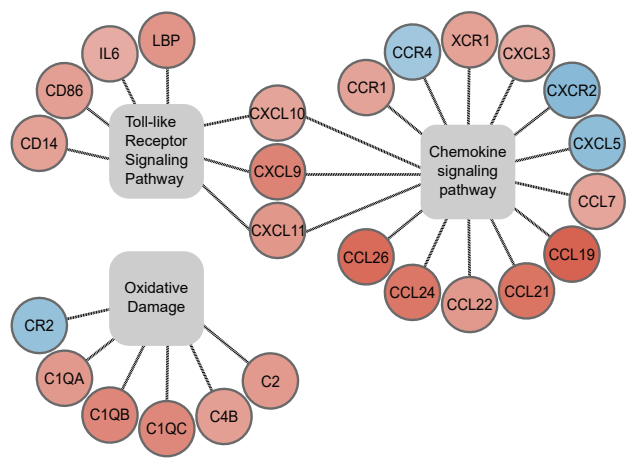

Figure 3. Four large pathways from the WikiPathways human curated collection with comprehensive information on inflammation and ECM remodeling were selected and integrated into two networks. Visualizations were created for the two networks for both the liver-IR vs no-IR and muscle-IR vs no-IR comparison: two diagrams representing ECM remodeling processes in the comparison between liver-IR vs no-IR (A) and muscle-IR vs no-IR (B); two diagrams representing inflammatory processes in the comparison between liver-IR vs no-IR (C) and muscle-IR vs no-IR (D). Only genes with $\mid$ fold change $\mid>1.1$ and $p<0.05$ for the liver-IR vs no-IR and/or muscle-IR vs no-IR comparison were included. Pathway nodes are visualized as rounded rectangles and genes as circles colored based on their fold change. Gradients of blue indicate downregulation, gradients of red indicate upregulation; the color white is used for unchanged genes. Significantly changed genes $(p<0.05)$ are visualized by a gray line around the circle representing the respective gene. 
In the muscle-IR vs no-IR comparison, mainly genes related to inflammatory processes were upregulated. The genes with a fold change $>1.2$ were chemokine genes $C C L 19,-21,-24,-26$ and $\mathrm{C}-\mathrm{X}-\mathrm{C}$ motif chemokine ligand 9 (CXCL9) (Figure 3b). In addition, complement component 1q (C1Q) genes were significantly upregulated (fold change > 1.2). In contrast, several chemokine receptors, such as C-X-C Motif Chemokine Receptor 2 (CXCR2) and C-C Motif Chemokine Receptor 4 (CCR4), were downregulated (fold change $<0.8$ ).

Notably, gene expression pathways as defined by WikiPathways showed similar patterns before and after adjustment for study center, sex, BMI and waist-to-hip ratio (Figure S1). Pathways related to oxidative phosphorylation and electron transport chain were significantly upregulated in the muscle-IR group vs no-IR group comparison in study center adjusted models. However, after additional adjustments for sex, these pathways were not significantly different anymore (Figure S1b).

\section{Systemic low-grade inflammation may be associated with muscle IR in CODAM}

Following up on these transcriptome analyses, we hypothesized that the observed link between upregulation of inflammation-related genes in abdominal ScAT and muscle IR may occur via systemic effects, e.g. via systemic low-grade inflammation. Because systemic inflammation markers were not available in DiOGenes, we performed a complementary analysis in the CODAM study in which MISI and HIRI also have been estimated (21).

CODAM participants characteristics can be found in Table S16. In general, CODAM participants were less often women (41\%), were older $(59 \pm 7$ years) and were less obese $\left(28.0 \pm 4.0 \mathrm{~kg} / \mathrm{m}^{2}\right)$ than DiOGenes participants. In addition, CODAM participants had higher hepatic IR (HIRI: $41.0 \pm 12.9$ AU), but comparable muscle insulin sensitivity (MISI: $0.06 \pm 0.04 \mathrm{AU}$ ).

In 420 non-diabetic individuals, we found that a combined score of eight plasma markers of low-grade inflammation may be specifically related to muscle insulin sensitivity. The low grade inflammation score was negatively associated with MISI (standardized (std) $\beta$ : -0.125 ; 95\% CI [-0.211, -0.039]; $p=0.004)$ in a linear regression analysis that was adjusted for hepatic IR. Notably, the low-grade inflammation score was not significantly associated with HIRI $(\operatorname{std} \beta: 0.045,95 \%$ CI [-0.043, 0.132]; $p=0.316)$. After additional adjustments for sex, BMI and waist-to-hip ratio, the association between the low-grade inflammation and MISI was attenuated ( $\operatorname{std} \beta:-0.07195 \%$ CI [-0.160, 0.018]; $p=0.116)$. 


\section{Discussion}

The present study evaluated whether specific transcriptome patterns in abdominal ScAT were associated with more pronounced IR in either the liver or skeletal muscle. These IR phenotypes were derived from an 5-point OGTT, as validated previously (22). Here, we show in a cross-sectional evaluation of non-diabetic overweight and obese individuals without cardiovascular disorders that abdominal ScAT gene expression related to inflammation (including chemokines and complement) was increased in individuals with more pronounced muscle IR, while ECM-related genes were higher expressed in more pronounced liver-IR individuals.

Increased abdominal ScAT inflammation appeared to be a predominant phenotype in muscle-IR individuals. This was mainly determined by upregulation of genes involved in chemotaxis, complement activation and immune cell function related to lysosomes (e.g. cathepsins) and ubiquitin-proteasome. Adipose tissue inflammation has been hypothesized as a central factor in the development of IR, at least in rodents, but the initial trigger and the sequence of events related to the infiltration of multiple immune cells is largely unknown (31). In this study, T-cell recruiting chemokine genes such as CCL19, -21 and CXCL9 were significantly upregulated (fold change $>1.2$ ) in the muscle-IR individuals as compared to noIR individuals. In line, several chemokines have been reported to be of importance in the etiology of obesity-associated inflammation and IR in recent years (32). Chemokines are crucial for the attraction of leukocytes from the circulation into tissues, including macrophages and T-cells. For instance, it is known that higher total leukocyte counts precede and predict the incident risk of type 2 diabetes (33). Additionally, overrepresentation of T-cell-recruiting and activating genes is of interest, given the recent implication of $\mathrm{T}$-cell recruitment in obesity-related adipose tissue inflammation and IR in animal models (34), although T-cell infiltration in humans is much less characterized (35).

Next to the upregulation of chemokine genes, we found an upregulation of lysosomal genes such as cathepsins, and genes in the ubiquitin-proteasome pathway by which many intracellular proteins are degraded, in muscle-IR versus no-IR individuals. In addition, several oxidative damage factors, including complement factor $\mathrm{C} 1 \mathrm{q}$, were upregulated in ScAT of muscle-IR individuals. All these processes are related to removal of cell debris and may point towards an increased adipocyte apoptosis (36). Moreover, complement factors are known to enhance phagocytosis by linking apoptotic cells and phagocytes, and contribute to the rapid clearance of dead cells (37). Notably, cell death is associated with an increased immune cell 
infiltration (e.g. macrophages) and local tissue inflammation (38). Upregulation of ScAT C1Q is consistent with previous reports on ScAT gene expression. For instance, C1Q was found to be upregulated in monozygotic twins discordant for BMI (39), in metabolically unhealthy individuals (40), dyslipidemic individuals (41) and whole-body IR vs insulin-sensitive individuals $(18,42)$. Notably, C1Qa knockout mice were protected from high-fat diet-induced adipose tissue inflammation, systemic glucose intolerance and hepatic IR (43). In addition, obesity-related adipocyte death was slightly increased in C1Qa knockout mice, implying that a reduction in the efficacy of clearing dead adipocytes may reduce macrophage inflammatory activation (43). Together, these data may point towards involvement of $\mathrm{C} 1 \mathrm{q}$ in ScAT (dys)function. Alternatively, it has been shown that $\mathrm{C} 1 \mathrm{q}$ is closely related to impaired regenerative capacity of skeletal muscle via Wnt signaling in rodents (44) and sarcopenia in humans (45). Therefore, our ScAT transcriptome data might also reflect simultaneous processes developing in the muscle that are related to C1q. Nevertheless, how these differential transcriptome profiles specifically are linked to muscle IR remains to be studied.

Interestingly, the ScAT inflammatory gene expression profile was only found in individuals with a more pronounced muscle-IR phenotype. A possible mechanism that might link ScAT transcriptome with peripheral insulin sensitivity is the secretion of pro- and antiinflammatory adipokines into the circulation (8). For instance, secretion media derived from ScAT explants of obese individuals impaired insulin signaling in human myotubes $(46,47)$ and hepatocytes (47). Based on the present ScAT transcriptome data, we hypothesized that the upregulation of inflammation-related genes in abdominal ScAT may contribute to a more pro-inflammatory profile in the circulation, which might be more related to peripheral tissues (e.g. muscle) than liver. This may possibly be due to a differential blood supply to tissues since the liver is also strongly affected by portal vein supply and factors derived from the visceral adipose tissue. Indeed, in a comparable cohort, the CODAM study, we showed that a lowgrade inflammation score composed out of eight plasma inflammatory markers, was inversely associated with muscle insulin sensitivity (MISI), while we did not observe an association between with hepatic IR (HIRI) and the systemic low-grade inflammation score. Notably, after adjustments for sex and body composition (i.e. BMI and waist-to-hip ratio), the association between MISI and the low-grade inflammation score was attenuated. How the individual plasma inflammatory markers specifically relate to ScAT gene expression remains to be further studied. Nevertheless, these data may provide support for the hypothesis that the link between an inflammatory ScAT gene expression profile as found in DiOGenes, may 
translate into an increased systemic inflammatory profile, thereby explaining the link with peripheral insulin sensitivity.

In the fully adjusted analyses for sex and body composition, we did not observe pathways related to adipose tissue oxidative and lipid metabolism. Notably, before these adjustments, pathways related to oxidative phosphorylation and electron transport chain were significantly different in the muscle-IR group vs no-IR group. After adjustment for sex, these pathways were not significant anymore. This may not be entirely consistent with several previous studies, showing that genes related to adipose tissue lipid metabolism and cellular energy homeostasis might play an important role in the development of IR. Indeed, increased basal and an impaired catecholamine-stimulated lipolysis from larger adipocytes (48) resulting in higher release of non-esterified fatty acids may be a characteristic of IR (9). Additionally, genes related to lipid metabolism were among the most pronounced downregulated pathways in whole-body IR conditions $(17,42,49)$. However, another ScAT gene expression study in obesity-matched individuals showed that lipid metabolism-related pathways were only slightly differentially regulated following insulin stimulation (50). Since the present analysis in the DiOGenes study was only performed in fasted ScAT biopsies, we cannot exclude that minor transcriptional changes in lipid metabolism pathways may be of more importance in the postprandial state.

In liver-IR individuals, increased ECM remodeling in the abdominal ScAT was a predominant phenotype in the present study. In obese conditions, increased adipose tissue accumulation of ECM components may decrease ECM flexibility and reduce adipose tissue plasticity by triggering adipocyte necrosis. This might ultimately lead to adipocyte dysfunction (51). In general, abnormal collagen deposition is tightly associated with increased local inflammation, characterized by infiltration of macrophages and other immune cells (52). Remarkably, we observed neither a significant upregulation of inflammatory genes in liver-IR individuals when compared to no-IR individuals, nor a relationship between the systemic lowgrade inflammation score and hepatic IR. It may be that our ScAT transcriptome data might reflect simultaneous processes related to ECM remodeling and fibrosis in the liver, which could in turn contribute to hepatic IR. Indeed, it has been shown that hepatic IR is also closely associated with an increased ECM remodeling and fibrosis in the liver (53).

The major strength of our study is the availability of abdominal ScAT transcriptome data in combination with a 5-point OGTT in a relatively large cohort. This enabled us to estimate muscle IR as well as hepatic IR in each participant. Importantly, the calculated MISI and 
HIRI represent different responses to the OGTT and they have been validated against the gold standard hyperinsulinemic-euglycemic clamp (22). For the first time, we related this detailed information regarding metabolic phenotype to comprehensive information on abdominal ScAT transcriptome. Therefore, this adds new information to deepen our understanding of the IR etiology. In addition, our results likely represent early events in the process of IR because the data were generated in non-diabetic overweight and obese individuals without cardiometabolic diseases. The main limitation of our study is its crosssectional design which prohibits causal inference. Furthermore, we have no information on the cellular composition of the ScAT samples in term of e.g. immune cell infiltration.

In conclusion, an inflammatory gene expression profile in abdominal ScAT was present in obese individuals with pronounced muscle IR, and muscle IR but not hepatic IR was associated with an increased systemic inflammatory profile. Based on these findings, we hypothesize that an increased systemic inflammatory profile is a putative mechanism linking the increased expression of inflammatory genes in abdominal ScAT to muscle IR. In contrast, in obese individuals with pronounced hepatic IR, expression of genes related to ECM remodeling was observed. We speculate that the ECM remodeling-related expression profile in ScAT might reflect simultaneous processes occurring in other tissues, including the liver. In the individuals with hepatic IR no clear relation with inflammation was observed, either in ScAT or systemically. The mechanisms that relate abdominal ScAT transcriptome profiles to tissue-specific IR should be further explored. 


\section{References}

1. Ng M, Fleming T, Robinson M, Thomson B, Graetz N, Margono C, et al. Global, regional, and national prevalence of overweight and obesity in children and adults during 1980-2013: a systematic analysis for the Global Burden of Disease Study 2013. Lancet. 2014;384:766-81.

2. Van Gaal LF, Mertens IL, De Block CE. Mechanisms linking obesity with cardiovascular disease. Nature. 2006;444:875-80.

3. Kahn SE, Hull RL, Utzschneider KM. Mechanisms linking obesity to insulin resistance and type 2 diabetes. Nature. 2006;444:840-6.

4. Goossens GH. The Metabolic Phenotype in Obesity: Fat Mass, Body Fat Distribution, and Adipose Tissue Function. Obes Facts. 2017;10:207-15.

5. Klöting N, Blüher M. Adipocyte dysfunction, inflammation and metabolic syndrome. Rev Endocr Metab Disord. 2014;15:277-87.

6. Hoffstedt J, Arner E, Wahrenberg H, Andersson DP, Qvisth V, Löfgren P, et al. Regional impact of adipose tissue morphology on the metabolic profile in morbid obesity. Diabetologia. 2010;53:2496-503.

7. McArdle MA, Finucane OM, Connaughton RM, McMorrow AM, Roche HM. Mechanisms of ObesityInduced Inflammation and Insulin Resistance: Insights into the Emerging Role of Nutritional Strategies. Front Endocrinol (Lausanne). 2013;4:1-23.

8. Kwon H, Pessin JE. Adipokines Mediate Inflammation and Insulin Resistance. Front Endocrinol (Lausanne). 2013;4:1-13.

9. Stinkens R, Goossens GH, Jocken JWE, Blaak EE. Targeting fatty acid metabolism to improve glucose metabolism. Obes Rev. 2015;16:715-57.

10. Goossens G, Moors C, Jocken J, van der Zij1 N, Jans A, Konings E, et al. Altered Skeletal Muscle Fatty Acid Handling in Subjects with Impaired Glucose Tolerance as Compared to Impaired Fasting Glucose. Nutrients. 2016;8:164-15.

11. Blaak EE. Characterisation of fatty acid metabolism in different insulin-resistant phenotypes by means of stable isotopes. Proc Nutr Soc. 2017;:1-7.

12. Stefan N, Fritsche A, Schick F, Häring H-U. Phenotypes of prediabetes and stratification of cardiometabolic risk. Lancet Diabetes Endocrinol. 2016;4:789-98.

13. Bird SR, Hawley JA. Update on the effects of physical activity on insulin sensitivity in humans. BMJ Open Sport Exerc Med. 2016;2:e000143.

14. Zheng J, Woo S-L, Hu X, Botchlett R, Chen L, Huo Y, et al. Metformin and metabolic diseases: a focus on hepatic aspects. Front Med. 2015;9:173-86.

15. Blanco-Rojo R, Alcala-Diaz JF, Wopereis S, Perez-Martinez P, Quintana-Navarro GM, Marin C, et al. The insulin resistance phenotype (muscle or liver) interacts with the type of diet to determine changes in disposition index after 2 years of intervention: the CORDIOPREV-DIAB randomised clinical trial. Diabetologia. 2016;59:67-76.

16. Keller MP, Attie AD. Physiological Insights Gained from Gene Expression Analysis in Obesity and Diabetes. Annu Rev Nutr. 2010;30:341-64.

17. Elbein SC, Kern PA, Rasouli N, Yao-Borengasser A, Sharma NK, Das SK. Global gene expression profiles of subcutaneous adipose and muscle from glucose-tolerant, insulin-sensitive, and insulin-resistant individuals matched for BMI. Diabetes. 2011;60:1019-29. 
18. Soronen J, Laurila P-P, Naukkarinen J, Surakka I, Ripatti S, Jauhiainen M, et al. Adipose tissue gene expression analysis reveals changes in inflammatory, mitochondrial respiratory and lipid metabolic pathways in obese insulin-resistant subjects. BMC Med Genomics. 2012;5:9.

19. Armenise C, Lefebvre G, Carayol J, Bonnel S, Bolton J, Di Cara A, et al. Transcriptome profiling from adipose tissue during a low-calorie diet reveals predictors of weight and glycemic outcomes in obese, nondiabetic subjects. Am J Clin Nutr. 2017;106:736-46.

20. Larsen TM, Dalskov S-M, van Baak M, Jebb SA, Papadaki A, Pfeiffer AFH, et al. Diets with high or low protein content and glycemic index for weight-loss maintenance. N Engl J Med. 2010;363:2102-13.

21. Hertle E, van Greevenbroek MM, Arts IC, van der Kallen CJ, Geijselaers SL, Feskens EJ, et al. Distinct associations of complement $\mathrm{C} 3 \mathrm{a}$ and its precursor $\mathrm{C} 3$ with atherosclerosis and cardiovascular disease. The CODAM study. Thromb Haemost. 2014;111:1102-11.

22. Abdul-Ghani MA, Matsuda M, Balas B, DeFronzo RA. Muscle and liver insulin resistance indexes derived from the oral glucose tolerance test. Diabetes Care. 2007;30:89-94.

23. Dobin A, Davis CA, Schlesinger F, Drenkow J, Zaleski C, Jha S, et al. STAR: ultrafast universal RNAseq aligner. Bioinformatics. 2012;29:15-21.

24. Morgan M, Pagès H, Obenchain V, Hayden N. Rsamtools: Binary alignment (BAM), FASTA, variant call (BCF), and tabix file import. R package version 1.18. 2. 2010.

25. Love MI, Huber W, Anders S. Moderated estimation of fold change and dispersion for RNA-seq data with DESeq2. Genome Biol. 2014;15:31-21.

26. Eden E, Navon R, Steinfeld I, Lipson D, Yakhini Z. GOrilla: a tool for discovery and visualization of enriched GO terms in ranked gene lists. BMC Bioinformatics. 2009;10:48-7.

27. Kelder T, Eijssen L, Kleemann R, van Erk M, Kooistra T, Evelo C. Exploring pathway interactions in insulin resistant mouse liver. BMC Syst Biol. 2011;5:127.

28. Shannon P, Markiel A, Ozier O, Baliga NS, Wang JT, Ramage D, et al. Cytoscape: A software environment for integrated models of biomolecular interaction networks. Genome Res. 2003;13:2498-504.

29. Kutmon M, Evelo CT, Coort SL. A network biology workflow to study transcriptomics data of the diabetic liver. BMC Genomics. 2014;15:971.

30. Wlazlo N, van Greevenbroek MMJ, Ferreira I, Feskens EJM, van der Kallen CJH, Schalkwijk CG, et al. Complement factor 3 is associated with insulin resistance and with incident type 2 diabetes over a 7-year follow-up period: the CODAM Study. Diabetes Care. 2014;37:1900-9.

31. Lee B-C, Lee J. Cellular and molecular players in adipose tissue inflammation in the development of obesity-induced insulin resistance. Biochim Biophys Acta. 2014;1842:446-62.

32. Tourniaire F, Romier-Crouzet B, Lee JH, Marcotorchino J, Gouranton E, Salles J, et al. Chemokine Expression in Inflamed Adipose Tissue Is Mainly Mediated by NF-кB. Xu H, editor. PLoS ONE. 2013;8:e66515-9.

33. Vozarova B, Weyer C, Lindsay RS, Pratley RE, Bogardus C, Tataranni PA. High white blood cell count is associated with a worsening of insulin sensitivity and predicts the development of type 2 diabetes. Diabetes. 2002;51:455-61.

34. Guzik TJ, Skiba DS, Touyz RM, Harrison DG. The role of infiltrating immune cells in dysfunctional adipose tissue. Cardiovasc Res. 2017;113:1009-23.

35. Travers RL, Motta AC, Betts JA, eacute AB, Thompson D. The impact of adiposity on adipose tissueresident lymphocyte activation in humans. Int J Obes (Lond). 2014;39:762-9. 
36. Jaishy B, Abel ED. Lipids, lysosomes, and autophagy. J Lipid Res. 2016;57:1619-35.

37. Trouw LA, Blom AM, Gasque P. Role of complement and complement regulators in the removal of apoptotic cells. Mol Immunol. 2008;45:1199-207.

38. Kuroda M, Sakaue H. Adipocyte Death and Chronic Inflammation in Obesity. J Med Invest. 2017;64:193-6.

39. Pietiläinen KH, Naukkarinen J, Rissanen A, Saharinen J, Ellonen P, Keränen H, et al. Global transcript profiles of fat in monozygotic twins discordant for BMI: pathways behind acquired obesity. Groop LC, editor. PLoS Med. 2008;5:e51.

40. Das SK, Ma L, Sharma NK. Adipose tissue gene expression and metabolic health of obese adults. Int J Obes (Lond). 2015;39:869-73.

41. van Greevenbroek MMJ, Ghosh S, van der Kallen CJH, Brouwers MCGJ, Schalkwijk CG, Stehouwer CDA. Up-Regulation of the Complement System in Subcutaneous Adipocytes from Nonobese, Hypertriglyceridemic Subjects Is Associated with Adipocyte Insulin Resistance. J Clin Endocrinol Metab. 2012;97:4742-52.

42. Wiklund P, Zhang X, Pekkala S, Autio R, Kong L, Yang Y, et al. Insulin resistance is associated with altered amino acid metabolism and adipose tissue dysfunction in normoglycemic women. Sci Rep. 2016;6:24540.

43. Hillian AD, McMullen MR, Sebastian BM, Roychowdhury S, Rowchowdhury S, Kashyap SR, et al. Mice lacking $\mathrm{C} 1 \mathrm{q}$ are protected from high fat diet-induced hepatic insulin resistance and impaired glucose homeostasis. J Biol Chem. 2013;288:22565-75.

44. Naito AT, Sumida T, Nomura S, Liu M-L, Higo T, Nakagawa A, et al. Complement C1q activates canonical Wnt signaling and promotes aging-related phenotypes. Cell. 2012;149:1298-313.

45. Watanabe S, Sato K, Hasegawa N, Kurihara T, Matsutani K, Sanada K, et al. Serum C1q as a novel biomarker of sarcopenia in older adults. FASEB J. 2015;29:1003-10.

46. Sarr O, Strohm R, MacDonald T, Gaudio N, Reed J, Foute-Nelong J, et al. Subcutaneous and Visceral Adipose Tissue Secretions from Extremely Obese Men and Women both Acutely Suppress Muscle Insulin Signaling. Int J Mol Sci. 2017;18:959-7.

47. Kranendonk MEG, Visseren FLJ, van Herwaarden JA, Nolte-'t Hoen ENM, de Jager W, Wauben MHM, et al. Effect of extracellular vesicles of human adipose tissue on insulin signaling in liver and muscle cells. Obesity. 2014;22:2216-23.

48. Laurencikiene J, Skurk T, Kulyté A, Hedén P, Åström G, Sjölin E, et al. Regulation of Lipolysis in Small and Large Fat Cells of the Same Subject. J Clin Endocrinol Metab. 2011;96:E2045-9.

49. Klimcakova E, Roussel B, Márquez-Quiñones A, Kováčová Z, Kováčiková M, Combes M, et al. Worsening of Obesity and Metabolic Status Yields Similar Molecular Adaptations in Human Subcutaneous and Visceral Adipose Tissue: Decreased Metabolism and Increased Immune Response. J Clin Endocrinol Metab. 2011;96:E73-E82.

50. Rydén M, Hrydziuszko O, Mileti E, Raman A, Bornholdt J, Boyd M, et al. The Adipose Transcriptional Response to Insulin Is Determined by Obesity, Not Insulin Sensitivity. Cell Rep. 2016;16:2317-26.

51. Sun K, Tordjman J, Clement K, Scherer PE. Fibrosis and Adipose Tissue Dysfunction. Cell Metab. 2013;18:470-7.

52. Lin D, Chun T-H, Kang L. Adipose extracellular matrix remodelling in obesity and insulin resistance. Biochem Pharmacol. 2016;119:8-16.

53. Koyama Y, Brenner DA. Liver inflammation and fibrosis. J Clin Invest. 2017;127:55-64. 


\section{Supplementary Data}

A.
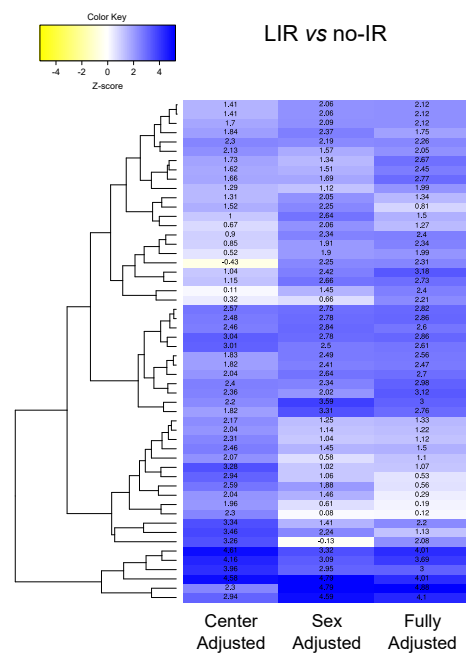

B.
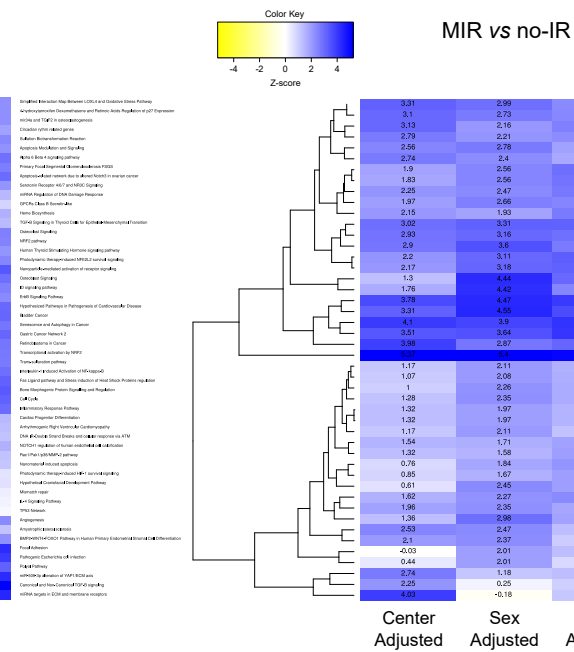

Figure S1 Heatmaps of the pathway enrichment analysis using the WikiPathways curated collection of human pathways for (A) liver-IR vs no-IR comparison (B) muscle-IR vs no-IR comparison. The analyses were performed based on the differential expression analysis adjusted for i) study center, ii) study center and sex, and iii) study center, sex, BMI and waist-to-hip ratio (referred to as 'Fully Adjusted)'. Z-scores > 0 are indicative of enrichment for significantly changes genes, indicated by gradients of a blue color. Z-scores $<0$ are indicative of absence of enrichment for significantly changes genes, indicated by a yellow color. Pathways were considered significantly changed when i) $\mathrm{Z}$-score $>1.96$, ii) permuted $p<0.05$ and iii) the number of significantly changed genes $(p<0.05)$ in the pathway $\geq 3$. 
Table S16. Participants characteristics of the CODAM study

\begin{tabular}{|c|c|c|c|c|c|}
\hline & $\begin{array}{c}\text { no-IR } \\
(\mathrm{n}=232)\end{array}$ & $\begin{array}{c}\text { muscle-IR } \\
(n=63)\end{array}$ & $\begin{array}{l}\text { liver-IR } \\
(\mathrm{n}=46)\end{array}$ & $\begin{array}{c}\text { muscle/liverIR } \\
(\mathrm{n}=79)\end{array}$ & $p$ \\
\hline Female sex (\%) & 38 & 49 & 41 & 42 & 0.405 \\
\hline Age (y) & $58.9 \pm 7.3$ & $59.62 \pm 7.6$ & $57.8 \pm 7.1$ & $59.8 \pm 6.3$ & 0.405 \\
\hline BMI $\left(\mathrm{kg} / \mathrm{m}^{2}\right)$ & $26.4 \pm 3.1$ & $28.7 \pm 3.5^{*}$ & $29.2 \pm 5.1^{*}$ & $31.1 \pm 4.2^{* \#}$ & $<0.001$ \\
\hline Waist (cm) & $93.4 \pm 9.6$ & $98.2 \pm 8.5^{\circ}$ & $102.1 \pm 13.4^{*}$ & $105.6 \pm 11.8^{* *}$ & $<0.001$ \\
\hline Waist-to-hip ratio & $0.93 \pm 0.08$ & $0.93 \pm 0.07$ & $0.96 \pm 0.08^{*}$ & $0.97 \pm 0.08^{*}$ & 0.002 \\
\hline Body fat (\%) & $28.9 \pm 7.0$ & $32.2 \pm 7.9^{\circ}$ & $32.1 \pm 7.4$ & $35.1 \pm 6.9^{*}$ & $<0.001$ \\
\hline $\mathrm{SBP}(\mathrm{mmHg})$ & $135 \pm 18$ & $144 \pm 21^{*}$ & $136 \pm 16$ & $142 \pm 17^{*}$ & $<0.001$ \\
\hline $\mathrm{DBP}(\mathrm{mmHg})$ & $79 \pm 9$ & $84 \pm 10^{\circ}$ & $81 \pm 9$ & $84 \pm 8^{*}$ & $<0.001$ \\
\hline Cholesterol $(\mathrm{mmol} / \mathrm{L})$ & $5.2 \pm 0.9$ & $5.4 \pm 1.0$ & $5.3 \pm 0.8$ & $5.3 \pm 0.9$ & 0.276 \\
\hline $\mathrm{HDL}(\mathrm{mmol} / \mathrm{L})$ & $1.3 \pm 0.4$ & $1.3 \pm 0.4$ & $1.2 \pm 0.3$ & $1.1 \pm 0.3^{*}$ & $<0.001$ \\
\hline $\mathrm{LDL}(\mathrm{mmol} / \mathrm{L})$ & $3.3 \pm 0.9$ & $3.4 \pm 0.9$ & $3.5 \pm 0.8$ & $3.4 \pm 0.8$ & 0.585 \\
\hline TAG (mmol/L) & $1.3 \pm 0.6$ & $1.5 \pm 0.6^{*}$ & $1.6 \pm 0.8^{*}$ & $1.9 \pm 0.8^{\approx \#}$ & $<0.001$ \\
\hline NEFA (mmol/L) & $0.5 \pm 0.2$ & $0.5 \pm 0.2$ & $0.5 \pm 0.2$ & $0.6 \pm 0.2^{*}$ & 0.013 \\
\hline Fasting glucose $(\mathrm{mmol} / \mathrm{L})$ & $5.4 \pm 0.5$ & $5.3 \pm 0.4$ & $5.5 \pm 0.5^{\#}$ & $5.7 \pm 0.5^{*}$ & $<0.001$ \\
\hline Fasting insulin (mU/L) & $7.4[5.7-9.2]$ & $10.6[7.8-12.6]^{*}$ & $12.8[8.9-16.5]^{*}$ & $19.2[15.4-26.3]^{* \# \S}$ & $<0.001$ \\
\hline HIRI (AU) & $33.5 \pm 6.1$ & $37.1 \pm 5.4^{*}$ & $54.4 \pm 8.0^{*}$ & $58.7 \pm 11.1^{* \# \S}$ & $<0.001$ \\
\hline MISI (AU) & $0.07[0.05-0.10]$ & $0.03[0.02-0.03]^{*}$ & $0.05[0.04-0.08]$ & $0.02[0.01-0.03]^{\star \S}$ & $<0.001$ \\
\hline LGI (AU) & $-0.21 \pm 0.95$ & $0.15 \pm 1.14$ & $-0.03 \pm 0.83$ & $0.14 \pm 0.88^{\circ}$ & 0.008 \\
\hline Haptoglobin (g/L) & $1.25 \pm 0.48$ & $1.24 \pm 0.64$ & $1.30 \pm 0.48$ & $1.25 \pm 0.47$ & 0.951 \\
\hline Ceruloplasmin (g/L) & $0.27 \pm 0.05$ & $0.27 \pm 0.06$ & $0.26 \pm 0.04$ & $0.27 \pm 0.06$ & 0.612 \\
\hline $\mathrm{CRP}(\mathrm{mg} / \mathrm{L})$ & $1.5[0.8-3.1]$ & $2.1[1.0-4.4]^{*}$ & $1.6[0.9-3.6]$ & $2.4[1.4-4.0]^{*}$ & 0.002 \\
\hline $\mathrm{SAA}(\mathrm{mg} / \mathrm{L})$ & $1.2[0.9-2.0]$ & $1.7[1.0-3.4]^{*}$ & $1.5[1.0-2.1]$ & $1.5[1.0-2.4]$ & 0.001 \\
\hline IL-6 (ng/L) & $1.4[1.0-2.2]$ & $1.4[1.1-2.1]$ & $1.3[1.0-2.1]$ & $1.8[1.3-2.5]^{*}$ & 0.027 \\
\hline IL-8 (ng/L) & $4.2[3.4-5.3]$ & $4.4[3.7-5.5]$ & $3.9[3.4-4.8]$ & $4.2[3.5-5.3]$ & 0.192 \\
\hline TNF- $\alpha(n g / L)$ & $6.0[5.1-7.4]$ & $6.2[5.6-8.0]$ & $6.8[5.4-7.8]$ & $6.2[5.1-7.8]$ & 0.158 \\
\hline sICAM-1 ( $\mu \mathrm{g} / \mathrm{L})$ & 202 [181-228] & 213 [190-251] & $227[191-250]^{*}$ & $219[198-254]^{*}$ & $<0.001$ \\
\hline
\end{tabular}

Data are mean $\pm \mathrm{SD}$ (normally distributed variables), median [interquartile range] (skewed variables) or proportion (\%, categorical variables). $p$-values were obtained by ANOVA, ANOVA of $\log _{e}$-transformed variables or Pearson $\mathrm{Chi}^{2}$. In addition, Bonferroni post hoc tests were performed. $p<0.05$ for the difference with no-IR group; ${ }^{*} p<0.05$ for the difference with muscle-IR group; ${ }^{\S} p<0.05$ for difference with liver-IR group. SBP: systolic blood pressure; DBP: diastolic blood pressure; HDL: high-density lipoprotein; LDL: low-density lipoprotein; NEFA: non-esterified fatty acids; HOMA-IR: homeostatic model for assessment of insulin resistance; HIRI: hepatic insulin resistance index; MISI: muscle insulin sensitivity index; LGI: low-grade inflammation score; CRP: C-reactive protein; SAA: serum amyloid A; IL-6: interleukin-6; IL-8: inteleukin-8; sICAM-1: soluble intercellular adhesion molecule 1. 


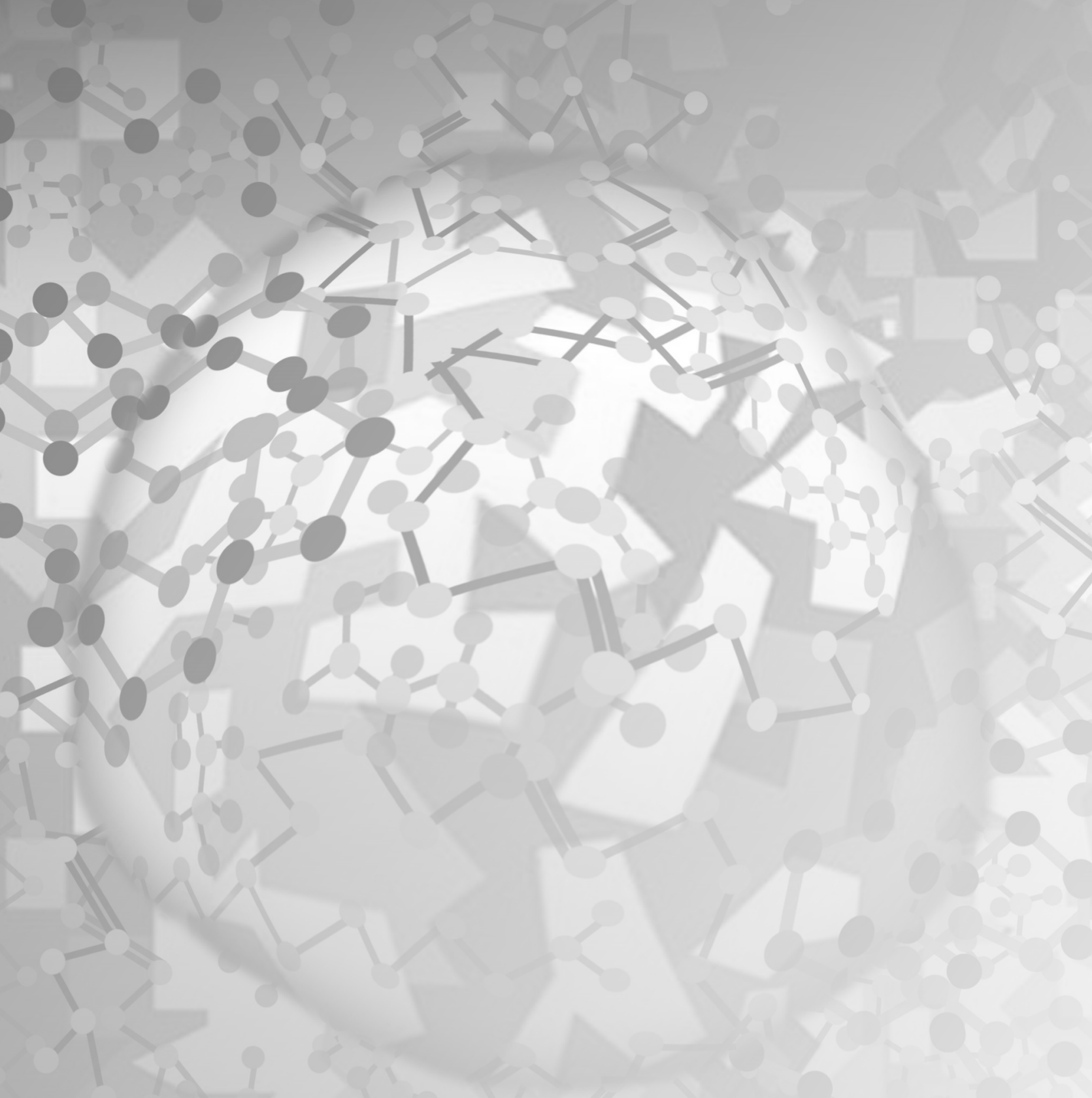


Chapter 7

General Discussion 
160 | Chapter 7 
Obesity and its metabolic consequences are major contributors to morbidity and mortality worldwide. Obesity is strongly linked to the development of insulin resistance, which in turn is a major risk factor in the development of cardiometabolic diseases.

Insulin resistance can develop simultaneously in multiple organs and severity may vary between organs. Over the years, it has been convincingly shown that there is a complex interplay between metabolic insulin sensitive organs involved in lipid metabolism, such as adipose tissue, skeletal muscle and liver. In addition, impairments in lipid metabolism play an important role in the development and progression of insulin resistance.

The present thesis therefore aimed to study multiple aspects of lipid metabolism in relation to whole-body and tissue-specific insulin resistance using a physiological approach. This final chapter summarizes and discusses the main findings of this thesis. First, methodological assessment of whole-body and tissue-specific insulin resistance will be addressed, followed by the discussion on skeletal muscle lipid metabolism in relation to wholebody insulin resistance. The second part of the discussion zooms in on tissue-specific aspects of insulin resistance in relation to the plasma lipidome and adipose tissue transcriptome profiles. Finally, the main conclusions and recommendations for future research are presented.

\section{Assessment of whole-body and tissue-specific insulin resistance}

Quantification and characterization of insulin resistance is a crucial step in phenotyping individuals who are at increased cardiometabolic risk. Many methods and indices are available for the estimation of insulin resistance and each method has its own pros and cons. In this paragraph, the gold standard to assess insulin resistance will be discussed as well as simpler or 'surrogate' approaches that were applied in this thesis.

The gold standard for measuring insulin sensitivity is the hyperinsulinemic-euglycemic clamp technique (1). It is a steady-state technique and consists of a constant intravenous infusion of insulin to achieve a constant hyperinsulinemic state combined with a variable glucose infusion to maintain a euglycemic state (2). The one-step clamp measures primarily peripheral insulin sensitivity, e.g. skeletal muscle. Hepatic and adipose insulin sensitivity can be assessed by using a two-step hyperinsulinemic-euglycemic clamp in combination with a $\left[6,6-{ }^{2} \mathrm{H}_{2}\right]$-glucose tracer. This method is appropriate to assess tissue-specific insulin sensitivity and is often applied in well-controlled human intervention and cross-sectional studies $(3,4)$. 
Despite its undoubted position as gold standard, it should be kept in mind that it is not physiological to increase plasma insulin concentrations for several hours. Additionally, intravenous insulin infusion bypasses the incretin effect of the gut and does not consider glucose effectiveness. However, due to its relatively low coefficient of variation, the clamp technique can be applied in relatively small intervention studies $(3,4)$, but it is time and money consuming (1). For this reason, simplified or 'surrogate' measures for the quantification of insulin sensitivity have been developed. Various indices of insulin sensitivity/resistance were proposed in the last 30 years (5) using data from fasting glucose and insulin concentrations or after the ingestion of an oral glucose load (oral glucose tolerance test, OGTT). The advantage is that these methods may be more suitable for studying large numbers of individuals. Notably, as for all methodologies, the investigator should be aware of the limitations that come along with these surrogate measures of insulin sensitivity.

In part I of this thesis (chapter 2), we measured insulin resistance by means of the homeostatic model assessment for insulin resistance (HOMA-IR) (6). HOMA-IR describes glucose and insulin homeostasis by means of a set of simple, mathematically derived nonlinear equations from a fasting blood sample. HOMA-IR may be primarily reflective of hepatic insulin resistance due to the use of only fasting glucose and insulin concentrations. Nevertheless, previous studies have also shown strong correlations between HOMA-IR and peripheral insulin sensitivity, as measured by the gold-standard hyperinsulinemic-euglycemic clamp (7). Therefore, HOMA-IR is often used as a marker for whole-body insulin resistance. In chapter 2, we divided participants into two groups based on the median of HOMA-IR: mild insulin resistance (mild-IR) and high insulin resistance (high-IR). Additionally, we measured postprandial insulin sensitivity by net glucose uptake across skeletal muscle after consumption of a standardized high-saturated fatty acid (high-SFA) rich mixed-meal. This reflects a more physiological postprandial response to insulin. The oral route of delivery certifies that gut-related factors, such as incretin hormone secretion and nutrient-sensing in the gut, are considered as well. Our data presented in chapter 2 show that high-IR individuals had a significantly lower postprandial net glucose uptake across forearm muscle compared to those with mild-IR, despite having significantly higher postprandial plasma insulin concentrations. Since skeletal muscle accounts for approximately $80 \%$ of insulin-mediated glucose uptake in humans (8), this clearly indicates that the individuals with high-IR had a more pronounced skeletal muscle insulin resistance as compared to those with mild-IR.

In part II of this thesis (chapter 5 and 6), we estimated tissue-specific insulin resistance by using a 0-120 min OGTT, with glucose and insulin measurements at five time-points. 
The muscle insulin sensitivity index (MISI) and hepatic insulin resistance index (HIRI) were estimated using the methods of Abdul-Ghani et al. (9). Importantly, both indexes were developed and validated against the two-step gold standard hyperinsulinemic-euglycemic clamp in combination with a glucose tracer. The MISI was calculated as the rate of decay of plasma glucose concentration during the OGTT, i.e. the slope of the least square fit to the decline in plasma glucose concentration from peak to nadir. The decline in plasma glucose concentration in the second part of the OGTT curve is thought to primarily reflect plasma glucose uptake by peripheral tissues. This index has been developed and validated against measures of peripheral insulin sensitivity as assessed during a hyperinsulinemic-euglycemic clamp using a stable isotope glucose tracer (9). The HIRI was calculated using the product of the area under curves for glucose and insulin during the first 30 minutes of the OGTT. This index has been developed and validated against the product of fasting plasma insulin and endogenous (hepatic) glucose production during a hyperinsulinemic-euglycemic clamp using a stable isotope glucose tracer (9). These indexes can be used to classify and identify tissuespecific insulin resistance phenotypes large cohorts. They were therefore applied to the Diet, Obesity and Genes (DiOGenes) cohort and the Cohort on Diabetes and Atherosclerosis Maastricht (CODAM), both including overweight/obese non-diabetic individuals who are at risk for developing cardiometabolic diseases. Subsequently, in DiOGenes, we studied crosssectional associations of tissue-specific insulin resistance with plasma lipidome (chapter 5) and abdominal subcutaneous adipose tissue transcriptome profiles (chapter 6). In CODAM, we studied the relationship between systemic low-grade inflammation and tissue-specific insulin resistance (chapter 6).

\section{Part I - Skeletal muscle lipid metabolism in insulin resistance}

The obese insulin resistant state is often accompanied by increased circulating concentrations of triacylglycerol (TAG) and non-esterified fatty acids (NEFAs). An impaired postprandial lipid buffering capacity of adipose tissue has been recognized as an important contributor to lipid overflow. This has been mainly characterized by impaired TAG extraction in the postprandial state and an impaired regulation of lipolysis (10). The resulting lipid overflow, in combination with an impaired capacity to adjust fat oxidation in skeletal muscle (11) leads to the intramuscular accumulation of bioactive lipid metabolites. This may contribute to lipidinduced insulin resistance (12). Up to now, little is known on the relative contribution of dietary fat (chylomicron-TAG) and endogenous fat (very-low-density-lipoprotein 
(VLDL)-TAG and NEFA) to the lipid overflow and to intramuscular lipid storage and handling in obese insulin resistant conditions.

In chapter 2 we studied i) the contribution of endogenous and dietary fatty acids to lipid overflow and ii) skeletal muscle lipid uptake and storage in overweight or obese individuals with a wide range of insulin resistance. We used a state-of-the-art dual stable isotope technique in combination with forearm balance technique to assess tracer and tracee concentration differences across forearm muscle. $\left[\mathrm{U}-{ }^{13} \mathrm{C}\right]$-palmitate was added to a high-SFA mixed-meal to label chylomicron-TAG (dietary TAG). $\left[{ }^{2} \mathrm{H}_{2}\right]$-palmitate was intravenously infused to label the circulating NEFA and VLDL-TAG (endogenous TAG) (13). This experimental setup allowed us to study the contribution of dietary and endogenous fatty acids to skeletal muscle fatty acid metabolism in overweight or obese individuals with a wide range of insulin resistance in more detail.

\section{Lipid uptake and accumulation in skeletal muscle}

In chapter 2, we showed that muscle VLDL-TAG extraction was elevated in high-IR individuals compared to mild-IR individuals after ingestion of a high-fat mixed-meal. This was observed despite a similar supply of systemic NEFAs, chylomicron- and VLDL-TAG. Moreover, we observed a significant linear association between VLDL-TAG extraction and insulin resistance, independent of sex and BMI. In line, our group previously showed an increased postprandial VLDL-TAG extraction in skeletal muscle in insulin resistant men compared to age and BMI matched control men with the metabolic syndrome (14). More recently, Goossens et al. also demonstrated an increased muscle VLDL-TAG extraction in humans with impaired glucose tolerance (IGT) compared to impaired fasting glucose (IFG) (15). Moreover, a recent tracer study, including men with type 2 diabetes, showed increased VLDL-TAG storage in skeletal muscle as well (16). In chapter 2, we extended these previous observations related to muscle VLDL-TAG extraction as we included a large group of individuals $(n=74)$ who encompassed the entire spectrum of insulin sensitivity and a wide range of adiposity. This allowed us to differentiate between the effect of obesity and insulin resistance per se. Together, our results imply that a more pronounced skeletal muscle insulin resistance was primarily related to an increased postprandial forearm muscle VLDL-TAG extraction.

In chapter 2, measurements were only performed in the early postprandial phase (i.e. $0-4 \mathrm{~h}$ ) and not in the late postprandial phase (i.e. $4-6 \mathrm{~h}$ postprandially). $\left[\mathrm{U}-{ }^{13} \mathrm{C}\right]$-palmitate in 
chylomicron-TAG is also cleared by the adipose tissue and can spillover into the circulation (17). In addition, $\left[\mathrm{U}-{ }^{13} \mathrm{C}\right]$-palmitate in chylomicron-TAG can be cleared by the liver. Subsequently, the $\left[\mathrm{U}-{ }^{13} \mathrm{C}\right]$-palmitate may be incorporated in VLDL-TAG. Indeed, it has been shown that dietary fatty acids appear in the VLDL-TAG fraction from 2 to $3 \mathrm{~h}$ after meal ingestion. This makes it difficult to separate chylomicron-TAG and VLDL-TAG in the late postprandial phase using the current dual stable isotope technique $(18,19)$. Therefore, we cannot exclude the possibility that the increased TAG extraction may also extend to chylomicron-TAG in insulin resistant conditions. Finally, it should be mentioned that our high-fat mixed-meal was high in SFA and that the observed disturbances in lipid handling in insulin resistance may depend on dietary fat quality. Indeed, Jans et al. showed an increased forearm muscle TAG extraction as well as an impaired muscle lipid turnover after a high-SFA mixed-meal, but not after a high-fat mixed-meal rich in polyunsaturated fatty acids (PUFA) or monounsaturated fatty acids (MUFA) in obese insulin resistant males (20).

Expression and activity of lipoprotein lipase (LPL) could be an important determinant of skeletal muscle TAG extraction and thereby contribute to the observed muscle VLDL-TAG extraction under insulin resistant conditions. In chapter 2, skeletal muscle mRNA expression of $L P L$ was not different between the mild-IR and high-IR individuals. In addition, plasma levels of the LPL inhibitor Angiopoietin-like 4 protein (ANGPTL4) were not associated with VLDL- and/or chylomicron-TAG extraction across skeletal muscle (chapter 3 and will be discussed more extensively below). Contrary to its stimulating effects on adipose tissue LPL activity, insulin has no stimulating (21) or even an inhibitory effect on muscle LPL activity $(22,23)$. However, the human data for this reciprocal tissue-specific LPL regulation are limited and not conclusive. Based on our findings in chapter 2, we hypothesize that insulin-mediated inhibition of skeletal muscle LPL may be impaired when the insulin resistant state is already present. Notably, LPL activity is mainly regulated at the posttranscriptional and post-translational level by several factors (24). In addition to ANGPTL4 and insulin, differences in the composition of the lipoprotein particles may explain a higher susceptibility for skeletal muscle LPL. Indeed, higher plasma apoCII:apoCIII ratios have been shown in diabetic individuals (25). This variation in lipoprotein composition may explain a higher degradation by LPL (24) and subsequently a higher TAG extraction in the high-IR individuals.

The observed higher net VLDL-TAG extraction in the high-IR individuals may contribute to lipid accumulation in skeletal muscle, which may aggravate muscle and wholebody insulin resistance in the long term (10). Therefore, we studied intramyocellular lipid 
content and composition in the muscle biopsies that were taken after an overnight fast from the mild-IR and high-IR individuals. In chapter 2 , we showed no differences in absolute lipid content (NEFA, diacylglycerol, TAG and phospholipids) in skeletal muscle, but observed distinct lipid composition patterns in skeletal muscle lipid pools. Firstly, the percentage of palmitate (C16:0) in the diacylglycerol pool was higher and the PUFA percentage was lower in those with high-IR. Secondly, an increased saturation of the intramuscular NEFA pool was observed in high-IR individuals, which was mainly confined to specific SFAs, namely myristic acid (C14:0), pentadecyclic acid (C15:0) and tricosylic acid (C23:0). An increased content of SFAs might be linked to an increased ceramide content and higher saturation in the long-chain fatty acyl-CoA in high-IR individuals (26). Nevertheless, Goossens et al. did not show differences in expression ceramide related genes in humans with IGT compared to IFG (15). Moreover, in chapter 2, reduced expression of glycerol-3-phosphate acyltransferase-1 (GPAT1) was observed, which is involved in the first step in TAG synthesis in muscle. However, this was not reflected in functionality since the fractional synthetic rate (i.e. incorporation) of palmitate into intramuscular TAG and diacylglycerol pools was not different between mild- and high-IR individuals. Together these data suggest that postprandial incorporation of fatty acids in TAG was not affected by degree of insulin resistance per se.

In conclusion, our findings in chapter 2 suggest that the insulin resistant state is characterized by an increased muscle VLDL-TAG extraction after a high-SFA mixed-meal and this was accompanied by a higher saturation of the intramuscular NEFA pool. This may give rise to increased muscle storage of detrimental bio-active lipid intermediates such ceramides. Nevertheless, these processes need to be investigated in more detail in future studies and underlying mechanisms behind this phenomenon remain to be elucidated.

\section{ANGPTL4 in lipid metabolism in overweight/obese conditions}

As mentioned above, the increased postprandial skeletal muscle TAG extraction (chapter 2) as well as the previously reported diminished adipose tissue TAG extraction in insulin resistant conditions (27) may be explained by an altered LPL activity. In recent years, the LPL inhibitor ANGPTL4 has been hypothesized to contribute significantly to lipid partitioning (28). Therefore, in chapter 3 and 4, the role of plasma ANGPTL4 in skeletal muscle and adipose tissue lipid metabolism in overweight or obese individuals was studied. In chapter 3 , the same forearm balance technique as in chapter 2 was used, using intravenously infused $\left[{ }^{2} \mathrm{H}_{2}\right]$-palmitate and $\left[\mathrm{U}-{ }^{13} \mathrm{C}\right]$-palmitate in a high-SFA mixed-meal. In chapter 4 , we 
used this unique approach to study adipose tissue lipid metabolism before and after weight loss. We measured arteriovenous concentration differences across abdominal subcutaneous adipose tissue in combination with adipose tissue blood flow before and after intake of a high-SFA mixed-meal with $\left[\mathrm{U}-{ }^{13} \mathrm{C}\right]$-palmitate, again in combination with biochemical analyses in tissue biopsies.

In this thesis, we showed that the plasma concentration of ANGPTL4 was not associated with TAG extraction across forearm muscle (chapter 3 ) and subcutaneous abdominal adipose tissue (chapter 4 ) in overweight and obese individuals. These results suggest that circulating ANGPTL4 is not a determinant of LPL activity during postprandial conditions in key metabolic organs. Instead, local ANGPTL4 might regulate LPL activity via autocrine and paracrine actions. Indeed, tissue-specific regulation of LPL activity by ANGPTL4 has been shown to take place in the sub-endothelial space rather than at the endothelium $(29,30)$. In addition, newly synthesized and locally produced ANGPTL4 might have more pronounced effects on LPL functionality than plasma ANGPTL4 (31,32). Likewise, more factors are involved in functional ANGPTL4 activity and related to LPL inhibition. For instance, glycosylphosphatidylinositol-anchored high-density lipoprotein-binding protein 1 (GPIHBP1) might compete with ANGPTL4 for LPL binding at either the interstitial space or capillary lumen (28). Together, these data suggest that locally produced ANGPTL4 rather than plasma ANGPTL4 may mediate LPL inhibition after a high-SFA mixed-meal and that there is a complex regulation of in vivo LPL activity with many factors involved.

As already indicated above, dietary fat quality rather than fat quantity may acutely affect muscle lipid handling. Jans et al. showed that a high-PUFA meal reduced muscle TAGderived fatty acid uptake as compared to a high-SFA meal (20). In chapter 3, we show that this reduced TAG extraction after the high-PUFA meal was accompanied by a blunted postprandial ANGPTL4 decline. This suggests that there may be a link between systemic ANGPTL4 and short-term lipid handling. However, this needs to be investigated in more detail in future research.

In addition to LPL inhibition, it has been suggested that ANGPTL4 stimulates fasting intracellular adipocyte lipolysis, thereby increasing the supply of NEFAs as fuel for oxidation by other tissues, e.g. skeletal muscle (28). Indeed, as observed in chapter 4, plasma ANGPTL4 was positively associated with estimates of intracellular adipose tissue lipolysis (i.e. net adipose tissue glycerol and NEFA release) both under fasting and postprandial conditions after weight loss. Up to now, evidence for a role of ANGPTL4 in human 
intracellular lipolysis is mainly based on association studies with plasma NEFA concentrations after an OGTT (33) and murine knock-out and in vitro cell studies $(34,35)$. Our human data extended the previous findings and suggest that plasma ANGPTL4 may play a role in adipose tissue lipolysis and possibly in lipid partitioning after weight loss.

Another aspect of ANGPTL4 metabolism that we studied in this thesis was the contribution of different tissues to circulating ANGPTL4 concentration. We provided in vivo evidence that ANGPTL4 is secreted from the human forearm muscle (chapter 3) and abdominal subcutaneous adipose tissue (chapter 4) after a high-SFA mixed-meal. This may be explained by an increased meal-induced ANGPTL4 mRNA and protein expression at tissue level. Indeed, it has been shown that basal mRNA ANGPTL4 expression in human myotubes correlated positively with fasting plasma ANGPTL4 levels of the donors (33). Moreover, fatty acids can increase plasma ANGPTL4 concentrations, likely in a peroxisome proliferator-activated receptors (PPAR)-mediated manner (36). Therefore, meal-derived fatty acids may increase ANGPTL4 release from these tissues. Alternatively, it is tempting to speculate that dissociation of ANGPTL4 from LPL may explain postprandial muscle and adipose tissue ANGPLT4 release. At the endothelial membrane, ANGPTL4 inhibits LPL activity via transient binding to LPL (29). During postprandial conditions, as LPL activity increases, it can be speculated that ANGPTL4 dissociates with LPL at the endothelium. If ANGPTL4 is then not taken up again by the underlying tissue, this could result in significant ANGPTL4 release into the circulation. Notably, our data show that plasma ANGPTL4 concentrations decline after a high-SFA meal, despite increases in ANGPTL4 release from skeletal muscle and adipose tissue. Therefore, our data indicate that these organs are not the main organs regulating postprandial plasma ANGPTL4 concentrations.

Finally, we could not detect significant ANGPTL4 release under fasting conditions from forearm muscle (chapter 3 ) and abdominal subcutaneous adipose tissue (chapter 4 ). However, it is important to note that our sample size may have been too small to detect significant but relatively small ANGPTL4 release from these tissues under fasting conditions. Nevertheless, it remains to be discussed whether ANGPTL4 is indeed a fasting induced adipose factor (FIAF) or rather a regulator of lipid metabolism under postprandial conditions in humans (37). Based on human ANGPTL4 mRNA expression studies (38) and ANGPTL4 overexpression studies in mice (39), we hypothesize that the liver may be the main contributor to fasting systemic ANGPTL4 concentrations. 
In conclusion, plasma levels of the LPL inhibitor ANGPTL4 were not associated with TAG extraction in forearm skeletal muscle and abdominal subcutaneous adipose tissue. In addition, after weight loss, plasma ANGPTL4 might play a role in adipose tissue lipolysis and therefore possibly in lipid partitioning as well. However, ANGPTL4s role in lipid metabolism warrants further investigation.

\section{Part II - Tissue-specific insulin resistance}

In part I of this thesis, insulin resistant subgroups were based on whole-body insulin resistance severity, i.e. mild-IR and high-IR as measured by HOMA-IR. In part II, we divided the participants into insulin resistant subgroups based on the affected metabolic tissue(s), i.e. skeletal muscle and/or liver insulin resistance. It has been shown in rodents that hepatic insulin resistance may precede adipose tissue and muscle insulin resistance (40), while hepatic and muscle insulin resistance may occur concomitantly in humans (41). Although the evidence is not conclusive so far (42-45), this indicates that whole-body IR and type 2 diabetes could originate within different tissues in humans. Moreover, intermediate states of impaired glucose metabolism are associated with distinct tissue-specific insulin resistance phenotypes as well and represent distinct pathophysiological pathways towards type 2 diabetes mellitus development. Hepatic insulin resistance may be the predominant disorder in IFG, while IGT individuals may have a reduced peripheral (muscle) insulin sensitivity (46).

In recent years, it has been shown that the effects of interventions improving health can be organ specific. For instance, physical activity was shown to mainly improve muscle insulin sensitivity (47), while metformin treatment might have positive effects on hepatic insulin sensitivity (48). Moreover, in prediabetic individuals with hepatic insulin resistance, a diet low in fat and high in complex carbohydrates may lead towards a more pronounced improvement in the disposition index. This is a composite measure of first phase insulin secretion multiplied by insulin sensitivity during an OGTT (49). Moreover, the same study showed that the Mediterranean diet may have a more beneficial effect on this parameter in individuals with muscle insulin resistance (49). Therefore, characterization of whole-body and tissue-specific insulin resistance is important to understand the mechanisms that underlie the metabolic consequences. Ultimately, this knowledge may provide directions for more targeted nutritional as well as pharmacological intervention strategies.

In chapter 5 and 6 , we acquired more information on the phenotypes of these distinct insulin resistance subgroups for plasma lipidome and abdominal subcutaneous adipose tissue 
transcriptome profiles. In chapter 5 and 6 , we included cross-sectional data from a large cohort of healthy overweight or obese non-diabetic individuals who are at risk for developing cardiometabolic diseases, i.e. the DiOGenes project. This study was a multicenter, randomized, controlled dietary intervention study and involved eight European countries. DiOGenes was originally initiated to assess the efficacy of moderate-fat diets that vary in protein content and glycemic index for preventing weight regain and obesity-related risk factors after weight loss (50). In addition, in chapter 6, we included individuals from CODAM, which is a prospective, observational study on, among others, the natural progression of insulin resistance and glucose tolerance. Notably, these cohorts are wellphenotyped and may therefore provide important early insights into factors related to tissuespecific insulin resistance and subsequently cardiometabolic diseases.

\section{Plasma lipidome profiles}

The plasma lipidome has gained special interest in recent years because it may reflect organ composition and metabolism. Circulating lipid species represent a read-out of different organs, particularly the liver, but also muscle or adipose tissue (51). Therefore, in chapter 5, 140 plasma lipids were quantified by liquid chromatography-mass spectrometry and crosssectionally related to measures of tissue-specific insulin resistance in 640 individuals of the DiOGenes cohort.

We found that distinct plasma lipid profiles were associated with either muscle insulin sensitivity or hepatic insulin resistance. We observed a positive association between lysophosphatidylcholine (LPC) levels and muscle insulin sensitivity, which was confined to two individual lipid species LPC(18:1) and LPC(18:2). In line, several studies have shown negative associations between LPC and 'surrogate' markers of whole-body insulin resistance (51,52). Fasting plasma levels of several LPCs, including LPC(18:1) and LPC(18:2), were increased in healthy male participants after completion of a ten-week exercise program (53). Additionally, an in vitro study showed that extracellular LPC(16:0) and LPC(18:1) can act as lipid signaling molecules in human myotubes. Subsequently, they may reduce fatty acidinduced inflammation and thereby possibly lipid-induced insulin resistance (54). In summary, our data indicate that muscle insulin resistance may be specifically related to reduced plasma LPC concentrations. Future research should elucidate whether elevated lipid-induced inflammation might mechanistically link reduced systemic LPC levels with muscle insulin resistance in humans. 
Likewise, we also identified a plasma lipid profile that was specifically associated with hepatic insulin resistance, but not with muscle insulin resistance (chapter 5). The associations were mainly present in women, pointing towards major sex differences in the associations between hepatic insulin resistance and the plasma lipidome profiles. Overall, women had less hepatic insulin resistance and lower TAG levels than men. However, in women, worsening of hepatic insulin resistance was associated with more pronounced increases in plasma TAG (44 out of 55 species) and both diacylglycerol species, whilst this was not observed in men. These data suggest that the plasma lipidome may be more responsive to a deterioration of hepatic insulin resistance in women than in men. Additionally, hepatic insulin resistance in women was characterized by a different lipid composition reflected by a lower abundance of odd-chain fatty acids and very-long-chain fatty acids in TAG. A possible explanation for these sex-related differences might be related to VLDL production in the liver (55). It is tempting to speculate that under conditions of hepatic insulin resistance, VLDL production might be differentially affected in men and women. Finally, women may have a more favorable cardiometabolic risk profile as compared to men at a young age, while this may reverse as they progress towards menopause (56). Our data may indicate that a worsening of the plasma lipidome with a more pronounced hepatic insulin resistance in premenopausal women may be one of early contributing factors to this phenomenon.

\section{Abdominal subcutaneous adipose tissue transcriptome profiles}

Next to plasma lipids, we further characterized tissue-specific insulin resistance phenotypes in 368 individuals of the $\mathrm{DiOGenes} \mathrm{cohort} \mathrm{by} \mathrm{studying} \mathrm{the} \mathrm{abdominal} \mathrm{subcutaneous} \mathrm{adipose}$ tissue transcriptome (chapter 6). Adipose tissue function is closely related to insulin resistance (57) and it is a dynamic endocrine organ, involved in the regulation of various homeostatic processes including lipid metabolism and inflammation (10,58). Analysis of gene expression in subcutaneous adipose tissue may therefore help to elucidate the physiological pathways and mechanisms involved in adipose tissue dysfunction that are linked to tissue-specific IR. RNA sequencing was used to assess subcutaneous adipose tissue gene expression profiles since this high-throughput technique can provide comprehensive insight into the transcriptome of a cell. Compared to previous microarray-based methods, RNA sequencing provides far higher coverage and greater resolution of the dynamic nature of the transcriptome. Subsequently, based on DiOGenes outcomes, we studied in 420 non-diabetic individuals from the CODAM cohort the relationship between systemic low-grade inflammation and tissuespecific insulin resistance (chapter 6). 
We found that distinct gene expression profiles in the abdominal subcutaneous adipose tissue were associated with either muscle or hepatic insulin resistance. WikiPathways, a human collection of curated pathways, and Gene Ontology classifications in combination with enrichment analyses were used to explore differential gene expression pathways. Using this workflow, we found that individuals with a more pronounced muscle insulin resistance were characterized by a more inflammatory gene expression profile in the abdominal subcutaneous adipose tissue (chapter 6). This was mainly determined by a pronounced $>1.2$ fold change upregulation of genes involved in chemotaxis (e.g. Chemokine (C-C motif) ligand $(C C L)-19,-21$ and (C-X-C motif chemokine ligand 9 (CXCL9) and complement activation (e.g. complement component $1 \mathrm{q}(C 1 Q)-a,-b$, and $-c$ ). In addition, multiple genes related to lysosomal and proteasomal removal of cell debris (e.g. cathepsins and proteasome subunits) were significantly upregulated. In contrast, an increased expression of abdominal subcutaneous adipose tissue genes related to extracellular remodeling was observed in individuals with hepatic insulin resistance. For instance, collagen genes (e.g. Collagen type IV alpha 4 chain (COL4A4), Collagen type $\mathrm{V}$ alpha 1 chain (COL5A1) and integrin genes (e.g. Integrin subunit alpha $\mathrm{D}(I T G A D))$ were upregulated with a pronounced fold change $>1.2$ in hepatic insulin resistance (chapter 6).

The subcutaneous adipose tissue inflammatory profile was only found in individuals with a more pronounced muscle insulin resistance phenotype (chapter 6). A possible mechanism that might link subcutaneous adipose tissue transcriptome with peripheral insulin sensitivity is the secretion of pro- and anti-inflammatory adipokines into the circulation (59). Because systemic inflammation markers were not available in DiOGenes, we performed a complementary analysis in CODAM. This comparable cohort had a systemic low-grade inflammation score available, by combining eight plasma markers of low-grade inflammation into one score (60). The individual inflammatory markers were $\mathrm{C}$-reactive protein $(\mathrm{CRP})$, interleukin-6 (IL-6), interleukin-8 (IL-8), serum amyloid A (SAA), soluble intercellular adhesion molecule 1 (sICAM-1), tumor necrosis factor $\alpha$ (TNF- $\alpha)$, ceruloplasmin and haptoglobin. Subsequently, we related this systemic low-grade inflammation score to tissuespecific insulin resistance measures. Indeed, we showed that low-grade inflammation was inversely associated with muscle insulin sensitivity (MISI), while we did not observe an association between low-grade inflammation and hepatic insulin resistance (HIRI). Notably, our approach of averaging eight markers of low-grade inflammation produced a robust estimate of the overall inflammatory state with minimization of random error (60). However, 
how these individual plasma inflammatory markers specifically are related to subcutaneous adipose tissue gene expression remains to be further studied.

Based on above findings, we hypothesize that an increased systemic inflammatory profile may be a putative mechanism linking the increased expression of inflammatory genes in subcutaneous adipose tissue and muscle insulin resistance, as found in the DiOGenes study. Indeed, it could be that upregulated subcutaneous adipose tissue inflammatory genes may have a more pronounced effect on peripheral tissues (e.g. muscle) than on liver, possibly due to a differential blood supply. For instance, the liver is also strongly affected by the portal vein that carries blood containing fatty acids, nutrients and pro-inflammatory factors released from the gastrointestinal tract, gallbladder, pancreas, spleen and mainly the visceral adipose tissue (61).

Finally, it remains to be elucidated how an increased subcutaneous adipose tissue expression of extracellular remodeling genes links to hepatic insulin resistance. In the CODAM study, there was no association between systemic low-grade inflammation and hepatic insulin resistance. It can be speculated that the subcutaneous adipose tissue transcriptome data might reflect simultaneous ongoing processes in other tissues, like the liver. Indeed, it has been shown that hepatic insulin resistance is also closely associated with an increased extracellular matrix remodeling and fibrosis in liver (62). This could specifically link subcutaneous adipose tissue extracellular matrix remodeling and hepatic insulin resistance.

In conclusion, the results from chapter 5 and $\mathbf{6}$ show distinct lipidome and transcriptome profiles in non-diabetic overweight and obese individuals in relation to tissue-specific insulin resistance phenotypes. These unique metabolic profiles require further mechanistic exploration and may serve as starting point for developing intervention strategies targeting different tissue-related or prediabetic phenotypes.

\section{Conclusions}

The present thesis aimed to study multiple aspects of lipid metabolism in relation to wholebody and tissue-specific insulin resistance by using a physiological approach. The main conclusions of this thesis are summarized below.

In chapter 2, we showed that insulin resistance is associated with increased postprandial VLDL-TAG extraction across the forearm muscle, despite a similar supply of TAG. In addition, distinct patterns of lipid composition were observed in the skeletal muscle lipid pools 
in insulin resistance, which were mainly related to an increased saturation of the intramyocellular NEFA pool. Ultimately, an elevated TAG extraction and changes in intramuscular lipid composition, may give rise to increased muscle storage of detrimental bio-active lipid intermediates such ceramides. In chapter 3 and 4 , as TAG extraction is mediated by LPL, we showed that these results could not be explained by altered plasma levels of the LPL inhibitor ANGPTL4.

In chapter 5 and 6 , we showed distinct lipidome and transcriptome profiles in non-diabetic overweight and obese individuals in relation to tissue-specific insulin resistance phenotypes. Muscle insulin resistance was associated with lower plasma LPC concentrations (chapter 5) and may be associated with an increased inflammatory gene expression profile in subcutaneous adipose tissue an increased systemic inflammatory profile (chapter 6). In contrast, hepatic insulin resistance was accompanied by an increased expression of genes related to extracellular remodeling in the subcutaneous adipose tissue (chapter 6). Moreover, the plasma lipidome profile showed clear sex differences, with a positive relation between plasma TAG, diacylglycerol and hepatic insulin resistance in women, but not in men (chapter 5).

\section{Suggestions for further research}

The main outcomes of the present work may serve as starting point for further characterization of different tissue-related insulin resistance or prediabetic phenotypes. Ultimately, this may provide directions for more targeted intervention strategies. However, several questions should be addressed in future research:

1. The post-translational regulation of LPL in skeletal muscle and adipose tissue lipid metabolism under insulin resistant conditions should be further explored. The increased skeletal muscle TAG extraction (chapter 2) as well as the previously reported diminished adipose tissue TAG extraction in insulin resistant conditions (27) may be partly explained by an altered LPL activity. However, studies investigating reciprocal tissue-specific regulation of LPL and its regulators (e.g. insulin and ANGPTL4) in obese insulin resistant conditions are currently limited. We showed that plasma levels of the LPL inhibitor ANGPTL4 could not explain in vivo forearm muscle and abdominal subcutaneous adipose tissue LPL activity in overweight and obese individuals (chapter 3 and 4). Nevertheless, studying the postprandial (insulin-mediated) regulation of LPL activity in key metabolic organs 
and the role of locally produced ANGPTL4, acting in autocrine and paracrine ways, might be promising for gaining more knowledge on role of LPL activity in disturbed lipid handling.

2. Future research should concentrate on sex differences in lipid metabolism, with a special focus on fasting and postprandial VLDL metabolism, e.g. VLDL production and secretion from liver and/or lipoprotein composition of VLDL particles. Despite a similar supply of TAG, we showed an increased postprandial skeletal muscle VLDL-TAG extraction in insulin resistance after a high-SFA mixed-meal (chapter 2). In addition, in women, increased fasting systemic TAG and diacylglycerol concentrations were associated with the degree of hepatic insulin resistance, even though women had less hepatic resistance and lower TAG concentrations (chapter 5). These results may suggest an altered VLDL metabolism in insulin resistance. Furthermore, there is a great need of studies comparing sex differences with respect to mechanisms of insulin sensitivity and lipid metabolism. So far, most human studies are based on studies including only males. In line with our data in chapter 5 , it is increasingly evident that pronounced differences between sexes in relation to lipid metabolism exist $(63,64)$. Additionally, hormonal status (e.g. pre- vs postmenopausal status and anticonceptive use) of women should be considered, as the risk for cardiometabolic diseases increases with progression towards the postmenopausal state (56).

3. If we aim to comprehensively improve prevention and care for individuals with cardiometabolic disease, we may need to move towards personalized treatment strategies. Manipulation of diet and physical activity should be the first-line treatment for obesity-related complications, but their treatment effect on health may depend on individual or sub-group-based pathophysiological factors. Therefore, detailed phenotyping of individuals is crucial. In chapter 5 and 6 , we showed distinct metabolic profiles for muscle or liver insulin resistant conditions, based on the surrogate insulin sensitivity indexes MISI and HIRI. In the future, these indexes may provide a relatively easy method to classify and identify tissue-specific insulin resistance sub phenotypes. However, future studies should examine whether these surrogate insulin sensitivity indexes can also be useful in the treatment or prevention of cardiometabolic diseases.

4. Future studies should additionally investigate the possibility of using specific plasma lipids or lipid profiles as biomarker for improving (tissue-specific) insulin resistance. We found that distinct plasma lipid profiles were associated with either muscle 
insulin sensitivity or hepatic insulin resistance (chapter 5). We showed that muscle insulin resistance was associated with lower plasma LPC concentrations in both sexes. In contrast, in women but not in men, increased systemic TAG and diacylglycerol concentrations were related to hepatic insulin resistance. Future clinical and mechanistic studies will have to investigate whether monitoring and using plasma lipids or lipid profiles as a risk marker is clinically useful in the treatment or prevention of cardiometabolic diseases. 


\section{References}

1. Borai A, Livingstone C, Kaddam I, Ferns G. Selection of the appropriate method for the assessment of insulin resistance. BMC Med Res Methodol. 2011;11:158.

2. Antuna-Puente B, Disse E, Rabasa-Lhoret R, Laville M, Capeau J, Bastard JP. How can we measure insulin sensitivity/resistance? Diabetes Metab. 2011;37:179-88.

3. Reijnders D, Goossens GH, Hermes GDA, Neis EPJG, van der Beek CM, Most J, et al. Effects of Gut Microbiota Manipulation by Antibiotics on Host Metabolism in Obese Humans: A Randomized DoubleBlind Placebo-Controlled Trial. Cell Metab. 2016;24:63-74.

4. Most J, Timmers S, Warnke I, Jocken JW, van Boekschoten M, de Groot P, et al. Combined epigallocatechin-3-gallate and resveratrol supplementation for $12 \mathrm{wk}$ increases mitochondrial capacity and fat oxidation, but not insulin sensitivity, in obese humans: a randomized controlled trial. Am J Clin Nutr. 2016;104:215-27.

5. Matsuda M. Measuring and estimating insulin resistance in clinical and research settings. Nutr Metab Cardiovasc Dis. 2010;20:79-86.

6. Matthews DR, Hosker JP, Rudenski AS, Naylor BA, Treacher DF, Turner RC. Homeostasis model assessment: insulin resistance and beta-cell function from fasting plasma glucose and insulin concentrations in man. Diabetologia. 1985;28:412-9.

7. Bonora E, Targher G, Alberiche M, Bonadonna RC, Saggiani F, Zenere MB, et al. Homeostasis model assessment closely mirrors the glucose clamp technique in the assessment of insulin sensitivity: studies in subjects with various degrees of glucose tolerance and insulin sensitivity. Diabetes Care. 2000;23:57-63.

8. DeFronzo RA, Jacot E, Jequier E, Maeder E, Wahren J, Felber JP. The effect of insulin on the disposal of intravenous glucose. Results from indirect calorimetry and hepatic and femoral venous catheterization. Diabetes. 1981;30:1000-7.

9. Abdul-Ghani MA, Matsuda M, Balas B, DeFronzo RA. Muscle and liver insulin resistance indexes derived from the oral glucose tolerance test. Diabetes Care. 2007;30:89-94.

10. Stinkens R, Goossens GH, Jocken JWE, Blaak EE. Targeting fatty acid metabolism to improve glucose metabolism. Obes Rev. 2015;16:715-57.

11. Turner N, Cooney GJ, Kraegen EW, Bruce CR. Fatty acid metabolism, energy expenditure and insulin resistance in muscle. J Endocrinol. 2014;220:T61-T79.

12. Badin P-M, Langin D, Moro C. Dynamics of skeletal muscle lipid pools. Trends Endocrinol Metab. 2013;24:607-15.

13. Blaak EE. Characterisation of fatty acid metabolism in different insulin-resistant phenotypes by means of stable isotopes. Proc Nutr Soc. 2017;:1-7.

14. van Hees AMJ, Jans A, Hul GB, Roche HM, Saris WHM, Blaak EE. Skeletal muscle fatty acid handling in insulin resistant men. Obesity. 2011;19:1350-9.

15. Goossens G, Moors C, Jocken J, van der Zijl N, Jans A, Konings E, et al. Altered Skeletal Muscle Fatty Acid Handling in Subjects with Impaired Glucose Tolerance as Compared to Impaired Fasting Glucose. Nutrients. 2016;8:164-15.

16. Andersen IR, Søndergaard E, Sørensen LP, Nellemann B, Gormsen LC, Jensen MD, et al. Increased VLDL-TG fatty acid storage in skeletal muscle in men with type 2 diabetes. J Clin Endocrinol Metab. 2016;:jc20162979. 
17. Frayn KN, Coppack SW, Fielding BA, Humphreys SM. Coordinated Regulation of Hormone-Sensitive Lipase and Lipoprotein-Lipase in Human Adipose-Tissue in-Vivo - Implications for the Control of Fat Storage and Fat Mobilization. Adv Enzyme Regul. 1995;35:163-78.

18. Heath RB, Karpe F, Milne RW, Burdge GC, Wootton SA, Frayn KN. Selective partitioning of dietary fatty acids into the VLDL TG pool in the early postprandial period. J Lipid Res. 2003;44:2065-72.

19. Heath RB, Karpe F, Milne RW, Burdge GC, Wootton SA, Frayn KN. Dietary fatty acids make a rapid and substantial contribution to VLDL-triacylglycerol in the fed state. Am J Physiol Endocrinol Metab. 2007;292:E732-9.

20. Jans A, Konings E, Goossens GH, Bouwman FG, Moors CC, Boekschoten MV, et al. PUFAs acutely affect triacylglycerol-derived skeletal muscle fatty acid uptake and increase postprandial insulin sensitivity. Am J Clin Nutr. 2012;95:825-36.

21. Taskinen MR, Nikkilä EA, of RNSJ, 1981. Lipoprotein lipase activity in adipose tissue and skeletal muscle of human diabetics during insulin deprivation and restoration. Scand J Clin Lab Invest. 1981;41:263-8.

22. Farese RV, Yost TJ, Eckel RH. Tissue-Specific Regulation of Lipoprotein-Lipase Activity by Insulin Glucose in Normal-Weight Humans. Metab Clin Exp. 1991;40:214-6.

23. Lithell H, Boberg J, Hellsing K, Lundqvist G, Vessby B. Lipoprotein-lipase activity in human skeletal muscle and adipose tissue in the fasting and the fed states. Atherosclerosis. 1978;30:89-94.

24. Kersten S. Physiological regulation of lipoprotein lipase. Biochim Biophys Acta. 2014;1841:919-33.

25. Hiukka A, Fruchart-Najib J, Leinonen E, Hilden H, Fruchart J-C, Taskinen M-R. Alterations of lipids and apolipoprotein CIII in very low density lipoprotein subspecies in type 2 diabetes. Diabetologia. 2005;48:1207-15.

26. Chaurasia B, Summers SA. Ceramides - Lipotoxic Inducers of Metabolic Disorders. Trends Endocrinol Metab. 2015;26:538-50.

27. Bickerton AST, Roberts R, Fielding BA, Tornqvist H, Blaak EE, Wagenmakers AJM, et al. Adipose tissue fatty acid metabolism in insulin-resistant men. Diabetologia. 2008;51:1466-74.

28. Dijk W, Kersten S. Regulation of lipoprotein lipase by Angptl4. Trends Endocrinol Metab. 2014;25:14655 .

29. Sukonina V, Lookene A, Olivecrona T, Olivecrona G. Angiopoietin-like protein 4 converts lipoprotein lipase to inactive monomers and modulates lipase activity in adipose tissue. Proc Natl Acad Sci USA. 2006;103:17450-5.

30. Makoveichuk E, Vorrsjö E, Olivecrona T, Olivecrona G. Inactivation of lipoprotein lipase in 3T3-L1 adipocytes by angiopoietin-like protein 4 requires that both proteins have reached the cell surface. Biochim Biophys Acta. 2013;441:941-6.

31. Nilsson SK, Anderson F, Ericsson M, Larsson M, Makoveichuk E, Lookene A, et al. Triacylglycerol-rich lipoproteins protect lipoprotein lipase from inactivation by ANGPTL3 and ANGPTL4. Biochim Biophys Acta. 2012;1821:1370-8.

32. Dijk W, Beigneux AP, Larsson M, Bensadoun A, Young SG, Kersten S. Angiopoietin-like 4 promotes intracellular degradation of lipoprotein lipase in adipocytes. J Lipid Res. 2016;57:1670-83.

33. Staiger H, Haas C, Machann J, Werner R, Weisser M, Schick F, et al. Muscle-derived angiopoietin-like protein 4 is induced by fatty acids via peroxisome proliferator-activated receptor (PPAR)-delta and is of metabolic relevance in humans. Diabetes. 2009;58:579-89.

34. Gray NE, Lam LN, Yang K, Zhou AY, Koliwad S, Wang J-C. Angiopoietin-like 4 (Angptl4) protein is 
a physiological mediator of intracellular lipolysis in murine adipocytes. J Biol Chem. 2012;287:8444-56.

35. Sanderson LM, Degenhardt T, Koppen A, Kalkhoven E, Desvergne B, Müller M, et al. Peroxisome proliferator-activated receptor beta/delta (PPARbeta/delta) but not PPARalpha serves as a plasma free fatty acid sensor in liver. Mol Cell Biol. 2009;29:6257-67.

36. Jonker JT, Smit JW, Hammer S, Snel M, van der Meer RW, Lamb HJ, et al. Dietary modulation of plasma angiopoietin-like protein 4 concentrations in healthy volunteers and in patients with type 2 diabetes. Am J Clin Nutr. 2013;97:255-60.

37. Dijk W, Kersten S. Regulation of lipid metabolism by angiopoietin-like proteins. Curr Opin Lipidol. 2016;27:249-56.

38. Kersten S, Lichtenstein L, Steenbergen E, Mudde K, Hendriks HFJ, Hesselink MK, et al. Caloric restriction and exercise increase plasma ANGPTL4 levels in humans via elevated free fatty acids. Arterioscler Thromb Vasc Biol. 2009;29:969-74.

39. Köster A, Chao YB, Mosior M, Ford A, Gonzalez-DeWhitt PA, Hale JE, et al. Transgenic angiopoietinlike (angptl)4 overexpression and targeted disruption of angptl4 and angptl3: regulation of triglyceride metabolism. Endocrinology. 2005;146:4943-50.

40. Turner N, Kowalski GM, Leslie SJ, Risis S, Yang C, Lee-Young RS, et al. Distinct patterns of tissuespecific lipid accumulation during the induction of insulin resistance in mice by high-fat feeding. Diabetologia. 2013;56:1638-48.

41. Chen DL, Liess C, Poljak A, Xu A, Zhang J, Thoma C, et al. Phenotypic Characterization of InsulinResistant and Insulin-Sensitive Obesity. J Clin Endocrinol Metab. 2015;100:4082-91.

42. DeFronzo RA, Tripathy D. Skeletal muscle insulin resistance is the primary defect in type 2 diabetes. Diabetes Care. 2009;32 Suppl 2:S157-63.

43. Pagotto U. Where does insulin resistance start? The brain. Diabetes Care. 2009;32 Suppl 2:S174-7.

44. Perseghin G. Viewpoints on the way to a consensus session: where does insulin resistance start? The liver. Diabetes Care. 2009;32 Suppl 2:S164-7.

45. Iozzo P. Viewpoints on the way to the consensus session: where does insulin resistance start? The adipose tissue. Diabetes Care. 2009;32 Suppl 2:S168-73.

46. Stefan N, Fritsche A, Schick F, Häring H-U. Phenotypes of prediabetes and stratification of cardiometabolic risk. Lancet Diabetes Endocrinol. 2016;4:789-98.

47. Bird SR, Hawley JA. Update on the effects of physical activity on insulin sensitivity in humans. BMJ Open Sport Exerc Med. 2016;2:e000143.

48. Zheng J, Woo S-L, Hu X, Botchlett R, Chen L, Huo Y, et al. Metformin and metabolic diseases: a focus on hepatic aspects. Front Med. 2015;9:173-86.

49. Blanco-Rojo R, Alcala-Diaz JF, Wopereis S, Perez-Martinez P, Quintana-Navarro GM, Marin C, et al. The insulin resistance phenotype (muscle or liver) interacts with the type of diet to determine changes in disposition index after 2 years of intervention: the CORDIOPREV-DIAB randomised clinical trial. Diabetologia. 2016;59:67-76.

50. Larsen TM, Dalskov S-M, van Baak M, Jebb SA, Papadaki A, Pfeiffer AFH, et al. Diets with high or low protein content and glycemic index for weight-loss maintenance. N Eng1 J Med. 2010;363:2102-13.

51. Tonks KT, Coster AC, Christopher MJ, Chaudhuri R, Xu A, Gagnon-Bartsch J, et al. Skeletal muscle and plasma lipidomic signatures of insulin resistance and overweight/obesity in humans. Obesity. 2016;24:908-16. 
52. Floegel A, Stefan N, Yu Z, Mühlenbruch K, Drogan D, Joost H-G, et al. Identification of serum metabolites associated with risk of type 2 diabetes using a targeted metabolomic approach. Diabetes. 2013;62:639-48.

53. Felder TK, Ring-Dimitriou S, Auer S, Soyal SM, Kedenko L, Rinnerthaler M, et al. Specific circulating phospholipids, acylcarnitines, amino acids and biogenic amines are aerobic exercise markers. J Sci Med Sport. 2017;20:700-5.

54. Klingler C, Zhao X, Adhikary T, Li J, Xu G, Häring H-U, et al. Lysophosphatidylcholines activate PPAR $\delta$ and protect human skeletal muscle cells from lipotoxicity. Biochim Biophys Acta. 2016;1861:1980-92.

55. Nielsen S, Karpe F. Determinants of VLDL-triglycerides production. Curr Opin Lipidol. 2012;23:321-6.

56. Regensteiner JG, Golden S, Huebschmann AG, Barrett-Connor E, Chang AY, Chyun D, et al. Sex Differences in the Cardiovascular Consequences of Diabetes Mellitus: A Scientific Statement From the American Heart Association. Circulation. 2015;132:2424-47.

57. Goossens GH. The Metabolic Phenotype in Obesity: Fat Mass, Body Fat Distribution, and Adipose Tissue Function. Obes Facts. 2017;10:207-15.

58. Reilly SM, Saltiel AR. Adapting to obesity with adipose tissue inflammation. Nat Rev Endocrinol. 2017;13:633-43.

59. Kwon H, Pessin JE. Adipokines Mediate Inflammation and Insulin Resistance. Front Endocrinol (Lausanne). 2013;4:1-13.

60. Hertle E, van Greevenbroek MM, Arts IC, van der Kallen CJ, Geijselaers SL, Feskens EJ, et al. Distinct associations of complement $\mathrm{C} 3 \mathrm{a}$ and its precursor $\mathrm{C} 3$ with atherosclerosis and cardiovascular disease. The CODAM study. Thromb Haemost. 2014;111:1102-11.

61. Item F, Konrad D. Visceral fat and metabolic inflammation: the portal theory revisited. Obes Rev. $2012 ; 13$ Suppl 2:30-9.

62. Koyama Y, Brenner DA. Liver inflammation and fibrosis. J Clin Invest. 2017;127:55-64.

63. Wang X, Magkos F, Mittendorfer B. Sex Differences in Lipid and Lipoprotein Metabolism: It's Not Just about Sex Hormones. J Clin Endocrinol Metab. 2011;96:885-93.

64. Lundsgaard A-M, Kiens B. Gender differences in skeletal muscle substrate metabolism - molecular mechanisms and insulin sensitivity. Front Endocrinol (Lausanne). 2014;5:195. 
General Discussion | 181 


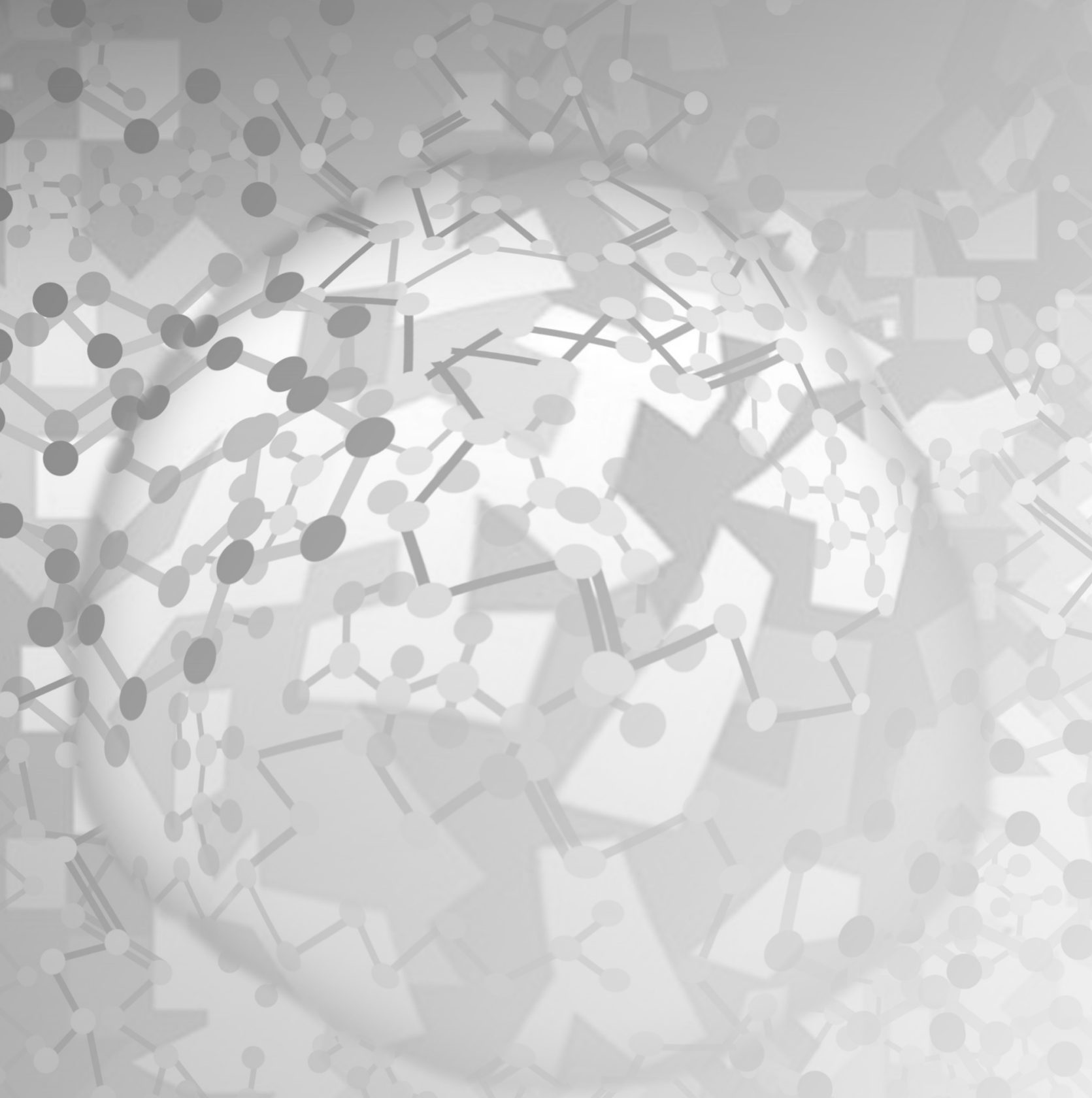


Addendum

\author{
Summary
}

Samenvatting

Valorization

Dankwoord

List of publications

About the author 
184 | Addendum 


\section{Summary}

Over the last decades, the prevalence of obesity has reached epidemic proportions and obesity and its metabolic consequences are major contributors to morbidity and mortality worldwide. Obesity is strongly linked to the development of insulin resistance, which in turn is a major risk factor in the development of cardiometabolic diseases. Insulin resistance can develop simultaneously in multiple organs and severity may vary between organs. Over the years, it has been convincingly shown that there is a complex interplay between metabolic insulin sensitive organs involved in lipid metabolism, such as adipose tissue, skeletal muscle and liver. In addition, impairments in lipid metabolism play an important role in the development and progression of insulin resistance. The present thesis therefore aimed to study multiple aspects of lipid metabolism in relation to whole-body and tissue-specific insulin resistance using a physiological approach.

In chapter 2 we studied the contribution of endogenous and dietary fatty acid sources to skeletal muscle uptake and storage in overweight or obese individuals with a wide range of insulin resistance. To study the metabolic fate of dietary versus endogenous fatty acids, a dual stable isotope technique was applied. $\left[\mathrm{U}-{ }^{13} \mathrm{C}\right]$-palmitate was added to a high-saturated fatty acid mixed meal to label chylomicron-triacylglycerol (TAG) (i.e. exogenous or dietary TAG) in the circulation. Simultaneously, $\left[{ }^{2} \mathrm{H}_{2}\right]$-palmitate was infused intravenously to label endogenous fatty acids. As $\left[{ }^{2} \mathrm{H}_{2}\right]$-palmitate can be incorporated into newly synthesized TAG in the liver, $\left[{ }^{2} \mathrm{H}_{2}\right]$-labelled TAG reflects very-low-density-lipoprotein (VLDL)-TAG (i.e. endogenous TAG) in the circulation. This stable isotope technique was combined with measurements of arterio-venous concentration differences across the forearm muscle to investigate skeletal muscle fatty acid handling and the specific contribution of the different fat sources to skeletal muscle fatty acid handling. We showed that insulin resistance is associated with increased postprandial VLDL-TAG extraction across the forearm muscle, despite a similar supply of TAG. In addition, distinct patterns of lipid composition were observed in the skeletal muscle lipid pools in insulin resistance, as reflected by an increased saturation of the intramyocellular non-esterified fatty acid pool. Ultimately, the elevated TAG extraction and an altered intramuscular lipid composition may lead to skeletal muscle insulin resistance, but exact underlying mechanisms remain to be defined.

In chapter 3 and 4 , we investigated the role of plasma angiopoietin-like protein 4 (ANGPTL4) in skeletal muscle and in abdominal subcutaneous adipose tissue lipoprotein lipase (LPL) activity as reflected by in vivo TAG extraction across these tissues. 
Chylomicron- and VLDL-TAG are hydrolyzed by LPL in the process of intravascular lipolysis and subsequently fatty acids are extracted by underlying tissues. Insulin is an important regulator of LPL activity, but a considerable part of the variation in LPL activity may also be explained by other factors. The LPL inhibitor ANGPTL4 is an interesting candidate and might be involved skeletal muscle and adipose tissue TAG extraction. In chapter 3 and 4 we show that plasma ANGPTL4 concentrations were not associated with TAG extraction (e.g. a measure for in vivo LPL activity) across the forearm skeletal muscle and abdominal subcutaneous adipose tissue. Interestingly, the data we additionally present in chapter 4, indicated that plasma ANGPTL4 might play a role in adipose tissue intracellular lipolysis after weight loss and therefore possibly in lipid partitioning after weight loss. Finally, we provided for the first time in vivo evidence that ANGPTL4 is secreted from the human skeletal muscle and adipose tissue after a high-saturated fatty acid mixed meal (chapter 3 and 4).

In chapter 5 and 6 , we acquired more information on distinct insulin resistant phenotypes, which is necessary to develop intervention strategies targeting different tissuerelated or prediabetic phenotypes. Tissue-specific insulin resistance was estimated by using a 2 hours oral glucose tolerance test, with glucose and insulin measurements at five time-points. We included cross-sectional data from the Diet, Obesity and Genes (DiOGenes) project, which is a large, multicenter, randomized, controlled dietary intervention study and involved eight European countries. In chapter 6, we additionally included individuals from the Cohort on Diabetes and Atherosclerosis Maastricht (CODAM). Both cohorts comprised overweight and obese non-diabetic individuals who are at risk for developing cardiometabolic diseases.

In chapter 5, we investigated cross-sectional associations of tissue-specific insulin resistance with the plasma lipidome. 140 plasma lipids were quantified by liquid chromatography-mass spectrometry. We showed a positive association between muscle insulin sensitivity and plasma lysophosphatidylcholine levels in both sexes. Furthermore, we identified sex differences in the associations between hepatic insulin resistance and the plasma lipidome. Hepatic insulin resistance was higher in men compared to women. However, in women an increase of hepatic insulin resistance was associated with an increase in plasma TAG and diacylglycerol and a decrease in the relative abundance of odd-chain and very-longchain TAG. In contrast, the degree of hepatic insulin resistance did not relate to alterations in the plasma lipidome in men. Combined with the observation that overweight/obese women had less hepatic insulin resistance and lower TAG levels than men, this would suggest that 
the plasma lipidome may be more responsive to worsening of hepatic insulin resistance in women, or vice versa.

In chapter 6 we further characterized tissue-specific insulin resistance phenotypes by studying the abdominal subcutaneous adipose tissue transcriptome by means of RNA sequencing. In individuals with primarily hepatic insulin resistance, extracellular matrix remodeling genes (e.g. collagens) were significantly upregulated, whilst in individuals with primarily muscle insulin resistance, genes related to inflammation (e.g. chemokines and complement activation) were significantly upregulated in abdominal subcutaneous adipose tissue. Subsequent analyses in the CODAM cohort showed that an increased systemic inflammatory profile compromised of eight plasma inflammatory markers may be specifically related to muscle insulin resistance. Based on these findings, we hypothesize that increased abdominal subcutaneous adipose tissue inflammatory gene expression in the muscle insulin resistant phenotype may translate into an increased systemic inflammatory profile, putatively linking subcutaneous adipose tissue inflammation to muscle insulin resistance.

In conclusion, the results from this thesis show distinct metabolic profiles in non-diabetic overweight and obese individuals in relation to (tissue-specific) insulin resistant phenotypes. We showed that insulin resistance is associated with increased postprandial VLDL-TAG extraction across the forearm muscle, despite a similar supply of TAG. As TAG extraction is mediated by LPL in skeletal muscle and adipose tissue, we showed that these results could not be explained by plasma levels of the LPL inhibitor ANGPTL4. In addition, a distinct lipid composition was observed in the skeletal muscle non-esterified fatty acid pool in insulin resistance, which were mainly related to an increased saturation of the intramyocellular nonesterified fatty acid pool. Finally, we showed distinct plasma lipidome and abdominal subcutaneous adipose tissue transcriptome profiles in overweight and obese individuals in relation to tissue-specific insulin resistance phenotypes. These unique metabolic profiles require further mechanistic exploration and may serve as starting point for developing intervention strategies targeting different tissue-related or prediabetic phenotypes. 
188 | Addendum 


\section{Samenvatting}

De prevalentie van obesitas heeft epidemische vormen aangenomen in de afgelopen decennia. Wereldwijd dragen obesitas en de metabole gevolgen ervan op grote schaal bij aan morbiditeit en mortaliteit. Obesitas gaat vaak gepaard met de ontwikkeling van insulineresistentie, wat op zijn beurt weer een grote risicofactor is voor de ontwikkeling van cardiometabole ziekten. Insulineresistentie kan zich in meerdere organen ontwikkelen en de ernst ervan kan varieren tussen verschillende organen. In de afgelopen jaren is het overtuigend bewezen dat, als het gaat om de vetstofwisseling, er een complexe samenwerking is tussen de verschillende metabole insulinegevoelige organen zoals vetweefsel, skeletspier en lever. Vetstofwisseling speelt dus een belangrijke rol in de ontwikkeling en het verloop van insulineresistentie. Het doel van het huidige proefschrift was daarom om meerdere aspecten van de vetstofwisseling in relatie tot insulineresistentie in het gehele lichaam of orgaanspecifiek te bestuderen. Daarbij werd gebruikt gemaakt van een fysiologische benadering.

In hoofdstuk 2 onderzochten we in vivo de afzonderlijke bijdrage van vetten afkomstig van voeding (exogene vetten; chylomicronen) en vetten reeds aanwezig in het lichaam (endogene vetten; vrije vetzuren en vetten in de vorm van VLDL-deeltjes) aan de vetopname en opslag in de skeletspier bij personen met overgewicht of obesitas met een brede spreiding in insulineresistentie. Hiertoe gebruikten we twee verschillende stabiele isotopen van het vetzuur palmitaat, in combinatie met metingen van arterieel-veneuze concentratieverschillen over de onderarmspier. We voegden $\left[\mathrm{U}-{ }^{13} \mathrm{C}\right]$-palmitaat toe aan een vetrijke milkshake met veel verzadigde vetten om chylomicronen te kunnen traceren. Tegelijkertijd infuseerden we $\left[{ }^{2} \mathrm{H}_{2}\right]$-palmitaat in de bloedbaan om vrije vetzuren en vetten in de vorm van VLDL-deeltjes te kunnen traceren. We vonden dat insulineresistentie was geassocieerd met een verhoogde extractie van VLDL-triacylglycerol (TAG) over de skeletspier bij insulineresistente personen, ondanks gelijke circulerende TAG-concentraties. De absolute hoeveelheid en de incorporatie van voedingsvetten in lipidenfracties van de spier (TAG, diacylglycerol, vrije vetzuren en fosfolipiden) was niet verschillend. Wel toonden we aan dat de vrije vetzuren fractie in de spier van insulineresistente personen een hoger gehalte aan verzadigde vetzuren bevatte. Deze data suggereren dat een verhoogde extractie van VLDL-TAG door de skeletspier na een maaltijd en een verhoogde verzadiging van de vrije vetzuren fractie in de spier geassocieerd zijn met insulineresistentie. Uiteindelijk kunnen deze verhoogde extractie van VLDL-TAG en veranderingen in samenstelling van lipidenfracties bijdragen aan de ontwikkeling van skeletspier insulineresistentie, maar de precieze onderliggende mechanismen moeten nog verder onderzocht worden. 
In hoofdstuk 3 en 4 onderzochten we de rol van het eiwit angiopoietin-like protein 4 (ANGPTL4) in lipoprotein lipase (LPL) activiteit in de skeletspier en het abdominale onderhuidse vetweefsel. Vetten in de vorm van chylomicronen en VLDL-deeltjes worden gehydrolyseerd door het eiwit LPL in de intravasculaire ruimte en de vrijgekomen vetzuren kunnen worden geëxtraheerd door de onderliggende weefsels (TAG-extractie). Insuline is een belangrijke regulateur van LPL activiteit, maar een deel van de variatie in TAG-extractie kan mogelijk ook verklaard worden door andere factoren. De LPL-remmer ANGPTL4 is daarom een interessante kandidaat en mogelijk betrokken bij de TAG-extractie in skeletspier en vetweefsel. In hoofdstuk 3 en 4 laten we zien dat ANGPTL4-concentraties in het plasma niet gerelateerd zijn aan TAG-extractie over de skeletspier en het abdominale onderhuids vetweefsel. Aanvullend laten onze data van hoofdstuk 4 zien dat ANGPTL4 in het plasma mogelijk gerelateerd is aan intracellulaire lipolyse in het onderhuidse vetweefsel na gewichtsverlies. Eventueel kan dit erop wijzen dat ANGPTL4 een rol speelt in de verdeling van vetten over het lichaam na gewichtsverlies. Tot slot tonen we in hoofdstuk 3 en 4 voor de eerste keer aan dat ANGPTL4 wordt uitgescheiden door de skeletspier en onderhuids vetweefsel na een vette maaltijd met veel verzadigde vetten.

In hoofdstuk 5 en 6 bestudeerden we verschillende weefselspecifieke insulineresistente fenotypes in meer detail. We bepaalden weefselspecifieke insulineresistentie met behulp van de orale glucosetolerantietest (OGTT), waarbij we gedurende twee uur vijf keer plasma glucose en insuline concentraties hebben gemeten. We makten gebruik van cross-sectionele data van het 'Diet, Obesity and Genes' (DiOGenes) project. Dit is een groot, gerandomiseerd en gecontroleerd dieet interventie onderzoek, uitgevoerd in acht Europese landen. In hoofdstuk 6 maakten we aanvullend ook gebruik van cross-sectionele data van het 'Cohort on Diabetes and Atherosclerosis Maastricht' (CODAM) project. Belangrijk om te vermelden is dat beide cohorten bestaan uit personen met overgewicht en obesitas zonder diabetes, maar een verhoogd risico hebben op het ontwikkelen van cardiometabole ziekten.

In hoofdstuk 5 analyseerden we cross-sectionele associaties tussen weefselspecifieke insulineresistentie en het circulerende lipidenprofiel. 140 lipiden werden gekwantificeerd met behulp van vloeistofchromatografie met tandem massaspectrometrie (LC-MS). We toonden aan dat er een positieve relatie is tussen spier insulinegevoeligheid en lysophosphatidylcholine concentraties. Verder lieten we zien dat er geslachtsverschillen zijn in de associaties tussen lever insulineresistentie en het circulerende lipidenprofiel. Lever insulineresistentie was hoger in mannen dan in vrouwen. Maar we vonden bij vrouwen een relatie tussen een slechtere lever insulineresistentie en verhoogde concentraties van plasma TAG en diacylglycerol. Bovendien 
hadden vrouwen ook een lagere dichtheid van oneven keten vetzuren en zeer lange keten vetzuren in TAG als ze een ongezondere lever insulineresistentie hadden. Daartegenover vonden we in mannen geen relatie tussen de mate van lever insulineresistentie en veranderingen in het lipidenprofiel. Als we deze waarnemingen combineren met de gegevens dat vrouwen met overgewicht of obesitas minder lever insulineresistentie hebben en lagere plasma TAG-concentraties, dan zou dit kunnen suggereren dat het vetprofiel in de circulatie bij vrouwen sneller reageert op een verslechtering van lever insulineresistentie, of vice versa.

In hoofdstuk 6 hebben we het transcriptoom van het abdominale onderhuidse vetweefsel in weefselspecifieke insulineresistente fenotypes gekarakteriseerd. Dit hebben we gedaan met behulp van $R N A$ sequencing. In personen met voornamelijk lever insulineresistentie waren extracellulaire matrix organisatie genen (bijvoorbeeld collagenen) significant opgereguleerd, terwijl genen die gerelateerd zijn aan ontstekingsfactoren waren opgereguleerd in personen met voornamelijk spier insulineresistentie, zoals chemokinen en complement factoren. Vervolganalyses in het CODAM-cohort lieten zien dat een verhoogd systemisch ontstekingsprofiel, bestaande uit acht plasma ontstekingsfactorenmarkers, mogelijk specifiek gerelateerd is aan spier insulineresistentie. Daarom hebben we de hypothese opgesteld dat een verhoogde genexpressie van ontstekingsfactoren in het abdominale onderhuidse vetweefsel kan leiden tot een verhoogd systemisch ontstekingsprofiel in het spier insulineresistentie fenotype. Dit kan eventueel de verbinding zijn tussen ontstekingen in het abdominale onderhuidse vetweefsel en spier insulineresistentie.

Concluderend kunnen we zeggen, op basis van de resultaten beschreven in dit proefschrift, dat er duidelijke onderscheidende metabole profielen zijn in (weefselspecifieke) insulineresistentie in personen met overgewicht en obesitas. We toonden aan dat insulineresistentie is geassocieerd met met een verhoogde VLDL-TAG-extractie over de onderarmspier na een maaltijd, ondanks gelijke TAG-concentraties in de circulatie. Aangezien TAG-extracie door LPL wordt geregeld in de skeletspier en het vetweefsel, lieten we ook zien dat bovenstaande resultaten niet verklaard konden worden door plasmawaarden van de LPL-remmer ANGPTL4. Verder toonden we aan dat de de vrije vetzuren fractie in de spier een hoger gehalte aan verzadigde vetzuren bevatte bij insulineresistente personen. Tot slot lieten we zien dat er een onderscheidend plasma lipidoom en abdominale onderhuidse vetweefsel transcriptoom zijn in relatie tot weefselspecifieke insulineresistentie in personen met overgewicht of obesitas. Deze unieke metabole profielen zullen nog verder onderzocht moeten worden, maar kunnen dienen als startpunt voor het ontwikkelen van nieuwe interventiestrategieën voor (weefselspecifieke) insulineresistentie of prediabetes. 
192 | Addendum 


\section{Valorization}

Knowledge valorization is described by the National Valorization Commission as "the process of creating value from knowledge, by making knowledge suitable and/or available for societal purposes, and suitable for translation into competitive products, services, processes, and new commercial activities". In this addendum we describe how society may benefit from the work conducted in this thesis.

Our research focused on extending fundamental knowledge about the underlying multiple aspects of lipid metabolism in relation to whole-body and tissue-specific insulin resistance. The main outcomes of the present thesis can serve as starting point for further characterization of different tissue-specific insulin resistant or prediabetic phenotypes. Ultimately, this may provide directions for more targeted and personalized intervention strategies. The valorization potential of these studies will be described in terms of social and economic relevance of obesity research, relevance of measurements for targeted prevention and innovation and translation into practice.

\section{Social and economic relevance of obesity research}

The prevalence of obesity has risen to epidemic proportions over the last decades and affects people of all ages and socioeconomic groups (1). More than $39 \%$ of the world adult population was overweight $\left(\mathrm{BMI}>25 \mathrm{~kg} / \mathrm{m}^{2}\right)$ and about $13 \%$ was obese $\left(\mathrm{BMI}>30 \mathrm{~kg} / \mathrm{m}^{2}\right)$ in $2014(2)$. In 2015, in the Netherlands, over $50 \%$ of the individuals over 20 years of age were overweight or obese (3).

The increasing prevalence of obesity is a major health concern. Obesity increases the risk for developing chronic diseases such as type 2 diabetes, cardiovascular diseases, mental disorders, several cancer types and reduces the quality of life. Overweight and obesity are the fifth leading risk for global deaths. $44 \%$ of the diabetes burden, $23 \%$ of the ischaemic heart disease burden and between $7-14 \%$ of certain cancers are attributable to overweight and obesity (4). In 2010, overweight and/or obesity was estimated to cause 3.4 million deaths worldwide (5). Additionally, obesity puts an enormous burden on patients, their families, and social health care systems. Therefore, it is important to explore underlying mechanisms that cause obesity and related chronic diseases.

Obesity is linked to the development of insulin resistance, which is a major contributor to hyperglycemia and hyperlipidemia. These are all risk factors towards the development of 
type 2 diabetes and cardiovascular diseases. Strikingly, insulin resistance increases the risk for cardiovascular diseases even in the absence of hyperglycemia (6).

From 2011 - 2012, in the USA, the direct cardiovascular disease-related costs were estimated on 193.1 billion US dollars, which reflect e.g. hospital services, prescribed medication and home health care. In addition, indirect cardiovascular disease-related costs, such as loss of future productivity, were estimated to be about 123.5 billion US dollars (7). For diabetes, it has been estimated that the direct annual cost of diabetes to the world is more than 827 billion US dollar (8). Together, for cardiovascular disease and diabetes costs combined, this adds up to more than 1,143 billion US dollars in one year. In 2011, in the Netherlands, the total direct cardiovascular disease-related costs were 8.3 billion euro, which was $9.2 \%$ of the total Dutch healthcare costs ( 89.4 billion euro), while diabetes-related costs were estimated to be 1.7 billion euro (1.9\%) (9). Although these numbers cannot only be subscribed to obesity-related cardiometabolic diseases, the expectation is that obesity and thus obesity-related morbidity will continue to increase in the coming years. Therefore, it will have major public health and socioeconomic consequences.

\section{Relevance of measurements for targeted prevention}

Recognition of symptoms at an early stage and early treatment of obesity and cardiometabolic diseases is important as it may prevent or delay the development of comorbidities. In addition, quality of life will be maintained or improved if weight and blood glucose concentrations can be well-controlled. However, obesity and cardiometabolic diseases are complex metabolic diseases whereby underlying mechanisms are yet not completely understood. Thus, understanding the etiology of obesity and insulin resistance is a key step in the prevention of cardiometabolic diseases. In this thesis, we focused on expanding fundamental knowledge about lipid metabolism in relation to early stages of insulin resistance. Although the findings may not lead to societal benefits at first glance, they generate improved insight into the pathophysiology of lipid metabolism in relation to whole-body and tissue-specific insulin resistance, which adds fuel for thought on future research initiatives.

The various measurements described in this thesis, e.g. plasma lipidomics and adipose tissue transcriptomics, may be future markers to detect the presence of insulin resistance at an early stage. One key finding in this thesis was that distinct plasma lipid profiles were associated with either muscle insulin sensitivity or hepatic insulin resistance in overweight and obese individuals. As an example: we showed that muscle insulin resistance was associated with lower plasma concentrations of the lipid lysophosphatidylcholine. Future clinical and 
mechanistic studies will have to investigate whether monitoring lipid profiles as a risk marker will prove to be clinically useful in the treatment or prevention of cardiometabolic diseases.

Importantly, we also observed distinct plasma lipid profiles for men and women. Hepatic insulin resistance was higher in men compared to women. However, in women worse hepatic insulin resistance was associated with an increase in plasma TAG and diacylglycerol concentrations. This aspect of lipid metabolism in relation to sexes is currently very much underemphasized in research and underscores the importance for sex-specific research as this may improve targeted prevention for the individual sexes.

In addition to fasting lipid metabolism measurements, it is a given that the majority of the population in the Western world spends a significant part of the day in the postprandial state. Increasing evidence suggests that not only fasting lipid, lipoprotein and glucose concentrations, but also a disturbed postprandial lipid or glucose metabolism are important risk markers for cardiometabolic diseases. Postprandial measurements are therefore of clinical importance when cardiometabolic disease risk is studied. In chapter 2, we extended existing knowledge on postprandial lipid metabolism. We showed that insulin resistance is associated with increased postprandial very-low-density-lipoprotein (VLDL) triacylglycerol extraction across the forearm muscle, despite a similar supply of triacylglycerol. In addition, different lipid composition patterns were observed in the skeletal muscle lipid pools in insulin resistance, which were mainly related to an increased saturation of the intramyocellular nonesterified fatty acid pool. Ultimately, these events, e.g. elevated skeletal muscle VLDLtriacylglycerol extraction and changes in intramuscular lipid composition, may give rise to increased muscle storage of detrimental bio-active lipid intermediates. They may affect insulin sensitivity in a negative way and contribute to cardiometabolic complications.

\section{Innovation and translation into practice}

The results described in this thesis have and will become available to the scientific community via publication of scientific reports in international peer-reviewed journals in the field of obesity and diabetes. Additionally, results have been presented at (inter)national conferences to scientists as well as physicians, healthcare professionals and dieticians, working in the fields of obesity, diabetes and metabolism.

Changes in lifestyle are considered to play an important role in the etiology of obesity and cardiometabolic diseases. Manipulation of diet and physical activity are the first-choice treatment for these complications. Lifestyle interventions including combined diet and physical activity have been shown to be effective in the prevention of type 2 diabetes as they 
reduce diabetes incidence by 47 - 57\% over a 3 - 6 year timeframe (10). In addition to lifestyle interventions, pharmacological modulation may also prevent or delay the onset of cardiometabolic complications (11). Healthcare professionals (e.g. dieticians, physiotherapists and physicians) play an important role in stimulating a healthy lifestyle among individuals who are at increased risk of developing obesity and cardiometabolic diseases. Although the results from this thesis do no provide direct guidelines for healthcare professionals, they provide better insight in metabolic parameters that can be targeted through lifestyle and pharmacological interventions.

In chapter 5 and 6, we showed distinct metabolic profiles for muscle or liver insulin resistant conditions, based on the surrogate insulin sensitivity indexes MISI and HIRI. We estimated tissue-specific insulin resistance by using a 2 hours oral glucose tolerance test (OGTT), with glucose and insulin measurements at five time-points. Importantly, both indexes were developed and validated against the two-step gold standard hyperinsulinemiceuglycemic clamp in combination with a glucose tracer (12). In the future, these indexes may provide a relatively easy method to classify and identify tissue-specific insulin resistant sub phenotypes as the OGTT is already widely used in the clinic to assess (gestational) diabetes.

In this thesis we revealed distinct metabolic profiles under different tissue-specific insulin resistant conditions, and the exact mechanisms behind this are possibly interesting for the food and pharmaceutical industry to guide development of more personalized targeted nutritional and lifestyle interventions. It should be noted that most associations presented here were based on cross-sectional data and therefore cannot distinquish cause and consequence. But the DiOGenes project is a valuable cohort study for follow-up measurements after dietinduced weight loss and weight regain. Therefore future follow-up of the data after the weight loss intervention may elucidate the temporality of the associations reported or elucidate potential interesting mechanisms. Still, more mechanistic studies are needed to find which pathway(s) need(s) to be targeted to maintain lipid homeostasis and insulin sensitivity.

Notably, key findings of this thesis, i.e. distinct metabolic profiles for muscle or liver insulin resistant conditions, have already served as starting point for developing personalized dietary intervention strategies. Recently, a new research project was started in collaboration with the public-private partnership Top Institute Food and Nutrition (TIFN) to investigate optimal diets to maintain postprandial blood glucose homeostasis in tissue-specific insulin resistant subphenotypes. The ambition of this private-public partnership is to provide the 
knowledge base that is needed for more targeted nutritional interventions in the prevention of cardiometabolic diseases and high-impact innovations in food and nutrition. The close collaboration between industry and academia leads to demand-driven research with societal and industrial relevance.

\section{References}

1. Ng M, Fleming T, Robinson M, Thomson B, Graetz N, Margono C, et al. Global, regional, and national prevalence of overweight and obesity in children and adults during 1980-2013: a systematic analysis for the Global Burden of Disease Study 2013. Lancet. 2014;384:766-81.

2. World Health Organization. Fact sheet 311: obesity and overweight. http://www. who.int/mediacentre/factsheets/fs311/en. 2015

3. GGD'en G. CBS en RIVM. Gezondheidsmonitor GGD'en; 2016.

4. EASO, European Association for Study of Obesity. Obesity Facts \& Figures. https://easo.org/educationportal/obesity-facts-figures/; Accessed 27 Feb 2018.

5. Lim SS, Vos T, Flaxman AD, Danaei G, Shibuya K, Adair-Rohani H, et al. A comparative risk assessment of burden of disease and injury attributable to 67 risk factors and risk factor clusters in 21 regions, 1990-2010: a systematic analysis for the Global Burden of Disease Study 2010. Lancet. 2012;380:2224-60.

6. Bornfeldt KE, Tabas I. Insulin Resistance, Hyperglycemia, and Atherosclerosis. Cell Metab. 2011;14:575-85.

7. Writing Group Members, Mozaffarian D, Benjamin EJ, Go AS, Arnett DK, Blaha MJ, et al. Heart Disease and Stroke Statistics-2016 Update: A Report From the American Heart Association. Circulation. 2016;133:e38-60.

8. World Health Organization. Global report on diabetes. 2016.

9. Rijksinstituut Volksgezondheid en Milieu (RIVM). Kosten van zorg voor diabetes mellitus. https://www.volksgezondheidenzorg.info/onderwerp/diabetes-mellitus/kosten/kosten; Accessed 19 Feb 2018.

10. Boer den AT, Herraets IJT, Stegen J, Roumen C, Corpeleijn E, Schaper NC, et al. Prevention of the metabolic syndrome in IGT subjects in a lifestyle intervention: results from the SLIM study. Nutr Metab Cardiovasc Dis. 2013;23:1147-53.

11. Pi-Sunyer X, Astrup A, Fujioka K, Greenway F, Halpern A, Krempf M, et al. A Randomized, Controlled Trial of $3.0 \mathrm{mg}$ of Liraglutide in Weight Management. N Engl J Med. 2015;373:11-22.

12. Abdul-Ghani MA, Matsuda M, Balas B, DeFronzo RA. Muscle and liver insulin resistance indexes derived from the oral glucose tolerance test. Diabetes Care. 2007;30:89-94. 
198 | Addendum 


\section{Dankwoord}

Zo, eindelijk is het moment daar dat ik het dankwoord mag gaan schrijven. Promoveren kun je zeker niet alleen doen en een goede samenwerking is onmisbaar. De afgelopen jaren hebben veel mensen mij hierbij geholpen en ik wil ze daar graag voor bedanken.

Ellen, als promotor verdien jij zeker de allereerste plaats hier. Ik ben ontzettend blij dat je mij de kans hebt gegeven om in de wereld van het humane onderzoek te stappen. Ik zal mijn eerste werkdag nooit meer vergeten, waarbij ik binnen een kwartier al naast een proefpersoon aan het bed stond. Ik heb ontzettend veel geleerd van jou. Jouw wetenschappelijke inzicht en je omgang met $\mathrm{PhD}$ studenten zijn bewonderenswaardig. Je hebt een snelle kritische blik en jouw vragen tijdens onze werkbesprekingen zorgden voor nieuwe energie en motivatie bij mij. Als ik weer eens gefrusteerd binnen kwam, vaak omdat ik teveel antwoorden uit mijn data wilde halen, dan wist jij me toch altijd weer te kalmeren en mij te wijzen op de kracht van de humane data.

Johan en Marleen, mijn copromotores, ben ik ook veel dank verschuldigd. Johan, bedankt voor al je inzichten en ondersteuning tijdens mijn promotietraject. Jouw fysiologische kennis en onuitputtelijke creatieve brein in het genereren van nieuwe ideeën waren heel inspirerend en zorgden ervoor dat ik steeds weer een stukje verder kwam. Marleen, jij werd pas in mijn laatste jaar officieel copromotor, maar je toegevoegde waarde was groot. Jouw zeer gedegen wetenschappelijke aanpak en jouw geduld om mij statistiek weer eens uit te leggen zorgden ervoor dat ik niet meer als een berg opkijk tegen data analyse. Ellen, Johan en Marleen, dank jullie wel voor een stimulerende omgeving, waarin mijn drang naar hoogwaardig onderzoek doen volledig werd gesteund.

I would also like to thank all members of the thesis assessment committee, prof. $\mathrm{M}$. Hesselink, prof. W. van Marken Lichtenbelt, prof. E. Feskens, dr. M. Brouwers and dr. L. Hodson for taking the time and effort to review my thesis and being present at the official PhD defence.

Gijs, ook al was je niet direct onderdeel van mijn promotieteam, bedankt dat ik altijd met mijn vragen bij je terecht kon en voor de vele wetenschappelijke discussies. Daarnaast was het ook altijd gezellig met jou op verschillende congressen en in de auto naar Eindhoven als je me weer eens een lift gaf. Dankjewel.

Wetenschap is een teamsport en onmogelijk zonder de input van de coauteurs. Zonder jullie hulp waren de artikelen in dit proefschrift niet zo uitgebreid geworden. Nicole V., ik wil 
jou heel erg bedanken voor je hulp bij allerlei statistische analyses en ook jouw uitleg om het voor mij begrijpbaar te maken. Ook vond ik het gezellig om met jou een kamer te delen in Porto! Mirella, we had a tough time with our RNAseq analyses, but we managed! Thank you for everything and especially the Friday morning chocolate croissants. Michiel, jouw kennis van RNAseq analyses was van onschatbare waarde. Gabby, het was gezellig en leerzaam om met jou over allerlei organisatorische zaken te praten. And all the other members of the MUMC2020 project and other coauthors, I would also like to thank you for the pleasant cooperation and for the excellent contributions to improve the work that is presented in this thesis. Dankjulliewel.

Zonder toegewijde proefpersonen had dit proefschrift nooit tot stand kunnen komen. Mijn oprechte dank gaat daarom uit naar alle mensen die hebben deelgenomen aan de onderzoeken in dit proefschrift; voor hun moeite en vooral voor het afstaan van bloed, vet- en spierweefsel. Dankjulliewel.

Mijn paranimfen verdienen een extra woordje van dank. Rudi, ik begon als onderzoeksassistent op jouw onderzoek en direct voelde ik dat het een goede samenwerking zou worden. Samen deelden wij een kantoor, vele intensieve testdagen en wisten we jouw hectische eerste studie efficiënt tot een goed einde te brengen. Ik heb je leren kennen als de rustige 'Belg' met droge humor die overdag ontzettend hard kan werken, maar's nachts ook heel hard kan feesten, zoals op het congres in Barcelona en alle andere feestjes. Bedankt voor alle leuke tijden die we samen hebben gehad. Kelly, we werden kantoorgenoten in een belangrijke fase van mijn promotietraject: het laatste jaar. Jouw vrolijke positieve instelling zorgden voor een fijne werksfeer: we werkten wanneer er gewerkt moest worden, maar er was meer dan genoeg tijd om plannen te maken voor congressen, feestjes en allerlei andere activiteiten. Ook bedankt voor het luisteren naar mij als ik weer eens teveel stress voelde. Succes met jouw promotieonderzoek! Rudi en Kelly, ik ben ontzettend blij dat jullie mijn paranimfen willen zijn en ik zie er naar uit dat jullie aan mijn zijde staan!

Nadia, jouw deur stond altijd open voor mij en daar maakte ik gretig gebruik van. Naast de vele wetenschappelijke discussies die we hebben gehad, waarbij ik jouw rustige meedenkende houding heel erg heb gewaardeerd, was er ook genoeg tijd voor ontspannende koffie-dates met uiteenlopende onderwerpen. Onze gezamelijke reis naar Oslo was een hoogtepunt (onder andere de skischans). Dankjewel en ik hoop dat we nog lang vriendinnen zullen blijven. 
Dorien, Emanuel en Cyril: wat een leuke jaren hebben we gehad tijdens onze promotie! Dorien, met jouw gigantische humane studie en jouw vele verhalen vlogen de dagen op het werk voorbij. Toffe congressen (sorry voor alle slapeloze nachten...), feestjes en allerlei andere activiteiten zijn door jou gelukkig ook altijd uitgebreid op beeld vastgelegd, zodat ik ze niet zal vergeten. Ik hoop dat we nog lang vriendinnen zullen blijven. Manu, brainstormen met jou was altijd heel fijn. Nadat je van kantoor verhuisd was, vond ik het fijn dat we dit bleven doen tijdens onze wandelingen en 'koffie'tjes', naast alle andere onderwerpen die we dan ook bespraken. Cyril, onze korte tijd als kantoorgenoten was zeer plezierig door jouw vriendelijke persoonlijkheid en grote kennis. En wat betreft de open ramen: die zorgden voor verfrissende ideeën ;). Bedankt voor jullie altijd positieve aanwezigheid!

Mattea, Qing, Max en Inez. You are great collegues and I enjoyed our regular lunches at work a lot! Mattea, we shared an office for almost two years and we always had fun if we managed to be there at the same time, haha. Qing, it was really nice to have you around and I learned a lot about China and its culture. Max, je bent een heel gezellige collega met wie ik het over van alles kan hebben. Inez, jouw stipte koffietijd om $9 \mathrm{u}$ ga ik zeker missen en dankjewel dat je mijn vooroordelen over korfbalmeisjes voor altijd positief hebt veranderd ;). Thank you all for being there and good luck with your PhDs!

De overige (ex)collega's van de onderzoeksgroep: Jasper, Laura, Kenneth V., Nicole H., Yvonne, Ruth, Rens, Roel, Adriyan, Manuel, Suzanne, Sini, Elaine, Kenneth P., bedankt voor alle wetenschappelijke discussies en de leuke tijden die we samen hebben gehad tijdens onze werkbesprekingen, congressen en feesten. Jullie zijn een toffe groep collega's waar het goed mee vertoeven was, ook buiten het werk om. Laura, ik had veel bewondering voor jouw omgang met proefpersonen en je open persoonlijkheid. Nicole H. en Yvonne, jullie zijn top analisten! Dankjulliewel voor de goede begeleiding op het lab en de vele gezellige uren die we samen op ons kantoor hebben doorgebracht.

De afgelopen jaren heb ik ook vele uren in de trein doorgebracht op het traject Eindhoven-Maastricht en gelukkig waren daar de 'Treinhomies' op ons vaste plekje voorin de trein. Sophie, onze BVO'tjes na (en meegenomen van) de vrijdagmiddagborrel smaakten altijd goed. Nik, jouw aanwezigheid maakte de dagelijkse treinreis meer dan goed met je onuitputtelijke verhalen en filmkennis. Boris, meerdere malen was onze treinreis één grote pubquiz en gaf je mij met al je (vreemde) gedachtenpatronen een grote glimlach :). Marije, we hebben het langst samen dit traject afgelegd en samen zaten we in de laatste loodjes van onze promotietraject. De uren in de trein, en niet te vergeten die op de wielrenfiets naar huis, 
waren altijd een lichtpuntje en een mooi moment om de dagelijkse beslommeringen door te nemen, mede door jouw opgewekte instelling. Binnenkort ga ook jij promoveren met een heel mooi proefschrift. Allemaal heel erg bedankt voor jullie gezelschap in deze vele reisuren!

Desiree, Cleo en Claudia, dankjulliewel voor een warm en verwelkomend secretariaat. Jullie prettige ondersteuning bij allerlei organisatorische zaken en jullie open deur zijn onmisbaar voor de afdeling!

Al mijn HB/BW collega's: bedankt voor de leuke momenten gedurende de afgelopen 5,5 jaar! Er waren veel activiteiten zoals meerdere keren in het jaar weekendjes weg in de Ardennen, carnaval, feestjes, lunches, de gezellige kerstdiners en de feestjes die daarop volgden. Ik zou iedereen hier wel persoonlijk willen bedanken, maar het zijn er gewoon te veel en ik wil niemand vergeten. Jullie hebben allemaal bijgedragen aan mijn fantastische tijd in Maastricht. Toch een speciaal woord van dank voor Jos die me altijd stipt op vrijdagmiddag om $16 \mathrm{u}$ aan de borrel herinnerde en zijn grote inzet om alle $\mathrm{HB} / \mathrm{BW}$ mensen bijeen te brengen. Ook alle 'M3 Cycling' collega's bedankt voor de vele prachtige fietstochten door Zuid-Limburg, dit waren mooie hoogtepunten afgelopen jaar!

Natuurlijk zijn er buiten het werk ook vele vrienden die me hebben bijgestaan afgelopen jaren. Jeroen, mijn practicummaatje vanaf dag 1 van onze studie. Ik hoop dat onze (wetenschappelijke) discussies, goede etentjes en vele uitstapjes nog lang zullen blijven doorgaan! Anne-Marie, Christy, Maria, dankjulliewel voor alle gezellige etentjes en uitjes. Jullie zijn allemaal stuk voor stuk topvriendinnen. Anika, many thanks for letting me escape to Cardiff every once in a while. It's great to have such a good friend! Quatsh 4/Squashtime 4: what's in a name? Alain, Cees, John, Joost, Maikel, Twan en Marloes; jullie zijn fantastische squashers en de wekelijkse squashtrainingen en competitiedagen waren een goede afleiding, dankzij jullie gezelligheid! Biologievrienden en 51+ vrienden: bedankt voor jullie interesse en afleiding van het promoveren met leuke dingen doen zoals biertjes drinken, barbecueën, spelletjes spelen en weekendjes weg.

Ook heel erg bedankt aan de schoonfamilie: Jan, Maria, Erica, Matthijs, Vivian, Sebastiaan, Vincent en Evelien. Jullie interesse in mijn werk en jullie ondersteuning zijn erg hartverwarmend.

Mijn familie mag hier zeker niet ontbreken! Lieve familie, bedankt voor jullie geduld en begrip de laatste jaren. Marinka en Merijn, Wilbert, ook al zien we elkaar minder vaak dan we zouden willen, dankjulliewel voor jullie steun en het zijn van een hechte familie. Dat is erg 
belangrijk voor mij. Als we samen zijn, dan is het altijd gezellig! Oma, ik heb veel bewondering voor jouw actieve levensstijl en ik wil je bedanken voor de motivatie die je me hebt gegeven in mijn promotietraject en jouw interesse in mijn werk.

Lieve pap en mam, het is niet altijd makkelijk voor jullie geweest dat ik voor mijn studie en werk steeds verder naar het zuiden van Nederland verhuisde en nu zelfs naar het buitenland. Ook neem ik aan dat jullie nog steeds niet goed begrijpen waar ik eigenlijk de voorbije vijf jaar mee bezig ben geweest. Desondanks hebben jullie alles nauwlettend op de voet gevolgd en steeds geïnteresseerd geluisterd naar wat ik te vertellen had. Ik wil jullie graag bedanken voor alle kansen die jullie mij hebben gegeven, omdat jullie er altijd voor me zijn en omdat ik altijd op jullie kan rekenen!

Lieve lieve Frank, er is niemand die deze periode van zo dichtbij heeft meegemaakt als jij. Ik zou niet weten hoe ik zonder jou deze klus had moeten klaren en ik kan je waarschijnlijk niet genoeg bedanken! Het is heerlijk om altijd maar weer terug te kunnen vallen op zo'n stabiele, rustige, relativerende, begripvolle, lekker kokende maar bovenal heel lieve man! Jouw hulp en liefde zijn van onschatbare waarde. Het proefschrift is nu eindelijk af en ik kan niet wachten op alle dingen die wij samen in de toekomst gaan meemaken, waaronder ons komende buitenlandse avontuur. Uit het diepst van mijn hart: dankjewel voor al je liefde en geduld. Ik hou van jou!

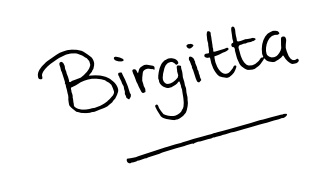


204 | Addendum 


\section{List of publications}

\section{Published papers}

van der Kolk BW, Goossens GH, Jocken JW, Blaak EE. Altered skeletal muscle fatty acid handling is associated with the degree of insulin resistance in overweight and obese humans. Diabetologia. 2016;59:2686-96.

van der Kolk BW, Goossens GH, Jocken JW, Kersten S, Blaak EE. Angiopoietin-Like Protein 4 and Postprandial Skeletal Muscle Lipid Metabolism in Overweight and Obese Prediabetics. J Clin Endocrinol Metab. 2016;101:2332-9.

Vink RG, Roumans NJ, van der Kolk BW, Fazelzadeh P, Boekschoten MV, Mariman EC, et al. Adipose tissue meal-derived fatty acid uptake before and after diet-induced weight loss in adults with overweight and obesity. Obesity. 2017;25:1391-9.

Stinkens R, van der Kolk BW, Jordan J, Jax T, Engeli S, Heise T, et al. The effects of angiotensin receptor neprilysin inhibition by sacubitril/valsartan on adipose tissue transcriptome and protein expression in obese hypertensive patients. Sci Rep. 2018;8:3933.

\section{Submitted}

van der Kolk BW, Vogelzangs N, Jocken JW, Valsesia A, Hankemeier T, Astrup A, Saris WH, Arts IC, van Greevenbroek MM, Blaak EE and the DiOGenes consortium. Plasma lipid profiling of tissue-specific insulin resistance in human obesity.

van der Kolk BW, Vink RG, Jocken JW, Roumans NJ, Goossens GH, Mariman EC, van Baak MA, Blaak EE. Effect of diet-induced weight loss on Angiopoietin-like protein 4 and adipose tissue lipid metabolism in overweight and obese humans.

\section{In preparation}

van der Kolk BW*, Kalafati $\mathrm{M}^{*}$, Adriaens M, van Greevenbroek MM, Saris WH, Astrup A, Valsesia A, Langin D, van der Kallen CJ, Schalkwijk CG, Stehouwer CD, Goossens $\mathrm{GH}$, Arts IC, Jocken JW, Evelo $\mathrm{CT}^{\S}$, Blaak $\mathrm{EE}^{\S}$ and the DiOGenes Consortium. Abdominal subcutaneous adipose tissue gene expression in relation to tissue-specific insulin resistance in human obesity.

*, $\S$ Authors contributed equally to this work 
206 | Addendum 


\section{About the author}

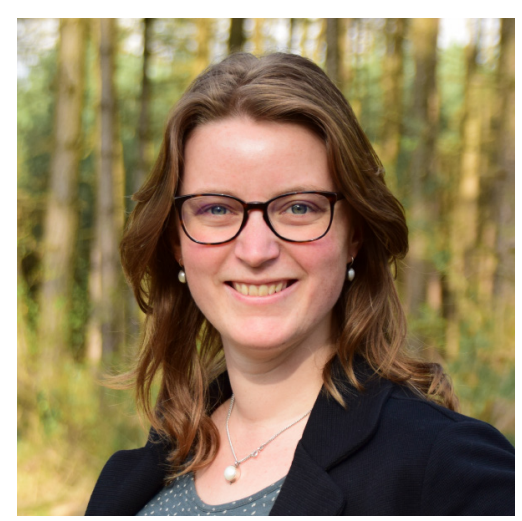

Birgitta van der Kolk was born on 23 September 1987 in IJsselmuiden (the Netherlands) and was raised in Kamperveen. In 2005, she obtained her Gymnasium (VWO) diploma from Ichthus College in Kampen. In the same year, she started her studies (Medical) Biology at the Radboud University in Nijmegen. For her masters degree, she performed an internship at the department of Human Genetics, Radboud University Nijmegen, in which she studied the protein network in the Usher syndrome. Subsequently, she did an internship at the Division of Pathophysiology and Repair at Cardiff University in Cardiff (United Kingdom), in which she studied the role of the extracellular calcium-sensing receptor in vascular calcification. She graduated in 2012 with distinction bene meritum.

In November 2012, Birgitta started as a research assistant at the department of Human Biology, Maastricht University, under supervision of prof. dr. Ellen Blaak and dr. Gijs Goossens. This is where her love for human physiology grew. In September 2013, she started her PhD project at the department of Human Biology, Maastricht University, under supervision of prof. dr. Ellen Blaak, dr. Johan Jocken and dr. Marleen van Greevenbroek. During her graduation research, she investigated (tissue-specific) insulin resistance in human obesity with a special focus on lipid metabolism, as demonstrated in this thesis and publications in scientific journals. In addition, she presented her research findings at several national and international conferences, including the yearly European Congress on Obesity (ECO) meetings. In 2016, she was nominated for the Foppe ten Hoor Young Investigator award at the Dutch Nutritional Science Days (NSD). In 2017, she was awarded with the Publication Prize from the Netherlands Association for the Study of Obesity (NASO) for the best paper in the field of obesity.

Birgitta will continue her career as a postdoctoral research fellow at the Obesity Research Unit, University of Helsinki in Helsinki (Finland) under supervision of prof. dr. Kirsi Pietiläinen, MD. Here she will study twins who are discordant for obesity. 
